\title{
Bench-Scale Testing of the Micronized Magnetite Process
}

\author{
January 1993 - January 1997
}

\section{Final Report}

\section{Volume I}

Authors:

Edward R. Torak

Peter J. Suardini

November 1997

(Contract No. DE-AC22-93PC92206 --17)

\section{Custom Coals Corporation}

3432 Perrysville Ave.

Pittsburgh, PA 15214

Ph: (412) 321-5711

Prepared For:

U.S. Department of Energy

Federal Energy Technology Center

P.O. Box 10940

Pittsburgh, PA 15236 


\section{Disclaimer}

This report was prepared as an account of work sponsored by an agency of the United States Government. Neither the United States Government nor any agency thereof, nor any of their employees, makes any warranty, express or implied, or assumes any legal liability or responsibility for the accuracy, completeness, or usefulness of any information, apparatus, product, or process disclosed, or represents that its use would not infringe privately owned rights. Reference herein to any specific commercial product, process, or service by trade

name, trademark, manufacturer, or otherwise does not necessarily constitute or imply its endorsement, recommendation, or favoring by the United States Government or any agency thereof. The views and opinions of authors expressed herein do not necessarily state or reflect those of the United States Government or any agency thereof. 


\section{VOLUME 1 \\ FINAL REPORT}

TABLE OF CONTENTS

SECTION

DESCRIPTION

$\underline{\text { PAGE }}$

Table of Contents $\ldots \ldots \ldots \ldots \ldots \ldots \ldots \ldots \ldots \ldots \ldots \ldots \ldots \ldots \ldots \ldots \ldots \ldots$

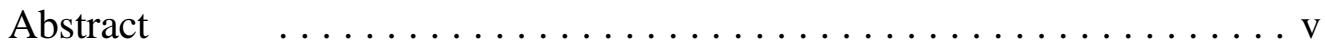

Executive Summary $\ldots \ldots \ldots \ldots \ldots \ldots \ldots \ldots \ldots \ldots \ldots \ldots \ldots \ldots \ldots$

$1 \quad$ Project Introduction $\ldots \ldots \ldots \ldots \ldots \ldots \ldots \ldots \ldots \ldots \ldots \ldots \ldots \ldots \ldots \ldots \ldots$

$1.1 \quad$ Program Description . . . . . . . . . . . . . . . . . . . 1

1.2 Technology Description $\ldots \ldots \ldots \ldots \ldots \ldots \ldots \ldots \ldots \ldots$

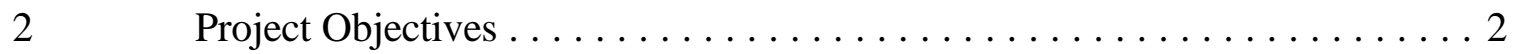

$3 \quad$ Project Team Organization $\ldots \ldots \ldots \ldots \ldots \ldots \ldots \ldots \ldots \ldots \ldots$

$4 \quad$ Project Accomplishments by Task Series $\ldots \ldots \ldots \ldots \ldots \ldots \ldots 6$

4.1 Task 100: Project Planning and Management $\ldots \ldots \ldots \ldots \ldots 6$

4.2 Task 200: Final Circuit Design $\ldots \ldots \ldots \ldots \ldots \ldots \ldots \ldots$

4.3 Task 300: Equipment Procurement and Fabrication . . . . . . . . 11

4.4 Task 400: Magnetite and Coal Procurement ............. 14

4.5 Task 500: Circuit Installation $\ldots \ldots \ldots \ldots \ldots \ldots \ldots \ldots \ldots \ldots \ldots \ldots$

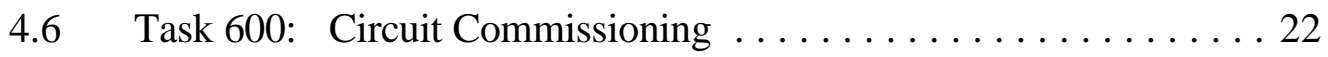

4.7 Task 700: Circuit Testing, Sampling and Monitoring ........ 27

4.8 Task 800: Analytical . . . . . . . . . . . . . . . . . . . 32

4.9 Task 900: Circuit Decommissioning . . . . . . . . . . . 36

4.10 Task 1000: Results Data Evaluation and Discussions ........ 36

4.10.1 Component Testing Results . . . . . . . . . . . . . 38

4.10.1.1 Classification Circuit Testing Results . . . . . . 38

4.10.1.2 Dense-Medium Cyclone Testing Results . . . . . . . 40

4.10.1.3 Medium Recovery Circuits Testing Results . . . . . 65

4.10.2 Primary Integrated Testing Results $\ldots \ldots \ldots \ldots \ldots 68$

4.10.3 Continuous Integrated Testing Results . . . . . . . . . 72

4.10.4 Quality Assurance and Quality Control Testing Results ... . 84

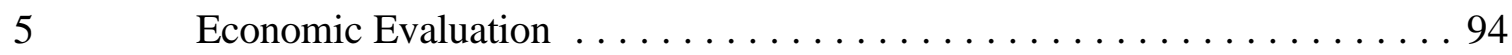

$6 \quad$ Conclusions and Recommendations $\ldots \ldots \ldots \ldots \ldots \ldots \ldots$ 


\section{TABLE OF CONTENTS, (cont'd.)}

FIGURE

$\underline{\text { PAGE }}$

Project Team Organization $\ldots \ldots \ldots \ldots \ldots \ldots \ldots \ldots \ldots$

Planned Micro-Mag Project Schedule by Task . . . . . . . . . . . . . 7

Micro-Mag Circuit Block Flow Diagram (3 Subcircuits) . . . . . . . . . . . 10

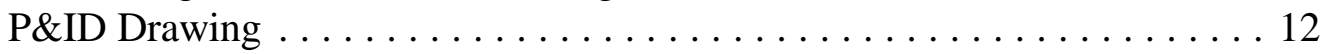

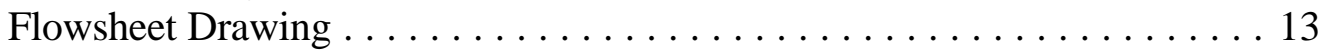

Circuit Interface $\&$ Tie In Drawing . . . . . . . . . . . . . . 23

Micro-Mag Project Analytical Structure . . . . . . . . . . . . . . . 37

Fitted Partition Curves for PHT \#23

(Grade K Mangetite, 88 PSI, 0\% Fines) . . . . . . . . . . . . . . 48

Fitted Partition Curves for PHT \#26

(Grade K Magnetite , 19 PSI, 0\% Fines) . . . . . . . . . . . . . . . . . 49

Fitted Partition Curves for PHT \#30

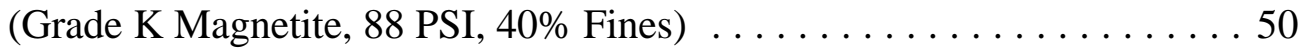

Fitted Partition Curves for PHT \#31

(Grade K Magnetite, 19 PSI, 40\% Fines) . . . . . . . . . . . 51

Fitted Partition Curves for PHT \#35

(Grade L Magnetite, 88 PSI, 0\% Fines) . . . . . . . . . . . . 52

Fitted Partition Curves for PHT \#32

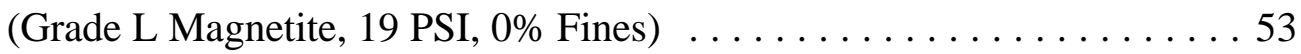

Fitted Partition Curves for PHT \#40

(Grade L Magnetite, 88 PSI, 40\% Fines) . . . . . . . . . . . . . . 54

Fitted Partition Curves for PHT \#39

(Grade L Magnetite, 17 PSI, 40\% Fines) $\ldots \ldots \ldots \ldots \ldots$

Fitted Partition Curves for PHT \#41

(Grade M Magnetite, 86 PSI, 0\% Fines) . . . . . . . . . . . . 56

Fitted Partition Curves for PHT \#42

(Grade M Magnetite, 20 PSI, 0\% Fines) . . . . . . . . . . . . 57

Fitted Partition Curves for the 48 x 200 Mesh Fraction for Grade K, L, and M Magnetites (High Pressure and $0 \%$ Fines) . . . . . . . . . 58

Fitted Partition Curves for the 200 x 500 Mesh Fraction for Grade K, L, and M Magnetites (High Pressure and 0\% Fines) . . . . . . . . . . 59

Fitted Partition Curves for the 48 x 500 Mesh Fraction for Grade K, L, and M Magnetites (High Pressure and 0\% Fines) . . . . . . . . . 60

Fitted Partition Curves for Plus-200-Mesh Fraction for Pittsburgh Seam Long Duration Run (Grade L Magnetite, 78 PSI, 0\% Fines) . . . . . . . 81 


\section{TABLE OF CONTENTS, (cont'd.)}

$\underline{\text { TABLE }}$

\section{DESCRIPTION}

PAGE

Project Reporting Requirements . . . . . . . . . . . . . . . 8

Custom Coals Corporation (Micro-Mag Project Equipment List) . . . . . . 15

As-Received Magnetite Head Analysis . . . . . . . . . . . . . . . . . . . 16

As-Received Magnetite Davis-Tube Recovery Profiles . . . . . . . . . . . . 16

As-Received Magnetite Size . . . . . . . . . . . . . . . . . 16

Ground Feed Coal Size Analysis and Washability Pittsburgh No. 8 Seam

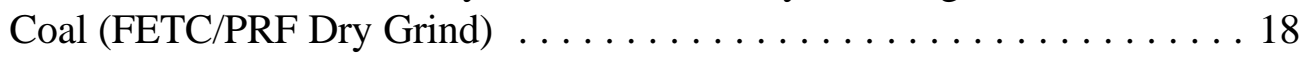

As-Received Raw Coal Size Analysis and Washability Longview Mine,

Kittanning "B" Seam . . . . . . . . . . . . . . . . . . . . . . . . . 19

Bulk Raw Coal Analyses (Dry Basis, Except Weight and Moisture) . . . . . 20

Classifying Circuit Commissioning Tests

(Pittsburgh No. 8 Seam Raw Coal) . . . . . . . . . . . . . . . 25

Dense-Medium Cyclone Splits Pittsburgh No. 8 Seam Commissioning

Tests (Grade-K Magnetite) . . . . . . . . . . . . . . . . . 26

Magnetite Losses Pittsburgh No. 8 Seam Commissioning Tests

(Grade-K Magnetite) . . . . . . . . . . . . . . . . . . 27

Micro-Mag Data Sheet . . . . . . . . . . . . . . . . . . . . . . 30

Solids Densities (Measured with Kerosene) . . . . . . . . . . . . . . . . 34

Davis-Tube and Moment Balances (Old and New PennMag Grade-K

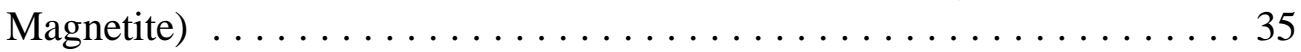

Classifying Circuit Optimization Tests . . . . . . . . . . . . . . . . 39

Typical Bulk Feed Samples for Dense-Medium Cyclone Component

Testing (Pittsburgh No. 8 Seam Coal) . . . . . . . . . . . . . . 41

Results from the Grade-K Dense-Medium Cyclone Component Testing

At a 5:1 Medium-to-Coal Ratio and a 1.40 Medium Density . . . . . . . . 42

Results from the Grade-K Dense-Medium Cyclone Component Testing

At a 10:1 Medium-to-Coal Ratio and a 1.40 Medium Density . . . . . . . . 43

Results from the Grade-K Dense-Medium Cyclone Component Testing

At a 5:1 Medium-to-Coal Ratio and a 1.40 Medium Density (2nd Series) . 44

Results from the Grade-L Dense-Medium Cyclone Component Testing

At a 5:1 Medium-to-Coal Ratio and a 1.40 Medium Density . . . . . . . . . 44

Results from the Grade-M Dense-Medium Cyclone Component Testing

At a 5:1 Medium-to-Coal Ratio and a 1.40 Medium Density . . . . . . . . . 45

Results from the Grade-E Dense-Medium Cyclone Component Testing

At a 5:1 Medium-to-Coal Ratio and a 1.40 Medium Density . . . . . . . . 45

Dense-Medium Cyclone Performance Results for Grades K, L, \& M

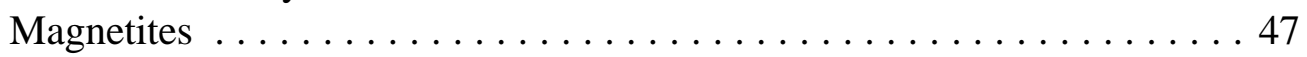

Expanded Dense-Medium Cyclone Performance Results for Grades K,

L, M \& E Magnetites . . . . . . . . . . . . . . . . . 62 


\section{TABLE OF CONTENTS, (cont'd.)}

TABLE

\section{DESCRIPTION}

PAGE

Medium Recovery Circuit Component Tests Simulated with No D\&R

Screens . . . . . . . . . . . . . . . . . . . 66

Medium Recovery Circuit Component Tests Simulated with D\&R

Screens . . . . . . . . . . . . . . . . . . . . . 67

Primary Integrated Testing Results $\ldots \ldots \ldots \ldots \ldots \ldots \ldots$. . . . . . . 70

Primary Integrated Testing Results for 4-Inch Dense-Medium Cyclone . . . 73

Continuous Integrated Magnetite Recovery Results for Grade-M

Magnetite . . . . . . . . . . . . . . . . . . . . 75

Continuous Integrated Dense-Medium Cyclone Results for Grade-M

Magnetite . . . . . . . . . . . . . . . . . . . . . . . . . . 75

Grade-M Long Duration Microtrac Results . . . . . . . . . . . . . . . . . 77

Continuous Integrated Magnetite Recovery Results for Grade-L

Magnetite . . . . . . . . . . . . . . . . . . . . . . . . . . . 79

Continuous Integrated Dense-Medium Cyclone Results for Grade-L

Magnetite . . . . . . . . . . . . . . . . . . . . . . 80

Grade-L Long Duration Microtrac Results . . . . . . . . . . . . . . 83

ASTM Standards for Coal Analytical Variances . . . . . . . . . . . . . 85

Comparison of Coal Analyses FETC and CT\&E Furnaces

(Test PCT \#1, 05/16/95) . . . . . . . . . . . . . . . 85

Davis-Tube Separation Accuracy and Repeatability Testing

(Pittsburgh No. 8 Seam Coal, Grade-K Magnetite) . . . . . . . . . . . . . 87

Magnetic Moment Measurement Reproducibility (Pittsburgh No. 8

Seam Coal, Grade-K Magnetite) . . . . . . . . . . . . . . 88

QA/QC Test for On-Site Wet Screening (Pittsburgh No. 8

Seam Coal, Grade-K Magnetite) . . . . . . . . . . . . . . . . . . . . . 89

Duplicate Test Results Dense-Medium Cyclone Component Tests

(Pittsburgh No. 8 Seam Coal, Grade-K Magnetite) . . . . . . . . . . . . . 90

Duplicate Feed Sample Results Dense-Medium Cyclone Component

Tests (Pittsburgh No. 8 Seam Coal, Grade-K Magnetite) . . . . . . . . . 91

Reconstituted Grade-L Magnetite Comparison . . . . . . . . . . . . . . . . . . . . . . . . . 92

Grade-L Magnetite Magnetics Comparison . . . . . . . . . . . . . . . . . . . . . . . . . . 93

Comparison of Duplicate Magnetic Moment Analysis . . . . . . . . . . . . . 94 


\begin{abstract}
Custom Coals, Corporation installed and tested a $500 \mathrm{lb} / \mathrm{hr}$ micronized-magnetite, fine-coal cleaning circuit at FETC's Process Research Facility (PRF). The cost-shared project was awarded as part of the Coal Preparation Program's, High efficiency Preparation Subprogram. The project included design, construction and testing of a fully-integrated, bench-scale circuit, complete with feed coal classification to remove the minus-500M slimes, dense-medium cycloning of the $48 \mathrm{M} \times 500 \mathrm{M}$ feed coal using three different size micronized-magnetite mediums, and medium recovery circuits using drain and rinse screens and various stages and types of magnetic separators. The results of this project.
\end{abstract}




\section{EXECUTIVE SUMMARY}

\section{Bench-Scale Testing of the Micronized Magnetite Process \\ (Contract No. DE-AC22-93PC92206)}

\section{PROJECT INTRODUCTION}

A recent emphasis of the Department of Energy's (DOE's), Coal Preparation Program has been the development of high-efficiency technologies that offer near-term, low-cost improvements in the ability of coal preparation plants to address problems associated with coal fines. In 1992, three cost-shared contracts were awarded to industry, under the first High-Efficiency Preparation (HEP I) solicitation. All three projects involved bench-scale testing of various emerging technologies, at the Federal Energy Technology Center's (FETC's), Process Research Facility (PRF). The first HEP I project, completed in mid-1993, was conducted by Process Technology, Inc., with the objective of developing a computerized, on-line system for monitoring and controlling the operation of a column flotation circuit. The second HEP I project, completed in mid-1994, was conducted by a team led by Virginia Polytechnic Institute to test the Mozely Multi-Gravity Separator in combination with the Microcel Flotation Column, for improved removal of mineral matter and pyritic sulfur from fine coal.

The last HEP I project, of which the findings are contained in this report, was conducted by Custom Coals Corporation to evaluate and advance a micronized-magnetite-based, fine-coal cycloning technology.

The micronized-magnetite coal cleaning technology, also know as the Micro-Mag process, is based on widely used conventional dense-medium cyclone applications, in that it utilizes a finely ground magnetite/water suspension as a separating medium for cleaning fine coal, by density, in a cyclone. However, the micronized-magnetite cleaning technology differs from conventional systems in several ways:

- It utilizes significantly finer magnetite (about 5 to 10 micron mean particle size), as compared to normal mean particle sizes of 20 microns.

- It can effectively beneficiate coal particles down to 500M in size, as compared to the most advanced, existing conventional systems that are limited to a particle bottom size of about $28 \mathrm{M}-100 \mathrm{M}$.

- Smaller diameter cyclones, 4 to 10 inches, are used to provide the higher G-force required to separate the finer feed coal.

- Cyclone feed pressures up to 10 times greater than those used in conventional cleaning systems are employed to enhance the separating forces. 


\section{Custom Coal Corporation}

- $\quad$ More advanced magnetite recovery systems, including rare-earth drums are required for recovery and reuse of the medium.

\section{PROJECT OBJECTIVES}

The general objective of the project, which occurred from September 1994 thru January 1996, was to design, construct, and operate a fully integrated, $500 \mathrm{lb} / \mathrm{hr}$., continuous micronized-magnetite cycloning circuit for cleaning fine coal. The work focused on the medium recovery circuit and the impact of recirculating medium quality on the separation performance of the cyclone.

The testing scope of the project was designed to accomplish two overall objectives. These objectives were to:

- Determine the effects of operating time on the characteristics of the recirculating medium in a continuous integrated processing circuit, and, subsequently, the sensitivity of cyclone separation performance to the quality of the recirculating medium.

- Determine the technical and economic feasibility of various unit operations and systems in optimizing the separation and recovery of the micronized magnetite from the coal products.

The specific technical objectives of the project were to:

- Establish the classifying circuit's operating conditions to make a separation at, or about 40 microns.

- Determine the effects of magnetite particle size and medium purity on cyclone separation performance.

- Determine the effects of medium-to-coal ratio, medium density, feed pressure, and cyclone configuration on the separation efficiency of the cyclone. This testing is to verify whether cyclone separation performance equivalent to that produced in earlier research can be achieved and to determine the potential ranges of medium-to-coal ratios and medium densities expected for each cyclone product to help establish recovery circuit feed conditions.

- Quantify the amount and size of the magnetite not recovered by the individual and combined recovery circuit unit operations.

- Assess the technical and economic feasibility of various magnetite recovery circuits. Technically, the focus is on establishing the least complicated, easiest to operate circuit, that will provide the correct recirculating medium properties. Economically, determinations will be made looking at the trade offs between circuit capital and maintenance costs and overall 
system performance, including expected makeup magnetite requirements and cyclone separation efficiency.

- Determine the characteristics of the recirculating medium (purity and size distribution), and cyclone separation performance over time, during continuous, integrated testing of the entire circuit.

\section{PROJECT TEAM ORGANIZATION AND SCHEDULE}

The project team was assembled to ensure that all expertise to successfully complete the project was accounted for within the project organization. The key organizations within the project included:

- $\quad$ DOE/FETC's project and site management personnel.

- $\quad$ Custom Coals' project and site management personnel.

- Parson's engineers and technicians who operated the existing PRF, during the circuit testing.

- $\quad \mathrm{H}-\mathrm{Tech}$ Corporation who procured all equipment required for the project.

- $\quad$ Dillner Storage who provided coal blending and storage services for the project.

- CLI Corporation who finalized the circuit design.

- $\quad$ Rizzo \& Sons who installed the circuit and assisted with the circuit commissioning.

- $\quad$ Michigan Technological University's (MTU) Institute of Materials Processing (IMP) who performed density, magnetics/nonmagnetics separations, ashing on 500M x 0 nonmagnetics and Microtrac analysis.

The planned project schedule is shown in Figure A. Custom Coals divided the project into major task and subtasks. The schedule is broken down on a bi-monthly basis and represent the planned schedule by which the project was to be accomplished except for completion of the final report.

\section{CIRCUIT DESIGN}

Figure B contains a block-flow diagram of the Micro-Mag test circuit used in this work. It consisted of three subcircuits:

- Classification Circuit - This circuit was to deslime the feed coal as received from the PRF at about $500 \mathrm{M}$. The classification circuit consisted of a feed sump and pump, a 2" Krebs 
Figure A. Planned Micro-Mag Project Schedule by Task (DOE Contract No. DE-AC22-93PC92206)

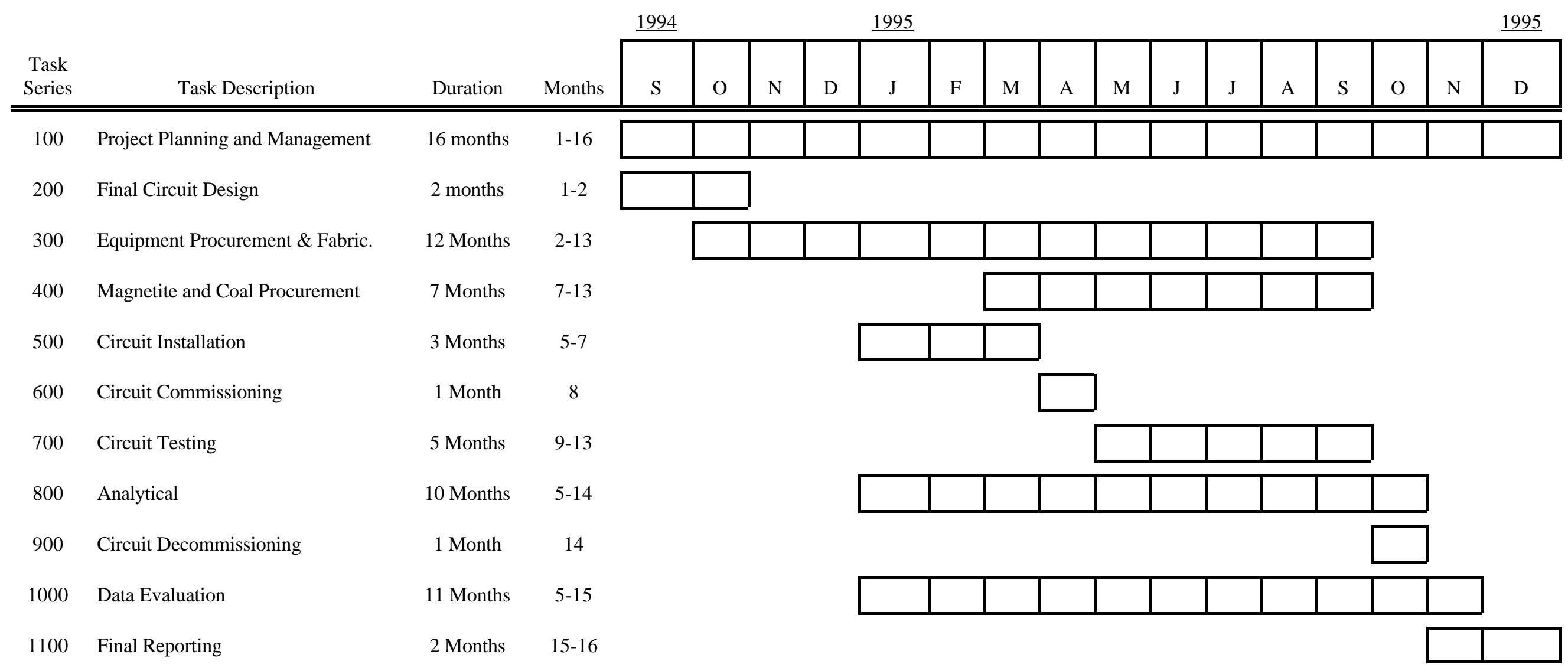



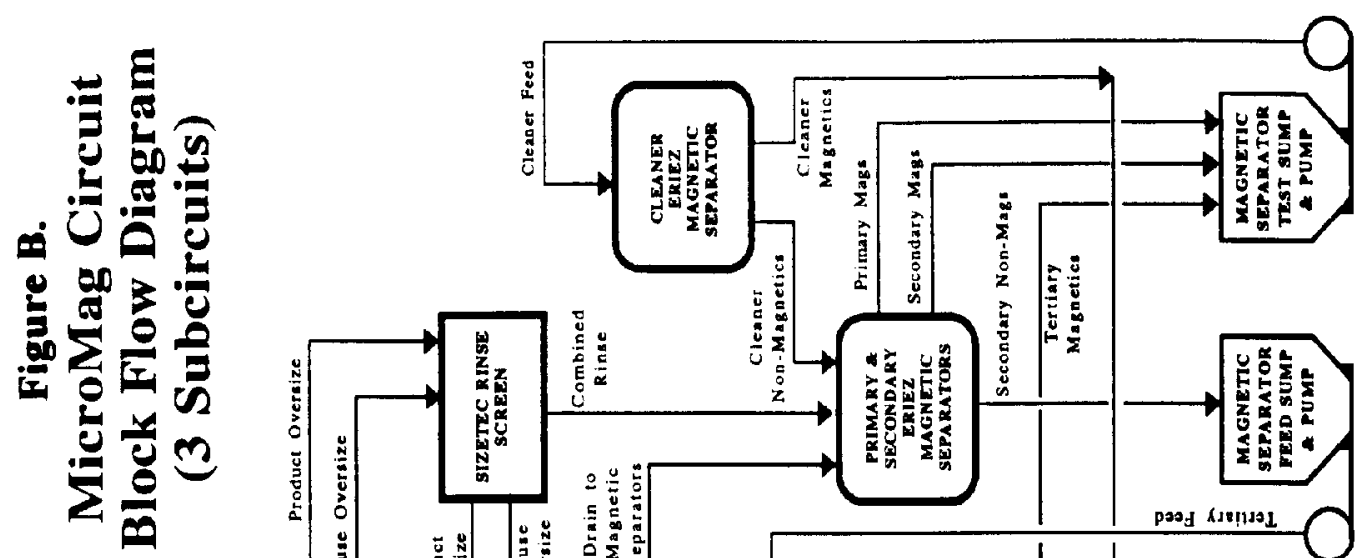

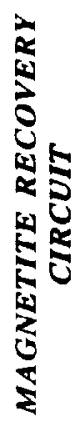

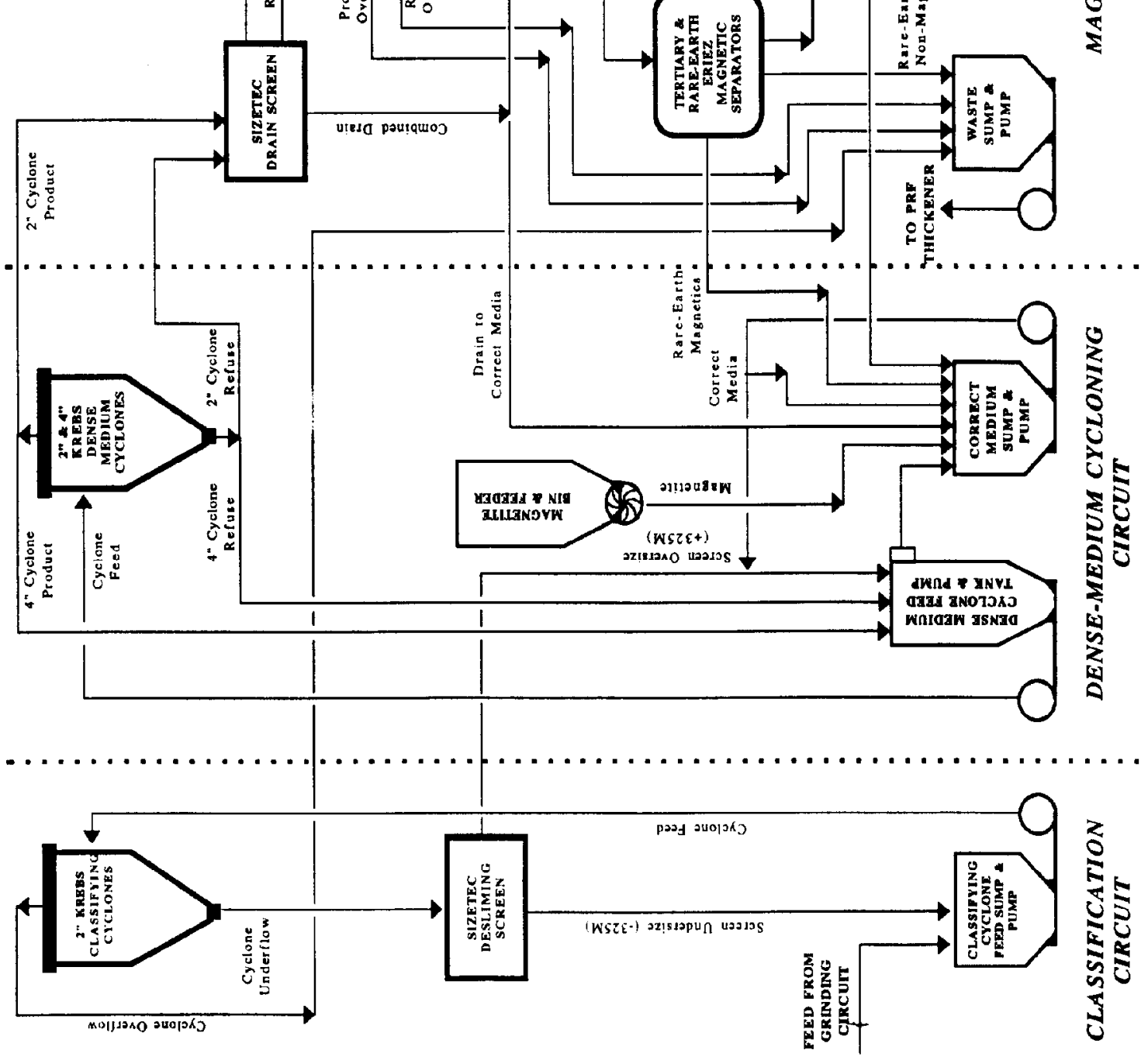


Classifying Cyclone, and a split 2' x 3' Sizetec Inclined Desliming Screen. The Classifying Cyclone was equipped with various orifices to make a cut (i.e., D-50) at 500M. The north side of the Desliming Screen was equipped with 325M layered screen panels for desliming while the south side of the Desliming Screen was equipped with 100M layered screen panels for dewatering. The Classification Circuit was fed 48M x 0 coal slurry from the existing PRF grinding circuit, and removed the majority of the slimes prior to the dense-medium cycloning circuit.

- Dense-Medium Cycloning Circuit - This circuit consisted of two dense-medium cyclones, wing tank and feed pump, a cyclone product sampling station, a magnetite supply bin, and a nuclear density gauge. Parallel-mounted Krebs 2" and 4" diameter Dense-Medium Cyclones were used during the testing. The 4" Cyclone products always recirculated back to the feed sump, and the 2" Cyclone products represented the feed to the Magnetite Recovery Circuit. Magnetite was added as required via a rotary air-lock feeder from a 0.5 ton magnetite bin.

- Magnetite Recovery Circuit - This circuit consisted of a 2' x 3' Sizetec Inclined Desliming Screen (Drain screen), and a 4' x 9' Sizetec Horizontal Dewatering Screen (Rinse Screen). These screens had screen panels of $100 \mathrm{M}$ or $200 \mathrm{M}$. The magnetite recovery circuit contained four 36" x 24" Eriez Conventional, Wet-Drum Magnetic Separators (CLIMAXX Models), as the Primary, Secondary, Tertiary, and Cleaner Magnetic Separators. There was also an Eriez High Gauss, Rare-Earth Magnetic Separator (Concurrent Flow), which was used as a Scavenger Magnetic Separator in the circuit. The final magnetic concentrates returned to the Correct Medium Sump, and the final non-magnetics tailings reported to the Waste Sump and Pump, along with the Classifying Cyclone Overflow and Rinse Screen Oversize (see Figure B). The Waste Sump discharge was dewatered using the Sharples Centrifuge and Thickener in the existing PRF process water clarification circuit.

The circuit was contained in a new permanent structure, that Custom Coals installed in the PRF Emerging Technology (ET) Area. In addition to the equipment shown in Figure B, the Micro-Mag circuit contained a Clarified Water Head Tank and Pump to provide all water additions to the circuit. A closed-loop system was utilized in the circuit. A Motor Control Center (MCC) in the PRF motor control room, and Control Cabinet (CC) in the field provided the power distribution to the circuit.

\section{FEED COALS AND MAGNETITES}

The two major test materials used for the project were magnetite and the test coals. Custom Coals tested three grades (K, L, and M) of micronized magnetites and two types of bituminous coals. Limited testing was also conducted using a commercial Grade E magnetite. 
Custom Coals used four magnetites Custom Coals for the project including:

- $\quad$ PennMag Grade-K Magnetite - Ground natural magnetite, with a mean particle size of 9.8 microns.

- $\quad$ PennMag Grade-L Magnetite - Finely ground natural magnetite with a mean particle size of 6.6 microns.

- $\quad$ Pea Ridge Grade-M Magnetite - Extremely fine magnetite ground to a mean particle size of 3.0 microns.

- $\quad$ Reiss Viking Grade-E Magnetite - The finest commercial grade magnetite currently available.

Particle size distributions and magnetic moment measurements of the four magnetites are shown in Table A.

Table A. As-Received Magnetite Size

\begin{tabular}{||l|c|c|c|c||}
\hline \multicolumn{1}{|c|}{ Analysis } & Grade-E & Grade-K & Grade-L & Grade-M \\
\hline \hline $\mathrm{D}_{90}(90 \%$ Passing) & 53.2 & 18.0 & 12.8 & 5.0 \\
\hline $\mathrm{D}_{50}(50 \%$ Passing) & 17.1 & 8.9 & 5.7 & 2.7 \\
\hline $\mathrm{D}_{10}$ (10\% Passing) & 3.9 & 3.5 & 2.4 & 1.4 \\
\hline MVD (Mean Volume Dia.) & 23.4 & 9.8 & 6.6 & 3.0 \\
\hline Magnetic Moment (EMU/g) & 86 & 87 & 77 & 82 \\
\hline \hline
\end{tabular}

Similarly, Custom Coals selected two test coals for the Micro-Mag circuit testing. The coals were:

- Pittsburgh No. 8 Seam bituminous raw coal from Ohio Valley Coal Company in Belmont County, Ohio.

- Lower Kittanning "B" Seam bituminous raw coal from PB\&S Coal Company's, Longview Mine in Somerset County, Pennsylvania.

Both coals were obtained from underground mines, and contained dry ash contents of between 20 and $30 \mathrm{Wt} \%$. Over half of the sulfur in both coals were in the pyritic form so they were good candidates for aggressive cleaning studies. They also both had yields of 70 to $80 \mathrm{Wt} \%$, when cleaned at about 1.60 SG. 


\section{ANALYTICAL CONSIDERATIONS}

Sample collection, handling, and analyses was one of the most challenging aspects of the project. Accurate, reliable, and reproducible sampling data was pivotal for conducting the circuit performance evaluations and completing the project objectives. The analytical efforts for the project were complicated by the fact that the circuit was evaluated for not only overall performance but also performance of individual unit operations. Unit operations sampling created a number of sampling and analytical problems, which included:

1. The collection of accurate timed samples of rather high volume flowrate streams (1 to 60 GPM) to determine flow balances around the circuit.

2. A reliable method needed to be found to identify the extremely-fine magnetic particles, and consistently separate them from non-magnetic particles in all samples.

3. Solids weights and/or solids contents determinations needed to be made on all samples, as well as for the magnetics and non-magnetics fractions from the separations in item 2 . Filtering and dewatering samples would be very difficult, particularly for the samples containing the micronized magnetic.

4. After separation, determinations of size content and composition would be required for the magnetics fraction.

5. After separation, accurate determinations of head composition, size content, and gravity distribution would be required for the non-magnetics. The larger sample sizes required to perform these analyses would present some significant logistical problems, due to the limited capacity of the laboratory magnetic separation units.

To address the most difficult analytical problems listed above, Custom Coals subcontracted Michigan Technological University's (MTU) Institute of Materials Processing (IMP) to perform a laboratory investigations to determine required laboratory procedures for the fine-coal and magnetite slurry and solid samples that were to be generated during the project testing. The main analytical concerns addressed by MTU included:

- density, and agglomeration measurements

- magnetics/nonmagnetics separations

- $\quad$ magnetics analyses (i.e., magnetic moments and compositions)

- magnetics and nonmagnetics size analyses, down to sub-micron sizes.

MTU's IMP provided laboratory analyses services, for the project test samples, using the equipment and procedures they developed during this investigation. A complete detailing of the work completed by MTU is included in the body of the report. 


\section{TESTING}

The test program was divided into three testing phases, which included:

- Component Testing

- $\quad$ Primary Integrated Testing, and

- Continuous Integrated Testing

Only selected portions of each of the testing phases are reported in this Executive Summary. Complete details of the testing are found in the body of the report.

\section{Component Testing}

The component testing phase involved the "closed-looped" testing of each of the classification, fourinch dense-medium cyclone, and medium recovery circuits individually. Testing was focused on optimizing these separate subcircuits.

\section{Dense Medium Cyclone Component Testing Results}

The two main goals of the dense medium cyclone component testing were to:

- Determine the effects of the magnetite particle size and medium purity on cyclone separation performance, and

- Determine the effects of medium-to-coal ratio, feed pressure, and cyclone configuration on the separation efficiency of the cyclone.

Ultimately, this testing led to the selection of the two magnetites and the dense-medium cyclone feed pressure that was used during the continuous integrated testing.

To accomplish this portion of the testing, the dense-medium cyclone sump was manually filled to obtain the desired test conditions. The feed coal $(+500 \mathrm{M})$ and the slimes or contamination $(-500 \mathrm{M})$ were generated by operating only the Micro-Mag's classification circuit and collecting the deslime screen's south side discharge $(+500 \mathrm{M}$ coal) in drums and valving the flowsheet such that only the minus 500M slimes reported to the PRF Sharples centrifuge. The Sharles cake (-500M slimes) was also collected in drums and then it and the south side deslime screen discharge $(+500 \mathrm{M})$ were air dried and mixed with magnetite and water to make the desired feed to the 4-inch dense-medium cyclone.

All the dense-medium cyclone component tests were conducted at 1.40 S.G. circulating medium using the Pittsburgh No. 8 seam coal. A total of six batches of tests were performed using different magnetite grades, contamination levels, cyclone configurations, media-to-coal ratios, and cyclone feed 
pressures. The Grade K, L, and M micronized magnetites were used in the testing along with a commercially available Grade E magnetite.

Based on the feed, clean coal, and refuse ash results in conjunction with the yield results from Batches $3,4, \& 5$, partition curves were constructed on ten selected tests in which the Grade K, L, \& M magnetites were used. No partition curves were constructed from the Grade E magnetite batch testing due to the limited laboratory funds budgeted for the project. Table B presents the results from the partition curves. Figure $\mathrm{C}$ and $\mathrm{D}$ show distribution curves for the $48 \mathrm{M}$ x $200 \mathrm{M}$ and $200 \mathrm{M} \mathrm{x}$ $500 \mathrm{M}$ fractions, respectively, for each of the three grades of micronized magnetites at high cyclone inlet pressure and low medium contamination.

The component testing of the dense-medium cyclone produced some interesting and in some cases surprising results. Some of the more important findings included:

- At low medium contamination levels, the separation performance of the 4-inch dense-medium cyclone is very efficient down to the $500 \mathrm{M}$ particle size for both the Grade $\mathrm{K} \& \mathrm{~L}$ magnetites. Probable errors were produced in the range of about 0.050 to 0.090 for the $48 \mathrm{M}$ x $200 \mathrm{M}$ fraction and 0.110 to 0.160 for the $200 \mathrm{M}$ x $500 \mathrm{M}$ fraction.

- Surprisingly, the finest magnetite, Grade-M, resulted in the worst dense-medium cyclone performance with an Ep of 0.094 on the 48M x 200M size fraction and a Ep of 0.282 on the $200 \mathrm{M}$ x 500M size fraction.

- Of the three grades of micronized magnetite tested, the Grade-L magnetite resulted in the best overall cyclone performance with the Grade-K magnetite closely approaching the Grade-L's overall performance.

- $\quad$ Performance using a Grade E magnetite appeared to be surprisingly good down to 500M when using the 4-inch dense-medium cyclone at high pressures.

- At high medium contamination levels the dense-medium cyclone performance deteriorated significantly. However, high feed pressures helped buffer the detrimental affects of the contamination.

- The $\mathrm{D}_{50}$ or separating gravity decreased as the magnetite size decreased. This was true in general for all size fractions with and without fines contamination present.

- Changing variables, such as cyclone inlet size and apex size appeared to have little affect on cyclone performance when using the same grade of magnetite. 
Table B. Dense-Medium Cyclone Performance Results for Grades K, L, \& M Magnetites

\begin{tabular}{|c|c|c|c|c|c|c|c|c|c|c|c|c|}
\hline & & & & & & & \multicolumn{6}{|c|}{ Dense-Medium Cyclone Performance } \\
\hline \multicolumn{4}{|c|}{ Operating Conditions } & \multicolumn{3}{|c|}{ Cyclone Orifice Combination } & \multicolumn{2}{|c|}{$48 M \times 200 M$} & \multicolumn{2}{|c|}{$200 \mathrm{M} \times 500 \mathrm{M}$} & \multicolumn{2}{|c|}{$48 M \times 500 M$} \\
\hline $\begin{array}{l}\text { Test } \\
\text { No. }\end{array}$ & $\begin{array}{c}\text { Magnetite } \\
\text { Grade }\end{array}$ & $\begin{array}{c}\text { Cont. Level } \\
(\mathrm{Wt} \%)\end{array}$ & $\begin{array}{l}\text { Feed Pre. } \\
\quad \text { (PSI) }\end{array}$ & $\begin{array}{l}\text { Feed Inlet } \\
\text { (sq. in.) }\end{array}$ & $\begin{array}{l}\text { Overflow } \\
\text { (in.) }\end{array}$ & $\begin{array}{c}\text { Apex } \\
\text { (in.) }\end{array}$ & Ep & D50 & Ep & D50 & Ep & D50 \\
\hline PHT \#23 & GRADE-K & 0 & 88 & 0.12 & 1.0 & 0.625 & 0.080 & 2.08 & 0.116 & 2.29 & 0.091 & 2.14 \\
\hline PHT \#26 & GRADE-K & 0 & 19 & 0.25 & 1.0 & 0.625 & 0.080 & 1.99 & 0.104 & 2.25 & 0.115 & 2.08 \\
\hline PHT \#30 & GRADE-K & 40 & 86 & 0.12 & 1.0 & 0.625 & 0.085 & 1.94 & 0.140 & 2.24 & 0.131 & 2.06 \\
\hline PHT \#31 & GRADE-K & 40 & 19 & 0.25 & 1.0 & 0.625 & 0.107 & 1.82 & 0.228 & 2.14 & 0.184 & 1.91 \\
\hline PHT \#35 & GRADE-L & 0 & 88 & 0.12 & 1.0 & 0.625 & 0.053 & 1.73 & 0.154 & 1.96 & 0.087 & 1.74 \\
\hline PHT \#32 & GRADE-L & 0 & 19 & 0.25 & 1.0 & 0.625 & 0.072 & 1.68 & 0.187 & 1.92 & 0.092 & 1.70 \\
\hline PHT \#40 & GRADE-L & 40 & 88 & 0.12 & 1.0 & 0.625 & 0.069 & 1.66 & 0.193 & 1.91 & 0.094 & 1.70 \\
\hline PHT \#39 & GRADE-L & 40 & 17 & 0.25 & 1.0 & 0.625 & 0.103 & 1.58 & 0.437 & 2.09 & 0.180 & 1.60 \\
\hline PHT \#41 & GRADE-M & 0 & 86 & 0.12 & 1.0 & 0.625 & 0.094 & 1.57 & 0.282 & 2.01 & 0.132 & 1.61 \\
\hline PHT \#42 & GRADE-M & 0 & 20 & 0.25 & 1.0 & 0.625 & 0.114 & 1.57 & 0.394 & 2.18 & 0.174 & 1.60 \\
\hline
\end{tabular}

NOTE: All Test Were Conducted at 5:1 Medium-To-Coal Ratio at 1.40 S.G. Medium Density. 


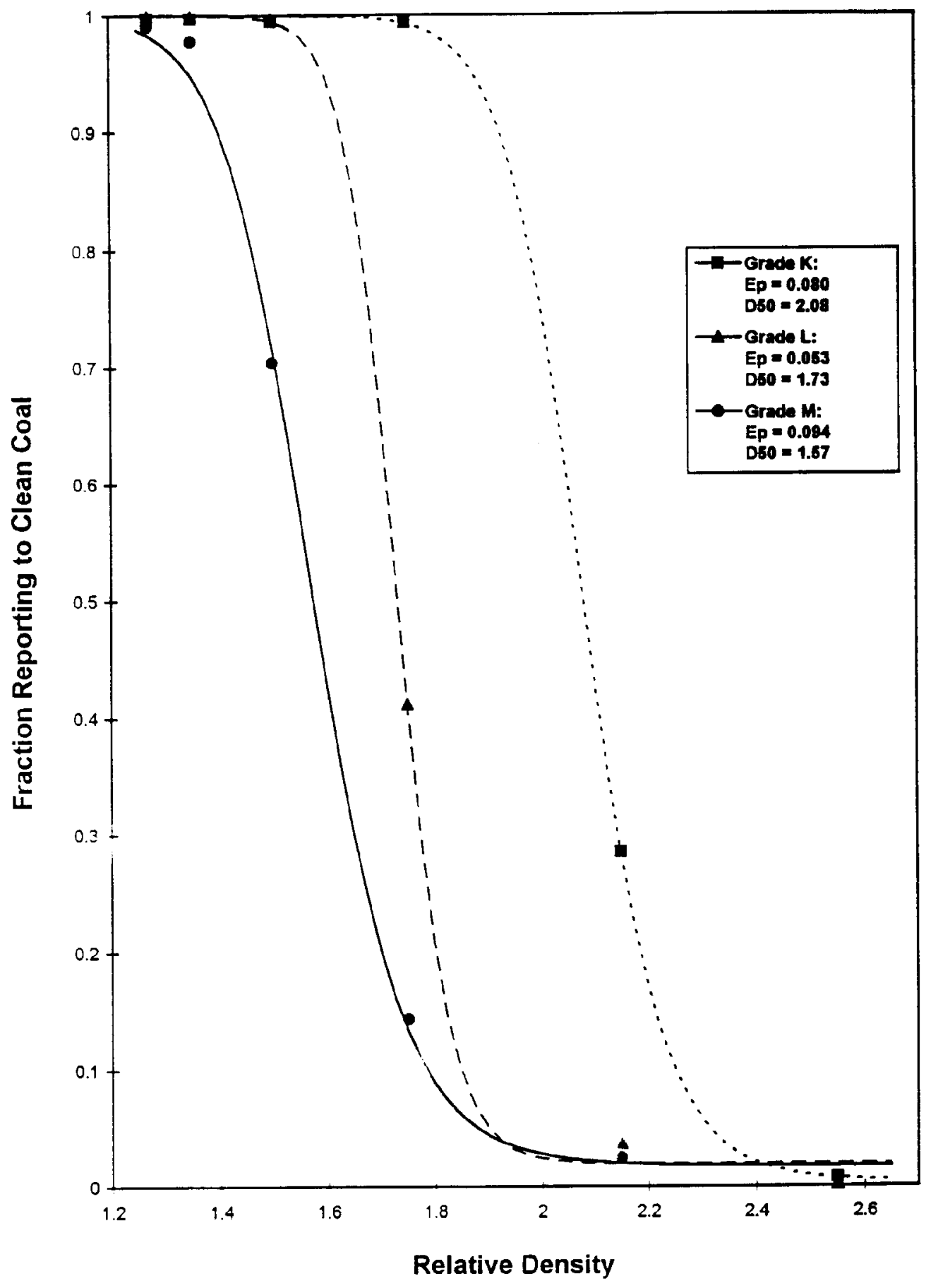

Figure C. Fitted Partition Curves for the $\mathbf{4 8} \times 200$ Mesh Fraction for Grade K, L, and $M$ Magnetites (High Pressure and 0\% Fines) 


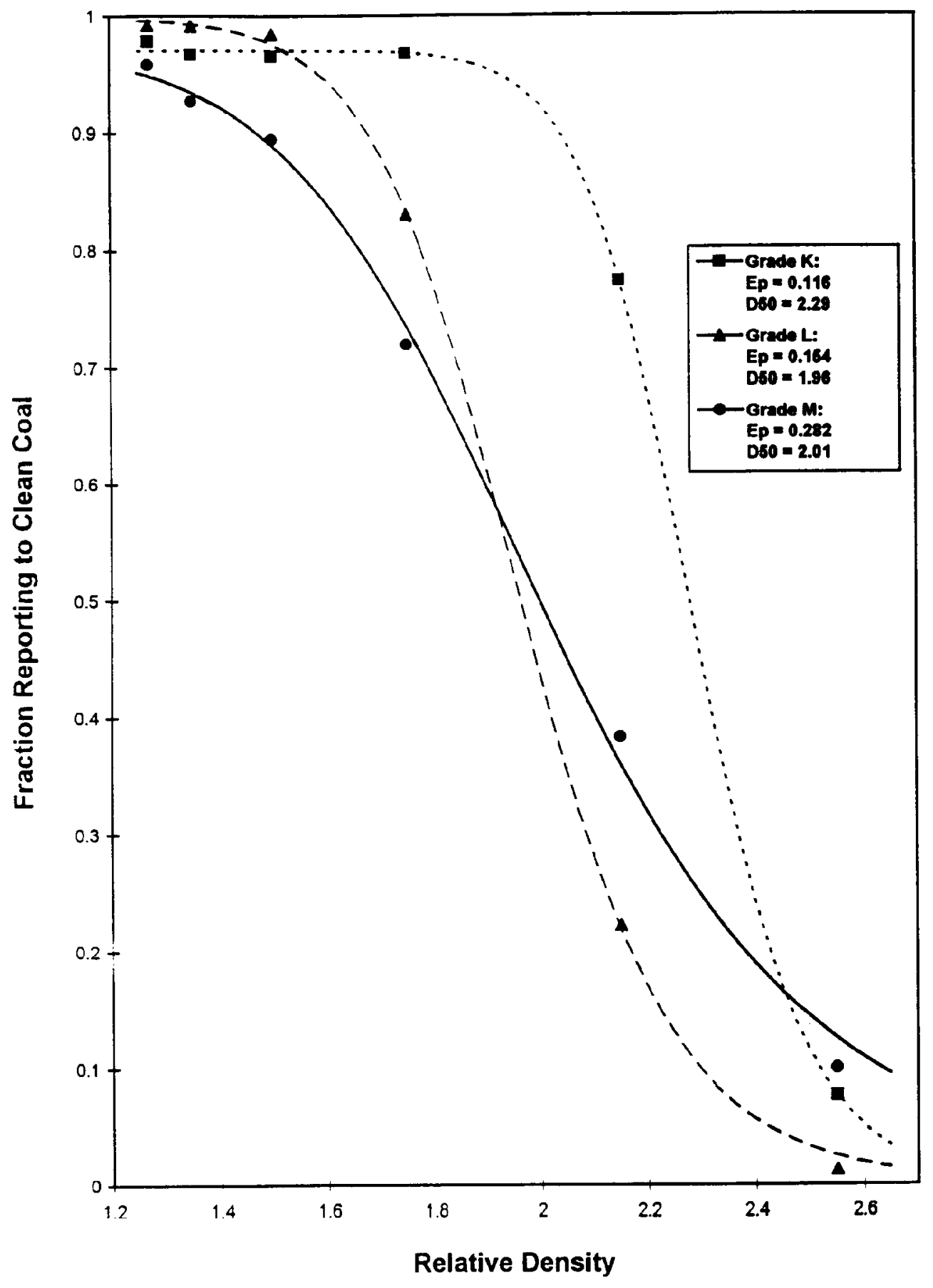

Figure D. Fitted Partition Curves for the $200 \times 500$ Mesh Fraction for Grade K, L, and M Magnetites (High Pressure and 0\% Fines) 


\section{Primary Integrated Testing Results}

The primary integrated testing was conducted by operating the entire Micro-Mag circuit for relatively short periods of time to observe the impact of key process variables and to ascertain the capability of the entire Micro-Mag circuit. This work focused on establishing the least complicated, easiest to operate circuit, that would provide the correct recirculating medium properties and to quantify the amount of magnetite not recovered by the individual and combined recovery circuit unit operations.

\section{Primary Integrated Magnetite Recovery Testing Results}

A total of ten primary integrated tests were conducted, five using the Grade-K magnetite, three using the Grade-L magnetite, and two using the Grade-M magnetite. During each of these tests various combinations of drain- and rinse-screen mesh sizes, wash rates, and screen angles were tested along with different magnetic separator configurations. Tests were run both with and without the use of drain and rinse screens to test if the magnetic separators were, by themselves, sufficient to recovery the magnetite.

Selected results from all ten tests are presented in Table C. Some of the conclusions that were drawn from the primary testing phase of the project include.

- In all tests, extremely large amounts of magnetite are being lost in the discharge of the rinse screen when 200M decks are used. It appears that a slight negative angle on the rinse screen helps to reduce the amount of magnetite lost when 200M decks are used but the losses even at the negative angle are significant.

- When using the Grade K and L magnetites with $100 \mathrm{M}$ decks only small amounts of magnetite are being lost in the discharge of the rinse screen. However, when coupled with the magnetite loss from the rare earth magnetic separator the total circuit losses for the Grade- $K$ are on the order of 4.1 to $4.6 \mathrm{lb} /$ ton of circuit feed and the total circuit losses for the Grade-L are slightly over $12.1 \mathrm{lb} /$ ton.

- When using the Grade-M magnetite with $100 \mathrm{M}$ decks huge amounts of magnetite are being lost in the discharge of the rinse screen. This was most likely caused by the magnetite becoming magnetized when being recovered by the magnetic separator circuits. This would of caused the magnetite particles to adhere together making it difficult for the sprays on the rinse screen to rinse the magnetite particles through the screen.

- The circuit that produced the best overall magnetite recovery was by-passing the drain and rinse screens which resulted in the 2-inch dense-medium cyclones products reporting directly to the magnetic separator circuits. This was true for all three magnetites tested. This circuit resulted in a $3.8 \mathrm{lb} /$ ton magnetite loss when using the Grade- $\mathrm{K}$ magnetite, a $5.8 \mathrm{lb} /$ ton 
Table C. Primary Integrated Testing Results

\begin{tabular}{|c|c|c|c|c|c|c|c|c|}
\hline \multirow[b]{2}{*}{$\begin{array}{c}\text { Test } \\
\text { Number }\end{array}$} & \multirow[b]{2}{*}{$\begin{array}{l}\text { Magnetite } \\
\text { Grade }\end{array}$} & \multirow[b]{2}{*}{$\begin{array}{c}\text { Test } \\
\text { Configuration }\end{array}$} & \multirow[b]{2}{*}{$\begin{array}{l}\text { D\&R Screen } \\
\text { Deck Size }\end{array}$} & \multirow[b]{2}{*}{$\begin{array}{c}\text { Rinse Scn. } \\
\text { Angle }\end{array}$} & \multicolumn{4}{|c|}{$\%$ Magnetics } \\
\hline & & & & & $\begin{array}{l}\text { Combined Drain } \\
\text { Screen Effluent }\end{array}$ & $\begin{array}{c}\text { Pri. Mag. Sep. } \\
\text { Concentrate }\end{array}$ & $\begin{array}{l}\text { Cln. Mag. Sep. } \\
\text { Concentrate }\end{array}$ & $\begin{array}{l}\text { Correct } \\
\text { Medium }\end{array}$ \\
\hline PIT \#1 & $\mathrm{K}$ & With D\&R Screens & $200 \mathrm{M}$ & Positive & 94.20 & 97.50 & 96.49 & 95.60 \\
\hline PIT \#2 & $\mathrm{K}$ & Without D\&R Screens & N.A. & N.A. & N.A. & 96.01 & 99.90 & - \\
\hline PIT \#3 & $\mathrm{K}$ & With D\&R Screens & $200 \mathrm{M}$ & Negative & 95.52 & 92.49 & 99.65 & 98.80 \\
\hline PIT \#4 & $\mathrm{K}$ & With D\&R Screens & $100 \mathrm{M}$ & Negative & 88.45 & 98.97 & 99.15 & 97.71 \\
\hline PIT \#5 & $\mathrm{K}$ & With D\&R Screens & $100 \mathrm{M}$ & Positive & 86.87 & 97.61 & 98.20 & 96.35 \\
\hline PIT \#6 & $\mathrm{L}$ & With D\&R Screens & $100 \mathrm{M}$ & Negative & 81.00 & 96.43 & 96.58 & 78.50 \\
\hline PIT \#7 & $\mathrm{L}$ & Without D\&R Screens & N.A. & N.A. & N.A. & 94.69 & 97.29 & 79.37 \\
\hline PIT \#8 & $\mathrm{L}$ & With D\&R Screens & $200 \mathrm{M}$ & Negative & 90.99 & 98.21 & 97.51 & 77.85 \\
\hline PIT \#9 & M & With D\&R Screens & $100 \mathrm{M}$ & Negative & - & 96.66 & 96.77 & 84.36 \\
\hline PIT \#10 & M & Without D\&R Screens & N.A. & N.A. & N.A. & 89.96 & 95.40 & 74.67 \\
\hline
\end{tabular}


Table C. Primary Integrated Testing Results, (continued)

\begin{tabular}{|c|c|c|c|c|c|c|c|c|c|c|c|c|c|}
\hline \multirow[b]{2}{*}{$\begin{array}{c}\text { Test } \\
\text { Number }\end{array}$} & \multirow[b]{2}{*}{$\begin{array}{c}\text { Magnetite } \\
\text { Grade }\end{array}$} & \multirow[b]{2}{*}{$\begin{array}{c}\text { Test } \\
\text { Configuration }\end{array}$} & \multirow[b]{2}{*}{$\begin{array}{c}\text { D\&R Screen } \\
\text { Deck Size }\end{array}$} & \multirow[b]{2}{*}{$\begin{array}{c}\text { Rinse Scn. } \\
\text { Angle }\end{array}$} & \multicolumn{4}{|c|}{ \% Magnetics } & \multicolumn{5}{|c|}{ Magnetite Loss Per Ton of Equipment Feed } \\
\hline & & & & & \begin{tabular}{|c|} 
Refuse Rinse \\
Discharge
\end{tabular} & $\begin{array}{l}\text { C.C. Rinse } \\
\text { Discharge }\end{array}$ & $\begin{array}{l}\text { Sec. Mag. } \\
\text { Sep. Tails }\end{array}$ & $\begin{array}{l}\text { Scav. Mag } \\
\text { Sep. Tails }\end{array}$ & $\begin{array}{l}\text { Refuse Rinse } \\
\text { Discharge }\end{array}$ & $\begin{array}{l}\text { C.C. Rinse } \\
\text { Discharge }\end{array}$ & $\begin{array}{l}\text { Sec. Mag. } \\
\text { Sep. Tails }\end{array}$ & $\begin{array}{l}\text { Scav. Mag } \\
\text { Sep. Tails }\end{array}$ & $\begin{array}{c}\text { Circuit } \\
\text { Magnetite } \\
\text { Loss (lb/ton) }\end{array}$ \\
\hline PIT \#1 & $\mathrm{K}$ & With D\&R Screens & $200 \mathrm{M}$ & Positive & 4.90 & 24.10 & 1.57 & 1.78 & 102.8 & 635.1 & 20.4 & 36.3 & 512.0 \\
\hline PIT \#2 & $\mathrm{K}$ & Without D\&R Screens & N.A. & N.A. & N.A. & N.A. & 0.15 & 0.19 & N.A. & N.A. & 2.6 & 3.8 & 3.8 \\
\hline PIT \#3 & $\mathrm{K}$ & With D\&R Screens & $200 \mathrm{M}$ & Negative & 0.37 & 7.99 & 0.90 & 0.43 & 7.5 & 173.8 & 13.4 & 8.6 & 108.6 \\
\hline PIT \#4 & $\mathrm{K}$ & With D\&R Screens & $100 \mathrm{M}$ & Negative & 0.07 & 0.00 & 0.41 & 0.36 & 1.3 & 0.0 & 7.9 & 6.2 & 4.6 \\
\hline PIT \#5 & $\mathrm{K}$ & With D\&R Screens & $100 \mathrm{M}$ & Positive & 0.08 & 0.00 & 0.06 & 0.37 & 1.6 & 0.0 & 6.4 & 6.0 & 4.1 \\
\hline PIT \#6 & $\mathrm{L}$ & With D\&R Screens & $100 \mathrm{M}$ & Negative & 0.00 & 0.00 & 0.65 & 0.60 & 0.0 & 0.0 & 11.4 & 12.1 & 12.1 \\
\hline PIT \#7 & $\mathrm{L}$ & Without D\&R Screens & N.A. & N.A. & N.A. & N.A. & 0.29 & 0.29 & N.A. & N.A. & 4.8 & 5.8 & 5.8 \\
\hline PIT \#8 & $\mathrm{L}$ & With D\&R Screens & $200 \mathrm{M}$ & Negative & 9.85 & 3.63 & 0.65 & 0.41 & 218.5 & 75.4 & 11.4 & 8.3 & 79.8 \\
\hline PIT \#9 & M & With D\&R Screens & $100 \mathrm{M}$ & Negative & 35.91 & 30.10 & 18.03 & 6.16 & 1120.0 & 861.0 & 440.0 & 131.0 & 486.4 \\
\hline PIT \#10 & M & Without D\&R Screens & N.A. & N.A. & N.A. & N.A. & 62.38 & 4.82 & N.A. & N.A. & 3157.0 & 94.0 & 94.0 \\
\hline
\end{tabular}




\section{Custom Coal Corporation}

magnetite loss when using the Grade-L magnetite and a $94.0 \mathrm{lb} /$ ton magnetite loss when using the Grade-M magnetite. The magnetite losses for the Grade $\mathrm{K}$ and $\mathrm{L}$ magnetites were fairly respectable. However, the Grade-M magnetite losses were extremely high. These large losses are not surprising since only about $81 \%$ of the as-received magnetite was recovered in the Davis-Tube at 1.7 amps (3,700 gauss).

- As might be expected, the combined drain screen effluent magnetics were higher (90.99\% to $95.52 \%$ ) when $200 \mathrm{M}$ decks were installed on the drain screen than when $100 \mathrm{M}$ decks were installed (81.00\% to $88.45 \%)$.

- The magnetic content of both the primary and cleaner magnetic separator concentrates were very high with magnetics generally in the mid to high nineties. This was true for all three grades of magnetite.

- The correct or circulating medium magnetic content was extremely good when using the Grade-K magnetite (95.60\% to $98.80 \%)$. However, the circulating medium deteriorated ( $74.67 \%$ to $84.36 \%$ ) when using the Grade-L and Grade-M magnetites. Since the cleaner magnetic separator concentrates were extremely high in magnetic content, the non-magnetic contamination in the circulating medium must have been contributed by the rare earth magnetic separator concentrate.

\section{Continuous Integrated Test Results}

The continuous integrated testing was conducted to quantify magnetite losses and determine the impact of changing medium quality on the performance of the dense-medium cyclone over long periods of operation using two different grades of micronized magnetites.

Continuous integrated testing was performed for four hours using the Grade-M magnetite to clean the Lower Kittanning "B" Seam coal and for 36 hours using the Grade-L magnetite to clean the Pittsburgh Seam coal. Samples of the dense-medium cyclone products and the recirculating medium were collected near the start, middle, and end of each run. A summary of the results for the Grade-M magnetite testing are contained in Tables D and $\mathrm{E}$ while a summary of the results for the Grade- $\mathrm{L}$ magnetite testing are contained in Tables F, G, and H. Distribution curves for the Grade-L magnetite testing are shown in Figure E.

The continuous integrated testing conclusions are fully supported by both the component testing and primary testing phase of the project. Some of the more important conclusions draw from this phase of the project testing include:

- $\quad$ Consistent with earlier findings, the dense-medium cyclone separation ash and yield results produced during the continuous, integrated testing using the Grade-M magnetite indicated poor separation performance. 
Table D. Continuous Integrated Magnetite Recovery Results for Grade-M Magnetite

\begin{tabular}{|c|c|c|c|c|c|c|c|c|c|c|}
\hline \multirow[b]{2}{*}{ Test No. } & \multirow[b]{2}{*}{$\begin{array}{c}\text { Hours } \\
\text { Into Test }\end{array}$} & \multicolumn{6}{|c|}{ Magnetics } & \multicolumn{2}{|c|}{$\begin{array}{l}\text { Mag. Loss/ton of } \\
\text { Equip. Feed }\end{array}$} & \multirow[b]{2}{*}{$\begin{array}{c}\text { Circuit } \\
\text { Magnetite } \\
\text { Loss (lb/ton) }\end{array}$} \\
\hline & & $\begin{array}{l}\text { Pri. Mag. Sep. } \\
\text { Concentrate }\end{array}$ & $\begin{array}{l}\text { Cln. Mag. Sep. } \\
\text { Concentrate }\end{array}$ & $\begin{array}{l}\text { Correct } \\
\text { Medium }\end{array}$ & $\begin{array}{l}\text { Cln. Mag. } \\
\text { Sep. Tails }\end{array}$ & $\begin{array}{l}\text { Sec. Mag. } \\
\text { Sep. Tails }\end{array}$ & $\begin{array}{l}\text { Scav. Mag. } \\
\text { Sep. Tails }\end{array}$ & $\begin{array}{l}\text { Sec. Mag. } \\
\text { Sep. Tails }\end{array}$ & $\begin{array}{l}\text { Scav. Mag. } \\
\text { Sep. Tails }\end{array}$ & \\
\hline KLD-M1 & 1 & 82.70 & 92.30 & 84.22 & 72.07 & 58.55 & 1.96 & 2725.0 & 31.7 & 31.7 \\
\hline KLD-M2 & 4 & 82.04 & 91.67 & 84.16 & 26.88 & 25.59 & 1.35 & 534.0 & 25.7 & 25.7 \\
\hline
\end{tabular}

NOTE: All tests conducted with Grade-M Magnetite and no D\&R Screens.

Table E. Continuous Integrated Dense-Medium Cyclone Results for Grade-M Magnetite

\begin{tabular}{|c|c|c|c|c|c|c|c|c|c|c|c|c|c|c|c|}
\hline \multirow[b]{3}{*}{ Test No. } & \multirow[b]{3}{*}{$\begin{array}{c}\text { Hours } \\
\text { Into Test }\end{array}$} & \multicolumn{14}{|c|}{ Dense-Medium Cyclone Results } \\
\hline & & \multicolumn{6}{|c|}{$48 M \times 200 M$} & \multicolumn{4}{|c|}{$200 M \times 500 M$} & \multicolumn{4}{|c|}{$48 M \times 500 M$} \\
\hline & & $\mathbf{E p}$ & D50 & $\begin{array}{c}\text { \% FD } \\
\text { Ash }\end{array}$ & $\begin{array}{c}\text { \%C.C. } \\
\text { Ash }\end{array}$ & $\begin{array}{c}\text { \%Ref. } \\
\text { Ash }\end{array}$ & $\%$ Yield & $\begin{array}{c}\text { \% FD } \\
\text { Ash }\end{array}$ & $\begin{array}{c}\text { \%C.C. } \\
\text { Ash }\end{array}$ & $\begin{array}{c}\text { \% Ref. } \\
\text { Ash }\end{array}$ & $\%$ Yield & $\begin{array}{c}\text { \% FD } \\
\text { Ash }\end{array}$ & $\begin{array}{c}\text { \%C.C. } \\
\text { Ash }\end{array}$ & $\begin{array}{c}\text { \% Ref. } \\
\text { Ash }\end{array}$ & $\%$ Yield \\
\hline KLD-M1 & 1 & --- & --- & 27.26 & 4.57 & 36.72 & 29.43 & 14.55 & 7.46 & 54.46 & 84.92 & 21.75 & 6.56 & 39.22 & 53.49 \\
\hline KLD-M2 & 4 & --- & --- & 26.87 & 4.62 & 45.10 & 45.04 & 27.64 & 7.98 & 54.37 & 57.62 & 27.01 & 5.37 & 46.47 & 47.35 \\
\hline
\end{tabular}

NOTE: All tests conducted with Grade-L magnetite and no D\&R screens. Dense-medium cyclone had 0.12 sq. in. feed inlet, 1.00 in. vortex finder, and 0.625 in. apex at 1.35 s.g. circulating medium. 
Table F. Continuous Integrated Magnetite Recovery Results for Grade-L Magnetite

\begin{tabular}{|c|c|c|c|c|c|c|c|c|c|c|}
\hline \multirow[b]{2}{*}{ Test No. } & \multirow[b]{2}{*}{$\begin{array}{c}\text { Hours } \\
\text { Into Test }\end{array}$} & \multicolumn{6}{|c|}{ Magnetics } & \multicolumn{2}{|c|}{$\begin{array}{l}\text { Mag. Loss/ton of } \\
\text { Equip. Feed }\end{array}$} & \multirow[b]{2}{*}{$\begin{array}{c}\text { Circuit } \\
\text { Magnetite } \\
\text { Loss (lb/ton) }\end{array}$} \\
\hline & & $\begin{array}{l}\text { Pri. Mag. Sep. } \\
\text { Concentrate }\end{array}$ & $\begin{array}{l}\text { Cln. Mag. Sep. } \\
\text { Concentrate }\end{array}$ & $\begin{array}{l}\text { Correct } \\
\text { Medium }\end{array}$ & $\begin{array}{l}\text { Cln. Mag. } \\
\text { Sep. Tails }\end{array}$ & $\begin{array}{l}\text { Sec. Mag. } \\
\text { Sep. Tails }\end{array}$ & $\begin{array}{l}\text { Scav. Mag. } \\
\text { Sep. Tails }\end{array}$ & $\begin{array}{l}\text { Sec. Mag. } \\
\text { Sep. Tails }\end{array}$ & $\begin{array}{l}\text { Scav. Mag. } \\
\text { Sep. Tails }\end{array}$ & \\
\hline PLD-L1 & 1 & 88.84 & 94.36 & 84.5 & 1.47 & 10.15 & 0.91 & 160.7 & 14.3 & 14.3 \\
\hline PLD-L3 & 12 & 84.31 & 91.50 & 88.47 & 1.53 & 3.07 & 0.61 & 70.7 & 6.8 & 6.8 \\
\hline PLD-L5 & 36 & 90.01 & 93.71 & 92.56 & 0.07 & 0.68 & 0.35 & 7.5 & 4.2 & 4.2 \\
\hline
\end{tabular}

NOTE: All tests conducted with Grade-L Magnetite and no D\&R Screens.

Table G. Continuous Integrated Dense-Medium Cyclone Results for Grade-L Magnetite

\begin{tabular}{|c|c|c|c|c|c|c|c|c|c|c|c|c|c|c|c|}
\hline \multirow[b]{3}{*}{ Test No. } & \multirow[b]{3}{*}{$\begin{array}{c}\text { Hours } \\
\text { Into Test }\end{array}$} & \multicolumn{14}{|c|}{ Dense-Medium Cyclone Results } \\
\hline & & \multicolumn{6}{|c|}{$48 M \times 200 M$} & \multicolumn{4}{|c|}{$200 \mathrm{M} \times 500 \mathrm{M}$} & \multicolumn{4}{|c|}{$48 M \times 500 M$} \\
\hline & & $\mathbf{E p}$ & D50 & $\begin{array}{c}\text { \% FD } \\
\text { Ash }\end{array}$ & $\begin{array}{c}\text { \% C.C. } \\
\text { Ash }\end{array}$ & $\begin{array}{c}\text { \%Ref. } \\
\text { Ash }\end{array}$ & $\%$ Yield & $\begin{array}{c}\text { \% FD } \\
\text { Ash }\end{array}$ & $\begin{array}{c}\text { \% C.C. } \\
\text { Ash }\end{array}$ & $\begin{array}{c}\text { \%Ref. } \\
\text { Ash }\end{array}$ & $\%$ Yield & $\begin{array}{c}\text { \% FD } \\
\text { Ash }\end{array}$ & $\begin{array}{c}\% \text { C.C. } \\
\text { Ash }\end{array}$ & $\begin{array}{c}\text { \% Ref. } \\
\text { Ash }\end{array}$ & $\%$ Yield \\
\hline PLD-L1 & 1 & 0.062 & 1.56 & 19.40 & 5.24 & 74.20 & 79.47 & 17.33 & 6.21 & 75.58 & 83.97 & 19.01 & 5.43 & 74.41 & 80.31 \\
\hline PLD-L3 & 12 & 0.054 & 1.58 & 19.95 & 6.88 & 73.75 & 80.38 & 17.44 & 5.96 & 78.73 & 82.97 & 19.56 & 6.73 & 74.56 & 81.09 \\
\hline PLD-L5 & 36 & 0.066 & 1.60 & 17.49 & 5.93 & 71.75 & 82.43 & 14.85 & 5.55 & 77.88 & 82.43 & 17.08 & 5.87 & 72.46 & 83.17 \\
\hline
\end{tabular}

NOTE: All tests conducted with Grade-L magnetite and no D\&R screens. Dense-medium cyclone had 0.12 sq. in. feed inlet, 1.00 in. vortex finder, and $0.625 \mathrm{in}$. apex at 1.35 s.g. circulating medium. 
Table H. Grade-L Continuous Integrated Testing Microtrac Results

\begin{tabular}{|c|c|c|c|c|c|c|c|}
\hline \multicolumn{8}{|c|}{ Test-PLD-L1 (One Hour) } \\
\hline $\begin{array}{l}\text { Microtrac } \\
\text { Results }\end{array}$ & $\begin{array}{l}\text { D.M. Cyclone } \\
\text { Underflow }\end{array}$ & $\begin{array}{l}\text { D.M. Cyclone } \\
\text { Overflow }\end{array}$ & $\begin{array}{l}\text { Circulating } \\
\text { Medium }\end{array}$ & $\begin{array}{l}\text { Mag. Sep. } \\
\text { Cln. Tails }\end{array}$ & $\begin{array}{l}\text { Mag. Sep. } \\
\text { Sec. Tails }\end{array}$ & $\begin{array}{l}\text { Mag. Sep. } \\
\text { Scav. Tails }\end{array}$ & $\begin{array}{c}\text { Bulk } \\
\text { Magnetite }\end{array}$ \\
\hline $90 \%$ Passing & 13.94 & 10.62 & 10.90 & 10.82 & 12.04 & 11.71 & 12.80 \\
\hline $50 \%$ Passing & 5.44 & 4.68 & 4.65 & 4.63 & 5.23 & 4.76 & 5.70 \\
\hline $10 \%$ Passing & 2.15 & 2.09 & 2.10 & 2.09 & 2.25 & 2.16 & 2.40 \\
\hline MVD & 6.75 & 5.61 & 5.69 & 5.70 & 6.23 & 5.93 & 6.60 \\
\hline
\end{tabular}

\begin{tabular}{||c|c|c|c|c|c|c|c||}
\hline \multicolumn{9}{|c|}{ Test-PLD-L3 (Twelve Hours) } \\
\hline $\begin{array}{c}\text { Microtrac } \\
\text { Results }\end{array}$ & $\begin{array}{c}\text { D.M. Cyclone } \\
\text { Underflow }\end{array}$ & $\begin{array}{c}\text { D.M. Cyclone } \\
\text { Overflow }\end{array}$ & $\begin{array}{c}\text { Circulating } \\
\text { Medium }\end{array}$ & $\begin{array}{c}\text { Mag. Sep. } \\
\text { Cln. Tails }\end{array}$ & $\begin{array}{c}\text { Mag. Sep. } \\
\text { Sec. Tails }\end{array}$ & $\begin{array}{c}\text { Mag. Sep. } \\
\text { Scav. Tails }\end{array}$ & $\begin{array}{c}\text { Bulk } \\
\text { Magnetite }\end{array}$ \\
\hline \hline $90 \%$ Passing & 13.58 & 10.64 & 12.29 & $*$ & 11.04 & $*$ & 12.80 \\
\hline $50 \%$ Passing & 5.46 & 4.83 & 5.47 & $*$ & 4.85 & $*$ & 5.70 \\
\hline $10 \%$ Passing & 2.21 & 2.31 & 2.37 & $*$ & 2.15 & $*$ & 2.40 \\
\hline MVD & 6.69 & 5.71 & 6.46 & $*$ & 5.87 & $*$ & 6.60 \\
\hline
\end{tabular}

\begin{tabular}{||c|c|c|c|c|c|c|c||}
\hline \multicolumn{9}{|c||}{ Test-PLD-L5 (Thirty-Six Hours) } \\
\hline $\begin{array}{c}\text { Microtrac } \\
\text { Results }\end{array}$ & $\begin{array}{c}\text { D.M. Cyclone } \\
\text { Underflow }\end{array}$ & $\begin{array}{c}\text { D.M. Cyclone } \\
\text { Overflow }\end{array}$ & $\begin{array}{c}\text { Circulating } \\
\text { Medium }\end{array}$ & $\begin{array}{c}\text { Mag. Sep. } \\
\text { Cln. Tails }\end{array}$ & $\begin{array}{c}\text { Mag. Sep. } \\
\text { Sec. Tails }\end{array}$ & $\begin{array}{c}\text { Mag. Sep. } \\
\text { Scav. Tails }\end{array}$ & $\begin{array}{c}\text { Bulk } \\
\text { Magnetite }\end{array}$ \\
\hline \hline $90 \%$ Passing & 13.16 & 10.13 & 11.33 & $*$ & $*$ & $*$ & 12.80 \\
\hline $50 \%$ Passing & 5.18 & 4.57 & 4.94 & $*$ & $*$ & $*$ & 5.70 \\
\hline $10 \%$ Passing & 2.10 & 2.03 & 2.15 & $*$ & $*$ & $*$ & 2.40 \\
\hline MVD & 6.42 & 5.37 & 5.97 & $*$ & $*$ & $*$ & 6.60 \\
\hline
\end{tabular}

\footnotetext{
*Insufficient material to complete analysis
} 


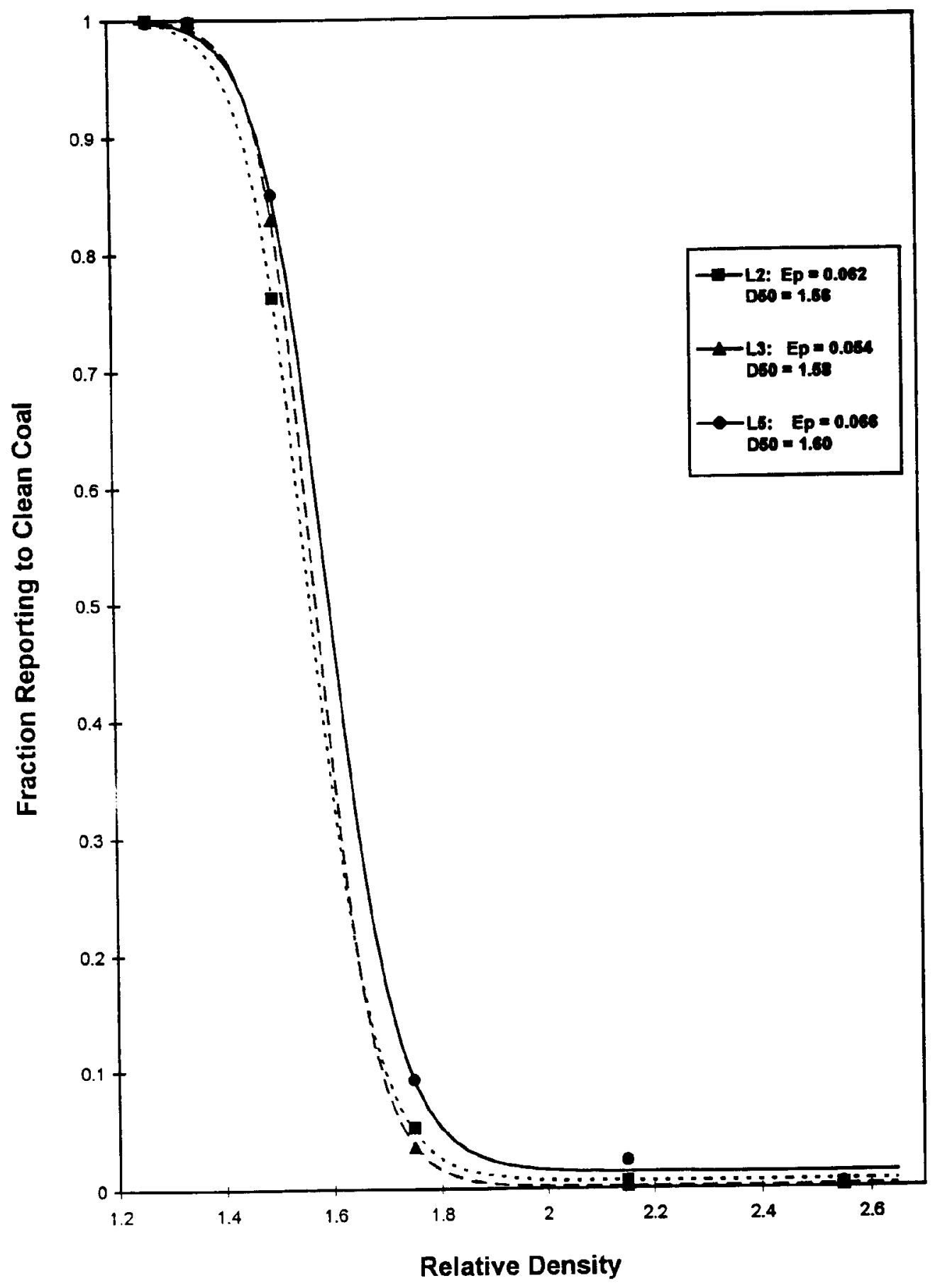

Figure E. Fitted Partition Curves for Plus-200-Mesh Fraction for Pittsburgh Seam Long-Duration Run (Grade L Magnetite, 78 PSI, 0\% Fines) 


\section{Custom Coal Corporation}

- Large magnetite losses on the order of $30 \mathrm{lb} / \mathrm{ton}$ were experienced when using the Grade-M magnetite during the four continuous hours of operation of the Micro-Mag circuit.

- When testing the Grade-M magnetite, the scavenger or rare earth magnetic separator recovered a large percentage of the magnetite that was lost by the other three conventional magnetic separators.

- Ash, yield, and Ep's results obtained from the continuous integrated testing using the Grade-L magnetite indicated that the performance of the dense-medium cyclone was excellent. Probable error values for the $48 \mathrm{M} \times 200 \mathrm{M}$ fraction were in the range of $0.054-0.066$ for the entire 36-hour testing period. Probable error values for the $200 \mathrm{M}$ x $500 \mathrm{M}$ fraction are not available but yield and ash values indicate performance equal to that obtained during the Primary Integrated Testing.

- Very low magnetite losses on the order of $4 \mathrm{lb} /$ ton after 36 hours of operation were experienced when using the Grade-L magnetite. As with the Grade-M magnetite, the rare earth scavenger separator play an important part in the recovery of the magnetite.

- Results from the Grade-L magnetite testing, indicate that a cleaner stage separator is desirable to maintain a reasonable level of magnetics in the circulating medium.

- When using the Grade-L magnetite, the correct medium magnetics continually increased in magnetics content throughout the thirty-six hours of continuous testing.

- When using the Grade-L magnetite, the percent magnetics in the cleaner magnetic separator tailings, the secondary magnetic separator tailings, and the scavenger magnetic separator tailings all significantly trended down indicating that as operating time progressed less magnetic material was being lost by the separators.

- Indications are that the magnetite being lost in the recovery circuits, when using both the Grade-M and Grade-L magnetites, include the entire size range of the magnetics. That is, the finest magnetics were being lost at the same rate as the coarser magnetics.

\section{Economic Evaluation}

The economics of installing and operating a commercial scale Micro-Mag type circuit are extremely complex and would have to be evaluated on a case by case basis. Some of the factors that would greatly influence the economics would include:

- The amount of additional yield realized from this type circuit. This would depend on such things as plant feed quality and size consist. This would also depend on comparing other 


\section{Custom Coal Corporation}

processes, such as column flotation, and their efficiency to that of the micronized magnetite process.

- The additional capital cost of installing a micronized magnetite process. These capital costs would then have to be compared to the capital cost of other processes capable of processing this fine material or combination of processes such as spiral concentrators cleaning the $48 \mathrm{M} \mathrm{x}$ $150 \mathrm{M}$ and column flotation cleaning the $150 \mathrm{M} \times 500 \mathrm{M}$.

- The additional maintenance and operating cost associated with the installation of a micronized magnetite process. Once again, these costs would have to be compared to other processes.

- The selling price of the clean coal. For example, a high-sulfur non-compliance coal would sell for much less than a low-sulfur compliance coal.

Additionally, some costs are not available, such as the price for a Grade K, L, or M magnetite. There are no commercial producers of bulk qualities of micronized magnetite. However, based on manufacturer estimates the cost for micronized magnetites are expected to be $\$ 150-200 /$ ton FOB.

However, to obtain at least a very rough economic analysis the following assumptions were made:

- A company wishes to build a $500 \mathrm{TPH}$ preparation plant capable of processing 2.5 million tons per year of raw coal. The plant is designed for a 30 year life expectance.

- The fine circuit of the plant consist of spiral concentrators processing $1 \mathrm{~mm} \times 150 \mathrm{M}$ with the $150 \mathrm{M} \times 500 \mathrm{M}$ being discarded to refuse.

- The $1 \mathrm{~mm} \times 150 \mathrm{M}$ comprises $20 \%$ of the raw feed and the $150 \mathrm{M} \times 500 \mathrm{M}$ comprises $4 \%$ of the raw feed.

- The clean coal produced at the plant is compliance quality and sells for $\$ 31.00$ per ton.

- A micronized magnetite circuit is installed to process the middlings of the spiral concentrators that is combined with the $150 \mathrm{M} \times 500 \mathrm{M}$ raw coal. The middlings of the spiral concentrators are $3 \%$ of the total plant feed.

- A total increase of $4 \%$ yield is realized by recleaning the spiral middlings combined with the $150 \mathrm{M} \times 500 \mathrm{M}$ raw coal.

- $\quad$ Operating and maintenance cost for the micronized magnetite circuit are $\$ 5$ per ton of circuit feed or in this case $\$ 875,000$ per year $(.07 \times 2,500,000 \times \$ 5.00)$. 


\section{Custom Coal Corporation}

Using the above assumptions, the preparation plant would gross an additional 100,000 tons of clean coal a year valued at $\$ 3.1$ million. Subtracting the $\$ 875,000$ per year operational cost, this would allow $\$ 2,225,000$ per year to support capital cost. A large capital cost such as $\$ 20$ million financed over 30 years at $12 \%$ interest would be approximately $\$ 1.4$ million per year still leaving an additional annual profit of $\$ 825,000$.

\section{Recommendations}

Recommendations on the findings in this report include:

- Additional component testing on the dense-medium cyclone using different grades of magnetite. This recommendation stems from the finding regarding the poor performance of the dense-medium cyclone when testing the finest magnetite (Grade-M). Traditionally, the finest magnetite used in dense-medium cyclones resulted in the best performance. The findings in this report indicate that at some point to fine of a magnetite results in extremely poor dense-medium cyclone performance. Additional, testing using a magnetite finer than the Grade- $\mathrm{L}$ and coarser than the Grade-M is recommended.

- $\quad$ Additional magnetite recovery tests using a different type of recovery circuit(s), perhaps such as a high-gradient magnetic separator, should be investigated. Although, low magnetite losses on the order of $4 \mathrm{lb} /$ ton were achieved during the Grade-L magnetite integrated testing improvements could possibly be made using a different type of recovery circuit.

- An in depth economic analysis of the micronized magnetite process should be investigated. Although, the limited economical analysis performed in this report suggest this process could be economical a more in depth approach should be investigated by a coal preparation design and engineering company. 


\section{VOLUME I}

\section{FINAL REPORT}

\section{Bench-Scale Testing of the Micronized Magnetite Process \\ (Contract No. DE-AC22-93PC92206)}

\section{SECTION 1 - INTRODUCTION}

This document constitutes the Final Report for a bench-scale micronized-magnetite fine coal cleaning project performed by Custom Coals Corporation. The 29-month project was sponsored by the U.S. Department of Energy's (DOE's) Federal Energy Technology Center (FETC). This report summarizes the results from all the major tasks within the project and contains an economic evaluation of the technology.

\section{Section 1.1 - Program Description}

A recent emphasis of the Department of Energy's (DOE's), Coal Preparation Program has been on the development of high-efficiency technologies that offer near-term, low-cost improvements in the ability of coal preparation plants to address problems associated with coal fines. In 1992, three costshared contracts were awarded to industry, under the first High-Efficiency Preparation (HEP I) solicitation. All three projects involved bench-scale testing of various emerging technologies, at the Federal Energy Technology Center's (FETC's), Process Research Facility (PRF). The first HEP I project, completed in mid-1993, was conducted by Process Technology, Inc., with the objective of developing a computerized, on-line system for monitoring and controlling the operation of a column flotation circuit. The second HEP I project, completed in mid-1994, was conducted by a team led by Virginia Polytechnic Institute to test the Mozely Multi-Gravity Separator in combination with the Microcel Flotation Column, for improved removal of mineral matter and pyritic sulfur from fine coal.

The last HEP I project, of which the findings are contained in this report, was conducted by Custom Coals Corporation to evaluate and advance a micronized-magnetite-based, fine-coal cycloning technology.

\section{Section 1.2 - Technology Description}

Over the last ten years, the use of micronized-magnetite cycloning for beneficiating fine coal has been researched by both the DOE and Genesis Research Corporation. Based on its work, the DOE received a patent in 1991 titled "Fine-Coal Cleaning via the Micro-Mag Process". Likewise, Genesis Research received patents in 1992 on more complicated processes (i.e., Carefree and Self-Scrubbing Coal Processes), involving the micronized-magnetite cycloning technology. In 1993, Custom Coals 
brought together these technologies by purchasing the rights to the various DOE and Genesis Research patents, and is actively marketing and commercializing the technology both domestically and internationally. In February of 1996, Custom Coals constructed a 500 TPH commercial cleaning plant in Somerset County, PA, employing these technologies, under the DOE's Clean Coal Technology Program.

The micronized-magnetite coal cleaning technology, also known as the Micro-Mag Process, is based on widely used conventional dense-medium cyclone applications, in that it utilizes a finely ground magnetite/water suspension as a separating medium for cleaning fine coal, by density, in a cyclone. However, the micronized-magnetite cleaning technology differs from conventional systems in several ways:

- It utilizes significantly finer magnetite (about 5 to 10 micron mean particle size), as compared to normal mean particle sizes of 20 microns.

- It can effectively beneficiate coal particles down to 500M in size, as compared to the most advanced, existing conventional systems that are limited to a particle bottom size of about $28 \mathrm{M}-100 \mathrm{M}$.

- Smaller diameter cyclones, 4 to 10 inches, are used to provide the higher G-force required to separate the finer feed coal.

- Cyclone feed pressures up to 10 times greater than those used in conventional cleaning systems are employed to enhance the separating forces.

- More advanced magnetite recovery systems, including rare-earth drums are required for recovery and reuse of the medium.

While the similarity of the micronized-magnetite technology to existing circuitry has contributed to its fairly rapid movement toward commercialization, only limited work has been done on the magnetite recovery aspects of the circuit, particularly in an integrated, continuous application. The Custom Coals HEP-I project was undertaken to evaluate and resolve some of these remaining issues and to better understand and improve the overall process and its economics.

\section{SECTION 2 - PROJECT OBJECTIVES}

The general objective of the project, which occurred from September 1994 thru January 1997, was to design, construct, and operate a fully integrated, $500 \mathrm{lb} / \mathrm{hr}$, continuous micronized-magnetite cycloning circuit for cleaning fine coal. The work focused on the medium recovery circuit and the impact of recirculating medium quality on the separation performance of the cyclone. 


\section{Custom Coal Corporation}

The testing scope of the project was designed to accomplish two overall objectives. These objectives were to:

- Determine the effects of operating time on the characteristics of the recirculating medium in a continuous integrated processing circuit, and, subsequently, the sensitivity of cyclone separation performance to the quality of the recirculating medium.

- Determine the technical and economic feasibility of various unit operations and systems in optimizing the separation and recovery of the micronized magnetite from the coal products.

The specific technical objectives of the project were to:

- Establish the classifying circuit's operating conditions to make a separation at, or about 40 microns.

- Determine the effects of magnetite particle size and medium purity on cyclone separation performance.

- Determine the effects of medium-to-coal ratio, medium density, feed pressure, and cyclone configuration on the separation efficiency of the cyclone. This testing is to verify whether cyclone separation performance equivalent to that produced in earlier research can be achieved and to determine the potential ranges of medium-to-coal ratios and medium densities expected for each cyclone product to help establish recovery circuit feed conditions.

- Quantify the amount and size of the magnetite not recovered by the individual and combined recovery circuit unit operations.

- Assess the technical and economic feasibility of various magnetite recovery circuits. Technically, the focus is on establishing the least complicated, easiest to operate circuit, that will provide the correct recirculating medium properties. Economically, determinations will be made looking at the trade offs between circuit capital and maintenance costs and overall system performance, including expected makeup magnetite requirements and cyclone separation efficiency.

- Determine the characteristics of the recirculating medium (purity and size distribution), and cyclone separation performance over time, during continuous, integrated testing of the entire circuit.

This Final Report contains a complete discussion of the project approach, as well as the results from the testing, as they relate to the objectives listed above. 


\section{SECTION 3 - PROJECT TEAM ORGANIZATION}

The project team was assembled to ensure that all expertise to successfully complete the project was accounted for within the project organization. Figure 1 contains the project team organization chart, including the FETC/PRF personnel involved in the project. The key organizations within the project included:

- DOE/FETC's project and site management personnel.

- Custom Coals’ project and site management personnel.

- Parson's engineers and technicians who operated the existing PRF during the circuit testing to supply feed slurry to the Micro-Mag circuit and receive all waste products.

- H-Tech Corporation who procured all equipment required for the project.

- Dillner Storage who provided coal blending and storage services for the project.

- CLI Corporation who finalized the circuit design.

- $\quad$ Rizzo \& Sons who installed the circuit and assisted with the circuit commissioning.

- Michigan Technological University's (MTU's) Institute of Materials Processing (IMP) who performed density, magnetics/nonmagnetics separations, ashing on 500M x 0 nonmagnetics and Microtrac analyses.

- Commercial Testing and Engineering's (CT\&E) Henderson, KY laboratory who performed all fine-coal washability analysis.

- Commercial Testing and Engineering's PA laboratory who performed sulfur, sulfur forms, and Btu analysis. Commercial Testing and Engineering also supplied technicians to operate, sample and maintain the circuit.

In addition to the sample analyses performed by MTU's IMP and CT\&E, Custom Coals maintained an on site laboratory to perform \% solids, ashing, wet screening, and sample preparation.

As Figure 1 illustrates, Custom Coals' Principle Investigator/Project Manager was Edward Torak. He was responsible for all project reporting and technical project management, as well as on-site laboratory efforts. He was also responsible for all communications, reporting and contracting requirements with DOE's Technical Project Manager (Carl Maronde) and DOE’s Contract Specialist (Eric Bell). 


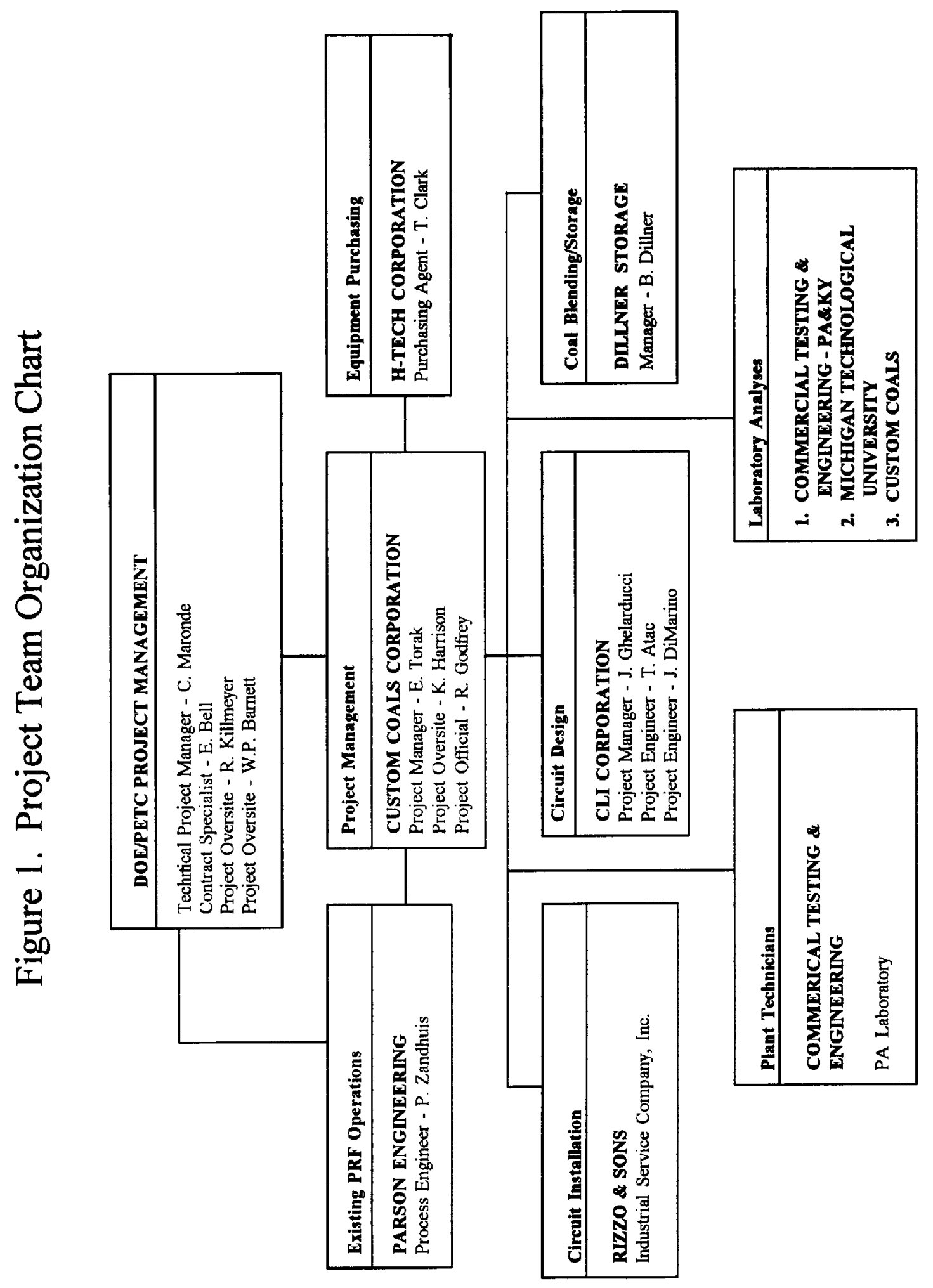




\section{SECTION 4 - PROJECT ACCOMPLISHMENTS BY TASK SERIES}

Custom Coals divided the project into major task and subtasks. The schedule in Figure 2 is broken down on a bi-monthly basis and represents the planned schedule by which the project was to be accomplished except for completion of the final report.

The remainder of this section summarizes the project accomplishments by the various tasks listed in Figure 2. The discussion includes the approach to accomplishing each task series.

\section{Section 4.1 - Task 100: Project Planning and Management}

Custom Coals Bench-Scale Testing Project was the last HEP I project performed on-site at FETC's PRF. As such, this permitted more than adequate time to plan and manage the project. As mentioned earlier, Custom Coal's Project Manager was responsible for all project reporting, management of the prime contract and subcontracts, and coordination of the day-to-day efforts at the PRF.

Below is a listing of one-time project reports which Custom Coals was required to submit during the project.

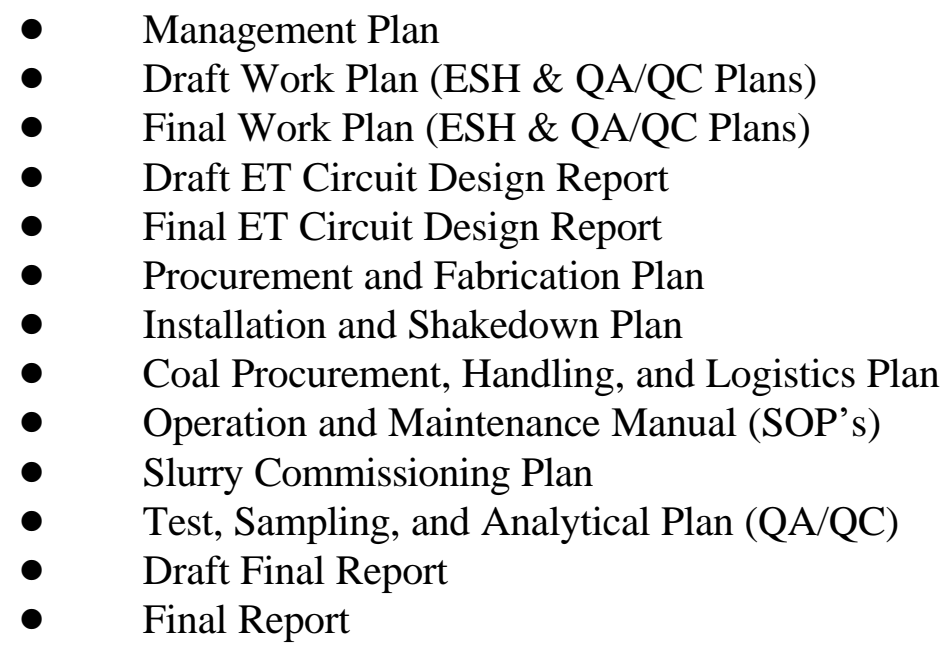

The one-time reporting requirements provided a method for DOE to review Custom Coal's work plan and assess the applicability of the work plan to achieve not only the project goals, but also meet FETC's contracting and on-site Environmental, Safety, and Health (ESH) regulations. The one-time project reporting was a key element of the overall project planning process. 
Figure 2. Planned Micro-Mag Project Schedule by Task (DOE Contract No. DE-AC22-93PC92206)

\begin{tabular}{|c|c|c|c|c|c|c|c|c|c|c|c|c|c|c|c|c|c|c|c|}
\hline \multirow[b]{2}{*}{$\begin{array}{c}\text { Task } \\
\text { Series }\end{array}$} & \multirow[b]{2}{*}{ Task Description } & \multirow[b]{2}{*}{ Duration } & \multirow[b]{2}{*}{ Months } & \multicolumn{4}{|c|}{$\underline{1994}$} & \multicolumn{11}{|l|}{$\underline{1995}$} & 1995 \\
\hline & & & & S & $\mathrm{O}$ & $\mathrm{N}$ & $\mathrm{D}$ & $\mathrm{J}$ & $\mathrm{F}$ & M & A & M & $\mathrm{J}$ & $\mathrm{J}$ & A & $S$ & $\mathrm{O}$ & $\mathrm{N}$ & $\mathrm{D}$ \\
\hline 100 & Project Planning and Management & 16 months & $1-16$ & & & & & & & & & & & & & & & & \\
\hline 200 & Final Circuit Design & 2 months & $1-2$ & & & & & & & & & & & & & & & & \\
\hline 300 & Equipment Procurement \& Fabric. & 12 Months & $2-13$ & & & & & & & & & & & & & & & & \\
\hline 400 & Magnetite and Coal Procurement & 7 Months & $7-13$ & & & & & & & & & & & & & & & & \\
\hline 500 & Circuit Installation & 3 Months & $5-7$ & & & & & & & & & & & & & & & & \\
\hline 600 & Circuit Commissioning & 1 Month & 8 & & & & & & & & & & & & & & & & \\
\hline 700 & Circuit Testing & 5 Months & $9-13$ & & & & & & & & & & & & & & & & \\
\hline 800 & Analytical & 10 Months & $5-14$ & & & & & & & & & & & & & & & & \\
\hline 900 & Circuit Decommissioning & 1 Month & 14 & & & & & & & & & & & & & & & & \\
\hline 1000 & Data Evaluation & 11 Months & $5-15$ & & & & & & & & & & & & & & & & \\
\hline 1100 & Final Reporting & 2 Months & $15-16$ & & & & & & & & & & & & & & & & \\
\hline
\end{tabular}


Table 1 contains the periodic project reporting requirements, which Custom Coals submitted on a regular basis (weekly, monthly and quarterly). The contract and financial reporting provided a means to check project accomplishments and spending-to-date, versus the initial schedule and spending plans. The monthly financial reporting provided an excellent means to assess the financial situation of the project and make necessary adjustments in the project work plans to assure that the overall project schedule and budget were met.

The lower part of Table 1 contains the routine technical reporting requirements. These weekly, monthly and quarterly status reports provided a chronology of the project successes and failures, as well as a means to document changes in the project work plan, which were required as the project progressed. The routine technical reporting requirements also ensured that Custom Coals was current on the data evaluation for the project. The monthly and quarterly technical status reports provided most of the detailed data evaluations used for this final report.

Table 1. Project Reporting Requirements

\begin{tabular}{||lll||}
\hline I. & Routine Financial Reporting Requirements: & \\
\hline 1. & Project Invoice & Frequency \\
\hline 2. & Cost Management Report (Form) & Monthly \\
\hline 3. & Summary Report (Form) & Monthly \\
\hline 4. & Financial Summary Report & Monthly \\
\hline \hline II. & Routing Technical Reporting Requirements: & Monthly \\
\hline & Description & Frequency \\
\hline 1. & Schedule/Status Sheet (On-Site Activities) & Weekly \\
\hline 2. & Milestone Schedule/Status Report (Form) & Monthly \\
\hline 3. & Technical Status Report & Monthly \\
\hline 4. & Key Personnel Staffing Report & Quarterly \\
\hline 5. & Technical Progress Report & Quarterly \\
\hline 6. & Property Reports & Yearly \& Semi-Annual \\
\hline
\end{tabular}




\section{Section 4.2 - Task 200: Final Circuit Design}

Custom Coal's subcontracted CLI Corporation to perform the final design of the ET Circuit. During the period from September through November, 1994, CLI completed the design package, and assisted Custom Coals' Project Manager in preparing the bid specification for the circuit installation. The design package included:

- $\quad$ P\&ID and Flowsheet Drawings, including all instrumentation, piping, and flow balance.

- General Arrangement Drawings, for equipment layout.

- Electrical Drawings, including all instrumentation.

- Structural Steel Drawings, for a permanent 3-level structure, including checkerplate flooring and removable handrail.

- $\quad$ Platework Drawings, including all chutes, sumps, and frames.

- $\quad$ Equipment and Piping List.

Figure 3 contains a block-flow diagram of the test circuit, which consisted of three subcircuits:

- Classification Circuit - This circuit consisted of a feed sump and pump, a 2" Krebs Classifying Cyclone, and a split 2' x 3' Sizetec Inclined Desliming Screen. The Classifying Cyclone was equipped with various orifices to make a cut (i.e., D-50) at 500M. The north side of the Desliming Screen was equipped with 325M layered screen panels for desliming while the south side of the Desliming Screen was equipped with 100M layered screen panels for dewatering. The Classification Circuit was fed 48M x 0 coal slurry from the existing PRF grinding circuit, and removed the majority of the slimes prior to the dense-medium cycloning circuit.

- Dense-Medium Cycloning Circuit - This circuit consisted of two dense-medium cyclones, a dense-medium cyclone feed tank and pump, a recirculating correct medium sump and pump, a magnetite supply bin, and a nuclear density gauge. Krebs 2" and 4" diameter DenseMedium Cyclones, mounted in a parallel arrangement, were used during the testing. The use of the two dense-medium cyclones was necessary because the 2-inch cyclone, while well suited to the feed rate limitations of the PRF and the rest of the Micro-Mag circuit, was too small to provide separation performance data that would be representative of an industrial application. Therefore, the 4-inch dense-medium cyclone was set up to operate in a closedloop fashion where the cyclone products reported directly back to the feed sump after passing through a sampling station. This sampling station provided for the collection of overflow 

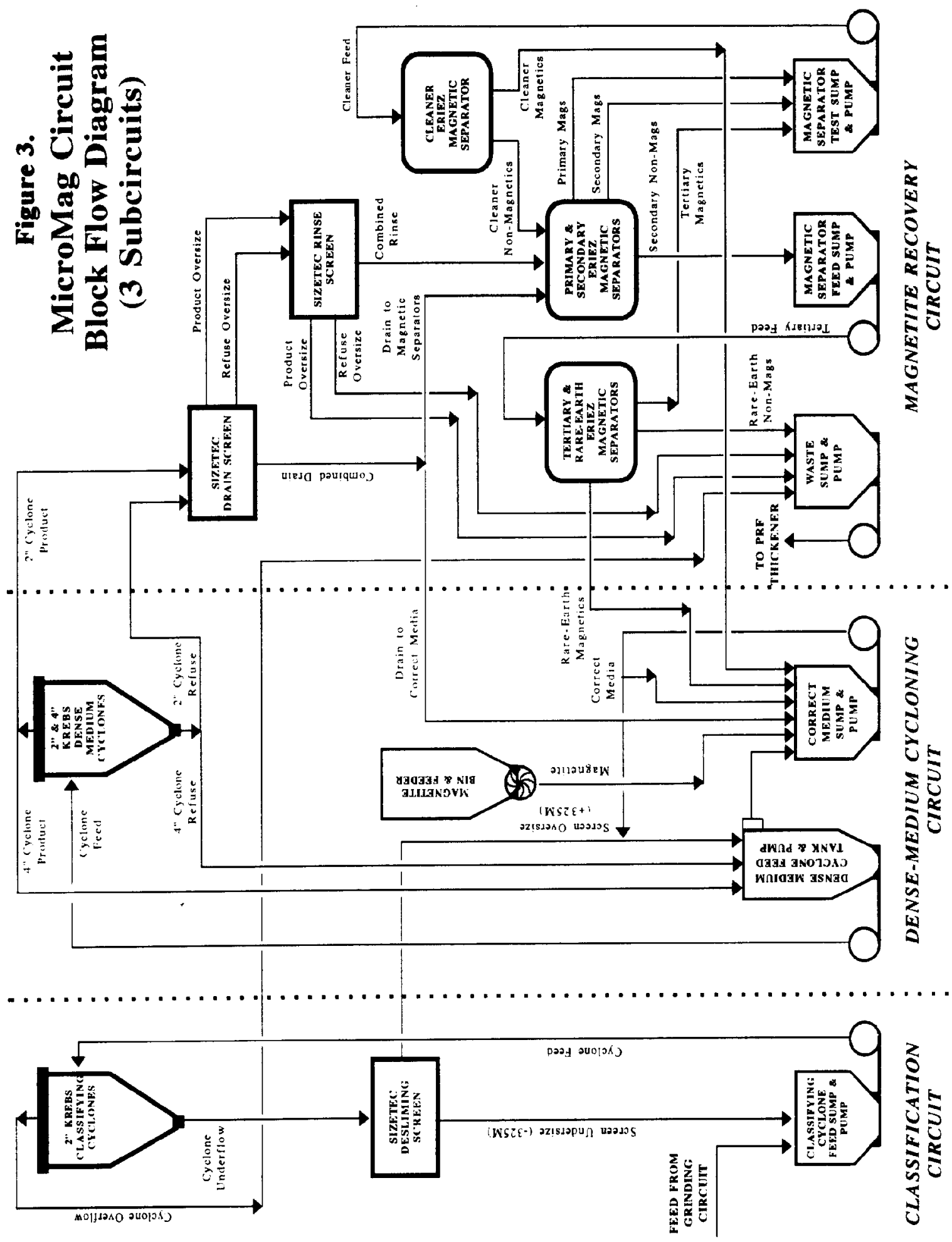
and underflow samples for use in determining dense-medium cyclone separation performance during both closed-loop and integrated-circuit testing. The 2-inch dense-medium cyclone was used to provide overflow and underflow streams to the Magnetite Recovery Circuit during integrated circuit testing. Magnetite was added as required via a rotary air-lock feeder from a 0.5 ton magnetite bin.

- Magnetite Recovery Circuit - This circuit consisted of a 2' x 3' Sizetec Inclined Desliming Screen (Drain Screen), and a 4' x 9' Sizetec Horizontal Dewatering Screen (Rinse Screen). These screens had screen panels of 100M or 200M. The magnetite recovery circuit contained four 36" x 24" Eriez Conventional, Wet-Drum Magnetic Separators (CLIMAXX Models), as the Primary, Secondary, Tertiary, and Cleaner Magnetic Separators. There was also an Eriez High Gauss, Rare-Earth Magnetic Separator (Concurrent Flow), which was used as a Scavenger Magnetic Separator in the circuit. The final magnetic concentrates returned to the Correct Medium Sump, and the final non-magnetics tailings reported to the Waste Sump and Pump, along with the Classifying Cyclone Overflow and Rinse Screen Oversize (see Figure 3). The Waste Sump discharge was dewatered using the Sharples Centrifuge and Thickener in the existing PRF process water clarification circuit.

The entire Micro-Mag circuit was contained in a new permanent structure that Custom Coals installed in the PRF Emerging Technology (ET) Area. In addition to the equipment shown in Figure 3, the Micro-Mag circuit contained a Clarified Water Head Tank and Pump to provide all water additions to the circuit. A closed-loop system was utilized in the circuit. A Motor Control Center (MCC) in the PRF motor control room, and Control Cabinet (CC) in the field provided the power distribution to the circuit.

Figures 4 and 5 contain the final detailed P\&ID and Flowsheet Drawings, respectively. Those drawings specify all equipment and the flow balance, and include all ancillary items (i.e., piping, valves, and instrumentation).

\section{Section 4.3 - Task 300: Equipment Procurement and Fabrication}

For organizational purposes, the equipment procurement and fabrication task was broken down into a number of subtasks which included:

$\begin{array}{llll}\text { - } & 301 & - & \text { Process Equipment Procurement } \\ \text { - } & 302 & - & \text { Structural Steel Fabrication and Procurement } \\ \text { - } & 303 & - & \text { Platework Steel Fabrication and Procurement } \\ \text { - } & 304 & - & \text { Electrical Equipment Procurement } \\ \text { - } & 305 & - & \text { Ancillary Equipment Procurement } \\ \text { - } & 306 & \text { - } & \text { Laboratory Equipment Procurement } \\ \text { - } & 307 & - & \text { Operating Supplies Procurement }\end{array}$




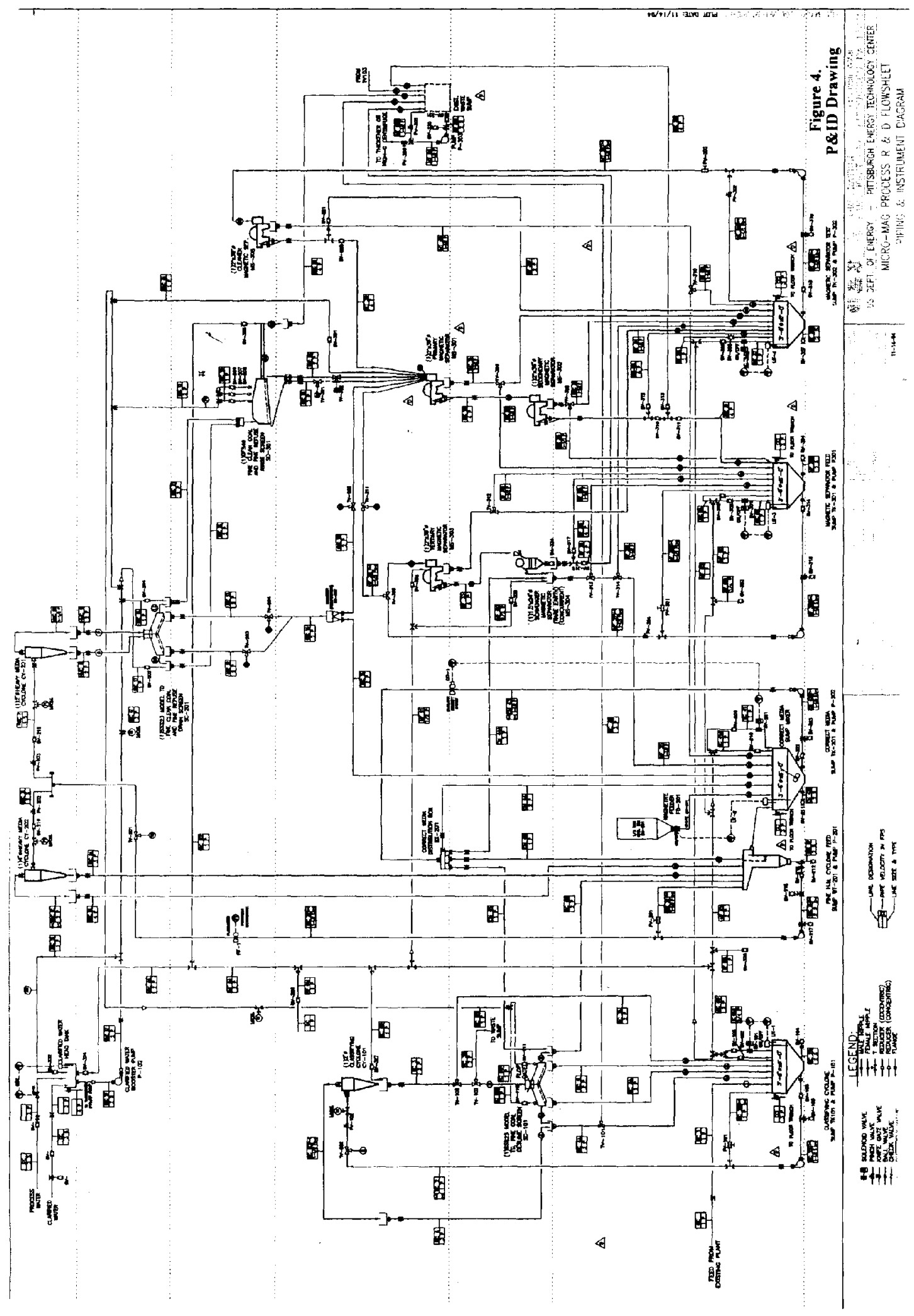




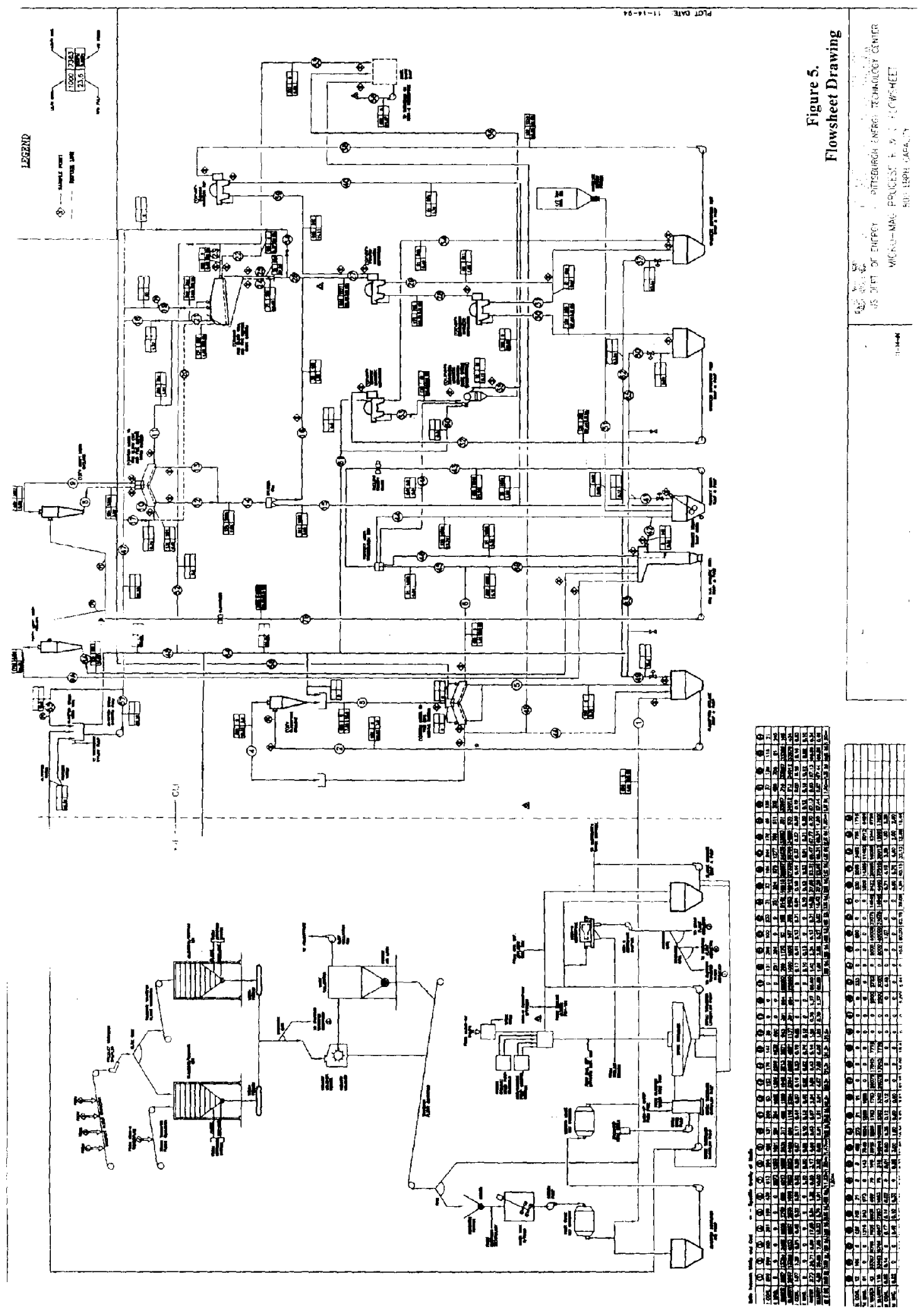




\section{Custom Coal Corporation}

Table 2 contains the equipment list and cost for all items purchased for the project. All major equipment was purchased near the end of 1994 and delivered to the site during the last week of January, 1995. Most of the laboratory equipment and project supplies were ordered during the first quarter of 1995.

\section{Section 4.4 - Task 400: Magnetite and Coal Procurement}

The two major test materials used for the project were magnetite and the test coals. Custom Coals tested three grades of micronized magnetites and two types of bituminous coals. Limited testing was also conducted using a commercial Grade-E magnetite.

The four magnetites that Custom Coals used for the project included:

- $\quad$ PennMag Grade-K Magnetite - Ground natural magnetite, with a mean particle size of 9.8 microns.

- $\quad$ PennMag Grade-L Magnetite - Finely ground natural magnetite with a mean particle size of 6.6 microns.

- $\quad$ Pea Ridge Grade-M Magnetite - Extremely fine magnetite ground to a mean particle size of 3.0 microns.

- $\quad$ Reiss Viking Grade-E Magnetite - The finest commercial grade magnetite currently available.

Tables 3, 4, and 5 contains a complete description of the four magnetites as-received. Table 3 shows magnetic moment measurements for each magnetite. This measurement indicates the magnetic susceptibility of the magnetites and was also used to determine the magnetite content of various flowstreams from which magnetite recovery values could then be derived. Tables 4 and 5 indicate the purity and particle size distribution of each of the magnetites, respectively.

Similarly, Custom Coals selected two test coals for the Micro-Mag circuit testing. The coals were:

- Pittsburgh No. 8 Seam bituminous raw coal from Ohio Valley Coal Company in Belmont County, Ohio.

- Lower Kittanning “B” Seam bituminous raw coal from PB\&S Coal Company’s, Longview Mine in Somerset County, Pennsylvania. 
Table 2. Custom Coals Corporation

Micro-Mag Project Equipment List

(Doe Contract No. DE-AC22-93-PC92206)

\begin{tabular}{|c|c|c|c|c|c|c|c|c|c|c|c|}
\hline $\begin{array}{l}\text { Unit } \\
\text { No. }\end{array}$ & Unit Description & $\begin{array}{c}\text { Equip. } \\
\text { Number } \\
\end{array}$ & Manufacturer & Equipment Description & $\begin{array}{c}\text { Motor } \\
\text { HP } \\
\end{array}$ & $\begin{array}{c}\text { Weight } \\
\text { Lbs }\end{array}$ & $\begin{array}{l}\text { Total } \\
\text { Cost } \\
\end{array}$ & Vendor & $\begin{array}{c}\text { FOB } \\
\text { Location }\end{array}$ & 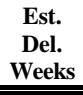 & $\begin{array}{c}\text { Est. } \\
\text { Shpg } \\
\text { Cost } \\
\end{array}$ \\
\hline 1001 & Classifying Cyclone Feed Pump & P-101 & Gould & 1"x1.5"x11" w/VS 1350/1800 RPM & 15 & 600 & 4160 & Buckley Ass., Pitts. & Ashland, PA & 6 & 0 \\
\hline 1002 & Heavy Media Feed Pump & P-201 & Gould & $1.5 " \mathrm{x} 2 " \mathrm{x} 14 " \mathrm{w} / \mathrm{VS}$ 1040/1640 RPM & 40 & 1100 & 8065 & Buckley Ass., Pitts. & Ashland, PA & 6 & 0 \\
\hline 1003 & Correct Media Pump & P-202 & Gould & 1"x1.5"x8" w/VS 1150 RPM (@ FETC) & 2 & 450 & 230 & Buckley Ass., Pitts. & Ashland, PA & 6 & 0 \\
\hline 1004 & Magnetic Separator Feed Pump & P-301 & Gould & 1"x1.5"x8" w/VS 1170 RPM (@FETC) & 3 & 490 & 364 & Buckley Ass., Pitts. & Ashland, PA & 6 & 0 \\
\hline 1005 & Magnetic Separator Test Pump & P-302 & Gould & 1"x1.5"x8" w/VS 1455 RPM & 5 & 540 & 3787 & Buckley Ass., Pitts. & Ashland, PA & 6 & 0 \\
\hline 1006 & Spray Water Pump & P-102 & Gould & $1.5 " x 2 " x 6 "$ w/DC 3500 RPM & 5 & 250 & 0 & At FETC & --- & --- & 0 \\
\hline 1007 & Waste Pump & P-303 & Gould & $1.5 " \mathrm{"} 2$ "x8" w/VS 1160 RPM & 3 & 500 & 3843 & Buckley Ass., Pitts. & Ashland, PA & 6 & 0 \\
\hline 1008 & Deslime Screen & SC-101 & Sizetec & SSS 2315TD 2x2'x3' & $.8 / .8 / .5$ & 1415 & 11175 & Sizetec, Inc. & Canton, $\mathrm{OH}$ & $10-12$ & 432 \\
\hline 1009 & Drain Screen & SC-201 & Sizetec & SSS 2315 TD $2 \times 2^{\prime} \times 3^{\prime}$ & $.8 / .8 / .5$ & 1415 & 11175 & Sizetec, Inc. & Canton, $\mathrm{OH}$ & $10-12$ & 0 \\
\hline 1010 & Rinse Screen & SC-301 & Sizetec & DSF 49 F $2 \times 2{ }^{\prime} \times 9^{\prime}$ & $2 / 2$ & 4196 & 22817 & Sizetec, Inc. & Canton, $\mathrm{OH}$ & $10-12$ & 0 \\
\hline 1011 & 325M Layered Screen Panels & SC--- & Sizetec & 2’x3’x1" Frame (10@\$320) & --- & 10 & 3200 & Sizetec, Inc. & Canton, $\mathrm{OH}$ & 1 & 0 \\
\hline 1012 & 100M Layered Screen Panels & SC--- & Sizetec & 2’x3’x1" Frame (6@\$273) & -- & 10 & 1638 & Sizetec, Inc. & Canton, $\mathrm{OH}$ & 1 & 20 \\
\hline 1013 & 200M Layered Screen Panels & SC--- & Sizetec & 2’x3’x1" Frame (6@\$286) & --- & 10 & 1716 & Sizetec, Inc. & Canton, $\mathrm{OH}$ & 1 & 0 \\
\hline 1014 & 90 Micron Profile Wire Screen Panels & SC-301 & Sizetec & 2’x3’x1" Frame (2@\$604) & --- & 30 & 1208 & Sizetec, Inc. & Canton, $\mathrm{OH}$ & 4 & 0 \\
\hline 1015 & 2" Classifying Cyclone & CY-101 & Krebs & PC2-1424 w/1 Fl, 3VF, \& 3 AP & -- & 40 & 766 & Krebs Engineers & Menlo Park, CA & 8 & 0 \\
\hline 1016 & 2" Heavy Media Cyclone & CY-201 & Krebs & PC2-1424 w/2 Fl, 3VF, \& 3AP & --- & 40 & 1051 & Krebs Engineers & Menlo Park, CA & 8 & 0 \\
\hline 1017 & 4" Heavy Media Cyclone & CY-202 & Krebs & $\mathrm{D} 4 \mathrm{~B} w / 2 \mathrm{Fl}, 3 \mathrm{VF}, \& 3 \mathrm{AP}$ & --- & 100 & 2470 & Krebs Engineers & Menlo Park, CA & 8 & 120 \\
\hline 1018 & Primary Magnetic Separator & MS-301 & Eriez & CLIMAXX Wet Drum 36" x 24" & 3 & 1250 & 12050 & Eriez Magnetics & Erie, PA & $9-12$ & 800 \\
\hline 1019 & Secondary Magnetic Separator & MS-302 & Eriez & CLIMAXX Wet Drum 36" x 24" & 3 & 1250 & 12050 & Eriez Magnetics & Erie, PA & $9-12$ & 0 \\
\hline 1020 & Tertiary Magnetic Separator & MS-303 & Eriez & CLIMAXX Wet Drum 36" x 24" & 3 & 1250 & 12050 & Eriez Magnetics & Erie, PA & $9-12$ & 0 \\
\hline 1021 & Cleaner Magnetic Separator & MS-305 & Eriez & CLIMAXX Wet Drum 36" x 24" & 3 & 1250 & 12050 & Eriez Magnetics & Erie, PA & $9-12$ & 0 \\
\hline 1022 & Scavenger Magnetic Separator & MS-304 & Eriez & Rare Earth Wet Drum 24" x 18" & 3 & 700 & 24800 & Eriez Magnetics & Erie, PA & $9-12$ & 0 \\
\hline 1023 & Magnetite Rotary Feeder & FD-201 & Prater & 6" Rotary Airlock Feeder & 0.5 & 185 & 2069 & $\mathrm{~J} \& \mathrm{~B}$ Industrial & Chicago, IL & $4-6$ & 150 \\
\hline 1024 & Motor Control Center (NEMA 12) & MCC-401 & Allen-Brad. & 4 Vertical Sections w/o TMCB & $200 \mathrm{~A}$ & 1000 & 8458 & Allen Bradley, Inc. & Milwaukee, WI & $4-6$ & 0 \\
\hline $1025 \mathrm{~A}$ & Customized Control Cabinet (NEMA 4) & CC-401 & CDI & Square D Comp. in Hoffman Box & --- & 150 & 3150 & Control Design, Inc. & Pittsburgh, PA & 4-6 & 40 \\
\hline $1025 \mathrm{~B}$ & TMCB \& Safety Switches & --- & Square D & TMCB \& 23 Man. Switches (17 New) & --- & 250 & 2880 & All Phase & Pittsburgh, PA & $1-2$ & 0 \\
\hline 1026 & Heavy Media Cyclone Feed Flowmeter & FIT-1 & Polysonics & MST-P Port. Ultrasonic Flowmeter & --- & 20 & 0 & At FETC & --- & --- & 0 \\
\hline $1027 \mathrm{~A}$ & Correct Media Nuclear Density Gauge & DIT-1 & Berthold & LB-389 w/Nal Detector \& Comm. & --- & 90 & 4825 & Berthold Systems & Aliquippa, PA & $4-6$ & 0 \\
\hline 1027B & Nuclear Density Gauge Digital Meter & DIT-1A & Red Lion & IMP-20102 Digital Meter w/Relays (2) & --- & 2 & 281 & Denko Engrg. & Bell Vernon, PA & $2-3$ & 0 \\
\hline 1028 & Classifying Cyclone Sump Level & LIT-1 & Warrick & 16ML1A4-X-03 w/2' \& 2’ 4" Probes & --- & 6 & 291 & Process Engrg. & Pittsburgh, PA & $3-4$ & 0 \\
\hline 1029 & Transmitter & LIT-2 & Warrick & 16ML1A4-X-03 w/2’ \& 2’4" Probes & --- & 6 & 291 & Process Engrg. & Pittsburgh, PA & 3-4 & 0 \\
\hline 1030 & Correct Media Sump Level Transmitter & LIT-3 & Warrick & 16ML1A4-X-03 w/2' \& 2’ 4" Probes & --- & 6 & 291 & Process Engrg. & Pittsburgh, PA & 3-4 & 0 \\
\hline 1031 & Mag. Sep. Feed Sump Level Transmitter & LIT-4 & Warrick & 16ML1A4-X-03 w/3’ \& 3’4" Probes & --- & 6 & 302 & Process Engrg. & Pittsburgh, PA & 3-4 & 0 \\
\hline 1032 & Mag. Sep. Test Sump Level Transmitter & LIT-5 & Warrick & 16ML1A4-X-03 w/2' \& 1'8" Probes & --- & 6 & 285 & Process Engrg. & Pittsburgh, PA & $3-4$ & 0 \\
\hline 1033 & Clarified Water Head Tank Level & LIT-- & Warrick & Spare Probes (4 @ 3’, 3’4", 4', \& 4’4") & --- & 4 & 91 & Process Engrg. & Pittsburgh, PA & 3-4 & 0 \\
\hline 1034 & Transmitter & MX-201 & Lightning & Mixer w/5' Long Agitator & 2.3 & 200 & 0 & At FETC & --- & --- & 0 \\
\hline 1035 & Spare Level Probes & SS-101 & Vangura & Fabricated Structure, Floor, \& Rail & --- & 26000 & 37680 & Vangura Iron, Inc. & W. Mifflin, PA & $4-6$ & 0 \\
\hline 1036 & Correct Media Sump Mixer & PS-101 & Vangura & Fabricated Sumps, Chutes, \& Frames & --- & 6000 & 18265 & Vangura Iron, Inc. & W. Mifflin, PA & 4-6 & 0 \\
\hline 1037 & Structural Steel, Flooring, \& Handrail & --. & Durex & 1-1/2" Beaver Tails (26@\$14.50) & --- & 13 & 386 & Howard Baird Ass. & Pittsburgh, PA & $3-4$ & 0 \\
\hline 1038 & Platework Steel & --- & Marcy & Hanging Scale with Spare Cup & --- & 20 & 203 & Gilson Co., Inc. & Worthinton, $\mathrm{OH}$ & $1-2$ & 0 \\
\hline 1039 & Deslime and Rinse Screen Spray Nozzles & --- & ABC Fire Prt. & Six Port. Units (5 Reg. \& 1 Elec.) & --- & 80 & 561 & Fire Fighter Sales & Pittsburgh, PA & $1-2$ & 0 \\
\hline 1040 & Marcy Liquid Density Gauge (Manual) & --- & Cole-Parmer & Four Units (3/4", 1", 1-1/2", \& 2") & --- & 15 & 1432 & Cole-Parmer Inst. & Niles, IL & $3-4$ & 0 \\
\hline 1041 & Fire Extinguishers & --- & Asahi/Grinnell & Steel Valves (41) \& CPVC Valves (68) & --. & 500 & 9840 & Lee Supply Co. & Charleroi, PA & 3-4 & 0 \\
\hline 1042 & Variable Area Bypass Flowmeters & --- & ASCO/Unitorq & 2" Unit (1) \& 1" Units (4), w/Spares & --- & 25 & 1453 & Techmatic, Inc. & Sylvan Lk., MI & $1-2$ & 0 \\
\hline 1043 & Manual Ball, 3-Way, and Diaphragm Valves & DIT-1A & Newport & INFCP-210 Meter \& SPC4 Cover & --- & 5 & 375 & Newport Elec., Inc. & Santa Ana, CA & 1 & 20 \\
\hline 1044 & Solenoid Operated Ball valves (w/Actuator) & --- & Grinnell & Flanges (168) \& Rubber Gaskets (99) & --- & 200 & 1377 & Lee Supply Co. & Charleroi, PA & 1 & 20 \\
\hline 1045 & Digital Meter (NEMA $4 \&$ UL Approved & --- & Ashcroft & Pressure Gauges (6) \& Regulators (5) & --- & 50 & 1682 & M.S. Jacobs & Pittsburgh, PA & $2-4$ & 20 \\
\hline 1047 & Steel Flanges and Gaskets & --- & Carpco & Wet Splitter (110 V.) \& 2 Samplers & --- & 100 & 5375 & Carpco & Jacksonville, FL & $2-4$ & 0 \\
\hline \multirow[t]{3}{*}{1048} & Air, Water, and Slurry Gauges \& Regulators & --- & Spray System & 36 Spray Nozzles & --- & 10 & 1251 & Workman Dev. & Alum Crk., WV & 1 & 0 \\
\hline & Wet Sample Splitter and Samplers & & & & & & & & & & \\
\hline & & & & & Purchase & Total & $\$ 256,499$ & & \multicolumn{2}{|c|}{$\begin{array}{l}\text { Shipping Total } \\
\text { Delivered Total }\end{array}$} & $\begin{array}{l}1,622 \\
\$ 258\end{array}$ \\
\hline
\end{tabular}


Table 3. As-Received Magnetite Head Analysis

\begin{tabular}{||l|c|c|c|c||}
\hline \multicolumn{1}{|c|}{ Analysis } & Grade-E & Grade-K & Grade-L & Grade-M \\
\hline \hline Moisture (Wt\%) & 0.1 & 0.1 & 0.20 & --- \\
\hline Ash (Wt\%) & 102 & 103 & 102 & 102 \\
\hline Specific Gravity & 4.9 & 5.0 & 4.9 & 5.1 \\
\hline Moment (EMU/g) & 84 & 86 & 75 & 81 \\
\hline \hline
\end{tabular}

Table 4. As-Received Magnetite Davis-Tube Recovery Profiles

\begin{tabular}{||c|c|c|c|c|c||}
\hline \hline \multicolumn{2}{||c|}{ Davis-Tube Settings } & \multicolumn{4}{|c||}{ Davis-Tube Recoveries (Wt\%) } \\
\hline Amps & Gauss & Grade-E & Grade-K & Grade-L & Grade-M \\
\hline \hline 0.30 & 750 & $94-95$ & $84-86$ & $20-22$ & 0 \\
\hline 0.50 & 1,250 & $96-97$ & $96-98$ & $70-72$ & 0 \\
\hline 1.70 & 3,700 & $97-98$ & $98-99$ & $95-97$ & $80-81$ \\
\hline
\end{tabular}

Table 5. As-Received Magnetite Size

\begin{tabular}{|l|c|c|c|c|}
\hline \multicolumn{1}{|c|}{ Microtrac Results } & Grade-E & Grade-K & Grade-L & Grade-M \\
\hline \hline $\mathrm{D}_{90}(90 \%$ Passing) & 53.2 & 18.0 & 12.8 & 5.0 \\
\hline $\mathrm{D}_{50}(50 \%$ Passing) & 17.1 & 8.9 & 5.7 & 2.7 \\
\hline $\mathrm{D}_{10}(10 \%$ Passing) & 3.9 & 3.5 & 2.4 & 1.4 \\
\hline MVD (Mean Volume Dia.) & 23.4 & 9.8 & 6.6 & 3.0 \\
\hline Moment (EMU/g) & 86 & 87 & 77 & 82 \\
\hline \hline
\end{tabular}


Tables 6 and 7 contain the size and washability analysis for the respective coals. Table 6 is for the Pittsburgh seam coal as prepared by the PRF and delivered to the Micro-Mag circuit. Table 7 is for the Lower Kittanning seam coal as received from PBS prior to pulverization by the PRF. Both coals were obtained from underground mines, and contained dry ash contents of between 20 and $30 \mathrm{Wt} \%$. Over half of the sulfur in both coals were in the pyritic form so they were good candidates for aggressive cleaning studies. They also both had yields of 70 to $80 \mathrm{Wt} \%$ when cleaned at about 1.60 SG.

Prior to initiating the test program, Custom Coal's procured an 80-ton sample of the Pittsburgh No. 8 seam coal and a 46-ton sample of Lower Kittanning "B" seam coal. Both coals were sampled and delivered to Dillner Storage where they were dried and split into 6-ton piles (i.e., lots) for separate transport to DOE's PRF as needed to supply feed for the testing. The individual piles were covered with poly tarps to avoid any moisture pickup. Large samples of each coal were collected during workup to represent the entire 80-ton lot of Pittsburgh coal and the entire 46-ton Lower Kittannning lots. Small samples were collected from each of the individual piles of coal prior to their transport to DOE's PRF. Table 8 contains the analysis of the composite samples collected during the initial workup at Dillner and individual lots for both seams.

As can be seen from Table 8, the individual lots matched the overall composite fairly closely and illustrate the good blending that was achieved at Dillners.

\section{Section 4.5 - Task 500: Circuit Installation}

Custom Coals subcontracted Rizzo \& Sons to perform the circuit installation, based on their experience working at the site and the competitiveness of their bid. The installation of the circuit began on January 23, 1995, and was completed on March 27, 1995.

For organizational purposes, Custom Coals broke down the circuit installation into 3 subtasks that Rizzo's performed according to the following schedule:

- Primary Installation: (January 23 - February 10) - Structure, flooring, handrail, equipment, and platework.

- $\quad$ Piping Installation: (February 14 - March 27)

- $\quad$ Electrical Installation: (February 14 - March 27)

From January 23 through February 28, Rizzo \& Sons had approximately 5-7 men working on-site on the circuit installation task. In March, the work became more detailed and the crew was reduced to 2-4 men. Custom Coals' Project Manager was on-site during the entire installation period to ensure that all installations occurred in accordance with the design drawings and DOE's Environmental Safety and Health (ESH) requirements. 
Table 6. Ground Feed Coal Size Analysis and Washability Pittsburgh No. 8 Seam Coal (FETC/PRF Dry Grind)

Ohio Valley Coal Company $($ HGI $=60-70)$

Top x 0 size analysis representing $100.00 \mathrm{Wt} \%$ of total raw coal sample

\begin{tabular}{|c|c|c|c|c|c|c|c|c|}
\hline \multicolumn{3}{|c|}{ Size Fraction } & \multicolumn{3}{|c|}{ Size Analysis (D.B.) } & \multicolumn{3}{|c|}{ Cumulative Analysis (D.B.) } \\
\hline Pass & & Retain & $\begin{array}{l}\text { Weight } \\
\text { (Wt\%) }\end{array}$ & $\begin{array}{c}\text { Ash } \\
(\mathrm{Wt} \%)\end{array}$ & $\begin{array}{l}\text { Sulfur } \\
\text { (Wt\%) }\end{array}$ & $\begin{array}{l}\text { Weight } \\
\text { (Wt\%) }\end{array}$ & $\begin{array}{c}\text { Ash } \\
(\mathrm{Wt} \%)\end{array}$ & $\begin{array}{l}\text { Sulfur } \\
(\mathrm{Wt} \%)\end{array}$ \\
\hline Top & $\mathrm{X}$ & $30 \mathrm{M}$ & 1.00 & 28.68 & 5.19 & 1.00 & 28.68 & 5.19 \\
\hline $30 \mathrm{M}$ & $\mathrm{X}$ & $50 \mathrm{M}$ & 3.30 & 28.68 & 5.19 & 4.30 & 28.68 & 5.19 \\
\hline $50 \mathrm{M}$ & $X$ & $70 \mathrm{M}$ & 3.50 & 21.50 & 4.64 & 7.80 & 25.46 & 4.94 \\
\hline $70 \mathrm{M}$ & $\mathrm{X}$ & $100 \mathrm{M}$ & 5.40 & 18.74 & 4.74 & 13.20 & 22.71 & 4.86 \\
\hline $100 \mathrm{M}$ & $\mathrm{X}$ & $200 \mathrm{M}$ & 16.00 & 14.98 & 5.00 & 29.20 & 18.47 & 4.94 \\
\hline $200 \mathrm{M}$ & $\mathrm{X}$ & $400 \mathrm{M}$ & 22.60 & 14.08 & 5.25 & 51.80 & 16.56 & 5.07 \\
\hline $400 \mathrm{M}$ & $X$ & 0 & 48.20 & 32.43 & 3.83 & 100.00 & 24.21 & 4.47 \\
\hline & & Total & 100.00 & 24.21 & 4.47 & & & \\
\hline & & Head & 100.00 & 23.40 & 4.51 & & & \\
\hline
\end{tabular}

Top x 0 washability representing $100.00 \mathrm{Wt} \%$ of total raw coal sample

\begin{tabular}{|c|c|c|c|c|c|c|c|c|}
\hline \multicolumn{3}{|c|}{ Gravity Fraction } & \multicolumn{3}{|c|}{ Direct Analysis (D.B.) } & \multicolumn{3}{|c|}{ Cumulative Analysis (D.B.) } \\
\hline Sink & & Float & $\begin{array}{l}\text { Weight } \\
\text { (Wt\%) }\end{array}$ & $\begin{array}{c}\text { Ash } \\
(\mathbf{W t} \%)\end{array}$ & $\begin{array}{c}\text { Sulfur } \\
(\mathrm{Wt} \%)\end{array}$ & $\begin{array}{l}\text { Weight } \\
(\text { Wt\%) }\end{array}$ & $\begin{array}{c}\text { Ash } \\
(\mathrm{Wt} \%)\end{array}$ & $\begin{array}{l}\text { Sulfur } \\
(\text { Wt\%) }\end{array}$ \\
\hline Float & $\mathrm{X}$ & 1.30 & 46.00 & 2.76 & 2.35 & 46.00 & 2.76 & 2.35 \\
\hline 1.30 & $\mathrm{X}$ & 1.40 & 20.20 & 8.13 & 2.60 & 66.20 & 4.40 & 2.43 \\
\hline 1.40 & $\mathrm{X}$ & 1.50 & 6.40 & 17.32 & 3.04 & 72.60 & 5.54 & 2.48 \\
\hline 1.50 & $\mathrm{X}$ & 1.60 & 2.50 & 33.31 & 4.67 & 75.10 & 6.46 & 2.55 \\
\hline 1.60 & $X$ & 1.80 & 2.00 & 34.30 & 4.94 & 77.10 & 7.18 & 2.62 \\
\hline 1.80 & $X$ & 2.20 & 3.10 & 52.69 & 3.23 & 80.20 & 8.94 & 2.64 \\
\hline 2.20 & $X$ & Sink & 19.80 & 83.19 & 10.36 & 100.00 & 23.64 & 4.17 \\
\hline & & Total & 100.00 & 23.64 & 4.17 & & & \\
\hline & & Head & 100.00 & 23.83 & 4.42 & & & \\
\hline
\end{tabular}


Table 7. As-Received Raw Coal Size Analysis and Washability Longview Mine, Kittanning "B' Seam

PB\&S Underground Mined Coal

(HGI = 90-100)

$1-1 / 2 "$ x 0 size analysis representing $100.00 \mathrm{Wt} \%$ of total raw coal sample

\begin{tabular}{|c|c|c|c|c|c|c|c|c|}
\hline & $\mathbf{F r}$ & tion & Siz & nalysis ( & & Cumula & e Analy & (D.B.) \\
\hline Pass & & Retain & $\begin{array}{l}\text { Weight } \\
(\text { Wt\%) }\end{array}$ & $\begin{array}{c}\text { Ash } \\
(\mathbf{W t} \%)\end{array}$ & $\begin{array}{l}\text { Sulfur } \\
(\mathrm{Wt} \%)\end{array}$ & $\begin{array}{l}\text { Weight } \\
\text { (Wt\%) }\end{array}$ & $\begin{array}{c}\text { Ash } \\
(\mathbf{W t} \%)\end{array}$ & $\begin{array}{c}\text { Sulfur } \\
(\mathrm{Wt} \%)\end{array}$ \\
\hline $1-1 / 2^{\prime \prime}$ & $X$ & $3 / 8^{\prime \prime}$ & 21.78 & 36.77 & 2.88 & 21.78 & 36.77 & 2.88 \\
\hline $3 / 8 "$ & $X$ & $1.0 \mathrm{~mm}$ & 50.44 & 18.72 & 2.03 & 72.22 & 24.16 & 2.29 \\
\hline $1.0 \mathrm{~mm}$ & $X$ & $150 \mathrm{M}$ & 21.64 & 12.74 & 1.93 & 93.86 & 21.53 & 2.20 \\
\hline $150 \mathrm{M}$ & $X$ & $500 \mathrm{M}$ & 3.69 & 11.82 & 1.88 & 97.55 & 21.16 & 2.19 \\
\hline $500 \mathrm{M}$ & $X$ & 0 & 2.45 & 18.43 & 1.21 & 100.00 & 21.10 & 2.17 \\
\hline & & Total & 100.00 & 21.10 & 2.17 & & & \\
\hline
\end{tabular}

$1-1 / 2 "$ x 500M washability representing $97.55 \mathrm{Wt} \%$ of total raw coal sample

\begin{tabular}{|c|c|c|c|c|c|c|c|c|}
\hline \multicolumn{3}{|c|}{ Gravity Fraction } & \multicolumn{3}{|c|}{ Direct Analysis (D.B.) } & \multicolumn{3}{|c|}{ Cumulative Analysis (D.B.) } \\
\hline Sink & & Float & $\begin{array}{l}\text { Weight } \\
(\mathbf{W t} \%)\end{array}$ & $\begin{array}{c}\text { Ash } \\
(\mathbf{W t} \%)\end{array}$ & $\begin{array}{l}\text { Sulfur } \\
(\mathrm{Wt} \%)\end{array}$ & $\begin{array}{l}\text { Weight } \\
(\text { Wt\%) }\end{array}$ & $\begin{array}{c}\text { Ash } \\
(\mathbf{W t} \%)\end{array}$ & $\begin{array}{l}\text { Sulfur } \\
(\mathrm{Wt} \%)\end{array}$ \\
\hline Float & $\mathrm{X}$ & 1.30 & 19.80 & 3.02 & 0.69 & 19.80 & 3.02 & 0.69 \\
\hline 1.30 & $\mathrm{X}$ & 1.40 & 42.10 & 7.95 & 0.83 & 61.90 & 6.37 & 0.79 \\
\hline 1.40 & $\mathrm{X}$ & 1.45 & 8.43 & 16.40 & 1.00 & 70.33 & 7.57 & 0.81 \\
\hline 1.45 & $\mathrm{X}$ & 1.55 & 5.66 & 25.22 & 1.40 & 75.99 & 8.89 & 0.85 \\
\hline 1.55 & $X$ & 1.65 & 3.06 & 32.93 & 1.87 & 79.05 & 9.82 & 0.89 \\
\hline 1.65 & $X$ & 1.80 & 2.87 & 40.85 & 2.19 & 81.92 & 10.91 & 0.94 \\
\hline 1.80 & $\mathrm{X}$ & Sink & 18.08 & 68.43 & 7.80 & 100.00 & 21.31 & 2.18 \\
\hline & & Total & 100.00 & 21.31 & 2.18 & & & \\
\hline & & Head & 100.00 & 21.16 & 2.19 & & & \\
\hline
\end{tabular}


Table 8. Bulk Raw Coal Analyses

(Dry Basis, Except Weight and Moisture)

\section{Pittsburgh No. 8 Raw Coal (HGI-66)}

\begin{tabular}{|c|c|c|c|c|c|c|c|}
\hline \multirow[b]{2}{*}{ Sample } & \multicolumn{3}{|c|}{ Short Proximate } & \multicolumn{4}{|c|}{ Sulfur Forms } \\
\hline & $\begin{array}{c}\text { Moisture } \\
(\mathbf{W t} \%)\end{array}$ & $\begin{array}{c}\text { Ash } \\
(\mathbf{W t} \%)\end{array}$ & $\begin{array}{l}\text { Heating Value } \\
\text { (Btu/lb) }\end{array}$ & $\begin{array}{c}\text { Total } \\
(\text { Wt\% })\end{array}$ & $\begin{array}{l}\text { Pyritic } \\
(\text { Wt\% })\end{array}$ & $\begin{array}{l}\text { Sulfate } \\
(\mathrm{Wt} \%)\end{array}$ & $\begin{array}{c}\text { Organic } \\
(\mathrm{Wt} \%)\end{array}$ \\
\hline Comp. & 4.88 & 30.36 & 10,011 & 4.51 & 2.30 & 0.06 & 2.15 \\
\hline Lot \#1 & 4.22 & 27.69 & ---- & 4.70 & 2.18 & 0.04 & 2.18 \\
\hline Lot \#2 & 4.61 & 28.27 & ---- & 4.68 & 2.15 & 0.05 & 2.48 \\
\hline Lot \#3 & 3.74 & 28.04 & 10,217 & 5.15 & 2.68 & 0.06 & 2.41 \\
\hline Lot \#4 & 2.64 & 30.08 & ---- & 4.38 & 2.56 & 0.07 & 1.75 \\
\hline Lot \#5 & 3.84 & 30.49 & ---- & 4.66 & 2.39 & 0.03 & 2.24 \\
\hline
\end{tabular}

\section{Lower Kittanning Raw Coal - (HGI-91)}

\begin{tabular}{||c|c|c|c|c|c|c|c||}
\hline \multicolumn{4}{|c|}{ Short Proximate } & \multicolumn{4}{c||}{ Sulfur Forms } \\
\hline Sample & $\begin{array}{c}\text { Moisture } \\
(\mathbf{W t} \%)\end{array}$ & $\begin{array}{c}\text { Ash } \\
(\mathbf{W t} \%)\end{array}$ & $\begin{array}{c}\text { Heating Value } \\
(\mathbf{B t u} / \mathbf{l b})\end{array}$ & $\begin{array}{c}\text { Total } \\
(\mathbf{W t} \%)\end{array}$ & $\begin{array}{c}\text { Pyritic } \\
(\mathbf{W t} \%)\end{array}$ & $\begin{array}{c}\text { Sulfate } \\
(\mathbf{W t} \%)\end{array}$ & $\begin{array}{c}\text { Organic } \\
(\mathbf{W t} \%)\end{array}$ \\
\hline \hline Comp. & 3.37 & 20.55 & 12,069 & 2.10 & 1.32 & 0.02 & 0.76 \\
\hline Lot \#1 & 2.40 & 18.10 & 12,477 & 2.07 & 1.21 & 0.03 & 0.83 \\
\hline
\end{tabular}




\section{Custom Coal Corporation}

The new structure that was installed is permanent and consists of a number of column rows, installed in the PRF's ET circuit area, and fastened to the existing structure. The floor levels match the existing structure on all except the highest floor, and consist of 3/8" checkerplate flooring with removable handrail and toeplate. Design specifications were 150\#/sq. ft. live load and 2000\# point loading.

The structure and equipment on each floor of the circuit was as follows:

- 1086' Elevation - The ground level concrete floor was part of the new structure. The 20' $\mathrm{x}$ 20' new equipment area contained the 6 slurry sumps and pumps shown on the bottom of Figure 3, as well as all sample prep equipment used at the site. All the sumps and pumps, as well as the structural steel were bolted to the concrete floor.

- 1096' Elevation - The second floor consisted of a new 22' x 13' structure adjacent to the existing circuit. It was enclosed in removable handrail and toeplate. This level contained the primary, secondary, tertiary, and scavenger rare-earth magnetic separators, as well as the magnetite hopper and deslime screen. It also contained the Berthold Density Gauge and the Polysonics Ultrasonic Flowmeter.

- 1106' Elevation - The third floor also consisted of a new 22' x 13' structure adjacent to the existing circuit, enclosed in removable handrail and toeplate. This level contained the rinse screen, the media distribution and splitter boxes, and the classifying cyclone. It also contained the control cabinet used to operate and monitor the circuit.

- 1116' Elevation - The fourth floor consisted of a new 10' x 20' structure adjacent to the existing circuit, and enclosed in removable handrail and toeplate. This level contained the clarified water head tank and pump, the two dense-medium cyclones, the drain screen, and the cleaner magnetic separator.

The general arrangement drawings were used to place the structural steel, flooring, handrails, equipment, and platework in the initial part of the installation.

The detailed process piping requirements are shown in the circuit P\&ID, (see Figure 4). Figure 4 contains all slurry and water piping lines, including all fittings and valves. Most of the slurry piping was specified as CPVC ("P") to reduce costs and increase ease of installation. Steel piping was used for the high-pressure, dense-medium cyclone feed lines.

A detailed piping list for the slurry lines, water lines, and compressed air lines was included in the design package. The piping routes were determined in the field during installation, by Custom Coals and Rizzo staff. All gravity lines were installed first to ensure maximum slope, while maintaining sampling capabilities. Pump discharge lines, water lines, and air lines were installed later, with priorities on maintaining access to the circuit and sampling capabilities. 
The final installation subtask, the electrical installation, started in mid-February and was completed in late-March. Rizzo \& Sons were responsible for installing the following units:

- A new 200 Amp. Thermal Magnetic Circuit Breaker (TMCB) in DOE's existing Square D, Model 5 MCC in the PRF MCC room.

- A new, NEMA-12 Allen Bradley MCC in the PRF MCC room (3 Vertical Sections).

- A new customized Control Cabinet in the field to operate and monitor the circuit.

- Twenty-three new disconnects in the field, one next to the each new 480 Volt motor.

The electrical work included all conduit runs, wiring, and terminations between these units, and the 23,480 -Volt motors in the circuit. It also included the conduit runs, wiring, and termination between the Control Cabinet and the 11 fixed instruments in the field (1 Berthold nuclear density gauge, 5 Warrick level probe systems, and 5 air solenoids). The circuit also included a Polysonics portable ultrasonic flowmeter, that did not require any permanent wiring. An illustration of these instrument locations is shown in Figure 4.

All aspects of the Micro-Mag Circuit needed to be tied into the existing PRF system. Figure 6 contains the interface drawing for these various tie-ins.

\section{Section 4.6 - Task 600: Circuit Commissioning}

The circuit slurry commissioning task was carried out during the entire month of April and was broken down into three subcircuits:

- Classification Circuit Commissioning Tests

- Dense-Medium Cyclone Commissioning Tests

- Magnetite Recovery Circuit Commissioning Tests

Each of these circuits was first operated using water only. Coal and magnetite were then introduced as required to establish system operability.

A coal slurry feed was supplied by the PRF for use in all the test work for this project. The PRF generated this slurry by dry pulverizing the raw feed coal to a nominal 50-mesh top size. This dry pulverized coal was then mixed with water to create a $30 \mathrm{wt} \%$ coal slurry that was pumped to the Micro-Mag Classifying Circuit at a rate of 700-800 lb/hr.

Two men from Rizzo's installation staff was on site for the entire commissioning period to assist with required modifications and troubleshooting. The following discussion describes the commissioning results from these three areas of the circuit. 


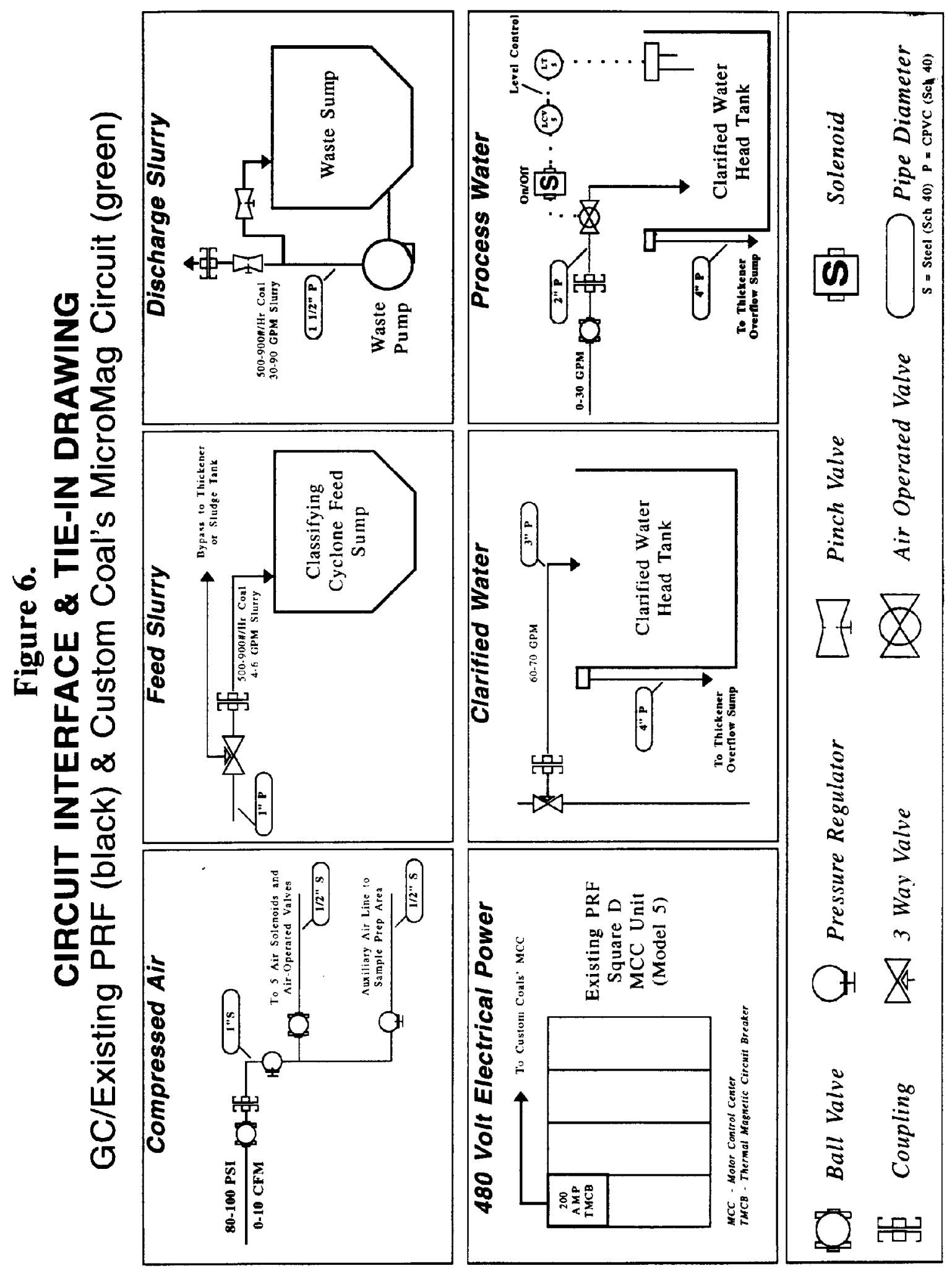




\section{Custom Coal Corporation}

\section{Classification Circuit Commissioning Tests}

The goal of the classification circuit commissioning was to test the functionality of the subcircuit and to preliminarily evaluate its ability to remove the majority of the -500M slimes (greater than $90 \mathrm{Wt} \%$ ), while recovering the majority of the $+325 \mathrm{M}$ particles (greater than $90 \mathrm{Wt} \%$ ), with a high solids content product (greater than $35 \mathrm{Wt} \%$ ). A total of 7 tests were performed during the testing, using two different circuits. The circuits were:

- Original circuit - PRF feed to classifying cyclone, followed by north side of deslime screen, with deslime screen undersize recycled. This circuit was used for the first 5 tests (CT\#1 thru CT\#5).

- $\quad$ Modified Circuit (See Figure 3) - PRF feed to north side of deslime screen (desliming), followed by classifying cyclone and south side of deslime screen (dewatering), with south side screen undersize recycled to the classifying cyclone. This circuit was used for the last 2 tests (CT\#6 and CT\#7).

Table 9 contains the operating conditions and results for the 7 tests.

As Table 9 illustrates, the initial circuit provided high recoveries, but it was impossible to simultaneously obtain efficient desliming and dewatering. Use of the modified circuit allowed the north side of the screen to focus on desliming and the south side of the screen to focus on dewatering. Tests CT\#6 and CT\#7 were the only two tests to achieve the goal of greater than $35 \mathrm{Wt} \%$ solids in the final product (i.e., 36.5 and $61.5 \mathrm{Wt} \%$, respectively). As a result, the modified circuit was used to optimize the classifying cyclone circuit during the component test work.

\section{Dense-Medium Cyclone Commissioning Tests}

The second slurry commissioning subtask involved two tests to assess the flow and performance of the parallel 2" and 4" Krebs Dense Medium Cyclones. Table 10 contains a summary of the test results and conditions. Table 10 suggests that the 4 " Cyclone was separating the $+500 \mathrm{M}$ particles very efficiently for the feedrate and operating conditions in CMT\#1 (i.e., $84 \mathrm{Wt} \%$ yield, with a 7.5 Wt\% Clean Coal Ash Content and $77 \mathrm{Wt} \%$ Refuse Ash Content, for an $18.9 \mathrm{Wt} \%$ Feed Ash Content), even with the relatively coarse Grade-K Magnetite. Unfortunately, the 2" Cyclone yield was only $11.2 \mathrm{Wt} \%$ for the $+500 \mathrm{M}$ particles in Test CMT\#1. Even with the smallest acceptable apex size of .25 inches, used in CMT\#2, the 2" Cyclone yield only increased to about $50 \mathrm{Wt} \%$. Different size inlets and pressures were used during the primary integrated test work in an attempt to improve the performance of the 2" Cyclone. However, this work with the 2" Cyclone was soon discontinued as it was determined that, since the drain and rinse screens were not working and the magnetic separator circuit was designed to process the combined cyclone overflow and underflow streams, it was no longer necessary to have the 2 " Cyclone in operation. 
Table 9. Classifying Circuit Commissioning Tests (Pittsburgh No. 8 Seam Raw Coal)

\begin{tabular}{|c|c|c|c|c|c|c|}
\hline \multirow[b]{2}{*}{ General Data } & \multicolumn{2}{|c|}{ Initial Tests } & \multicolumn{2}{|c|}{ New Spray Bars } & \multicolumn{2}{|c|}{ Modified Circuit } \\
\hline & CT\#1 & CT\#2 & CT\#4 & CT\#5 & CT\#6 & CT\#7 \\
\hline $\begin{array}{l}\text { Date } \\
\text { Circuit Type }\end{array}$ & $\begin{array}{c}04 / 03 / 95 \\
\text { Original }\end{array}$ & $\begin{array}{c}04 / 04 / 95 \\
\text { Original }\end{array}$ & $\begin{array}{c}04 / 13 / 95 \\
\text { Original }\end{array}$ & $\begin{array}{c}04 / 24 / 95 \\
\text { Original }\end{array}$ & $\begin{array}{l}\text { 04/27/95 } \\
\text { Modified }\end{array}$ & $\begin{array}{l}\text { 05/02/95 } \\
\text { Modified }\end{array}$ \\
\hline Feed Rate $(\# / \mathrm{hr})$ & 644 & 712 & 819 & 783 & 739 & 769 \\
\hline \multicolumn{7}{|l|}{ CYCLONE CONDITIONS } \\
\hline Feed Inlet (sq. in.) & 0.25 & 0.25 & 0.25 & 0.25 & 0.25 & 0.25 \\
\hline Vortex (Inches) & 0.25 & 0.625 & 0.625 & 0.625 & 0.625 & 0.80 \\
\hline Apex (Inches) & 0.375 & 0.375 & 0.25 & 0.25 & 0.25 & 0.25 \\
\hline Feed Pressure (PSI) & 33 & 42 & 46 & 46 & 48 & 45 \\
\hline Feed Rate (GPM) & 17.8 & 20.7 & 18.5 & 18.0 & 17.2 & 22.1 \\
\hline \multicolumn{7}{|l|}{$\underline{\text { SCREEN CONDITIONS }}$} \\
\hline North Side Panel (Mesh) & 325 & 325 & 200 & 200 & 325 & 325 \\
\hline North Side Sprays (GPM) & 5.0 & 5.8 & 9.8 & 14.5 & 15.0 & 18.5 \\
\hline South Side Panel (Mesh) & --- & --- & --- & --- & 200 & 100 \\
\hline South Side Sprays (GPM) & --- & --- & --- & --- & 2.4 & 0.0 \\
\hline \multicolumn{7}{|l|}{ PRODUCT QUALITY } \\
\hline Solids Content (Wt\%) & 26.5 & 16.1 & 31.5 & 18.6 & 36.5 & 61.5 \\
\hline Solids Flowrate (\#/hr) & 489 & 561 & 606 & 424 & 480 & 396 \\
\hline +325 Mesh $(\mathrm{Wt} \%)$ & --- & --- & 80.8 & 91.1 & 77.6 & 83.4 \\
\hline 325 x 500 Mesh $(\mathrm{Wt} \%)$ & --- & --- & 11.5 & 4.8 & 13.7 & 12.9 \\
\hline-500 Mesh (Wt $\%)$ & --- & --- & 7.7 & $4 . .1$ & 8.7 & 3.7 \\
\hline \multicolumn{7}{|l|}{ CIRCUIT PERFORMANCE } \\
\hline Overall Recovery (Wt\%) & 75.9 & 78.8 & 74.0 & 54.1 & 65.0 & 51.5 \\
\hline +325 Mesh Recovery (Wt\%) & --- & 98.5 & 99.1 & 88.0 & 99.7 & 85.9 \\
\hline-500 Mesh Rejection (Wt $\%)$ & --- & 61.2 & 81.7 & 93.9 & 85.0 & 94.8 \\
\hline
\end{tabular}


Table 10. Dense-Medium Cyclone Splits Pittsburgh No. 8 Seam Commissioning Tests (Grade-K Magnetite)

\begin{tabular}{|c|c|c|c|c|c|c|c|c|c|c|}
\hline \multirow[b]{2}{*}{ Test \# } & \multirow[b]{2}{*}{$\begin{array}{c}\text { D.M. } \\
\text { Cyclone }\end{array}$} & \multicolumn{2}{|c|}{ Conditions } & \multicolumn{2}{|c|}{ Feed } & \multicolumn{3}{|c|}{ Overflow } & \multicolumn{2}{|c|}{ Underflow } \\
\hline & & $\begin{array}{c}\text { Feed } \\
\text { Rate } \\
(\text { GPM) }\end{array}$ & $\begin{array}{l}\text { Feed } \\
\text { Pres. } \\
\text { (PSI) }\end{array}$ & $\begin{array}{l}\text { Slurry } \\
\text { SG }\end{array}$ & $\begin{array}{c}+\mathbf{5 0 0 M} \\
\text { Ash } \\
(\mathbf{W t} \%)\end{array}$ & $\begin{array}{c}\text { Slurry } \\
\text { SG }\end{array}$ & $\begin{array}{c}+500 \mathrm{M} \\
\text { Yield } \\
(\mathrm{Wt} \%)\end{array}$ & $\begin{array}{c}+500 \mathrm{M} \\
\text { Ash } \\
(\mathrm{Wt} \%)\end{array}$ & $\begin{array}{l}\text { Slurry } \\
\text { SG }\end{array}$ & $\begin{array}{c}+500 \mathrm{M} \\
\text { Ash } \\
(\mathrm{Wt} \%)\end{array}$ \\
\hline CMT\#1 & $4 "$ & 28 & 81 & 1.34 & 18.9 & 1.25 & 84.0 & 7.5 & 1.85 & 77.1 \\
\hline CMT\#1 & $2^{\prime \prime}$ & 10 & 22 & 1.34 & 18.9 & 1.13 & 11.2 & 4.6 & 1.56 & 20.7 \\
\hline СMT\#2 & $2^{\prime \prime}$ & 10 & 22 & 1.32 & 19.2 & 1.15 & 50.0 & 5.8 & 1.70 & 32.6 \\
\hline
\end{tabular}

Notes: - $\quad$ The 4" Cyclone had 0.12 sq. in. inlet, 1.00 inch vortex, and 0.625 inch apex.

- The 2" Cyclone had 0.09 sq. in. inlet, 0.375 inch vortex, and 0.375 inch apex in CMT\#1 and 0.25 inch apex in CMT\#2.

\section{Magnetite Recovery Circuit Commissioning Tests}

The third and final slurry commissioning subtask involved three tests to assess the magnetite recovery circuit performance (i.e., magnetite losses) for the screens and magnetic separators within the MicroMag circuit, once again using the relatively coarse, Grade-K Magnetite. Table 11 contains the total magnetite losses for each test, broken down by the two main sources:

- $\quad$ Rare-Earth Scavenger Magnetic Separator Tailing (Sample 36) - Which represents the total losses occurring within the 5 Eriez drum separators (see Figure 3).

- $\quad$ Combined Rinse Screen Products (Samples 22 \& 23) - Which represents the magnetite trapped in the coarse particles overflowing the refuse and clean-coal product screens (also see Figure 3).

The first test listed in Table 11 (MT\#2), was a test performed with only magnetite, and no coal slurry. As a result, the magnetics losses were extremely low in the magnetic separator tailings (0.3$0.8 \# /$ ton), and negligible in the combined Rinse Screen Products (i.e., because there were no products). The magnetics contents and losses are based on two calculations (Davis-Tube based and EMU based), with Davis-Tube based values being an initial approximation and EMU-based values being a correction due to the slight inefficiency of the Davis Tube (see discussion in Section 4.8). The EMU calculations are based on magnetic moment measurements of the feed, mags, and nonmags from the Davis-Tube tests. The actual losses are probably somewhere in between. 


\section{Table 11. Magnetite Losses \\ Pittsburgh No. 8 Seam Commissioning Tests \\ (Grade-K Magnetite)}

\begin{tabular}{||c|c|c|c|c|c|c|c||}
\hline \multirow{2}{*}{} & & \multicolumn{2}{|c|}{$\begin{array}{c}\text { Davis-Tube Based } \\
\text { Results }\end{array}$} & \multicolumn{2}{c||}{ EMU Based Results } \\
\cline { 3 - 9 } Test & Stream & Stream Info. & \multicolumn{2}{|c||}{$\begin{array}{c}\text { Solids } \\
\text { Sagnetics } \\
\text { (Wt\%) }\end{array}$} & $\begin{array}{c}\text { Magnetics } \\
\text { Losses } \\
\text { (\#/Ton) }\end{array}$ & $\begin{array}{c}\text { Solids } \\
\text { Magnetics } \\
\text { (Wt\%) }\end{array}$ & $\begin{array}{c}\text { Magnetics } \\
\text { Losses } \\
\text { (\#/Ton) }\end{array}$ \\
\hline \hline MT\#2 & 36-Scav. Sep. Tails & 5 & 60 & 1.5 & 0.3 & 3.9 & 0.8 \\
\hline CMT\#1 & 36-Scav. Sep. Tails & 100 & 60 & 0.6 & 2.2 & 0.9 & 3.3 \\
CMT\#1 & 22/23 - Rinse Products & 400 & -- & 5.0 & 880 & 5.5 & 88 \\
CMT\#1 & Total Circuit & 500 & -- & 4.1 & 82.2 & 4.6 & 91.3 \\
\hline CMT\#1 & 36-Scav. Sep. Tails & 100 & 60 & 0.3 & 1.1 & 0.6 & 2.2 \\
CMT\#2 & 22/23 - Rinse Products & 400 & -- & 2.2 & 35 & 2.5 & 40 \\
CMT\#2 & Total Circuit & 500 & -- & 1.8 & 36.1 & 2.1 & 42.2 \\
\hline
\end{tabular}

NOTES:- Stream 36 is Rare-Earth Scavenger Magnetic Separator Tailings (Final Magnetic Separator Nonmags).

- Stream 22 is Rinse Screen Refuse Discharge (Final Refuse Nonmags).

- Stream 23 is Rinse Screen Clean Coal Discharge (Final Clean Coal Nonmags).

- MT\#2 had only magnetite being fed and 22 and 23 streams were negligible.

- Data Assumes 500 \#/hr total coal feed, and that pure magnetics are 86 EMU/g.

- CMT\#1 done with 325M panels with $-3^{\circ}$ angle on rinse screen, and CMT\#2 done with $200 \mathrm{M}$ panels with $0^{\circ}$ angle on rinse screen.

The last two test results listed in Table 11 are for two tests done with coal and magnetite slurry; the first (CMT\#1) done with the finest, 325M drain and rinse screen panels and a deep bed in the rinse screen (slight negative angle), and the second (CMT\#2) done with coarser, 200M drain and rinse panels and a shallow bed on the rinse screen ( 0 degree angle). The results show that acceptable magnetics losses through the magnetic separators (1.1-3.3 \#/ton) were achieved for both tests. However, the magnetics losses in the rinse screen products were unacceptably high (35-88 \#/ton), for both tests. The coarser $200 \mathrm{M}$ panels and flattening of the rinse screen improved the results but the losses of 35-40 \#/ton are still significantly above acceptable targets (5-10 \#/ton). Additional detailed testing was conducted during the primary integrated test work in an effort to optimize the drain and rinse screens.

\section{Section 4.7 - Task 700: Circuit Testing, Sampling and Monitoring}

The circuit testing was the major focus of the project, and was conducted for an eight-month period from May 1995 through mid December 1995. The vast majority of the circuit testing occurred using the Pittsburgh No. 8 Seam coal with limited testing being conducted using the Lower Kittanning 
Seam coal. Three micronized magnetites (Grades K, L, M) were tested with limited work being conducted using a commercial, Grade-E magnetite.

The test program was divided into three testing phases, which included:

- $\quad$ Component Testing

- $\quad$ Primary Integrated Testing, and

- $\quad$ Continuous Integrated Testing

The component testing phase focused on "closed-looped" testing of the classifying cyclone, densemedium cyclone (4-inch), and medium recovery circuits. The component testing focused on optimizing these individual subcircuits. The primary integrated testing focused on operating the entire Micro-Mag circuit for relatively short periods of time to observe the impact of key process variables and to ascertain the capability of the entire Micro-Mag circuit. The continuous integrated testing was conducted to quantify magnetite losses and determine the impact of changing medium quality on the performance of the dense-medium cyclone over a lengthy period of operation using two different grades of micronized magnetites. Section 4.10 - Task 1000: Results and Discussion, details the number, configuration, and results from the component, primary integrated, and continuous integrated testing.

\section{Component Test Procedures}

All the dense-medium cyclone component testing was conducted using manually prepared feed mixtures and a closed-loop circuit configuration that included the dense-medium cyclone feed sump, the 4-inch dense-medium cyclone, and a manually-operated sampling station. Exact weights of feed coal $(+500 \mathrm{M})$, water, and magnetite were prepared and mixed in the feed sump for each test run according to the specified operating conditions. For those tests performed to evaluate the effect of contamination of the recirculating medium, specific amounts of $-500 \mathrm{M}$ coal fines were also added to the mix tank to simulate non-magnetic fines contamination.

The $+500 \mathrm{M}$ and $-500 \mathrm{M}$ materials were generated by operating only the Micro-Mag classification circuit using feed from the PRF. The $+500 \mathrm{M}$ material was prepared by collecting the discharge stream from the south side of the deslime screen in drums followed by air drying. The $-500 \mathrm{M}$ material was prepared by routing the $-500 \mathrm{M}$ slimes from the classifying cyclone circuit to the PRF Sharples high-g centrifuge, collecting the dewatered discharge product in drums, and air drying. Table 16 contains typical analyses for the $+500 \mathrm{M}$ feed coal and the $-500 \mathrm{M}$ contamination slimes from which the various feed batches were made. The Appendix volume details the exact quality and size consist of the feeds used for all the dense-medium cyclone component tests.

Full-stream, simultaneous sampling techniques were used to obtain samples of the dense-medium cyclone overflow and underflow products as they were discharged from the cyclone and prior to their returning back to the feed sump. A simple sliding tray with 5-gallon buckets was used for the 
collection of the cyclone products. Dense-medium cyclone feed samples were collected in a 5-gallon bucket at a diverter valve located near the 4-inch cyclone inlet.

The medium recovery component tests required running the entire Micro-Mag circuit in an integrated fashion to produce overflow and underflow product streams for delivery to the drain and rinse screens. For tests where drain and rinse screens were not used, the 2 " cyclone products were recombined and sent directly to the magnetic separator circuit. Feed slurry was continuously received from the PRF for once-through processing. All final product and waste streams were directed back to the PRF for disposal. Full-stream samples of the various screen discharges and magnetic separator products were collected using full-width, custom-made steel samplers and plastic buckets, respectively.

\title{
$\underline{\text { Primary Integrated and Continuous Integrated Test Procedures }}$
}

The primary integrated and continuous integrated tests were conducted in identical fashion requiring the operation of the entire Micro-Mag circuit in an integrated, continuous-mode. Feed slurry was continuously received from the PRF for once-through processing. All final product and waste streams were directed back to the PRF for disposal. Sampling of the Micro-Mag circuit required the collection of both slurry and cake samples. Slurry sampling of the circuit was accomplished in most cases by time filling $1 / 2,1,3$, or 5-gallon plastic containers. A few slurry samples which could not be collected by time filling were collected using a pulp sampler. Cake samples of the discharges off the various screens were collected using custom-made, full-width steel samplers to collect the entire screen discharge.

\section{Test Data Sheets}

When conducting tests on the Micro-Mag circuit a comprehensive data sheet for each test was completed and is illustrated in Table 12. Each data sheet contained the following information:

\author{
- Test Date \\ - A Unique Run Number \\ - Coal Seam \\ - Coal Size \\ - Magnetite Type \\ - Test Starting Time \\ - Test Ending Time \\ - $\quad$ Flowrates on the Seven Process Pumps and pressure on the Clarified Water Booster Pump \\ - $\quad$ Flowrates and Pressures on the Deslime and Rinse Screen Sprays \\ - $\quad$ Feed Pressures on the Two-Inch and Four-Inch Dense Medium Cyclones \\ - $\quad$ Feed Pressure on the Two-Inch Classifying Cyclone \\ - $\quad$ Correct Medium Circulating Specific Gravity \\ - Orifice Combinations of the Cyclones
}


Table 12. Micro-Mag Data Sheet

DATE:

RUN:

COAL SEAM:

COAL SIZE:
COAL FEED START TIME:

TEST START TIME:

TEST END TIME:

MAGNETITE TYPE:

\begin{tabular}{|c|c|c|c|c|c|c|}
\hline \multicolumn{4}{|c|}{$\overline{\overline{\text { Flows }}}$} & \multicolumn{3}{|c|}{ Pressures } \\
\hline Location & Time Taken & FPS & GPM & Location & Time Taken & PSI \\
\hline Fine H.M. Pump & & & & Classifying Cyc. & & \\
\hline Mag. Sep. Test Pump & & & & Two-Inch H.M. Cyc. & & \\
\hline Mag. Sep. Feed Pump & & & & Four-Inch H.M. Cyc. & & \\
\hline Correct Media Pump & & & & Deslime Screen Sprays & & \\
\hline Classifying Cyc. Pump & & & & Rinse Screen Sprays & & \\
\hline Waste Pump & & & & C.W. Water Booster Pump & & \\
\hline \multicolumn{7}{|l|}{ C.W. Booster Pump } \\
\hline \multicolumn{7}{|l|}{ Deslime Screen Sprays } \\
\hline Rinse Screen Sprays & & & & & & \\
\hline
\end{tabular}

\begin{tabular}{|c|c|c|c|c|c|c|c|c|}
\hline \multicolumn{3}{|c|}{ Correct Media Density } & \multicolumn{4}{|c|}{ Cyclone Configurations } & \multicolumn{2}{|c|}{ Screen Deck Sizes } \\
\hline Time Taken & $\begin{array}{c}\text { Nuclear } \\
\text { Gauge }\end{array}$ & $\begin{array}{c}\text { Marcy } \\
\text { Balance }\end{array}$ & Cyclone & $\begin{array}{l}\text { Feed Inlet } \\
\quad \text { (In)2 }\end{array}$ & $\begin{array}{c}\text { Vortex Finder } \\
\text { Dia. - In. }\end{array}$ & $\begin{array}{c}\text { APEX } \\
\text { Dia. - In. }\end{array}$ & Screen & Mesh Size \\
\hline & & & Class & & & & Deslime Screen & \\
\hline & & & 2-Inch H.M. & & & & Drain Screen & \\
\hline & & & 4-Inch H.M. & & & & Rinse Screen & \\
\hline
\end{tabular}

\begin{tabular}{||c|c||}
\hline Test Description & Comments \\
\hline \hline & \\
\hline
\end{tabular}


Samples

Run No:

Date:

\begin{tabular}{|c|c|c|c|c|}
\hline $\begin{array}{c}\text { Sample } \\
\text { Stream No. }\end{array}$ & Sample Stream Description & Sample Location & Time & $\begin{array}{c}\text { Container } \\
\text { I.D. No. }\end{array}$ \\
\hline 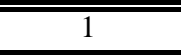 & $\begin{array}{ll}\text { P.R.F. Feed } \\
\end{array}$ & Above Deslime Screen & & \\
\hline 2 & Classifying Cyclone Feed & Second Floor TV-104 A\&B & & \\
\hline 3 & Classifying Cyclone Underflow & First Floor TV-103A\&B & & \\
\hline 4 & Classifying Cyclone Overflow & Second Floor Cyclone Overflow & & \\
\hline 5 & \begin{tabular}{|l|} 
Deslime Screen Underflow - South \\
\end{tabular} & \begin{tabular}{|l} 
Above Classifying Cyclone Sump-Bottom \\
\end{tabular} & & \\
\hline $5 \mathrm{~A}$ & Deslime Screen Underflow - North & Above Waste Sump & & \\
\hline 6 & \begin{tabular}{|l} 
Deslime Screen Discharge - South \\
\end{tabular} & \begin{tabular}{|l} 
First Floor Screen Discharge \\
\end{tabular} & & \\
\hline $6 \mathrm{~A}$ & Deslime Screen Discharge - North & Above Classifying Cyclone Sump & & \\
\hline 7 & Dense Medium Cyclone Feed & \begin{tabular}{|l|} 
Third Floor TV-201 \\
\end{tabular} & & \\
\hline 8 & Two-Inch D.M. Cyclone Underflow & Third Floor TV-206A\&B & & \\
\hline 9 & \begin{tabular}{|l} 
Two-Inch D.M. Cyclone Overflow \\
\end{tabular} & Third Floor Cyclone Overflow & & \\
\hline $8 \mathrm{~A}$ & Four-Inch D.M. Cyclone Underflow & Above D.M. Cyclone Sump-Bottom & & \\
\hline $9 \mathrm{~A}$ & \begin{tabular}{|l} 
Four-Inch D.M. Cyclone Overflow \\
\end{tabular} & Above D.M. Cyclone Sump-Bottom & & \\
\hline $10(20)$ & Drain Screen Discharge - Refuse & Third Floor Screen Discharge & & \\
\hline $11(21)$ & \begin{tabular}{|l} 
Drain Screen Discharge Clean Coal \\
\end{tabular} & Third Floor Screen Discharge & & \\
\hline 12 & Drain Screen Refuse Effluent & Second Floor TV-203A\&B & & \\
\hline 13 & \begin{tabular}{|l} 
Drain Screen Clean Coal Effluent \\
\end{tabular} & \begin{tabular}{|l} 
Second Floor TV-204A\&B \\
\end{tabular} & & \\
\hline $16(14 \& 15)$ & \begin{tabular}{|l} 
Combined Drain Screen Effluent \\
\end{tabular} & First TV-205A\&B & & \\
\hline 22 & $\begin{array}{l}\text { Rinse Screen Refuse Discharge } \\
\end{array}$ & \begin{tabular}{|l} 
Second Floor Screen Discharge \\
\end{tabular} & & \\
\hline 23 & \begin{tabular}{|l} 
Rinse Screen Clean Coal Discharge \\
\end{tabular} & \begin{tabular}{|l} 
Second Floor Screen Discharge \\
\end{tabular} & & \\
\hline 24 & $\begin{array}{l}\text { Rinse Screen Refuse Effluent } \\
\end{array}$ & First Floor TV-301A\&B & & \\
\hline 25 & $\begin{array}{l}\text { Rinse Screen Clean Coal Effluent } \\
\end{array}$ & First Floor TV-302A\&B & & \\
\hline 26 & \begin{tabular}{|l} 
Combined Rinse Screen Effluent \\
\end{tabular} & First Floor TV-301A\&B/TV-302A\&B & & \\
\hline 27 & \begin{tabular}{|l} 
Primary Magnetic Separator Feed \\
\end{tabular} & \begin{tabular}{|l} 
First Floor PMS Feed Box \\
\end{tabular} & & \\
\hline 28 & \begin{tabular}{|l|} 
Secondary Magnetic Separator Feed \\
\end{tabular} & \begin{tabular}{|l} 
First Floor SMS Feed Box \\
\end{tabular} & & \\
\hline 29 & \begin{tabular}{|l|} 
Primary Magnetic Separator Conc. \\
\end{tabular} & Above Magnetic Sep Test Sump - Bottom & & \\
\hline 30 & \begin{tabular}{|l|} 
Secondary Magnetic Separator Tails \\
\end{tabular} & Above Magnetic Sep. Feed Sump - Bottom & & \\
\hline 31 & \begin{tabular}{|l} 
Secondary Magnetic Separator Conc. \\
\end{tabular} & Above Magnetic Sep. Test Sump - Bottom & & \\
\hline 32 & \begin{tabular}{|l|l|} 
Tertiary Magnetic Separator Feed \\
\end{tabular} & First Floor TMS Feed Box & & \\
\hline 33 & \begin{tabular}{|l} 
Tertiary Magnetic Separator Conc. \\
\end{tabular} & Above Magnetic Sep. Test Sump - Bottom & & \\
\hline 34 & Scavenger Magnetic Separator Feed & \begin{tabular}{|l} 
First Floor REMS Feed Box \\
\end{tabular} & & \\
\hline 35 & Scavenger Magnetic Separator Conc. & \begin{tabular}{|l|} 
First Floor REMS Concentrate Box \\
\end{tabular} & & \\
\hline 36 & \begin{tabular}{|l} 
Scavenger Magnetic Separator Tails \\
\end{tabular} & \begin{tabular}{|l} 
Above Waste Sump Bottom \\
\end{tabular} & & \\
\hline 38 & Cleaner Magnetic Separator Feed & \begin{tabular}{|l} 
Third Floor CMS Feed Box \\
\end{tabular} & & \\
\hline 39 & \begin{tabular}{|l} 
Cleaner Magnetic Separator Tails \\
\end{tabular} & First Floor PMS Feed Box & & \\
\hline 40 & \begin{tabular}{|l|} 
Cleaner Magnetic Separator Conc. \\
\end{tabular} & Above Correct Medium Sump - Bottom & & \\
\hline 44 & \begin{tabular}{|l|} 
Correct Medium \\
\end{tabular} & First Floor TV-202A\&B & & \\
\hline 51 & Bulk Magnetite & Above Correct Medium Sump - Bottom & & \\
\hline
\end{tabular}


- Screen Deck Sizes Installed on the Deslime, Drain, and Rinse Screens

- Test Description

- Samples Collected, including the amount of time the sample was collected and the container number in which it was collected.

Information such as Run Number, Coal Seam, Sample Points, etc., was entered on the data sheet prior to testing. This ensured that the desired test was performed and the necessary samples were collected.

\section{Section 4.8 - Task 800: Analytical}

The sample collection, handling, and analyses was the most challenging aspect of the project. Accurate, reliable, and reproducible sampling data was pivotal for conducting the circuit performance evaluations and completing the project objectives. The analytical efforts for the project were complicated by the fact that the circuit was evaluated for not only overall performance but also performance of individual unit operations. Unit operations sampling created a number of sampling and analytical problems, which included:

1. The collection of accurate timed samples of rather high volume flowrate streams (1 to 60 GPM) to determine flow balances around the circuit.

2. A reliable method needed to be found to identify the extremely-fine magnetic particles, and consistently separate them from non-magnetic particles in all samples.

3. Solids weights and/or solids contents determinations needed to be made on all samples, as well as for the magnetics and non-magnetics fractions from the separations in item 2 . Filtering and dewatering samples would be very difficult, particularly for the samples containing the micronized magnetic.

4. After separation, determinations of size content and composition would be required for the magnetics fraction.

5. After separation, accurate determinations of head composition, size content, and gravity distribution would be required for the non-magnetics. The larger sample sizes required to perform these analyses would present some significant logistical problems, due to the limited capacity of the laboratory magnetic separation units.

To address the most difficult analytical problems listed above, Custom Coals subcontracted Michigan Technological University (MTU), Institute of Materials Processing (IMP) to perform a laboratory investigation to determine required laboratory procedures for the fine-coal and magnetite slurry and solid samples that were to be generated during the project testing. The main analytical concerns addressed by MTU included: 


\section{Custom Coal Corporation}

- density, and agglomeration measurements

- magnetics/nonmagnetics separations

- $\quad$ magnetics analyses (i.e., magnetic moments and compositions)

- magnetics and nonmagnetics size analyses, down to sub-micron sizes.

MTU's IMP provided laboratory analyses services, for the project test samples, using the equipment and procedures they developed during this investigation.

\section{Microtrac Size Analyses}

The first area of concern was developing sample pretreatment methods to obtain accurate size analysis of solids and slurry samples, using the IMP's Leeds and Northrup, Microtrac Particle Size Analyzer. During the testing, the IMP staff found that three pretreatment steps were necessary to obtain accurate and reproducible size analyses with the unit. They included that:

- The samples had to be wetted in the presence of a surfactant, if they were dry, to enhance both wetting and dispersion.

- The samples had to be demagnetized to ensure that any magnetite agglomerates were broken up.

- $\quad$ The samples had to be treated with an ultrasonic probe, for 5-10 minutes to ensure that all coal agglomerates were broken up.

The samples had to also be well agitated during these steps, as well as during removal of the small portion for analyses, to ensure good dispersion and a representative sample.

Once these procedures were followed, the IMP staff found that they could obtain essentially identical analyses for parallel splits, even when one split had been filtered and dried and the other had not. They also found that the Microtrac analyses for feed, magnetics, and nonmagnetics balanced around their magnetics separations, which was also an important QA/QC test.

As a check of their Microtrac analyses for bias, the IMP also sent samples of the feed magnetite to another laboratory (PTLL) for testing in a similar machine (a Malvern Unit), and also did an elaborate particle counting analysis using their SEM to determine the particle size populations. The size distribution proved to be very similar with the following reported results:

- MTU's IMP Microtrac

- PTLL's Malvern

- MTU's IMP SEM
- $\quad 5.7$ micron mean volume diameter (MVD).

- 5.8 micron mean volume diameter (MVD).

- 6.2 micron mean volume diameter (MVD).

As a result, the $-500 \mathrm{M}$ particle size analyses for the entire project was done using IMP's Microtrac. 


\section{Density Measurements}

Table 13 shows some solids density measurements that the IMP performed as part of their investigation. Measurements were conducted using both water and kerosene as the measuring medium. The use of kerosene greatly improved the reproducibility of the measurements (to +/-.02 SG units), due to improved wetting. All required solids density measurements for the project were done by the IMP.

\section{Table 13. Solids Densities} (Measured with Kerosene)

\begin{tabular}{||c|c||}
\hline \multicolumn{1}{|c|}{ Sample } & SG \\
\hline \hline PennMag Grade-K “Old” Magnetite & 4.73 \\
DOE 90-X Magnetite & 4.86 \\
Hi-Temp. Magnetite & 4.57 \\
\hline Pittsburgh No. 8 (-325 M) & 1.68 \\
Lower Kittanning (-325 M) & 1.42 \\
\hline
\end{tabular}

\section{Davis-Tube Separation Testing (Magnetite Only)}

The first step in MTU's IMP Davis-Tube separation testing was to determine a profile of Amps vs. Gauss for their Davis Tube and see if the separations matched earlier work by Eriez Magnetics. The results proved essentially identical, except that MTU recovered all nonmags, so they could reconstitute yields from weights of both products, as well as from feed and mags weights. The IMP also determined that once magnetics saturations were reached on the Davis-Tube (i.e., at about 0.7 amps), the recoveries remained constant, up to the maximum setting of 1.7 amps. This indicated that any amp level could be used between 0.7 and 1.7 amps to led to similar results. However, MTU later found that when the highest 1.7 amp level was used the Davis-Tube had much higher capacity (i.e., up to 6 grams of magnetics). This proved to be desirable to allow bigger samples, and subsequently provide for more nonmagnetics to analyze, and better overall particle recovery (i.e., approaching 99 $\mathrm{Wt} \%$ ). Therefore, all Davis-Tube separations were conducted at 1.7 amps for the duration of the test program.

\section{Davis-Tube Separations \& Magnetic Moment Measurements (Coal \& Magnetite)}

In combination with the Davis-Tube separations, the MTU's IMP made magnetic moment measurements of the feed, mags, and nonmags to compliment the measurements. Table 14 shows the results for separations with the initial PennMag Grade-K magnetite (old magnetite), which has 
Table 14. Davis-Tube and Moment Balances

(Old and New PennMag Grade-K Magnetite)

\section{Old Magnetite:}

\begin{tabular}{|c|c|c|c|c|c|c|}
\hline $\begin{array}{c}\text { Test } \\
\text { Number }\end{array}$ & Feed Description & Sample & $\begin{array}{c}\text { Weight } \\
\text { (Grams) }\end{array}$ & $\begin{array}{l}\text { Weight } \\
\text { (Wt\%) }\end{array}$ & $\begin{array}{l}\text { Moment } \\
\text { (Emu/g) }\end{array}$ & $\begin{array}{c}\text { Moment } \\
\text { Dist. } \\
\text { (Wt\%) }\end{array}$ \\
\hline DT-24 & Magnetite Only & $\begin{array}{l}\text { Mags } \\
\text { Non Mags } \\
\text { Total }\end{array}$ & $\begin{array}{l}5.64 \\
\underline{0.27} \\
5.91\end{array}$ & $\begin{array}{r}95.5 \\
\quad 4.5 \\
100.0\end{array}$ & $\begin{array}{r}84.30 \\
1.00 \\
80.55\end{array}$ & $\begin{array}{r}99.94 \\
0.06 \\
100.0\end{array}$ \\
\hline DT-37 & Pitts. No. 8 Coal Only & $\begin{array}{l}\text { Mags } \\
\text { Non Mags } \\
\text { Total }\end{array}$ & $\begin{array}{l}0.00 \\
5.87 \\
5.87\end{array}$ & $\begin{array}{r}0.0 \\
100.0 \\
100.0\end{array}$ & $\begin{array}{l}0.00 \\
0.21 \\
0.21\end{array}$ & $\begin{array}{r}0.00 \\
100.00 \\
100.00\end{array}$ \\
\hline DT-33 & $\begin{array}{l}\text { Sim. Cyclone Feed } \\
\text { (1.0/4.7g. Coal/Mag.) }\end{array}$ & $\begin{array}{l}\text { Mags } \\
\text { Non Mags } \\
\text { Total }\end{array}$ & $\begin{array}{l}4.32 \\
1.30 \\
5.62\end{array}$ & $\begin{array}{r}76.9 \\
23.1 \\
100.0\end{array}$ & $\begin{array}{r}80.40 \\
1.67 \\
62.21\end{array}$ & $\begin{array}{r}99.39 \\
0.61 \\
100.0\end{array}$ \\
\hline
\end{tabular}

\section{New Magnetite:}

\begin{tabular}{|c|c|c|c|c|c|c|}
\hline $\begin{array}{c}\text { Test } \\
\text { Number }\end{array}$ & Feed Description & Sample & $\begin{array}{c}\text { Weight } \\
\text { (Grams) }\end{array}$ & $\begin{array}{l}\text { Weight } \\
\text { (Wt\%) }\end{array}$ & $\begin{array}{l}\text { Moment } \\
\text { (Emu/g) }\end{array}$ & $\begin{array}{c}\text { Moment } \\
\text { Dist. } \\
\text { (Wt\%) }\end{array}$ \\
\hline DT-54 & Magnetite Only & $\begin{array}{l}\text { Mags } \\
\text { Non Mags } \\
\text { Total }\end{array}$ & $\begin{array}{l}4.92 \\
\underline{0.04} \\
4.96\end{array}$ & $\begin{array}{r}99.2 \\
0.8 \\
100.0\end{array}$ & $\begin{array}{r}86.74 \\
7.35 \\
86.10\end{array}$ & $\begin{array}{r}99.94 \\
0.06 \\
100.00\end{array}$ \\
\hline DT-13 & Cyclone Feed & $\begin{array}{l}\text { Mags } \\
\text { Non Mags } \\
\text { Total }\end{array}$ & $\begin{array}{l}4.00 \\
1.83 \\
5.83\end{array}$ & $\begin{array}{r}68.7 \\
31.3 \\
100.0\end{array}$ & $\begin{array}{r}87.07 \\
0.53 \\
59.98\end{array}$ & $\begin{array}{r}99.73 \\
0.27 \\
100.00\end{array}$ \\
\hline DT-15 & Final Coal Product & $\begin{array}{l}\text { Mags } \\
\text { Non Mags } \\
\text { Total }\end{array}$ & $\begin{array}{r}0.05 \\
15.76 \\
15.81\end{array}$ & $\begin{array}{r}0.3 \\
99.7 \\
100.0\end{array}$ & $\begin{array}{r}83.71 \\
0.12 \\
0.37\end{array}$ & $\begin{array}{r}67.88 \\
32.12 \\
100.00\end{array}$ \\
\hline S-16 & $\begin{array}{l}\text { Scav. Mag. Sep. } \\
\text { Tailings }\end{array}$ & $\begin{array}{l}\text { Mags } \\
\text { Non Mags } \\
\text { Total }\end{array}$ & $\begin{array}{l}0.05 \\
\underline{8.40} \\
8.45 \\
\end{array}$ & $\begin{array}{r}0.6 \\
9.4 \\
100.0 \\
\end{array}$ & $\begin{array}{r}70.67 \\
0.36 \\
.78 \\
\end{array}$ & $\begin{array}{r}54.23 \\
45.77 \\
100.00 \\
\end{array}$ \\
\hline
\end{tabular}


a pure magnetics moment of about 84 EMU/g, and the coarser Lot \#1, PennMag Grade-K Magnetite from PeaRidge (new magnetite) which has a pure magnetics moment of about $87 \mathrm{EMU} / \mathrm{g}$. The results indicate the occasional and unexplained inefficiency of magnetics separation with the DavisTube, for coal and magnetite mixtures, as shown by the drop in EMU/g of the magnetics product and the higher than expected EMU/g of the nonmagnetics.

Since the inefficiencies, illustrated in Table 14, were not able to be explained, the project team complimented the Davis-Tube separation results, with magnetics moment measurements, so that magnetics contents and magnetics losses could be calculated two ways:

- $\quad$ From Davis-Tube magnetics at 1.70 amps.

- $\quad$ From magnetics moment of all samples (feeds, mags, and nonmags).

Another advantage of the magnetic moment measurements is that they allow for a quick and inexpensive method of magnetics content of a sample. For instance, for the new magnetite testing the magnetics content can be measured by dividing its EMU/g by $87 \mathrm{Emu} / \mathrm{g}$ (the magnetic moment of pure magnetics). This proved to be a valuable tool in the project testing.

To accomplish the remaining analytical requirements for the project, Custom Coals subcontracted Commercial Testing and Engineer's (CTE) Charleroi, PA laboratory to perform sulfur, sulfur forms and Btu analysis and CTE's Henderson, KY laboratory to perform all fine washability analysis. The Henderson laboratory used Process Technology, Inc.'s fine float/sink process to perform the fine washability analysis. Custom Coals on site laboratory performed \% solids, ashing, wet screening, and sample preparation. Figure 7 represents the Micro-Mag Project's analytical structure.

\section{Section 4.9 - Task 900: Circuit Decommissioning}

Custom Coals' original contract with the Department of Energy included decommissioning of the Micro-Mag circuit. However, midway through the contract DOE decided to keep the circuit intact for additional in-house and possibly industry testing of the technology. As a result, the decommissioning of the Micro-Mag circuit was deleted from Custom Coal's contract and the circuit was left intact at FETC's Process Research Facility.

\section{Section 4.10 - Task 1000: Results, Data Evaluation, and Discussion}

The data evaluation task occurred over the entire project period. During that period, Custom Coals compiled results from all aspects of the Micro-Mag circuit testing including all the detailed analytical work and fine washabilities. The following discussion summarizes the results from the various testing aspects performed during the project. The discussion is broken down into four subsections, which include:

- Component Testing Results 


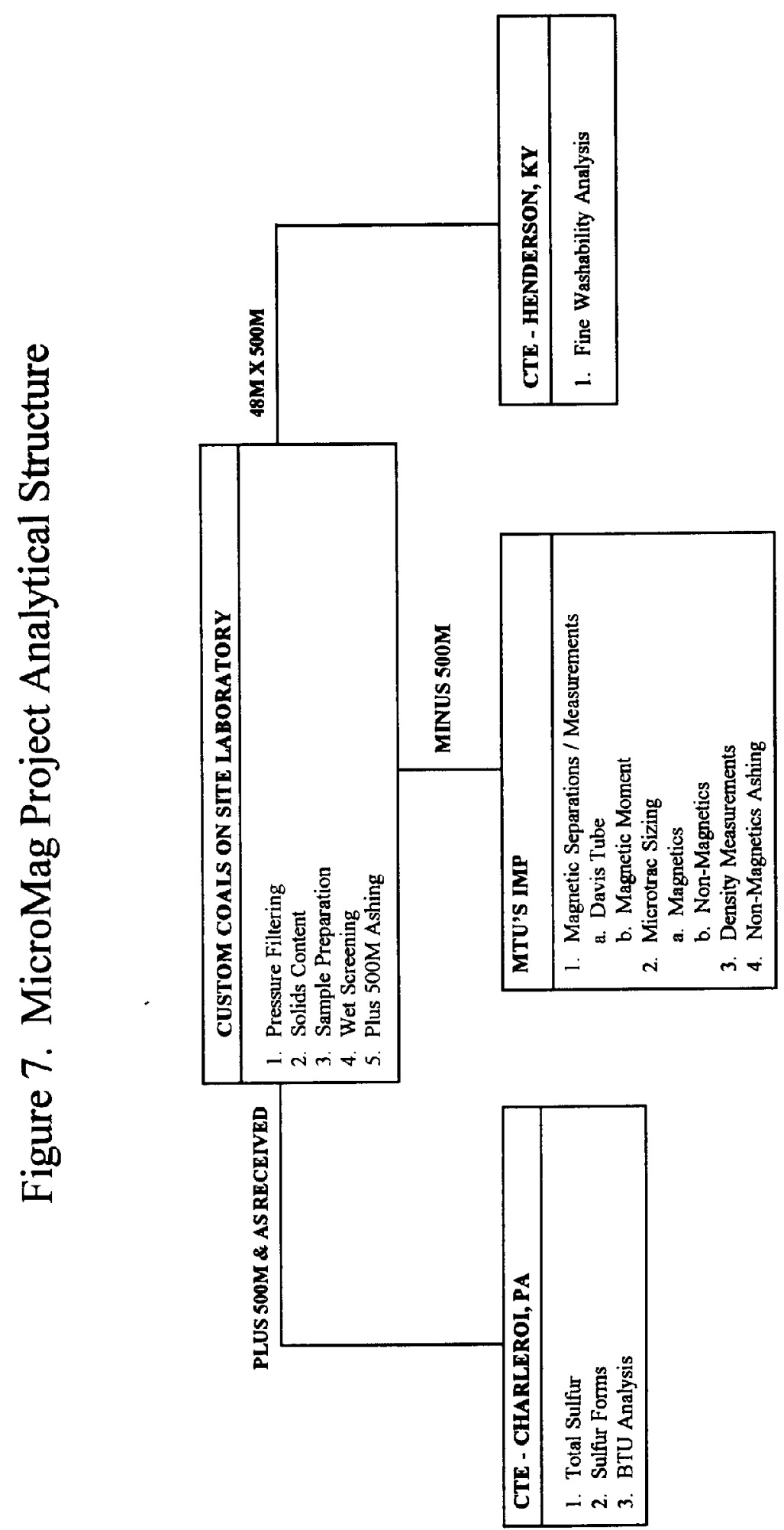


- $\quad$ Primary Integrated Testing Results

- Continuous Integrated Testing Results

- Quality Assurance and Quality Control Testing Results

Complete listings of all the laboratory test results and test conditions are included in Appendices A through $\mathrm{F}$ of the Appendix volume.

\section{Section 4.10.1 - Component Testing Results}

The following discussion summarizes the results from the component testing phase of the project. This phase of the testing was conducted via independent batch mode operations of each of the various subcircuits. The discussion is broken down into three sections, which include:

- Classification Circuit Testing Results

- Dense-Medium Cyclone Component Testing Results

- Medium Recovery Circuit Component Testing Results

\section{Section 4.10.1.1 - Classification Circuit Testing Results}

The goal of the classification circuit testing was to test that subcircuit's ability to remove the majority of the $-500 \mathrm{M}$ slimes (greater than $90 \mathrm{Wt} \%$ ), while recovering the majority of the $+325 \mathrm{M}$ particles (greater than $90 \mathrm{Wt} \%$ ), with a high solids content product (greater than $60 \mathrm{Wt} \%$ ) for feeding the dense-medium cyclone feed tank. The classifying circuit as originally installed consisted of the PRF feed reporting to the classifying cyclone followed by the classifying cyclone underflow reporting to the north side of the deslime screen $(325 \mathrm{M})$ with the deslime screen undersize recycled back to the classifying cyclone. This initial circuit provided high recoveries, but it was impossible to simultaneously obtain efficient desliming and dewatering. As a result, the circuit was modified with the PRF feed reporting to the north side of the desliming screen (325M desliming), followed by the classifying cyclone underflow reporting to the south side of the desliming screen (dewatering). The south side screen undersize was recycled to the classifying cyclone.

To optimize this "modified circuit" a total of 7 tests were conducted varying the classifying cyclone's orifice sizes and the deslime screens desk sizes. Five tests were conducted using the Pittsburgh No. 8 Seam coal and two tests were conducted using the Lower Kittanning "B" Seam coal. A summary of the results is presented in Table 15.

As can be seen from Table 15, tests PCT\#5 and KCT\#2 resulted in the highest product solids contents $(63.9 \%$ and $64.3 \%)$ with +325 Mesh recoveries of $95.9 \%$ and $97.6 \%$ respectively. The $500 \mathrm{M}$ x 0 rejection for these two tests was also quite good with $89.1 \%$ being rejected for test PCT\#5 and $91.3 \%$ being rejected for test KCT\#2. In general, the +325 Mesh recovery and the $500 \mathrm{M} \times 0$ 
Table 15. Classifying Circuit Optimization Tests

\begin{tabular}{|l|c|c|c|c|c|c|c||}
\hline GENERAL DATA & & & & & & & \\
Test Number & PCT\#1 & PCT\#2 & PCT\#3 & PCT\#4 & PCT\#5 & KCT\#1 & KCT\#2 \\
\hline \hline Coal Seam & Pitt. \#8 & Pitt. \#8 & Pitt. \#8 & Pitt. \#8 & Pitt. \#8 & Low. Kitt. & Low. Kitt. \\
Feed Rate (\#/hr.) & 815 & 824 & 765 & 807 & 767 & 699 & 872 \\
\hline CYCLONE CONDITIONS & & & & & & & \\
Feed Inlet (sq. in.) & & & & & & & \\
Vortex (Inches) & 0.08 & 0.08 & 0.05 & 0.08 & 0.07 & 0.07 & 0.07 \\
Apex (Inches) & 0.80 & 0.80 & 0.88 & 0.88 & 0.88 & 0.88 & 0.88 \\
& 0.25 & 0.375 & 0.375 & 0.375 & 0.50 & 0.50 & 0.50 \\
Feed Pressure (PSI) & 57 & 59 & 58 & 56 & 51 & 48 & 47 \\
Feed Rate (GPM) & 15.7 & 14.0 & 12.5 & 18.1 & 15.1 & 15.7 & 17.7 \\
\hline SCREEN CONDITIONS & & & & & & & \\
North Side Panel (Mesh) & 325 & 325 & 325 & 325 & 325 & 325 & 325 \\
North Side Sprays (GPM) & 16.7 & 16.2 & 16.3 & 17.7 & 14.8 & 13.5 & 14.9 \\
& & & & & & & \\
South Side Panel (Mesh) & 200 & 100 & 200 & 100 & 100 & 100 & 100 \\
South Side Sprays (GPM) & 0.0 & 0.0 & 0.0 & 0.0 & 0.5 & 0.0 & 0.0 \\
\hline PRODUCT OUALITY & & & & & & & \\
Solids Content (Wt\%) & 49.8 & 61.3 & 40.7 & 57.7 & 63.9 & 58.9 & 64.3 \\
Solids Flowrate (\#/hr) & 456 & 421 & 425 & 445 & 446 & 399 & 527 \\
& & & & & & & \\
+325 Mesh (Wt\%) & 85.7 & 82.2 & 86.8 & 93.0 & 81.0 & 70.0 & 83.2 \\
325 x 500 Mesh (Wt\%) & 9.7 & 13.3 & 8.8 & 4.9 & 12.0 & 19.9 & 12.0 \\
-500 Mesh (Wt\%) & 4.6 & 4.5 & 4.4 & 2.1 & 7.0 & 10.1 & 4.8 \\
\hline CIRCUIT PERFORMANCE & & & & & & & \\
Overall Recovery (Wt\%) & 56.0 & 51.1 & 55.6 & 55.1 & 58.2 & 57.1 & 60.4 \\
+325 Mesh Recovery (Wt\%) & 98.1 & 96.8 & 95.0 & 91.0 & 95.9 & 90.5 & 97.6 \\
-500 Mesh Rejection (Wt\%) & 93.4 & 94.5 & 93.3 & 96.5 & 89.1 & 86.6 & 91.3 \\
\hline
\end{tabular}




\section{Custom Coal Corporation}

rejection was very respectable for all seven tests. However, since researchers wanted to maintain the highest possible solids content as feed to the dense-medium cyclone wing tank, the cyclone and screen conditions listed in Table 15 for PCT\#5 and KCT\#2 were used for the remainder of the test program.

\section{Section 4.10.1.2 - Dense-Medium Cyclone Component Testing Results}

The two main goals of the dense medium cyclone component testing were to test that subcircuit to:

- Determine the effects of the magnetite particle size and medium purity on cyclone separation performance, and

- Determine the effects of medium-to-coal ratio, feed pressure, and cyclone configuration on the separation efficiency of the cyclone.

Ultimately, this testing led to the selection of the two magnetites and the dense-medium cyclone configuration and pressure that were used during the continuous integrated testing.

All the dense-medium cyclone component tests were conducted using a 1.40 S.G. circulating medium and the Pittsburgh No. 8 Seam coal. A total of six batches of tests were performed using different magnetite grades, contamination levels, cyclone configurations, media-to-coal ratios, and cyclone feed pressures. Table 16 shows the ash and size characteristics for the feed coal and contamination used for this component testing. The six batches of tests included:

- $\quad$ Batch \#1 (9 Tests) at 5:1 Media-to-Coal ratio using Grade-K magnetite. (Results are contained in Table 17.)

- $\quad$ Batch \#2 (9 Tests) at 10:1 Media-to-Coal ratio using Grade-K magnetite. (Results are contained in Table 18.)

- $\quad$ Batch \#3 (9 Tests) at 5:1 Media-to-Coal ratio using Grade-K magnetite. (Results are contained in Table 19.)

- Batch \#4 (9 Tests) at 5:1 Media-to-Coal ratio using Grade-L magnetite. (Results are contained in Table 20.)

- $\quad$ Batch \#5 (4 Tests) at 5:1 Media-to-Coal ratio using Grade-M magnetite. (Results are contained in Table 21.)

- $\quad$ Batch \#6 (2 Tests) at 5:1 Media-to-Coal ratio using Grade-E magnetite. (Results are contained in Table 22.) 
Table 16. Typical Bulk Feed Samples for Dense-Medium Cyclone Component Testing (Pittsburgh No. 8 Seam Coal)

I. Feed Coal (Deslime Discharge): 3.1 Wt\% Moisture (Air Dried)

\begin{tabular}{|c|c|c|c|c|}
\hline Size Fraction & $\begin{array}{c}\text { Direct } \\
(\text { Wt\%) }\end{array}$ & $\begin{array}{c}\text { Ash } \\
(\mathrm{Wt} \%)\end{array}$ & & \\
\hline Top x 200M & 57.0 & 14.17 & & \\
\hline $200 \times 325 \mathrm{M}$ & 25.8 & 14.79 & & \\
\hline $325 \times 500 M$ & 12.2 & 22.70 & & \\
\hline $500 \mathrm{M} \times 0$ & 5.0 & $\underline{62.63}$ & & \\
\hline Total & 100.0 & 17.79 & $\begin{array}{l}\text { Sulfur } \\
(\mathrm{Wt} \%)\end{array}$ & $\begin{array}{l}\text { Per. S. } \\
(\text { Wt \% ) }\end{array}$ \\
\hline Head & 100.0 & 16.51 & 5.03 & 2.63 \\
\hline
\end{tabular}

II. Contamination (Sharples Cake): 6.0 Wt\% Moisture (Air Dried)

\begin{tabular}{||c|c|c|c|c||}
\hline Size Fraction & $\begin{array}{c}\text { Direct } \\
(\mathbf{W t} \%)\end{array}$ & $\begin{array}{c}\text { Ash } \\
(\mathbf{W t \%})\end{array}$ & \\
\hline \hline Top x 200M & 8.8 & 54.18 & & \\
\hline $200 \times 325 \mathrm{M}$ & 3.8 & 11.13 & & \\
\hline $325 \times 500 \mathrm{M}$ & 17.9 & 6.90 & & \\
\hline $500 \mathrm{M} \times 0$ & 68.5 & $\underline{34.35}$ & & $\begin{array}{c}\text { Per. S. } \\
(\mathbf{W t} \%)\end{array}$ \\
\hline Total & 100.0 & 30.07 & $\begin{array}{c}\text { Sulfur } \\
(\mathbf{W t \%})\end{array}$ & 1.93 \\
\hline Head & 100.0 & 29.66 & 4.28 & \\
\hline
\end{tabular}


Table 17. Results from the Grade-K Dense-Medium Cyclone Component Testing

At a 5:1 Medium-to-Coal Ratio and a 1.40 Medium Density

\begin{tabular}{|c|c|c|c|c|c|c|c|c|c|c|c|c|c|c|c|c|}
\hline \multicolumn{5}{|c|}{ Operating Conditions } & \multicolumn{12}{|c|}{ Cyclone Performance Results } \\
\hline \multirow[b]{2}{*}{$\begin{array}{l}\text { Test } \\
\text { I.D. }\end{array}$} & \multirow{2}{*}{$\begin{array}{c}\text { Fines } \\
\text { Contamination } \\
\text { Level (\%) }\end{array}$} & \multicolumn{3}{|c|}{ Cyclone Parameters } & \multicolumn{4}{|c|}{ +325 Mesh Fraction } & \multicolumn{4}{|c|}{325 x 500 Mesh Fraction } & \multicolumn{4}{|c|}{ +500 Mesh Fraction } \\
\hline & & $\begin{array}{l}\text { Pressure } \\
\text { (PSI) }\end{array}$ & $\begin{array}{c}\text { Inlet } \\
\text { Opening } \\
\text { (Sq Inch) }\end{array}$ & $\begin{array}{c}\text { Apex } \\
\text { Diameter } \\
\text { (Inch) }\end{array}$ & $\begin{array}{l}\text { Yield } \\
(\%)\end{array}$ & \begin{tabular}{|c|} 
Recon \\
Feed Ash \\
$(\%)$
\end{tabular} & $\begin{array}{c}\text { Clean } \\
\text { Coal Ash } \\
(\%)\end{array}$ & $\begin{array}{l}\text { Reject } \\
\text { Ash } \\
(\%)\end{array}$ & $\begin{array}{l}\text { Yield } \\
(\%)\end{array}$ & $\begin{array}{c}\text { Recon } \\
\text { Feed Ash } \\
(\%)\end{array}$ & $\begin{array}{c}\text { Clean } \\
\text { Coal Ash } \\
(\%)\end{array}$ & $\begin{array}{l}\text { Reject } \\
\text { Ash } \\
(\%)\end{array}$ & $\begin{array}{l}\text { Yield } \\
(\%)\end{array}$ & $\begin{array}{c}\text { Recon } \\
\text { Feed Ash } \\
(\%)\end{array}$ & $\begin{array}{c}\text { Clean } \\
\text { Coal Ash } \\
(\%)\end{array}$ & $\begin{array}{l}\text { Reject } \\
\text { Ash } \\
(\%)\end{array}$ \\
\hline$\overline{P H T} \# 1$ & $\overline{0}$ & 90 & 0.12 & 0.625 & 93.8 & 10.77 & 6.8 & 70.9 & 85.4 & 17.09 & 9.0 & 64.4 & 92.78 & 11.54 & 7.05 & 69.30 \\
\hline PHT \#2 & 0 & 90 & 0.12 & 0.875 & 90.1 & 12.78 & 7.1 & 64.5 & 81.0 & 17.10 & 7.2 & 59.3 & 88.66 & 13.28 & 7.11 & 63.10 \\
\hline PHT \#4 & 0 & 20 & 0.25 & 0.625 & 93.7 & 11.03 & 6.9 & 72.4 & 87.6 & 15.89 & 8.6 & 67.4 & 92.87 & 11.63 & 7.12 & 71.20 \\
\hline PHT \#3 & 0 & 20 & 0.25 & 0.875 & 92.3 & 9.64 & 5.8 & 55.7 & 76.2 & 17.62 & 7.1 & 51.3 & 90.41 & 10.61 & 5.93 & 54.43 \\
\hline PHT \#7 & 20 & 90 & 0.12 & 0.625 & 90.6 & 12.91 & 7.1 & 68.9 & 87.3 & 12.72 & 6.9 & 52.7 & 89.98 & 12.86 & 7.06 & 65.04 \\
\hline PHT \#6 & 20 & 90 & 0.12 & 0.875 & 88.4 & 13.19 & 7.0 & 60.4 & 79.1 & 12.96 & 6.1 & 38.9 & 86.53 & 13.06 & 6.84 & 53.69 \\
\hline PHT \#5 & 20 & 20 & 0.25 & 0.875 & 85.8 & 13.99 & 7.2 & 55.0 & 77.2 & 13.53 & 6.3 & 38.0 & 84.09 & 13.83 & 7.04 & 50.16 \\
\hline PHT \#8 & 40 & 90 & 0.12 & 0.625 & 85.3 & 15.64 & 7.1 & 65.2 & 86.4 & 10.38 & 6.6 & 34.4 & 85.59 & 14.95 & 6.97 & 57.61 \\
\hline PHT \#10 & 40 & 20 & 0.25 & 0.875 & 61.0 & 17.04 & 7.8 & 31.5 & 55.0 & 10.12 & 7.6 & 13.2 & 59.43 & 16.12 & 7.75 & 26.19 \\
\hline
\end{tabular}


Table 18. Results from the Grade-K Dense-Medium Cyclone Component Testing At a 10:1 Medium-to-Coal Ratio and a 1.40 Medium Density

\begin{tabular}{|c|c|c|c|c|c|c|c|c|c|c|c|c|c|c|c|c|}
\hline \multicolumn{5}{|c|}{ Operating Conditions } & \multicolumn{12}{|c|}{ Cyclone Performance Results } \\
\hline \multirow[b]{2}{*}{$\begin{array}{l}\text { Test } \\
\text { I.D. }\end{array}$} & \multirow{2}{*}{$\begin{array}{c}\text { Fines } \\
\text { Contamination } \\
\text { Level }(\%)\end{array}$} & \multicolumn{3}{|c|}{ Cyclone Parameters } & \multicolumn{4}{|c|}{ +325 Mesh Fraction } & \multicolumn{4}{|c|}{325 x 500 Mesh Fraction } & \multicolumn{4}{|c|}{ +500 Mesh Fraction } \\
\hline & & $\begin{array}{c}\text { Pressure } \\
\text { (PSI) }\end{array}$ & $\begin{array}{c}\text { Inlet } \\
\text { Opening } \\
\text { (Sq Inch) }\end{array}$ & $\begin{array}{c}\text { Apex } \\
\text { Diameter } \\
\text { (Inch) }\end{array}$ & $\begin{array}{c}\text { Yield } \\
(\%)\end{array}$ & $\begin{array}{c}\text { Recon } \\
\text { Feed Ash } \\
(\%)\end{array}$ & \begin{tabular}{|c|} 
Clean \\
Coal Ash \\
$(\%)$
\end{tabular} & $\begin{array}{c}\text { Reject } \\
\text { Ash } \\
(\%)\end{array}$ & $\begin{array}{c}\text { Yield } \\
(\%)\end{array}$ & $\begin{array}{c}\text { Recon } \\
\text { Feed Ash } \\
(\%)\end{array}$ & $\begin{array}{c}\text { Clean } \\
\text { Coal Ash } \\
(\%)\end{array}$ & $\begin{array}{c}\text { Reject } \\
\text { Ash } \\
(\%)\end{array}$ & $\begin{array}{c}\text { Yield } \\
(\%)\end{array}$ & \begin{tabular}{|c|} 
Recon \\
Feed Ash \\
$(\%)$
\end{tabular} & \begin{tabular}{|c|} 
Clean \\
Coal Ash \\
$(\%)$ \\
\end{tabular} & $\begin{array}{c}\text { Reject } \\
\text { Ash } \\
(\%)\end{array}$ \\
\hline PHT \#12 & 0 & 90 & 0.12 & 0.625 & 92.2 & 12.39 & 7.3 & 72.5 & 85.4 & 16.97 & 9.0 & 63.6 & 91.26 & 13.02 & 7.52 & 70.43 \\
\hline PHT \#11 & 0 & 90 & 0.12 & 0.875 & 89.7 & 12.84 & 6.8 & 65.4 & 78.2 & 17.278 & 7.3 & 53.1 & 88.09 & 13.45 & 68.6 & 62.25 \\
\hline PHT \#13 & 0 & 20 & 0.25 & 0.625 & 92.3 & 12.77 & 7.8 & 72.3 & 81.9 & 19.65 & 8.9 & 68.3 & 90.85 & 13.72 & 7.94 & 71.17 \\
\hline PHT \#14 & 0 & 20 & 0.25 & 0.875 & 88.9 & 12.39 & 6.9 & 56.4 & 75.4 & 17.95 & 7.2 & 50.9 & 86.96 & 13.16 & 6.94 & 54.90 \\
\hline PHT \#17 & 20 & 90 & 0.12 & 0.625 & 89.8 & 14.12 & 7.5 & 72.4 & 86.7 & 12.95 & 6.7 & 53.7 & 89.06 & 13.86 & 7.31 & 66.97 \\
\hline PHT \#16 & 20 & 90 & 0.12 & 0.875 & 89.2 & 15.58 & 6.2 & 65.3 & 82.4 & 11.59 & 5.2 & 41.5 & 87.64 & 12.34 & 5.99 & 57.52 \\
\hline РHT \#15 & 20 & 20 & 0.25 & 0.875 & 85.3 & 13.68 & 6.4 & 55.9 & 77.8 & 12.07 & 5.5 & 35.1 & 83.50 & 13.34 & 6.20 & 49.18 \\
\hline PHT \#19 & 40 & 90 & 0.12 & 0.875 & 78.8 & 17.64 & 6.3 & 59.8 & 75.0 & 10.30 & 5.0 & 26.2 & 77.53 & 16.39 & 5.88 & 47.29 \\
\hline PHT \#20 & 40 & 20 & 0.25 & 0.875 & 72.0 & 17.57 & 6.9 & 45.0 & 65.8 & 9.33 & 5.5 & 16.7 & 69.94 & 16.17 & 6.46 & 34.31 \\
\hline
\end{tabular}


Table 19. Results from the Grade-K Dense-Medium Cyclone Component Testing

At a 5:1 Medium-to-Coal Ratio and a 1.40 Medium Density

(Second Series)

\begin{tabular}{|c|c|c|c|c|c|c|c|c|c|c|c|c|c|c|c|c|}
\hline \multicolumn{5}{|c|}{ Operating Conditions } & \multicolumn{12}{|c|}{ Cyclone Performance Results } \\
\hline \multirow[b]{2}{*}{$\begin{array}{l}\text { Test } \\
\text { I..D. }\end{array}$} & \multirow[b]{2}{*}{$\begin{array}{c}\text { Fines } \\
\text { Contamination } \\
\text { Level } \\
(\%)\end{array}$} & \multicolumn{3}{|c|}{ Cyclone Parameters } & \multicolumn{4}{|c|}{ +200 Mesh Fraction } & \multicolumn{4}{|c|}{$200 \times 500$ Mesh Fraction } & \multicolumn{4}{|c|}{ +500 Mesh Fraction } \\
\hline & & $\begin{array}{l}\text { Pressure } \\
\text { (PSI) }\end{array}$ & $\begin{array}{c}\text { Inlet } \\
\text { Opening } \\
\text { (Sq Inch) } \\
\text { Inch) }\end{array}$ & $\begin{array}{c}\text { Apex } \\
\text { Diameter } \\
\text { (Inch) }\end{array}$ & $\begin{array}{l}\text { Yield } \\
(\%)\end{array}$ & $\begin{array}{l}\text { Recon } \\
\text { Feed Ash } \\
\quad(\%)\end{array}$ & $\begin{array}{c}\text { Clean } \\
\text { Coal Ash } \\
(\%)\end{array}$ & $\begin{array}{c}\text { Reject } \\
\text { Ash } \\
(\%)\end{array}$ & $\begin{array}{l}\text { Yield } \\
(\%)\end{array}$ & $\begin{array}{l}\text { Recon } \\
\text { Feed Ash } \\
(\%)\end{array}$ & $\begin{array}{c}\text { Clean } \\
\text { Coal Ash } \\
(\%)\end{array}$ & $\begin{array}{c}\text { Reject } \\
\text { Ash } \\
(\%)\end{array}$ & $\begin{array}{l}\text { Yield } \\
(\%)\end{array}$ & $\begin{array}{l}\text { Recon } \\
\text { Feed Ash } \\
\quad(\%)\end{array}$ & $\begin{array}{c}\text { Clean } \\
\text { Coal Ash } \\
(\%)\end{array}$ & $\begin{array}{c}\text { Reject } \\
\text { Ash } \\
(\%)\end{array}$ \\
\hline PHT \#23 & $\overline{0}$ & 88 & 0.12 & 0.625 & 87.7 & 18.15 & 9.0 & 83.4 & 79.7 & 23.35 & 10.7 & 73.0 & 85.79 & 19.39 & 9.38 & 79.85 \\
\hline PHT \#24 & 0 & 88 & 0.12 & 0.875 & 87.7 & 15.93 & 7.8 & 73.9 & 75.2 & 23.48 & 8.6 & 68.6 & 84.76 & 17.71 & 7.97 & 71.88 \\
\hline PHT \#26 & 0 & 19 & 0.25 & 0.625 & 89.3 & 16.54 & 8.7 & 82.0 & 80.3 & 22.70 & 9.8 & 75.3 & 87.16 & 18.01 & 8.94 & 79.55 \\
\hline PHT \#25 & 0 & 19 & 0.25 & 0.875 & 87.7 & 16.09 & 8.0 & 73.8 & 74.1 & 23.09 & 8.4 & 65.1 & 84.63 & 17.67 & 8.08 & 70.49 \\
\hline PHT \#28 & 20 & 88 & 0.12 & 0.625 & 88.8 & 18.27 & 10.4 & 80.7 & 83.6 & 17.78 & 8.6 & 64.6 & 87.01 & 18.10 & 9.80 & 73.71 \\
\hline PHT \#29 & 20 & 88 & 0.12 & 0.625 & 92.8 & 13.48 & 8.3 & 80.3 & 87.4 & 14.62 & 7.5 & 64.0 & 91.01 & 13.86 & 8.04 & 72.75 \\
\hline PHT \#27 & 20 & 19 & 0.25 & 0.625 & 88.2 & 18.48 & 10.3 & 79.6 & 82.4 & 18.77 & 8.3 & 67.8 & 86.29 & 18.57 & 9.67 & 74.61 \\
\hline PHT \#30 & 40 & 86 & 0.12 & 0.625 & 90.6 & 14.37 & 7.9 & 76.7 & 88.4 & 11.65 & 6.0 & 54.7 & 89.63 & 13.16 & 7.07 & 65.84 \\
\hline PHT \#31 & 40 & 19 & 0.25 & 0.625 & 90.1 & 13.97 & 7.6 & 71.9 & 87.6 & 11.58 & 6.0 & 51.0 & 88.99 & 12.90 & 6.90 & 61.44 \\
\hline
\end{tabular}

Table 20. Results from the Grade-L Dense-Medium Cyclone Component Testing

At a 5:1 Medium-to-Coal Ratio and a 1.40 Medium Density

\begin{tabular}{|c|c|c|c|c|c|c|c|c|c|c|c|c|c|c|c|c|}
\hline \multicolumn{5}{|c|}{ Operating Conditions } & \multicolumn{12}{|c|}{ Cyclone Performance Results } \\
\hline \multirow{2}{*}{ Test I.D. } & \multirow[b]{2}{*}{$\begin{array}{c}\text { Fines } \\
\text { Contamination } \\
\text { Level }(\%)\end{array}$} & \multicolumn{3}{|c|}{ Cyclone Parameters } & \multicolumn{4}{|c|}{ +200 Mesh Fraction } & \multicolumn{4}{|c|}{$200 \times 500$ Mesh Fraction } & \multicolumn{4}{|c|}{ +500 Mesh Fraction } \\
\hline & & $\begin{array}{c}\text { Pressure } \\
\text { (PSI) }\end{array}$ & $\begin{array}{c}\text { Inlet } \\
\text { Opening } \\
\text { (Sq Inch) }\end{array}$ & $\begin{array}{c}\text { Apex } \\
\text { Diameter } \\
\text { (Inch) }\end{array}$ & $\begin{array}{c}\text { Yield } \\
(\%)\end{array}$ & $\begin{array}{l}\text { Recon } \\
\text { Feed Ash } \\
(\%)\end{array}$ & $\begin{array}{c}\text { Clean } \\
\text { Coal Ash } \\
(\%)\end{array}$ & $\begin{array}{l}\text { Reject } \\
\text { Ash } \\
(\%)\end{array}$ & $\begin{array}{l}\text { Yield } \\
(\%)\end{array}$ & $\begin{array}{l}\text { Recon } \\
\text { Feed Ash } \\
(\%)\end{array}$ & $\begin{array}{l}\text { Clean } \\
\text { Coal Ash } \\
(\%)\end{array}$ & $\begin{array}{l}\text { Reject } \\
\text { Ash } \\
(\%)\end{array}$ & $\begin{array}{l}\text { Yield } \\
(\%)\end{array}$ & $\begin{array}{l}\text { Recon } \\
\text { Feed Ash } \\
\quad(\%)\end{array}$ & $\begin{array}{c}\text { Clean } \\
\text { Coal Ash } \\
(\%)\end{array}$ & $\begin{array}{l}\text { Reject } \\
\text { Ash } \\
(\%)\end{array}$ \\
\hline PHT \#35 & 0 & 88 & 0.12 & 0.625 & 87.0 & 16.0 & 7.2 & 74.8 & 80.9 & 19.6 & 7.3 & 71.8 & 84.9 & 16.8 & 7.2 & 70.8 \\
\hline PHT \#34 & 0 & 88 & 0.12 & 0.875 & 83.7 & 16.0 & 6.3 & 65.8 & 71.8 & 21.5 & 5.9 & 61.2 & 80.9 & 17.3 & 6.2 & 64.2 \\
\hline PHT \#32 & 0 & 19 & 0.25 & 0.625 & 84.8 & 17.0 & 7.0 & 72.8 & 78.5 & 21.0 & 7.8 & 69.2 & 83.3 & 18.0 & 7.2 & 81.7 \\
\hline PHT \#33 & 0 & 19 & 0.25 & 0.875 & 80.3 & 16.8 & 6.4 & 59.4 & 67.1 & 21.8 & 6.9 & 52.1 & 77.1 & 18.0 & 6.5 & 56.9 \\
\hline PHT \#36 & 20 & 88 & 0.12 & 0.625 & 87.2 & 15.1 & 6.8 & 71.3 & 85.0 & 15.0 & 5.8 & 67.2 & 86.3 & 15.1 & 6.4 & 69.8 \\
\hline PHT \#37 & 20 & 88 & 0.12 & 0.625 & 87.9 & 14.9 & 7.0 & 72.3 & 84.6 & 15.5 & 6.0 & 67.5 & 86.9 & 15.1 & 6.7 & 70.5 \\
\hline PHT \#38 & 20 & 19 & 0.25 & 0.625 & 86.6 & 14.3 & 6.6 & 64.2 & 82.7 & 15.0 & 6.1 & 57.4 & 85.3 & 14.5 & 6.4 & 61.6 \\
\hline PHT \#40 & 40 & 88 & 0.12 & 0.625 & 87.8 & 13.8 & 6.6 & 65.9 & 87.8 & 11.5 & 5.3 & 55.8 & 87.6 & 12.9 & 6.0 & 61.6 \\
\hline PHT \#39 & 40 & 17 & 0.25 & 0.625 & 82.2 & 14.9 & 6.6 & 53.0 & 81.0 & 12.2 & 7.0 & 34.3 & 81.3 & 13.7 & 6.6 & 44.7 \\
\hline
\end{tabular}


Table 21. Results from the Grade-M Dense-Medium Cyclone Component Testing At a 5:1 Medium-to-Coal Ratio and a 1.40 Medium Density

\begin{tabular}{|c|c|c|c|c|c|c|c|c|c|c|c|c|c|c|c|c|}
\hline \multicolumn{5}{|c|}{ Operating Conditions } & \multicolumn{12}{|c|}{ Cyclone Performance Results } \\
\hline \multirow[b]{2}{*}{$\begin{array}{l}\text { Test } \\
\text { I..D. }\end{array}$} & \multirow{2}{*}{$\begin{array}{c}\text { Fines } \\
\text { Contamination } \\
\text { Level } \\
(\%)\end{array}$} & \multicolumn{3}{|c|}{ Cyclone Parameters } & \multicolumn{4}{|c|}{ +200 Mesh Fraction } & \multicolumn{4}{|c|}{$200 \times 500$ Mesh Fraction } & \multicolumn{4}{|c|}{ +500 Mesh Fraction } \\
\hline & & $\begin{array}{l}\text { Pressure } \\
\text { (PSI) }\end{array}$ & $\begin{array}{c}\text { Inlet } \\
\text { Opening } \\
\text { (Sq Inch) }\end{array}$ & $\begin{array}{c}\text { Apex } \\
\text { Diameter } \\
\text { (Inch) }\end{array}$ & $\begin{array}{c}\text { Yield } \\
(\%)\end{array}$ & $\begin{array}{c}\text { Recon } \\
\text { Feed Ash } \\
(\%)\end{array}$ & $\begin{array}{c}\text { Clean } \\
\text { Coal Ash } \\
(\%)\end{array}$ & $\begin{array}{l}\text { Reject } \\
\text { Ash } \\
(\%)\end{array}$ & $\begin{array}{c}\text { Yield } \\
(\%)\end{array}$ & $\begin{array}{c}\text { Recon } \\
\text { Feed Ash } \\
(\%)\end{array}$ & $\begin{array}{c}\text { Clean } \\
\text { Coal Ash } \\
(\%)\end{array}$ & $\begin{array}{l}\text { Reject } \\
\text { Ash } \\
(\%)\end{array}$ & $\begin{array}{c}\text { Yield } \\
(\%)\end{array}$ & $\begin{array}{c}\text { Recon } \\
\text { Feed Ash } \\
(\%)\end{array}$ & $\begin{array}{c}\text { Clean } \\
\text { Coal Ash } \\
(\%)\end{array}$ & $\begin{array}{c}\text { Rejec } \\
\text { Ash } \\
(\%)\end{array}$ \\
\hline PHT \#41 & 0 & 86 & 0.12 & 0.625 & 83.0 & 15.13 & 6.2 & 58.6 & 86.0 & 12.83 & 7.0 & 48.6 & 83.77 & 14.54 & 6.44 & 56.33 \\
\hline PHT \#42 & 0 & 20 & 0.25 & 0.625 & 83.3 & 15.57 & 7.5 & 55.7 & 85.1 & 12.94 & 8.3 & 39.2 & 83.78 & 14.88 & 7.74 & 51.72 \\
\hline PHT \#43 & 40 & 20 & 0.25 & 0.625 & 79.7 & 13.49 & 7.6 & 36.9 & 81.0 & 10.64 & 9.6 & 15.2 & 80.18 & 12.47 & 8.28 & 29.43 \\
\hline PHT \#44 & 40 & 80 & 0.12 & 0.625 & 82.9 & 13.62 & 7.5 & 43.2 & 84.1 & 10.38 & 8.4 & 20.8 & 83.33 & 12.47 & 7.84 & 35.61 \\
\hline
\end{tabular}

Table 22. Results from the Grade-E Dense-Medium Cyclone Component Testing At a 5:1 Medium-to-Coal Ratio and a 1.40 Medium Density

\begin{tabular}{|c|c|c|c|c|c|c|c|c|c|c|c|c|c|c|c|c|}
\hline \multicolumn{5}{|c|}{ Operating Conditions } & \multicolumn{12}{|c|}{ Cyclone Performance Results } \\
\hline \multirow[b]{2}{*}{$\begin{array}{l}\text { Test } \\
\text { I..D. }\end{array}$} & \multirow[b]{2}{*}{$\begin{array}{c}\text { Fines } \\
\text { Contamination } \\
\text { Level } \\
(\%)\end{array}$} & \multicolumn{3}{|c|}{ Cyclone Parameters } & \multicolumn{4}{|c|}{ +200 Mesh Fraction } & \multicolumn{4}{|c|}{$200 \times 500$ Mesh Fraction } & \multicolumn{4}{|c|}{ +500 Mesh Fraction } \\
\hline & & $\begin{array}{c}\text { Pressure } \\
\text { (PSI) }\end{array}$ & $\begin{array}{c}\text { Inlet } \\
\text { Opening } \\
\text { (Sq Inch) }\end{array}$ & $\begin{array}{c}\text { Apex } \\
\text { Diameter } \\
\text { (Inch) }\end{array}$ & $\begin{array}{c}\text { Yield } \\
(\%)\end{array}$ & $\begin{array}{c}\text { Recon } \\
\text { Feed Ash } \\
(\%)\end{array}$ & $\begin{array}{c}\text { Clean } \\
\text { Coal Ash } \\
(\%)\end{array}$ & $\begin{array}{c}\text { Reject } \\
\text { Ash } \\
(\%) \\
\end{array}$ & $\begin{array}{c}\text { Yield } \\
(\%)\end{array}$ & $\begin{array}{c}\text { Recon } \\
\text { Feed Ash } \\
(\%)\end{array}$ & $\begin{array}{c}\text { Clean } \\
\text { Coal Ash } \\
(\%)\end{array}$ & $\begin{array}{c}\text { Reject } \\
\text { Ash } \\
(\%) \\
\end{array}$ & $\begin{array}{l}\text { Yield } \\
(\%)\end{array}$ & $\begin{array}{c}\text { Recon } \\
\text { Feed Ash } \\
(\%)\end{array}$ & $\begin{array}{c}\text { Clean } \\
\text { Coal Ash } \\
(\%)\end{array}$ & $\begin{array}{c}\text { Reject } \\
\text { Ash } \\
(\%)\end{array}$ \\
\hline PHT \#45 & 0 & 86 & 0.12 & 0.625 & 87.1 & 16.64 & 8.5 & 71.6 & 84.7 & 16.34 & 7.1 & 67.6 & 86.13 & 16.51 & 7.84 & 70.30 \\
\hline PHT \#46 & 0 & 20 & 0.25 & 0.625 & 87.3 & 17.43 & 8.6 & 78.2 & 88.2 & 17.43 & 7.3 & 69.2 & 87.72 & 16.12 & 7.98 & 74.29 \\
\hline
\end{tabular}


During testing of Batch \#1 inadequate mixing within the dense-medium sump occurred which caused significant uncontrolled feed variations from test to test. This limited the applicability of the results. This problem was corrected by adding additional mixers to the dense-medium cyclone sump and the tests conducted in Batch \#1 were repeated during the Batch \#3 testing.

For Batches \#1 \& \#2 size cuts were made to fractionate the products into plus-325-mesh and $325 \mathrm{x}$ 500 mesh fractions. While the results are still valid, very little material was found in the $325 \times 500$ mesh fraction so it was establish that samples would be split at 200 mesh for all future tests.

After analyzing the cyclone configuration results, the feed, clean coal, and refuse ash results in conjunction with the yield results from Batches $3,4, \& 5$, partition curves were constructed on ten selected tests in which the Grade K, L, \& M magnetites were used. No partition curves were constructed from the Grade-E magnetite Batch testing due to the limited laboratory funds budgeted for the project.

The partition curves and the curve-derived performance parameters, including probable error and specific gravity of separation, presented in this report were generated using laboratory float-sink data and a Weibull-based, curve-fitting mathematical function applied through the Solver routine as found in the Excel spreadsheet software. Hand-drawn curves were not used as, very early on in the testing, it was found that different project personnel produced significantly different probable error values from the same distribution data. In a brief study related to this project, Science Applications International Corporation researchers found that the curve-fitting mathematical function technique provided for a fairly accurate and, more importantly, an unbiased and consistent methodology for generating the distribution curves and the curve-derived performance parameters.

Commercial Testing and Engineering in Henderson, KY was contracted to perform the fine-size centrifugal float-sink testing on the 4" cyclone clean-coal and refuse products. This laboratory was selected to perform this analytical work as it was very experienced in centrifugal float-sink testing and was using the latest available techniques as developed by Process Technology, Inc. The raw floatsink data along with product yields and size distribution data were used to produce partition data. This data was then used to generate the partition curves and probable error and specific gravity of separation values by using the Weibull curve-fitting function according to the following equation:

$\mathrm{K}=(1-\mathrm{a}-\mathrm{b})\left(1 /\left(1+\mathrm{z}^{\mathrm{c}}\right)+\mathrm{a}\right.$

where $\mathrm{K}$ is the partition factor, $\mathrm{a}$ and $\mathrm{b}$ are bypass factors, $\mathrm{c}$ is a function parameter, and $\mathrm{z}=x / \mathrm{D}_{50}$, where $x$ is the density and $\mathrm{D}_{50}$ the specific gravity of separation.

Table 23 and Figures 8 through 17 present the results from the partition curve analysis. In addition, Figures 18 through 20 and Table 24 were generated to better illustrate the key results of the densemedium cyclone testing. Figures 18 through 20 show the dense medium partition curves at $0 \%$ 
Table 23. Dense-Medium Cyclone Performance Results for Grades K, L, \& M Magnetites

\begin{tabular}{|c|c|c|c|c|c|c|c|c|c|c|c|c|}
\hline \multicolumn{4}{|c|}{ Operating Conditions } & \multicolumn{3}{|c|}{ Cyclone Orifice Combination } & \multicolumn{6}{|c|}{ Dense-Medium Cyclone Performance } \\
\hline \multirow{2}{*}{$\begin{array}{l}\text { Test } \\
\text { No. }\end{array}$} & \multirow{2}{*}{$\begin{array}{l}\text { Magnetite } \\
\text { Grade }\end{array}$} & \multirow{2}{*}{$\begin{array}{l}\text { Cont. Level } \\
\text { (Wt\%) }\end{array}$} & \multirow{2}{*}{$\begin{array}{l}\text { Feed Pre. } \\
\quad \text { (PSI) }\end{array}$} & \multirow{2}{*}{$\begin{array}{l}\text { Feed Inlet } \\
\text { (sq. in.) }\end{array}$} & \multirow{2}{*}{$\begin{array}{l}\text { Overflow } \\
\text { (in.) }\end{array}$} & \multirow{2}{*}{$\begin{array}{c}\text { Apex } \\
\text { (in.) }\end{array}$} & \multicolumn{2}{|c|}{$48 \times 200 \mathrm{M}$} & \multicolumn{2}{|c|}{$200 \times 500 M$} & \multicolumn{2}{|c|}{$48 \times 500 M$} \\
\hline & & & & & & & Ep & D50 & Ep & D50 & Ep & D50 \\
\hline PHT \#23 & GRADE-K & 0 & 88 & 0.12 & 1.0 & 0.625 & 0.080 & 2.08 & 0.116 & 2.29 & 0.091 & 2.14 \\
\hline PHT \#26 & GRADE-K & 0 & 19 & 0.25 & 1.0 & 0.625 & 0.080 & 1.99 & 0.104 & 2.25 & 0.115 & 2.08 \\
\hline PHT \#30 & GRADE-K & 40 & 86 & 0.12 & 1.0 & 0.625 & 0.085 & 1.94 & 0.140 & 2.24 & 0.131 & 2.06 \\
\hline PHT \#31 & GRADE-K & 40 & 19 & 0.25 & 1.0 & 0.625 & 0.107 & 1.82 & 0.228 & 2.14 & 0.184 & 1.91 \\
\hline PHT \#35 & GRADE-L & 0 & 88 & 0.12 & 1.0 & 0.625 & 0.053 & 1.73 & 0.154 & 1.96 & 0.087 & 1.74 \\
\hline PHT \#32 & GRADE-L & 0 & 19 & 0.25 & 1.0 & 0.625 & 0.072 & 1.68 & 0.187 & 1.92 & 0.092 & 1.70 \\
\hline PHT \#40 & GRADE-L & 40 & 88 & 0.12 & 1.0 & 0.625 & 0.069 & 1.66 & 0.193 & 1.91 & 0.094 & 1.70 \\
\hline PHT \#39 & GRADE-L & 40 & 17 & 0.25 & 1.0 & 0.625 & 0.103 & 1.58 & 0.437 & 2.09 & 0.180 & 1.60 \\
\hline PHT \#41 & GRADE-M & 0 & 86 & 0.12 & 1.0 & 0.625 & 0.094 & 1.57 & 0.282 & 2.01 & 0.132 & 1.61 \\
\hline PHT \#42 & GRADE-M & 0 & 20 & 0.25 & 1.0 & 0.625 & 0.114 & 1.57 & 0.394 & 2.18 & 0.174 & 1.60 \\
\hline
\end{tabular}

NOTE: All tests were conducted at 5:1 Medium-to-Coal Ratio at 1.40 S.G. Medium Density. 


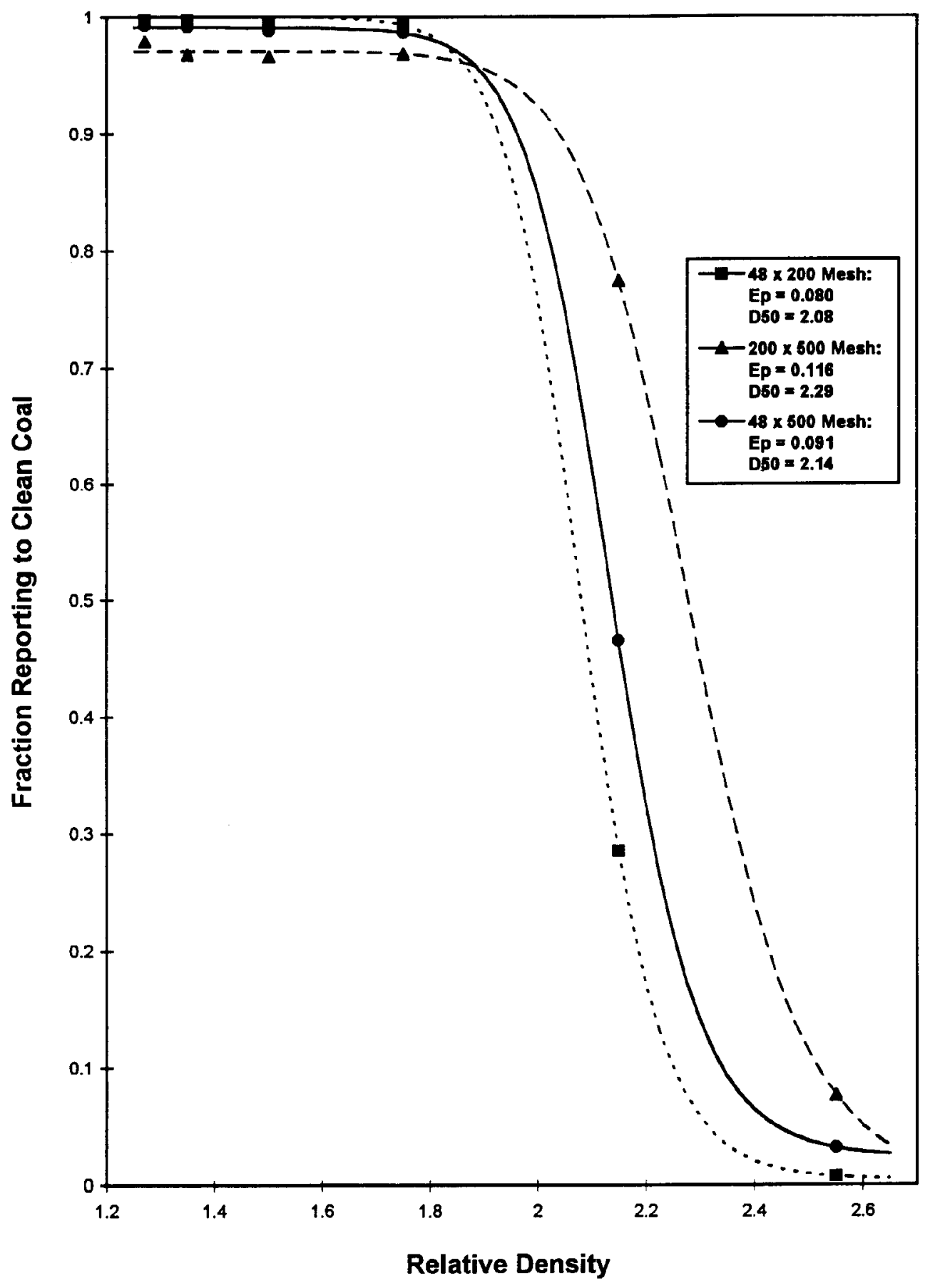

Figure 8. Fitted Partition Curves for PHT \#23

(Grade K Magnetite, 88 PSI, 0\% Fines) 


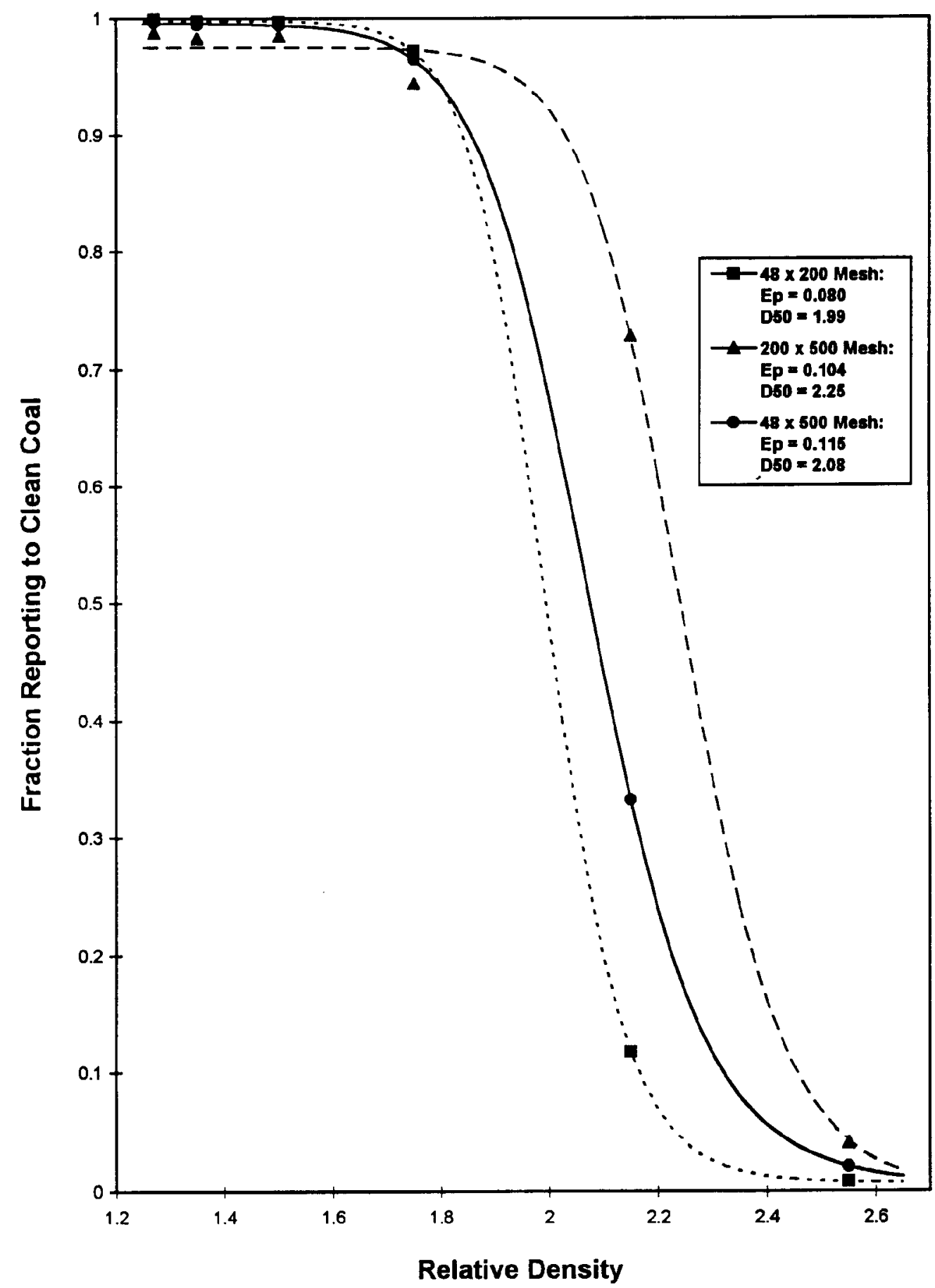

Figure 9. Fitted Partition Curves for PHT \#26 (Grade K Magnetite, 19 PSI, 0\% Fines) 


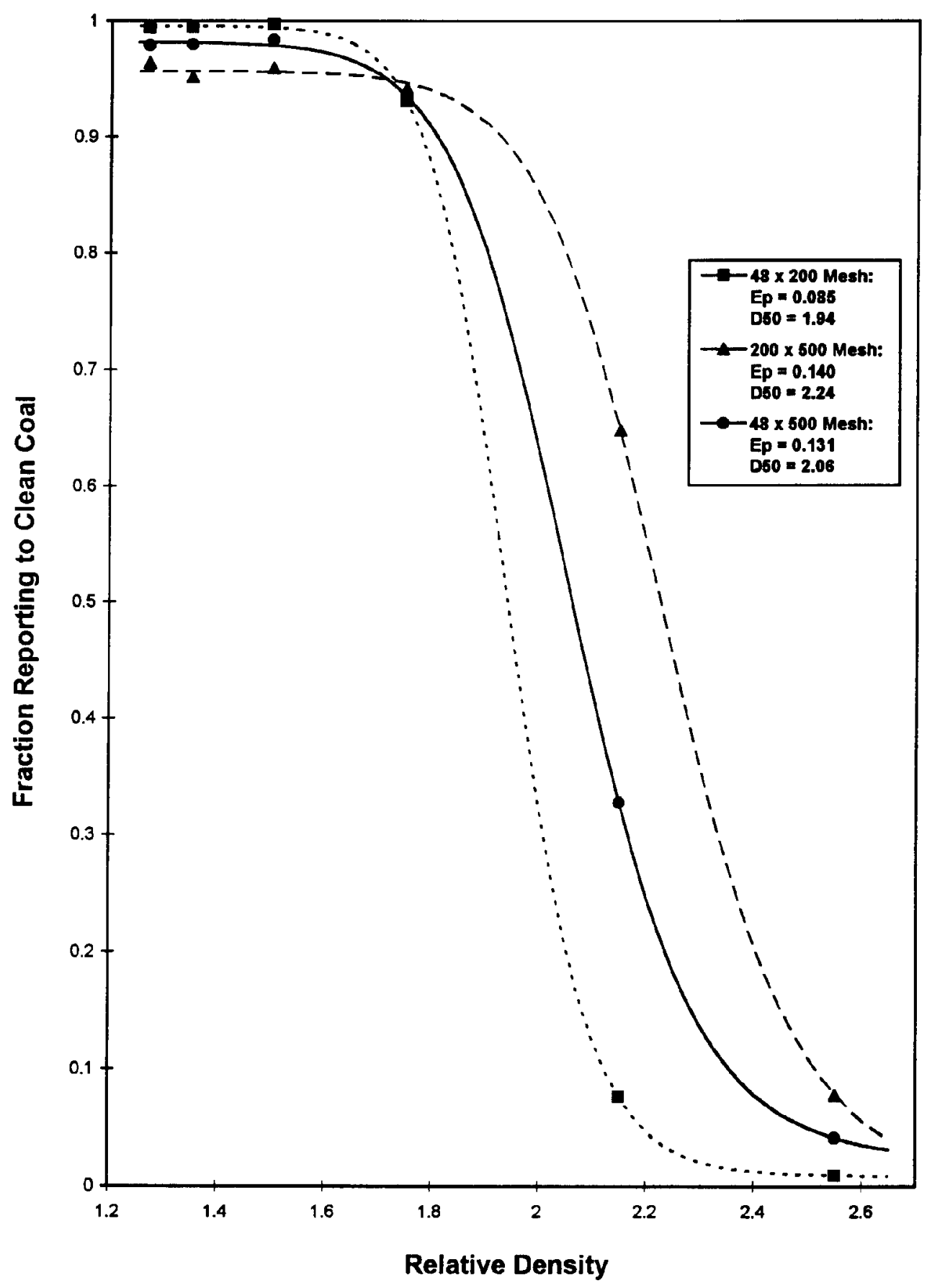

Figure 10. Fitted Partition Curves for PHT \#30 (Grade K Magnetite, 88 PSI, 40\% Fines) 


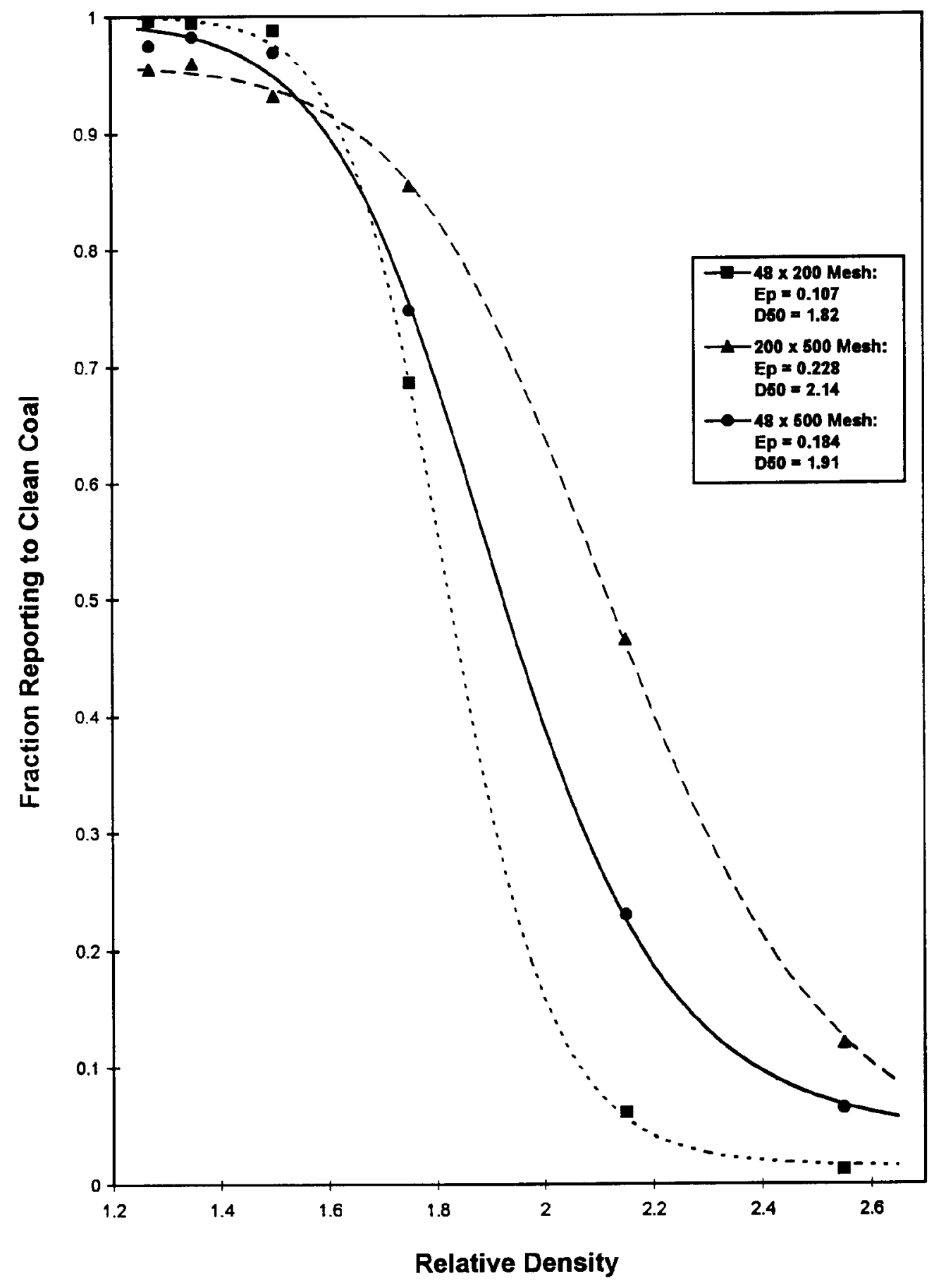

Figure 11. Fitted Partition Curves for PHT \#31 (Grade K Magnetite, 19 PSI, 40\% Fines) 


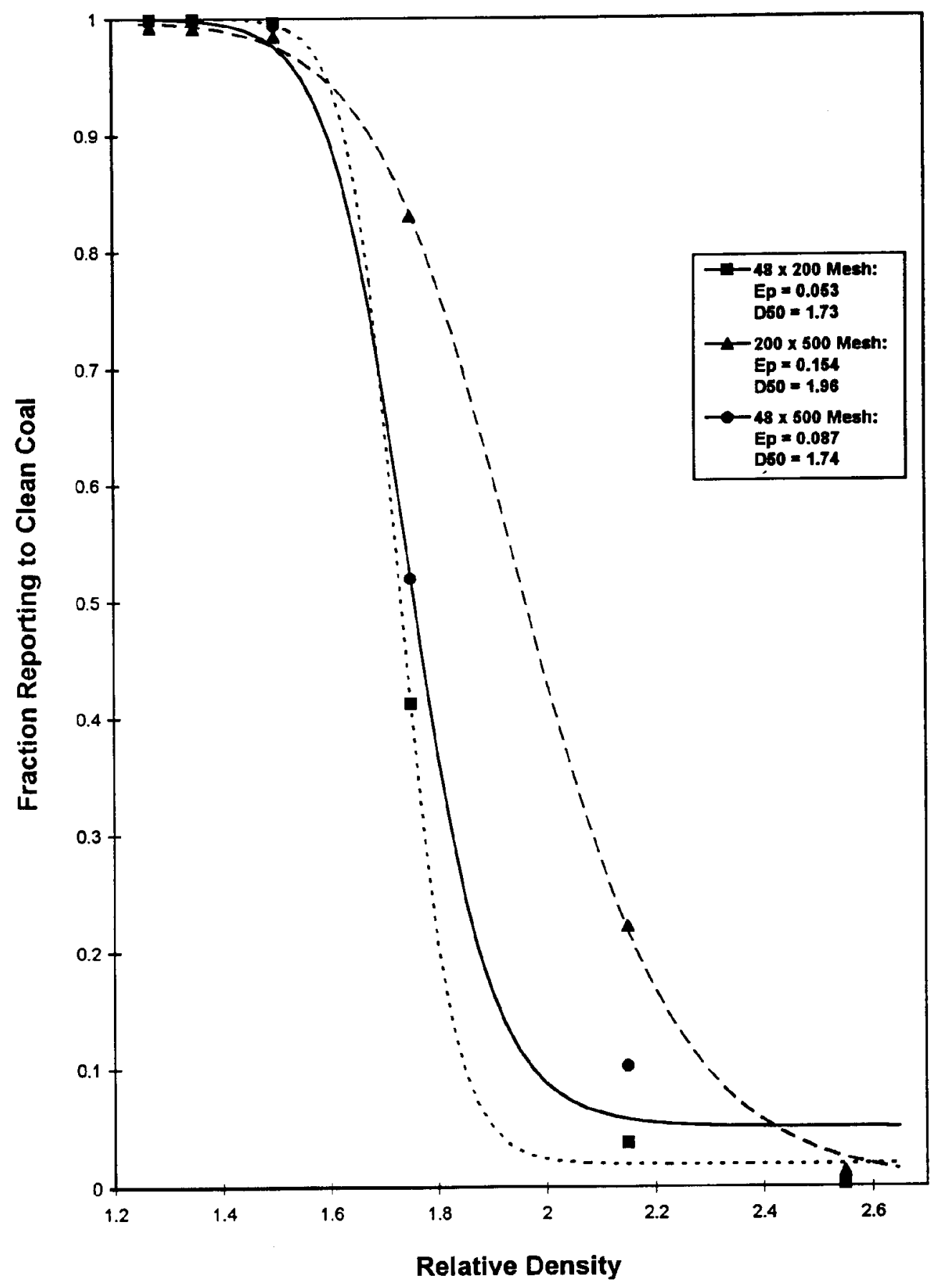

Figure 12. Fitted Partition Curves for PHT \#35 (Grade L Magnetite, 88 PSI, 0\% Fines) 


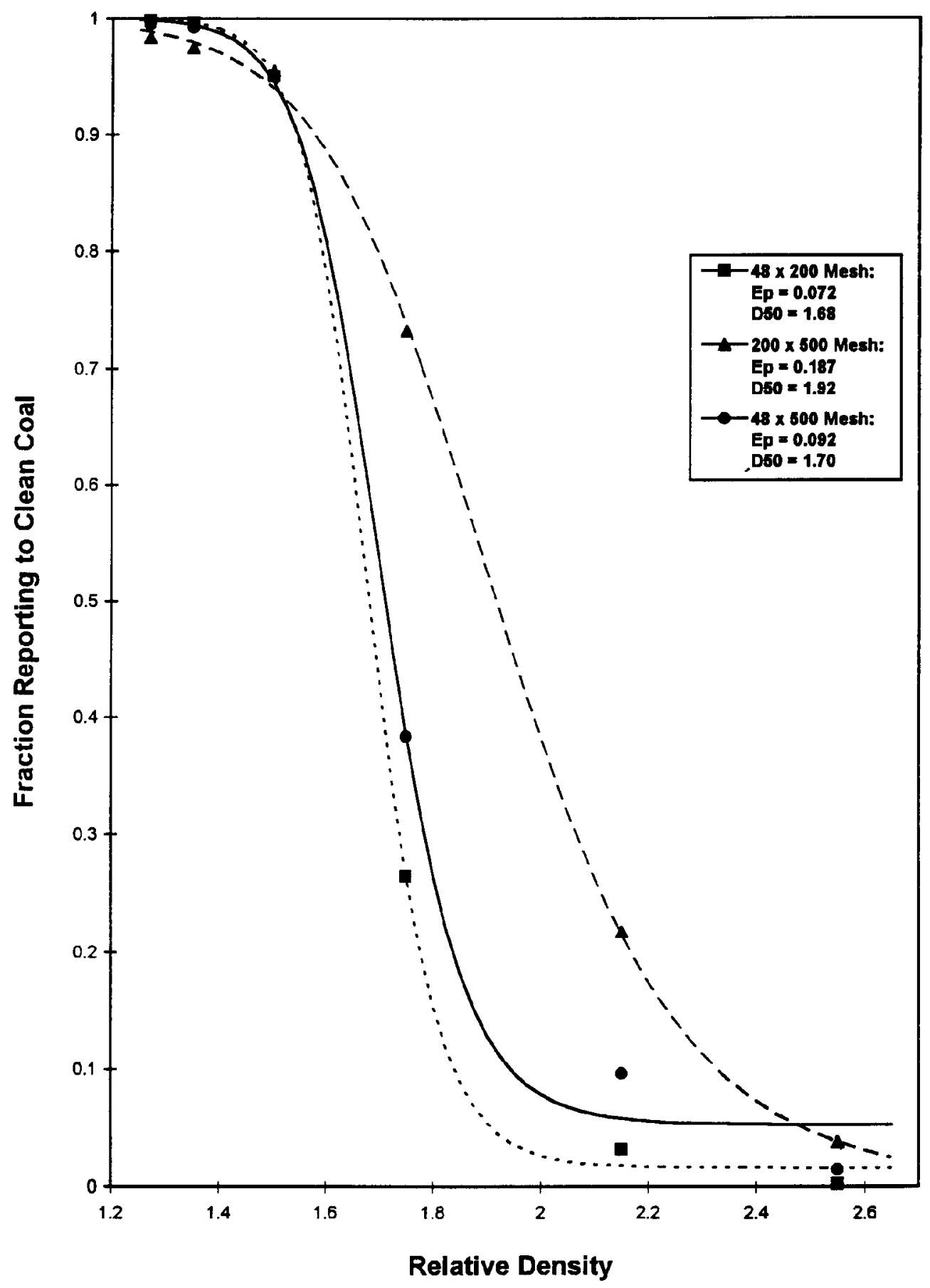

Figure 13. Fitted Partition Curves for PHT \#32

(Grade L Magnetite, 19 PSI, 0\% Fines) 


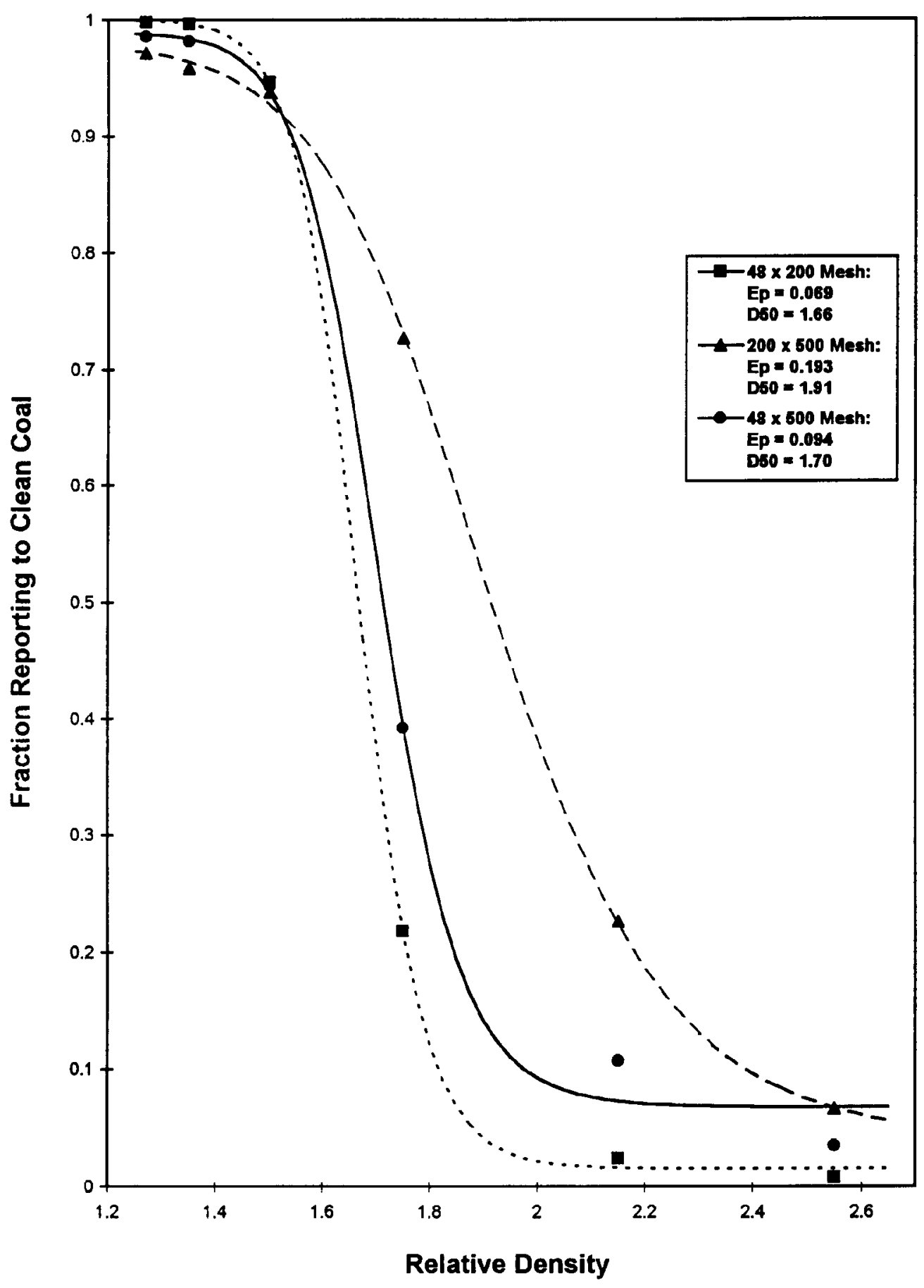

Figure 14. Fitted Partition Curves for PHT $\# \mathbf{4 0}$ (Grade L Magnetite, 88 PSI, 40\% Fines) 


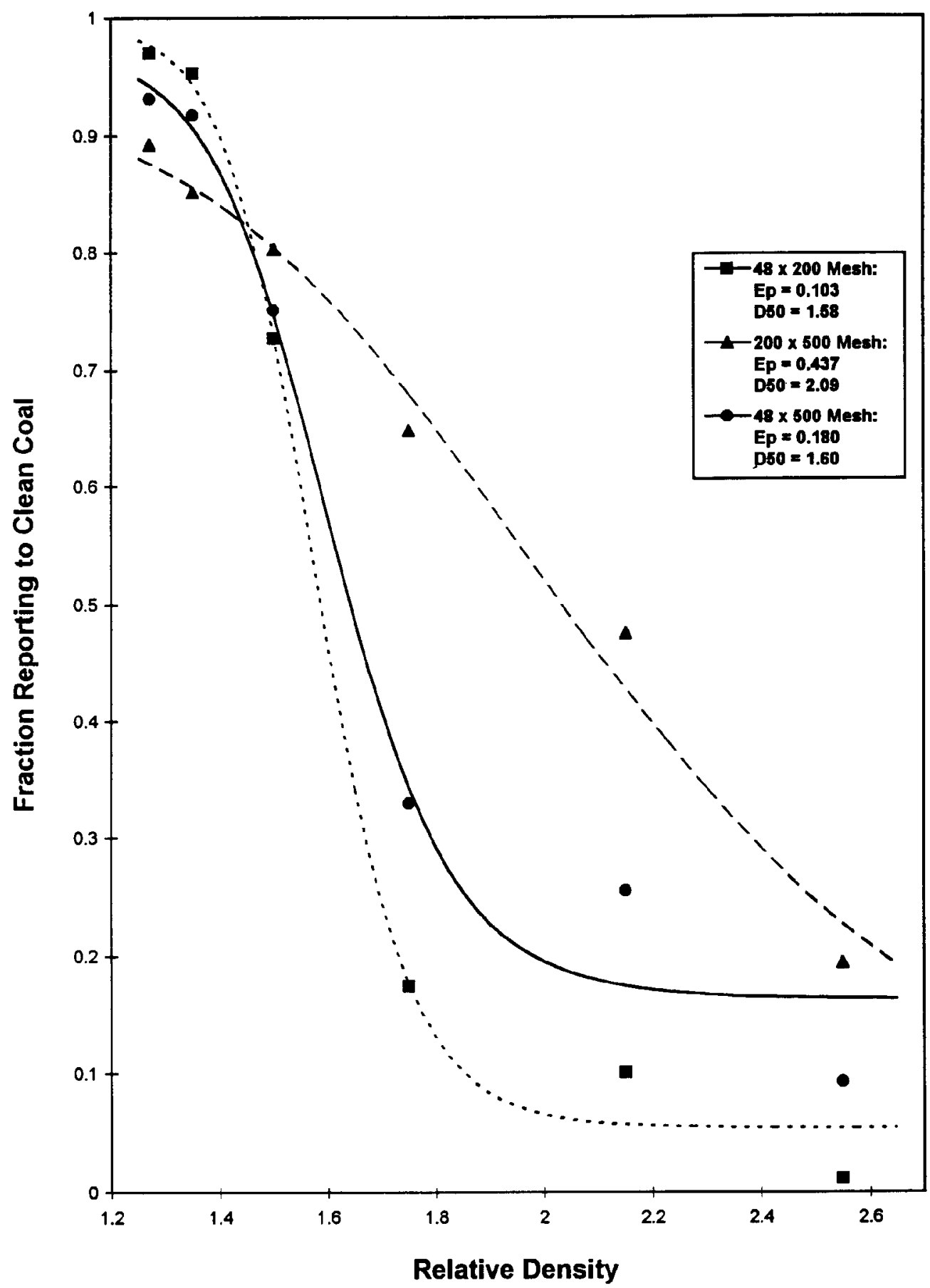

Figure 15. Fitted Partition Curves for PHT \#39

(Grade L Magnetite, 17 PSI, 40\% Fines) 


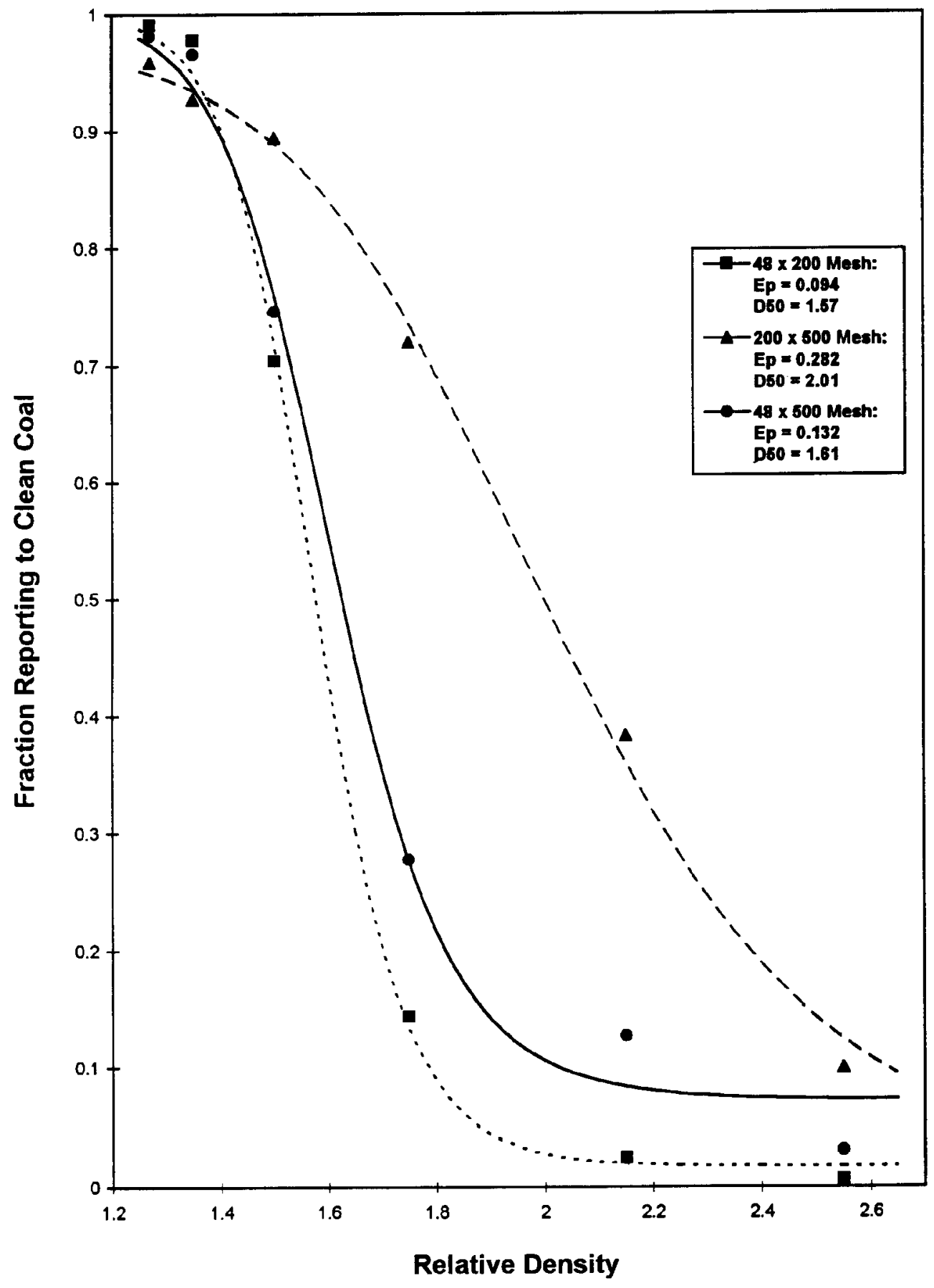

Figure 16. Fitted Partition Curves for PHT \#41 (Grade M Magnetite, 86 PSI, 0\% Fines) 


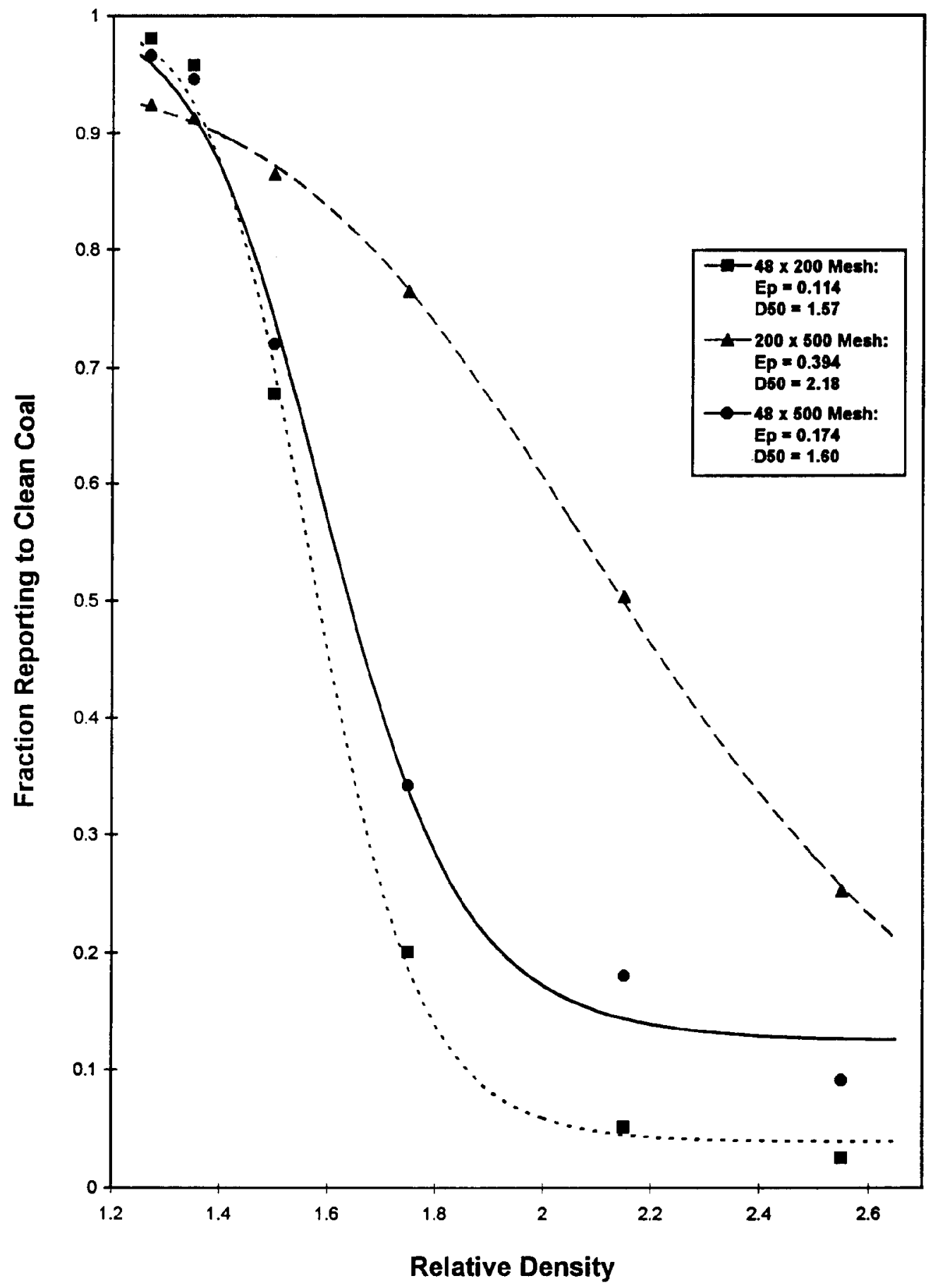

Figure 17. Fitted Partition Curves for PHT \#42 (Grade M Magnetite, 20 PSI, 0\% Fines) 


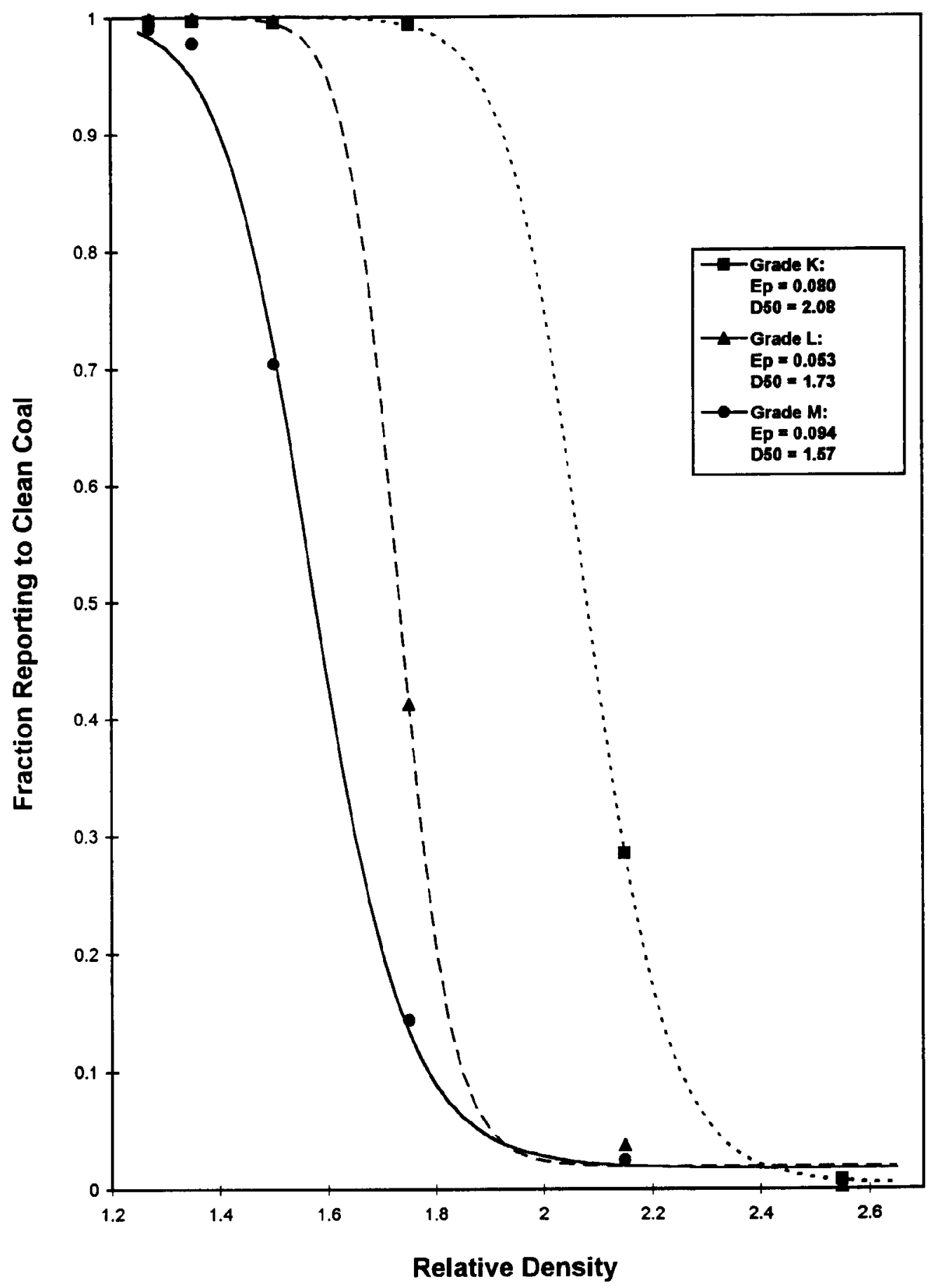

Figure 18. Fitted Partition Curves for the $48 \times 200$ Mesh Fraction for Grade K, L, and M Magnetites

(High Pressure and 0\% Fines) 


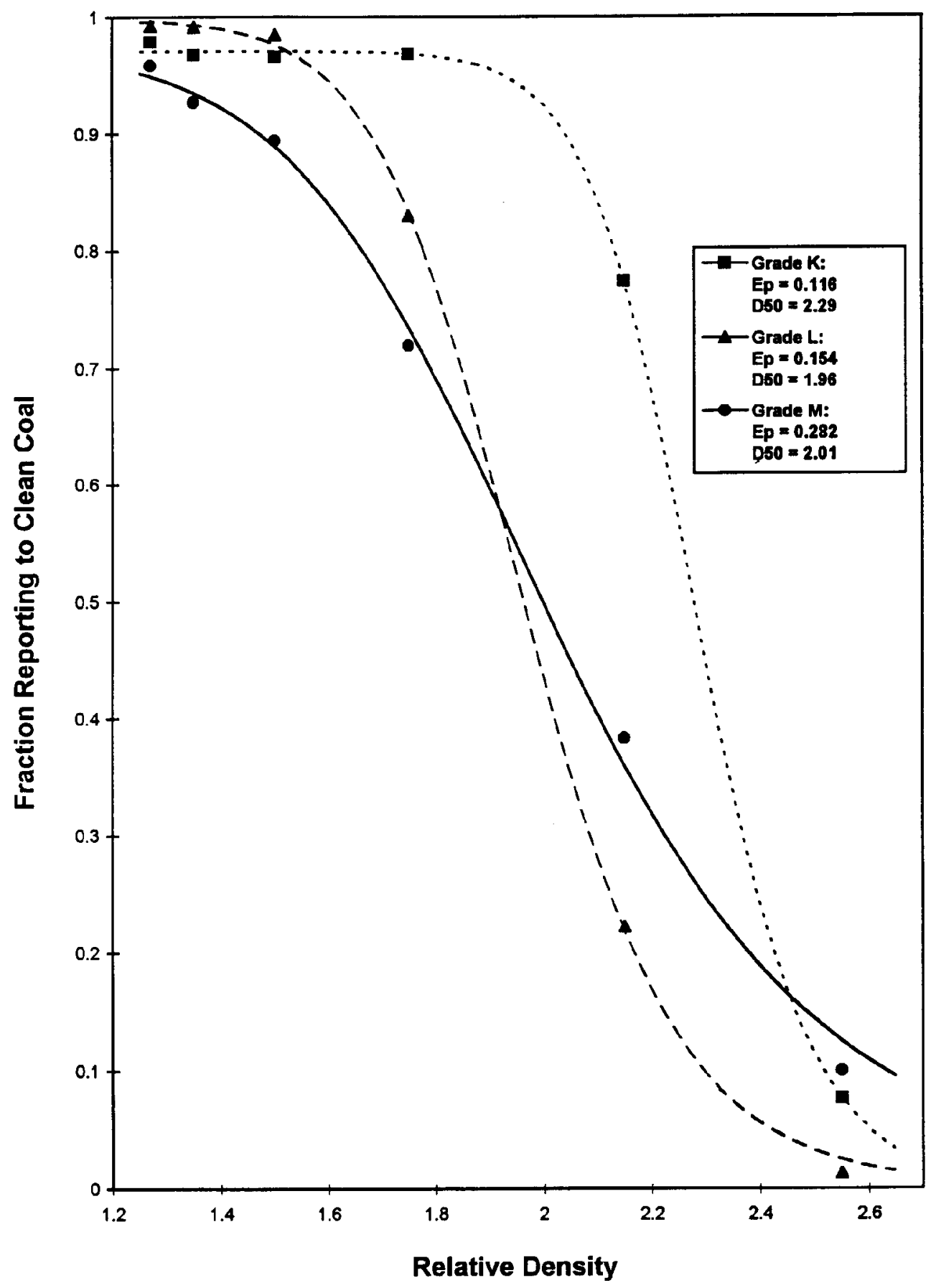

Figure 19. Fitted Partition Curves for the $200 \times 500$ Mesh Fraction for Grade K, L, and M Magnetites (High Pressure and 0\% Fines) 


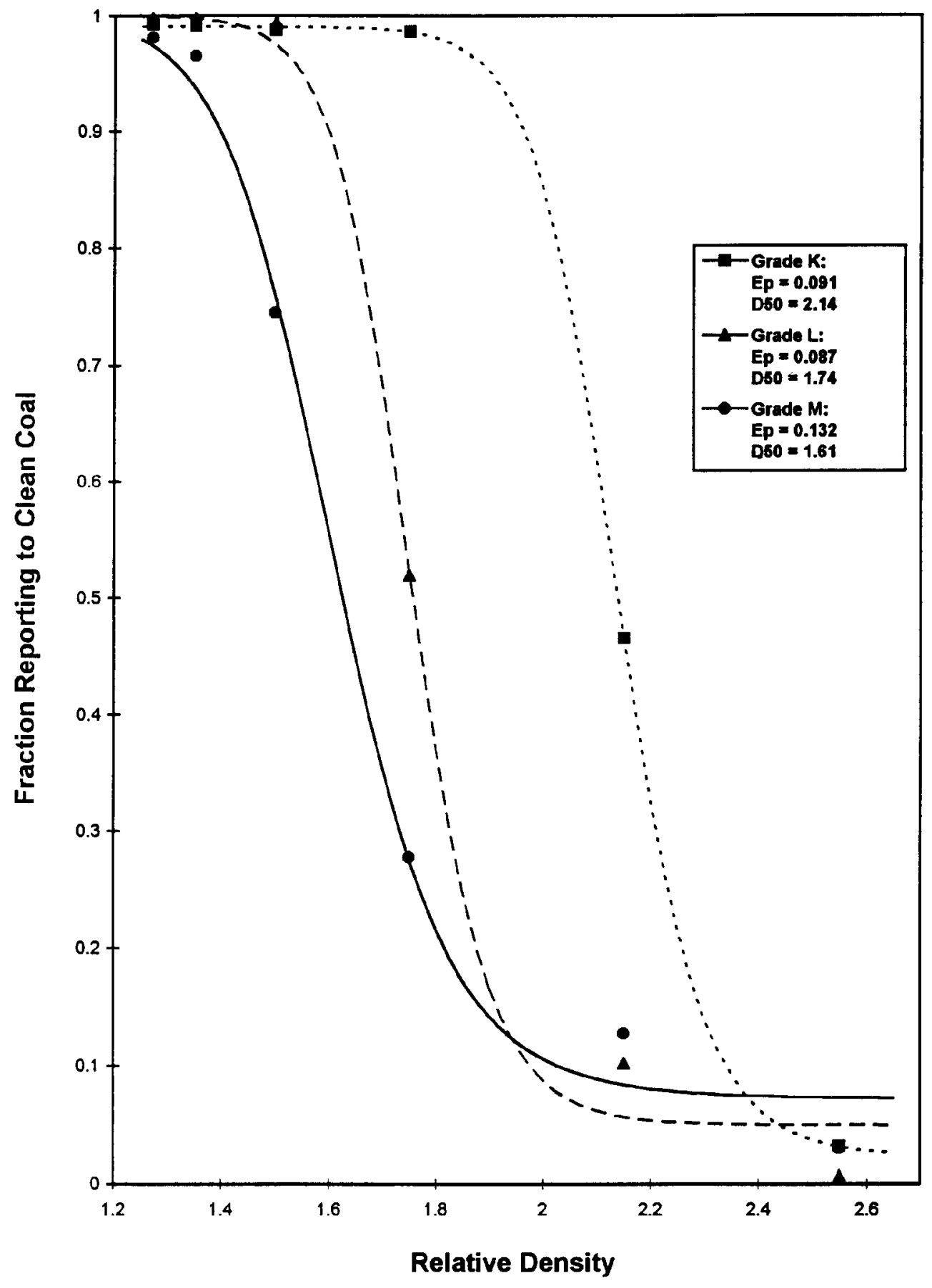

Figure 20. Fitted Partition Curves for the $48 \times 500$ Mesh

Fraction for Grade K, L, and M Magnetites

(High Pressure and 0\% Fines) 


\section{Custom Coal Corporation}

contamination level, high pressure, and the same orifice combination (PHT \#23, \#35, \#41) for each of the micronized magnetites by size fraction (48M x 200M, 200M x 500M, 48M x 500M) and Table 24 shows the results of all four magnetites tested using the same orifice combinations at high feed pressures. As can be seen from Tables 17 thru 24 and Figures 8 thru 20 the following observations and conclusions can be made:

- At $0 \%$ contamination, the cyclone separation performance is very efficient down to $500 \mathrm{M}$ particle size when using the Grade K\&L magnetites.

- For all three micronized magnetites, cyclone performance improved slightly at higher feed pressures and $0 \%$ contamination. At high contamination levels (i.e., $20-40 \mathrm{Wt} \%-500 \mathrm{M}$ coal in the media) cyclone performance deteriorated significantly. However, high feed pressures help buffer the detrimental affects of the contamination.

- The smaller apex size appeared to give the best cyclone performance when using the same grade of magnetite.

- Of the three grades of micronized magnetite the Grade-L magnetite resulted in the best overall (48M x 500M) cyclone performance with the Grade-K magnetite closely matching the Grade-L's overall performance (0.087 Ep vs $0.091 \mathrm{Ep})$.

- On the 48M x 200M size fraction the Grade-L magnetite produced significantly better results than the Grade-K magnetite regarding the cyclones performance (0.053 Ep vs. 0.080 Ep). However, on the $200 \mathrm{M} \times 500 \mathrm{M}$ size fraction the coarser Grade-K magnetite unexpectedly produced the better results (0.116 Ep vs. $0.154 \mathrm{Ep})$.

- The $\mathrm{D}_{50}$ or separating gravity decreased as the magnetite size decreased. This was true in general for all size fractions with and without fines contamination present.

- Cyclone separation performance appears to be very similar for either 10:1 or 5:1 media/coal ratios when using the Grade-K magnetite. No 10:1 media/coal ratio tests were conducted using the Grade-L or Grade-M magnetite.

- Although partition curves were not constructed on the Grade-E magnetite tests due to the limited budget, the yield, reject ash, and clean coal ash were very good at $0 \%$ contamination suggesting that the cyclone separation performance was very respectable even when using a commercial Grade-E magnetite.

- The finest micronized magnetite, Grade-M, resulted in the worst dense-medium cyclone performance with an Ep of 0.132 on the 48M x 500M size fraction and a Ep of 0.282 on the $200 \mathrm{M} \times 500 \mathrm{M}$ size fraction. This last finding is extremely surprising since this finest magnetite 
Table 24. Expanded Dense-Medium Cyclone Performance Results for Grades K, L, M \& E Magnetites

\begin{tabular}{|c|c|c|c|c|c|c|c|c|c|c|c|c|}
\hline \multicolumn{4}{|c|}{ Operating Conditions } & \multicolumn{3}{|c|}{ Cyclone Orifice Combination } & \multicolumn{6}{|c|}{ Dense-Medium Cyclone Performance } \\
\hline \multirow{2}{*}{$\begin{array}{l}\text { Test } \\
\text { No. }\end{array}$} & \multirow{2}{*}{$\begin{array}{c}\text { Magnetite } \\
\text { Grade }\end{array}$} & \multirow{2}{*}{$\begin{array}{c}\text { Cont. Level } \\
\text { (Wt.\%) }\end{array}$} & \multirow{2}{*}{$\begin{array}{c}\text { Feed Pre. } \\
\text { (PSI) }\end{array}$} & \multirow{2}{*}{$\begin{array}{l}\text { Feed Inlet } \\
\text { (sq. in.) }\end{array}$} & \multirow{2}{*}{\begin{tabular}{|c} 
Overflow \\
(in.)
\end{tabular}} & \multirow{2}{*}{$\begin{array}{c}\text { Apex } \\
\text { (in.) }\end{array}$} & \multicolumn{6}{|c|}{$48 \mathrm{M} \times 200 \mathrm{M}$} \\
\hline & & & & & & & $\%$ Yield & $\%$ Feed Ash & \% C.C. Ash & \% Ref. Ash & $\%$ Ash Rej. & $\mathbf{E p}$ \\
\hline PHT \#23 & GRADE-K & 0 & 88 & 0.12 & 1.0 & 0.625 & 87.7 & 18.2 & 9.0 & 83.4 & 56.5 & 0.080 \\
\hline PHT \#35 & GRADE-L & 0 & 88 & 0.12 & 1.0 & 0.625 & 87.0 & 16.0 & 7.2 & 74.8 & 60.8 & 0.053 \\
\hline PHT \#41 & GRADE-M & 0 & 86 & 0.12 & 1.0 & 0.625 & 83.0 & 15.1 & 6.2 & 58.6 & 65.8 & 0.094 \\
\hline PHT \#45 & GRADE-E & 0 & 86 & 0.12 & 1.0 & 0.625 & 87.1 & 16.6 & 8.5 & 71.6 & 55.5 & - \\
\hline PHT \#28 & GRADE-K & 20 & 88 & 0.12 & 1.0 & 0.625 & 88.8 & 18.3 & 10.4 & 80.7 & 49.5 & - \\
\hline PHT \#36 & GRADE-L & 20 & 88 & 0.12 & 1.0 & 0.625 & 87.2 & 15.1 & 6.8 & 71.3 & 60.4 & - \\
\hline PHT \#30 & GRADE-K & 40 & 86 & 0.12 & 1.0 & 0.625 & 90.6 & 14.4 & 7.9 & 76.7 & 50.2 & 0.085 \\
\hline PHT \#40 & GRADE-L & 40 & 88 & 0.12 & 1.0 & 0.625 & 87.8 & 13.8 & 6.6 & 65.9 & 58.3 & 0.069 \\
\hline PHT \#44 & GRADE-M & 40 & 80 & 0.12 & 1.0 & 0.625 & 82.9 & 13.6 & 7.5 & 43.2 & 54.2 & - \\
\hline
\end{tabular}

NOTE: All Test Were Conducted at 5:1 Medium-To-Coal Ratio at 1.40 S.G. Medium Density. 
Table 24. Expanded Dense-Medium Cyclone Performance Results for Grades K, L, M \& E Magnetites, (cont'd.)

\begin{tabular}{|c|c|c|c|c|c|c|c|c|c|c|c|c|}
\hline \multicolumn{4}{|c|}{ Operating Conditions } & \multicolumn{3}{|c|}{ Cyclone Orifice Combination } & \multicolumn{6}{|c|}{ Dense-Medium Cyclone Performance } \\
\hline \multirow{2}{*}{$\begin{array}{l}\text { Test } \\
\text { No. }\end{array}$} & \multirow{2}{*}{$\begin{array}{c}\text { Magnetite } \\
\text { Grade }\end{array}$} & \multirow{2}{*}{$\begin{array}{c}\text { Cont. Level } \\
\text { (Wt.\%) }\end{array}$} & \multirow{2}{*}{$\begin{array}{c}\text { Feed Pre. } \\
\text { (PSI) }\end{array}$} & \multirow{2}{*}{$\begin{array}{l}\text { Feed Inlet } \\
\text { (sq. in.) }\end{array}$} & \multirow{2}{*}{$\begin{array}{l}\text { Overflow } \\
\text { (in.) }\end{array}$} & \multirow{2}{*}{$\begin{array}{c}\text { Apex } \\
\text { (in.) }\end{array}$} & \multicolumn{6}{|c|}{$200 M \times 500 M$} \\
\hline & & & & & & & $\%$ Yield & $\%$ Feed Ash & \% C.C. Ash & \%Ref. Ash & $\%$ Ash Rej. & $\mathbf{E p}$ \\
\hline PHT \#23 & GRADE-K & 0 & 88 & 0.12 & 1.0 & 0.625 & 79.7 & 23.4 & 10.7 & 73.0 & 63.3 & 0.116 \\
\hline PHT \#35 & GRADE-L & 0 & 88 & 0.12 & 1.0 & 0.625 & 80.9 & 19.6 & 7.3 & 71.8 & 70.0 & 0.154 \\
\hline PHT \#41 & GRADE-M & 0 & 86 & 0.12 & 1.0 & 0.625 & 86.0 & 12.8 & 7.0 & 48.6 & 53.2 & 0.282 \\
\hline PHT \#45 & GRADE-E & 0 & 86 & 0.12 & 1.0 & 0.625 & 84.7 & 16.3 & 7.1 & 67.6 & 63.5 & - \\
\hline PHT \#28 & GRADE-K & 20 & 88 & 0.12 & 1.0 & 0.625 & 83.6 & 17.8 & 8.6 & 64.6 & 59.5 & - \\
\hline PHT \#36 & GRADE-L & 20 & 88 & 0.12 & 1.0 & 0.625 & 85.0 & 15.0 & 5.8 & 67.2 & 67.2 & - \\
\hline PHT \#30 & GRADE-K & 40 & 86 & 0.12 & 1.0 & 0.625 & 88.4 & 11.7 & 6.0 & 54.7 & 54.2 & 0.140 \\
\hline PHT \#40 & GRADE-L & 40 & 88 & 0.12 & 1.0 & 0.625 & 87.8 & 11.5 & 5.3 & 55.8 & 59.2 & 0.193 \\
\hline PHT \#44 & GRADE-M & 40 & 80 & 0.12 & 1.0 & 0.625 & 84.1 & 10.4 & 8.4 & 20.8 & 31.8 & - \\
\hline
\end{tabular}

NOTE: All Test Were Conducted at 5:1 Medium-To-Coal Ratio at 1.40 S.G. Medium Density. 
Table 24. Expanded Dense-Medium Cyclone Performance Results for Grades K, L, M \& E Magnetites, (cont'd.)

\begin{tabular}{|c|c|c|c|c|c|c|c|c|c|c|c|c|}
\hline \multicolumn{4}{|c|}{ Operating Conditions } & \multicolumn{3}{|c|}{ Cyclone Orifice Combination } & \multicolumn{6}{|c|}{ Dense - Medium Cyclone Performance } \\
\hline \multirow{2}{*}{$\begin{array}{l}\text { Test } \\
\text { No. }\end{array}$} & \multirow{2}{*}{$\begin{array}{l}\text { Magnetite } \\
\text { Grade }\end{array}$} & \multirow{2}{*}{$\mid \begin{array}{c}\text { Cont. Level } \\
\text { (Wt.\%) }\end{array}$} & \multirow{2}{*}{$\begin{array}{l}\text { Feed Pre. } \\
\quad \text { (PSI) }\end{array}$} & \multirow{2}{*}{$\begin{array}{l}\text { Feed Inlet } \\
\text { (sq. in.) }\end{array}$} & \multirow{2}{*}{$\begin{array}{c}\text { Overflow } \\
\text { (in.) }\end{array}$} & \multirow{2}{*}{$\begin{array}{c}\text { Apex } \\
\text { (in.) }\end{array}$} & \multicolumn{6}{|c|}{$48 \mathrm{M} \times 500 \mathrm{M}$} \\
\hline & & & & & & & $\%$ Yield & $\%$ Feed Ash & \% C.C. Ash & \% Ref. Ash & $\%$ Ash Rej. & $\mathbf{E p}$ \\
\hline PHT \#23 & GRADE-K & 0 & 88 & 0.12 & 1.0 & 0.625 & 85.8 & 19.4 & 9.4 & 79.9 & 58.5 & 0.091 \\
\hline PHT \#35 & GRADE-L & 0 & 88 & 0.12 & 1.0 & 0.625 & 84.9 & 16.8 & 7.2 & 70.8 & 63.6 & 0.087 \\
\hline PHT \#41 & GRADE-M & 0 & 86 & 0.12 & 1.0 & 0.625 & 83.8 & 14.5 & 6.4 & 56.3 & 62.9 & 0.132 \\
\hline PHT \#45 & GRADE-E & 0 & 86 & 0.12 & 1.0 & 0.625 & 86.1 & 16.5 & 7.8 & 70.3 & 59.2 & - \\
\hline PHT \#28 & GRADE-K & 20 & 88 & 0.12 & 1.0 & 0.625 & 87.0 & 18.1 & 9.8 & 73.7 & 52.9 & - \\
\hline РHT \#36 & GRADE-L & 20 & 88 & 0.12 & 1.0 & 0.625 & 86.3 & 15.1 & 6.4 & 69.8 & 63.3 & - \\
\hline PHT \#30 & GRADE-K & 40 & 86 & 0.12 & 1.0 & 0.625 & 89.6 & 13.2 & 7.1 & 65.8 & 51.8 & 0.131 \\
\hline PHT \#40 & GRADE-L & 40 & 88 & 0.12 & 1.0 & 0.625 & 87.6 & 12.9 & 6.0 & 61.6 & 59.2 & 0.094 \\
\hline PHT \#44 & GRADE-M & 40 & 80 & 0.12 & 1.0 & 0.625 & 83.3 & 12.5 & 7.8 & 35.6 & 47.6 & - \\
\hline
\end{tabular}

NOTE: All Test Were Conducted at 5:1 Medium-To-Coal Ratio at 1.40 S.G. Medium Density. 
should have resulted in the most stable medium thereby enhancing the cyclone's performance. The most reasonable explanation for the poor results obtained using the Grade-M magnetite is that the magnetite was so extremely fine that it created a viscosity problem within the cyclone.

\section{Section 4.10.1.3 - Medium Recovery Circuit Component Testing Results}

The medium recovery circuit component testing was conducted in June of 1995. These tests were completed using the Pittsburgh No. 8 Seam coal and the Grade-K magnetite. The primary goal of this testing was to preliminarily determine the best medium recovery configuration for maintaining low losses of magnetite. The two batches of tests performed included:

- $\quad$ Batch \#1 (PMT \#1 - \#9) simulating the various magnetite recovery circuits with no drain and rinse screens.

- Batch \#2 (PMT \#11 - \#20) simulating the various magnetite recovery circuits with 200 mesh drain and rinse screens.

The results from these nineteen tests are contained in Tables 25 and 26 . Table 25 presents the results of nine medium recovery circuit component tests in which drain and rinse screens were not incorporated in the Micro-Mag circuit while Table 26 presents the results of ten medium recovery circuit component tests that included the use of drain and rinse screens in the Micro-Mag circuit.

The following observations and conclusions can be made from the overall results presented in Tables $25 \& 26$.

- The viability of recovering the Grade K magnetite was demonstrated, as very good overall magnetite losses were achieved for most configurations and levels of contamination. Loss values were typically below $10 \mathrm{lb} / \mathrm{ton}$.

- In general, the loss of magnetite to the magnetic separator tails was not dependent upon incorporating or excluding the drain and rinse screens.

- The percent magnetics in all the magnetic separator concentrates were very good, ranging from $94 \%$ to $99 \%$ magnetics. However, it is evident that the percent magnetics deteriorates slightly as the percent contamination of non-magnetics increases. However, this slight deterioration is probably not enough to justify recleaning the concentrate of any of the magnetic separators.

- As the \% non-magnetics in the magnetic separator feed increased the loss of magnetics in the magnetic separator tails also increased. 
Table 25. Medium Recovery Circuit Component Tests Simulated with No D\&R Screens

\begin{tabular}{|c|c|c|c|c|c|c|c|c|}
\hline \multirow[b]{2}{*}{$\begin{array}{c}\text { Test } \\
\text { Number }\end{array}$} & \multirow[b]{2}{*}{$\begin{array}{c}\text { Test } \\
\text { Configuration } \\
\end{array}$} & \multirow[b]{2}{*}{$\begin{array}{l}\text { Contam. } \\
\text { Level }(\%) \\
\end{array}$} & \multirow[b]{2}{*}{$\begin{array}{c}\text { Feed } \\
\% \text { Solids }\end{array}$} & \multicolumn{2}{|c|}{ Feed Non-Magnetics } & \multirow[b]{2}{*}{$\begin{array}{c}\text { Feed } \\
\% \text { Magnetics } \\
\end{array}$} & \multirow[b]{2}{*}{$\begin{array}{l}\text { Concentrate } \\
\% \text { Magnetics } \\
\end{array}$} & \multirow[b]{2}{*}{$\begin{array}{c}\text { Magnetite } \\
\text { Loss (lb./ton) }\end{array}$} \\
\hline & & & & Total $(\%)$ & $-500 M(\%)$ & & & \\
\hline PMT \#1 & R. Earth Only & 0 & 12.1 & 8.7 & 2.0 & 91.3 & 98.0 & 1.2 \\
\hline PMT \#2 & Tert. \& R.E. & 0 & 10.7 & 8.7 & 1.7 & 91.3 & 98.4 & 2.3 \\
\hline PMT \#3 & Primary \& Sec. & 0 & 6.4 & 8.7 & 3.0 & 91.3 & 98.3 & 2.7 \\
\hline PMT \#4 & Primary \& Sec. & 20 & 9.0 & 29.4 & 23.4 & 70.6 & 96.8 & 5.8 \\
\hline PMT \#5 & Tert. \& R.E. & 20 & 9.8 & 29.4 & 21.1 & 70.6 & 97.5 & 6.5 \\
\hline PMT \#6 & R. Earth Only & 20 & 10.2 & 29.4 & 20.4 & 70.6 & 97.6 & 12.1 \\
\hline PMT \#7 & R. Earth Only & 40 & 10.1 & 45.4 & 35.1 & 54.6 & 97.4 & 26.6 \\
\hline PMT \#8 & Tert. \& R.E. & 40 & 14.0 & 45.4 & 36.5 & 54.6 & 96.2 & 3.7 \\
\hline PMT \#9 & Tert. \& R.E. & 40 & 15.2 & 45.4 & 36.6 & 54.6 & 95.2 & 4.0 \\
\hline
\end{tabular}


Table 26. Medium Recovery Circuit Component Tests Simulated with D\&R Screens

\begin{tabular}{|c|c|c|c|c|c|c|c|c|}
\hline \multirow[b]{2}{*}{$\begin{array}{c}\text { Test } \\
\text { Number }\end{array}$} & \multirow[b]{2}{*}{$\begin{array}{c}\text { Test } \\
\text { Configuration }\end{array}$} & \multirow[b]{2}{*}{$\begin{array}{l}\text { Contam. } \\
\text { Level }(\%)\end{array}$} & \multirow[b]{2}{*}{$\begin{array}{c}\text { Feed } \\
\% \text { Solids }\end{array}$} & \multicolumn{2}{|c|}{ Feed Non-Magnetics } & \multirow[b]{2}{*}{$\begin{array}{c}\text { Feed } \\
\% \text { Magnetics } \\
\end{array}$} & \multirow[b]{2}{*}{$\begin{array}{l}\text { Concentrate } \\
\% \text { Magnetics }\end{array}$} & \multirow[b]{2}{*}{$\begin{array}{c}\text { Magnetite } \\
\text { Loss (lb./ton) }\end{array}$} \\
\hline & & & & Total $(\%)$ & $-500 M(\%)$ & & & \\
\hline PMT \#11 & Tert. \& R.E. & 0 & 5.0 & 8.6 & 3.8 & 91.4 & 98.8 & 2.1 \\
\hline PMT \#12 & R. Earth Only & 0 & 4.5 & 8.6 & 3.4 & 91.4 & 99.6 & 2.6 \\
\hline PMT \#13 & Primary Only & 0 & 4.6 & 8.6 & 3.6 & 91.4 & 99.3 & 7.5 \\
\hline PMT \#14 & Primary \& Sec. & 0 & 5.5 & 8.6 & 4.7 & 91.4 & 98.0 & 2.9 \\
\hline PMT \#15 & Primary \& Sec. & 20 & 10.1 & 24.0 & 18.4 & 76.0 & 97.6 & 7.3 \\
\hline PMT \#16 & R. Earth Only & 20 & 9.3 & 24.0 & 18.4 & 76.0 & 98.5 & 6.8 \\
\hline PMT \#17 & Tert. \& R.E. & 20 & 9.3 & 24.0 & 18.3 & 76.0 & 97.6 & 4.9 \\
\hline PMT \#18 & Tert. \& R.E. & 40 & 12.6 & 43.3 & 35.9 & 56.7 & 93.9 & 8.5 \\
\hline PMT \#19 & Tertiary Only & 40 & 12.3 & 43.3 & 35.9 & 56.7 & 94.3 & 12.7 \\
\hline PMT \#20 & R. Earth Only & 40 & 12.3 & 43.3 & 35.8 & 56.7 & 96.2 & 17.0 \\
\hline
\end{tabular}


With the given magnetite tested, two conventional magnetic separators in series had nearly the same performance as one conventional magnetic separator and one rare earth magnetic separator in series implying that the rare earth separator is not needed to recovery the Grade-K magnetite. However, it must be remembered that the quality of the Grade-K magnetite was extremely good and it was also the coarsest of the three micronized magnetites. As will be illustrated in Section 4.10.2 - Primary Integrated Testing Results and 4.10.3 - Continuous Integrated Testing Results, the rare earth separator was needed to recover the finer micronized magnetites.

\section{Section 4.10.2 - Primary Integrated Testing Results}

The primary integrated testing for the Grade-K and Grade-L magnetites was conducted from mid-July thru the first week of August in 1995 while the Grade-M magnetite tests were conducted in midOctober 1995. The overall objective of the primary integrated testing was to determine the technical and economic feasibility of various unit operations and systems in optimizing the separation and recovery of the micronized magnetite from the coal products. Technically, the focus was on establishing the least complicated, easiest to operate circuit, that would provide the correct recirculating medium properties and to quantify the amount of magnetite not recovered by the individual and combined recovery circuit unit operations.

A total of ten primary integrated tests were conducted, five using the Grade-K magnetite, three using the Grade-L magnetite, and two using the Grade-M magnetite. The five test (PIT \#1-\#5) using the Grade-K magnetite included operating the circuit:

- With 200M drain and rinse screens with a slight positive angle on the rinse screen with the underflow from the drain screen reporting to the primary magnetic separator (PIT \#1).

- With no drain and rinse screens with the 2-inch dense-medium cyclone products reporting to the primary magnetic separator (PIT \#2).

- With 200M drain and rinse screens with a slight negative angle on the rinse screen with the underflow from the drain screen reporting to the primary magnetic separator (PIT \#3).

- With $100 \mathrm{M}$ drain and rinse screens with a slight negative angle on the rinse screen with the underflow from the drain screen reporting to the primary magnetic separator (PIT \#4).

- With $100 \mathrm{M}$ drain and rinse screens with a slight positive angle on the rinse screen with the underflow from the drain screen reporting to the primary magnetic separator (PIT \#5).

The three tests (PIT \#6-\#8) using the Grade-L magnetite included operating the circuit:

- With $100 \mathrm{M}$ drain and rinse screens with a slight negative angle on the rinse screen with the underflow from the drain screen reporting to the primary magnetic separator (PIT \#6). 


\section{Custom Coal Corporation}

- With no drain and rinse screens with the 2-inch dense-medium cyclone products reporting to the primary magnetic separator (PIT \#7).

- With 200M drain and rinse screens with a slight negative angle on the rinse screen with the underflow from the drain screen reporting to the primary magnetic separator (PIT \#8).

The two tests (PIT \#9 and \#10) using the Grade-M magnetite included operating the circuit:

- With no drain and rinse screens with the 2-inch dense-medium cyclone products reporting to the primary separator (PIT \#9).

- With 100M drain and rinse screens with a slight negative angle on the rinse screen with the underflow from the drain screen reporting to the primary magnetic separator (PIT \#10).

Selected results from all ten tests are presented in Table 27 and detailed results are presented in the Appendices. From Table 27 and the detailed results, the following observations and conclusions can be made.

- In all cases, extremely large amounts of magnetite were lost in the discharge of the rinse screen when 200M decks are used. It appears that a slight negative angle on the rinse screen helps to reduce the amount of magnetite lost when 200M decks were used but the losses even at the negative angle were significant.

- When using the Grade $\mathrm{K}$ and L magnetites with $100 \mathrm{M}$ decks only small amounts of magnetite were lost in the discharge of the rinse screen. However, when coupled with the magnetite loss from the rare earth magnetic separator the total circuit losses for the Grade- $\mathrm{K}$ were on the order of 4.1 to $4.6 \mathrm{lb} /$ ton of circuit feed and the total circuit losses for the Grade-L were slightly over $12.1 \mathrm{lb} /$ ton.

- When using the Grade-M magnetite with 100M decks huge amounts of magnetite were lost in the discharge of the rinse screen. This was most likely caused by the magnetite particles becoming magnetized when being recovered by the magnetic separator circuits. This caused the magnetite particles to adhere together making it difficult for the sprays on the rinse screen to rinse the magnetite particles through the screen. 
Table 27. Primary Integrated Testing Results

\begin{tabular}{|c|c|c|c|c|c|c|c|c|}
\hline \multirow[b]{2}{*}{$\begin{array}{c}\text { Test } \\
\text { Number }\end{array}$} & \multirow[b]{2}{*}{$\begin{array}{c}\text { Magnetite } \\
\text { Grade }\end{array}$} & \multirow[b]{2}{*}{$\begin{array}{c}\text { Test } \\
\text { Configuration }\end{array}$} & \multirow[b]{2}{*}{$\begin{array}{c}\text { D\&R Screen } \\
\text { Deck Size }\end{array}$} & \multirow[b]{2}{*}{$\begin{array}{c}\text { Rinse Scn. } \\
\text { Angle }\end{array}$} & \multicolumn{4}{|c|}{$\begin{array}{c}\% \text { Magnetics } \\
\text { (EMU/g Based) }\end{array}$} \\
\hline & & & & & $\begin{array}{l}\text { Combined Drain } \\
\text { Screen Effluent }\end{array}$ & $\begin{array}{l}\text { Pri. Mag. Sep. } \\
\text { Concentrate }\end{array}$ & $\begin{array}{l}\text { Cln. Mag. Sep. } \\
\text { Concentrate }\end{array}$ & $\begin{array}{l}\text { Correct } \\
\text { Medium }\end{array}$ \\
\hline PIT \#1 & $\mathrm{K}$ & With D\&R Screens & $200 \mathrm{M}$ & Positive & 94.20 & 97.50 & 96.49 & 95.60 \\
\hline PIT \#2 & $\mathrm{K}$ & Without D\&R Screens & N.A. & N.A. & N.A. & 96.01 & 99.90 & - \\
\hline PIT \#3 & $\mathrm{K}$ & With D\&R Screens & $200 \mathrm{M}$ & Negative & 95.52 & 92.49 & 99.65 & 98.80 \\
\hline PIT \#4 & $\mathrm{K}$ & With D\&R Screens & $100 \mathrm{M}$ & Negative & 88.45 & 98.97 & 99.15 & 97.71 \\
\hline PIT \#5 & $\mathrm{K}$ & With D\&R Screens & $100 \mathrm{M}$ & Positive & 86.87 & 97.61 & 98.20 & 96.35 \\
\hline PIT \#6 & $\mathrm{L}$ & With D\&R Screens & $100 \mathrm{M}$ & Negative & 81.00 & 96.43 & 96.58 & 78.50 \\
\hline PIT \#7 & $\mathrm{L}$ & Without D\&R Screens & N.A. & N.A. & N.A. & 94.69 & 97.29 & 79.37 \\
\hline PIT \#8 & $\mathrm{L}$ & With D\&R Screens & $200 \mathrm{M}$ & Negative & 90.99 & 98.21 & 97.51 & 77.85 \\
\hline PIT \#9 & M & With D\&R Screens & $100 \mathrm{M}$ & Negative & - & 96.66 & 96.77 & 84.36 \\
\hline PIT \#10 & $\mathrm{M}$ & Without D\&R Screens & N.A. & N.A. & N.A. & 89.96 & 95.40 & 74.67 \\
\hline
\end{tabular}


Table 27. Primary Integrated Testing Results, (cont'd.)

\begin{tabular}{|c|c|c|c|c|c|c|c|c|c|c|c|c|c|}
\hline \multirow[b]{2}{*}{\begin{tabular}{|c|} 
Test \\
Number
\end{tabular}} & \multirow[b]{2}{*}{$\begin{array}{c}\text { Magnetite } \\
\text { Grade }\end{array}$} & \multirow[b]{2}{*}{$\begin{array}{c}\text { Test } \\
\text { Configuration }\end{array}$} & \multirow[b]{2}{*}{\begin{tabular}{|c} 
D\&R Screen \\
Deck Size
\end{tabular}} & \multirow[b]{2}{*}{$\begin{array}{c}\text { Rinse Scn. } \\
\text { Angle }\end{array}$} & \multicolumn{4}{|c|}{$\begin{array}{l}\% \text { Magnetics } \\
\text { (EMU/g based) }\end{array}$} & \multicolumn{5}{|c|}{ Magnetite Loss per Ton of Equipment Feed } \\
\hline & & & & & $\begin{array}{c}\text { Refuse Rinse } \\
\text { Discharge }\end{array}$ & \begin{tabular}{|l} 
C.C. Rinse \\
Discharge
\end{tabular} & $\begin{array}{c}\text { Sec. } \\
\text { Mag. } \\
\text { Sep. Tails }\end{array}$ & $\begin{array}{l}\text { Scav. Mag. } \\
\text { Sep. Tails }\end{array}$ & $\begin{array}{c}\text { Refuse Rinse } \\
\text { Discharge }\end{array}$ & \begin{tabular}{|l} 
C.C. Rinse \\
Discharge
\end{tabular} & $\begin{array}{l}\text { Sec. Mag. } \\
\text { Sep. Tails }\end{array}$ & $\begin{array}{c}\text { Scav. } \\
\text { Mag. } \\
\text { Sep. Tails }\end{array}$ & $\begin{array}{c}\text { Circuit } \\
\text { Magnetite } \\
\text { Loss (lb/ton) }\end{array}$ \\
\hline PIT \#1 & K & With D\&R Screens & $200 \mathrm{M}$ & Positive & 4.90 & 24.10 & 1.57 & 1.78 & 102.8 & 635.1 & 20.4 & 36.3 & 512.0 \\
\hline PIT \#2 & $\mathrm{K}$ & Without D\&R Screens & N.A. & N.A. & N.A. & N.A. & 0.15 & 0.19 & N.A. & N.A. & 2.6 & 3.8 & 3.8 \\
\hline PIT \#3 & $\mathrm{K}$ & With D\&R Screens & $200 \mathrm{M}$ & Negative & 0.37 & 7.99 & 0.90 & 0.43 & 7.5 & 173.8 & 13.4 & 8.6 & 108.6 \\
\hline PIT \#4 & $\mathrm{K}$ & With D\&R Screens & $100 \mathrm{M}$ & Negative & 0.07 & 0.00 & 0.42 & 0.36 & 1.3 & 0.0 & 7.9 & 6.2 & 4.6 \\
\hline PIT \#5 & $\mathrm{K}$ & With D\&R Screens & $100 \mathrm{M}$ & Positive & 0.08 & 0.00 & 0.06 & 0.37 & 1.6 & 0.0 & 6.4 & 6.0 & 4.1 \\
\hline PIT \#6 & $\mathrm{L}$ & With D\&R Screens & $100 \mathrm{M}$ & Negative & 0.00 & 0.00 & 0.65 & 0.60 & 0.0 & 0.0 & 11.4 & 12.1 & 12.1 \\
\hline PIT \#7 & $\mathrm{L}$ & Without D\&R Screens & N.A. & N.A. & N.A. & N.A. & 0.29 & 0.29 & N.A & N.A & 4.8 & 5.8 & 5.8 \\
\hline PIT \#8 & $\mathrm{L}$ & With D\&R Screens & $200 \mathrm{M}$ & Negative & 9.85 & 3.63 & 0.65 & 0.41 & 218.5 & 75.4 & 11.4 & 8.3 & 79.8 \\
\hline PIT \#9 & $\mathrm{M}$ & With D\&R Screens & $100 \mathrm{M}$ & Negative & 35.91 & 30.10 & 18.03 & 6.16 & 1120.0 & 861.0 & 440.0 & 131.0 & 486.4 \\
\hline PIT \#10 & $\mathrm{M}$ & Without D\&R Screens & N.A. & N.A. & N.A. & N.A. & 62.38 & 4.82 & N.A & N.A & 3157.0 & 94.0 & 94.0 \\
\hline
\end{tabular}




\section{Custom Coal Corporation}

- The circuit that produced the best overall magnetite recovery was by-passing the drain and rinse screens which resulted in the 2-inch dense-medium cyclone products reporting directly to the magnetic separator circuits. This was true for all three magnetites tested. This circuit resulted in a $3.8 \mathrm{lb} /$ ton magnetite loss when using the Grade-K magnetite, a $5.8 \mathrm{lb} / \mathrm{ton}$ magnetite loss when using the Grade-L magnetite, and a $94.0 \mathrm{lb} /$ ton magnetite loss when using the Grade-M magnetite.

- $\quad$ As can be seen, the magnetite losses for the Grade K\&L magnetites were fairly respectable. However, the Grade-M magnetite losses were extremely high. These large losses are not surprising since only about $81 \%$ of the as-received magnetite was recovered in the DavisTube at 1.7 amps $(3,700$ gauss $)$.

- As might be expected the percent magnetics in the combined drain screen effluent were higher (90.99\% to $95.52 \%$ ) when $200 \mathrm{M}$ decks were installed on the drain screen than when $100 \mathrm{M}$ decks were installed ( $81.00 \%$ to $88.45 \%)$.

- The magnetic content of both the primary and cleaner magnetic separator concentrates were very high with the percent magnetics generally in the mid to high nineties. This was true for all three grades of magnetite.

- The correct or circulating medium magnetic content was extremely good when using the Grade-K magnetite (95.60\% to $98.80 \%$ ). However, the circulating medium deteriorated $(74.67 \%$ to $84.36 \%$ ) when using the Grade-L and Grade-M magnetites. Since the cleaner magnetic separator concentrates were extremely high in magnetic content, the non-magnetic contamination in the circulating medium must have been contributed by the rare earth magnetic separator concentrate.

On tests PIT \#2 (Grade-K), \#7 (Grade-L), and \#10 (Grade-M), samples of the four-inch densemedium cyclone products were collected. The results are presented in Table 28. When comparing the limited results in Table 28 to those of the dense-medium cyclone component tests it appears that the 4-inch dense-medium cyclone's performance is very similar. For example, the clean coal and refuse ash values presented in Table 28 indicate that the separating gravity decreased as the magnetite size decreased. The ash values also indicate that the Grade-M magnetite appears to produce the worst dense-medium cyclone performance.

\section{Section 4.10.3 - Continuous Integrated Testing Results}

The continuous integrated testing occurred during the first two weeks of December 1995. The test plan called for testing the Lower Kittanning "B" Seam coal for 40 continuous hours using the GradeM magnetite followed by testing the Pittsburgh No. 8 Seam for 40 continuous hours using the GradeL magnetite. 
Table 28. Primary Integrated Testing Results for 4-Inch Dense-Medium Cyclone

\begin{tabular}{|c|c|c|c|c|c|c|c|c|c|c|c|c|c|c|}
\hline \multirow{3}{*}{$\begin{array}{c}\text { Test } \\
\text { Number }\end{array}$} & \multirow{3}{*}{$\begin{array}{c}\text { Magnetite } \\
\text { Grade }\end{array}$} & \multirow{3}{*}{$\begin{array}{c}\text { Test } \\
\text { Configuration }\end{array}$} & \multicolumn{12}{|c|}{ Dense-Medium Cyclone Results } \\
\hline & & & \multicolumn{4}{|c|}{$48 \mathrm{M} \times 200 \mathrm{M}$} & \multicolumn{4}{|c|}{$200 \mathrm{M} \times 500 \mathrm{M}$} & \multicolumn{4}{|c|}{$48 \mathrm{M} \times 500 \mathrm{M}$} \\
\hline & & & $\begin{array}{c}\% \\
\text { FD. } \\
\text { Ash }\end{array}$ & $\begin{array}{c}\% \\
\text { C.C. } \\
\text { Ash } \\
\end{array}$ & $\begin{array}{c}\% \\
\text { Ref. } \\
\text { Ash }\end{array}$ & $\begin{array}{c}\% \\
\text { Yield } \\
\end{array}$ & $\begin{array}{c}\% \\
\text { FD. } \\
\text { Ash }\end{array}$ & $\begin{array}{c}\% \\
\text { C.C. } \\
\text { Ash } \\
\end{array}$ & $\begin{array}{c}\% \\
\text { Ref. } \\
\text { Ash } \\
\end{array}$ & $\begin{array}{c}\% \\
\text { Yield } \\
\end{array}$ & $\begin{array}{c}\% \\
\text { FD. } \\
\text { Ash }\end{array}$ & $\begin{array}{c}\% \\
\text { C.C. } \\
\text { Ash } \\
\end{array}$ & $\begin{array}{c}\% \\
\text { Ref. } \\
\text { Ash }\end{array}$ & $\begin{array}{c}\% \\
\text { Yield }\end{array}$ \\
\hline PIT \#2 & K & Without D\&R Scn. & 22.01 & 9.27 & 81.26 & 82.31 & 28.09 & 9.30 & 75.24 & 71.50 & 23.50 & 9.28 & 79.19 & 79.66 \\
\hline PIT \#7 & $\mathrm{L}$ & Without D\&R Scn. & 17.27 & 7.47 & 74.80 & 85.45 & 24.58 & 8.61 & 77.02 & 76.66 & 18.87 & 7.70 & 75.49 & 83.52 \\
\hline PIT \#10 & $\mathrm{M}$ & Without D\&R Scn. & 15.83 & 5.28 & 39.62 & 69.29 & 17.09 & 6.50 & 54.23 & 77.80 & 16.46 & 5.93 & 45.75 & 73.55 \\
\hline
\end{tabular}

Note: All test conducted with 0.12 sq. in. feed inlet, 1.00 in. vortex finder, and 0.625 in. apex at 1.35 s.g. circulating medium. 
Testing of the Pittsburgh Seam coal using the Grade L magnetite was performed as planned. However, the Lower Kittanning "B" Seam coal was only tested for four continuous hours due to the inability to maintain respectable clarified water quality. The inability to maintain the clarified water clarity resulted from the extremely low $\mathrm{pH}$ that developed when the circuit began processing of the Lower Kittanning seam. The Lower Kittanning coal was stockpiled for a few months at Dillners before testing it in the Micro-Mag circuit which more than likely contributed to the low $\mathrm{pH}$ that developed in the clarified water circuit. Nevertheless, material balances and laboratory analysis were completed for the samples collected after one hour and four hours of continuous testing. However, researchers decided not to perform any float/sink analysis for the development of partition curves since these curves may have been misleading due to the fines contamination from the clarified water circuit.

\section{Grade M Lower Kittanning Continuous Integrated Testing}

Table 29 presents the percent magnetics in various flow streams and the magnetite loss per ton of equipment feed and the total circuit magnetite loss for the Grade M testing of the Lower Kittanning Seam coal.

The data indicate that the percent magnetics in the primary magnetic separator concentrate, the cleaner magnetic separator concentrate, and the correct medium were nearly identical after one and four hours of continuous testing. However, the percent magnetics in the cleaner magnetic separator tailings and the secondary magnetic separator tailings was extremely high (72.07\% and 58.55\%) after one hour of continuous testing but seemed to level off, although still significantly high $(26.88 \%$ and $25.59 \%$ ), after four hours of continuous testing. The percent magnetics in the scavenger magnetic separator tails was slightly less after four hours of continuous testing when compared to one hour of continuous testing $(1.35 \%$ to $1.96 \%)$.

The magnetite loss per ton of equipment feed was extremely high in the secondary magnetic separator after one hour of continuous operation ( $2,725 \mathrm{lb} /$ ton) but improved slightly ( $534 \mathrm{lb} / \mathrm{ton})$, although still significantly high, after four hours of continuous operation. This conclusion is supported by the large amount of magnetics in the tailings of this separator. The magnetite loss in the scavenger magnetic separator per ton of equipment feed, which is also the total magnetite loss for the entire Micro-Mag circuit, was slightly less after four hours of continuous operation when compared to the first hour of continuous operation $(31.7 \mathrm{lb} /$ ton vs $25.7 \mathrm{lb} / \mathrm{ton})$. It is evident that the scavenger magnetic separator (rare earth) recovered a large percentage of the magnetite lost in the secondary magnetite separator. However, total circuit magnetite losses on the order of $30 \mathrm{lb} /$ ton in the MicroMag circuit are unacceptably high. To try to improve the large magnetite loss when using the GradeM magnetite a different recovery circuit, perhaps using a high-gradient magnetic separator, would be required. 
Table 29. Continuous Integrated Magnetite Recovery Results for Grade-M Magnetite

\begin{tabular}{|c|c|c|c|c|c|c|c|c|c|c|}
\hline \multirow{2}{*}{$\begin{array}{l}\text { Test } \\
\text { No. }\end{array}$} & \multirow{2}{*}{$\begin{array}{c}\text { Hours } \\
\text { Into Test }\end{array}$} & \multicolumn{6}{|c|}{ Percent Magnetics } & \multicolumn{2}{|c|}{ Mag. Loss/ton of Equip. Feed } & \multirow{2}{*}{$\begin{array}{c}\text { Circuit } \\
\text { Magnetite } \\
\text { Loss (lb/ton) }\end{array}$} \\
\hline & & $\begin{array}{l}\text { Pri. Mag. Sep. } \\
\text { Concentrate }\end{array}$ & $\begin{array}{l}\text { Cln. Mag. Sep. } \\
\text { Concentrate }\end{array}$ & $\begin{array}{l}\text { Correct } \\
\text { Medium }\end{array}$ & $\begin{array}{l}\text { Cln. Mag. } \\
\text { Sep. Tails }\end{array}$ & $\begin{array}{l}\text { Sec. Mag. } \\
\text { Sep. Tails }\end{array}$ & $\begin{array}{c}\text { Scav. Mag. } \\
\text { Sep. Tails }\end{array}$ & $\begin{array}{l}\text { Sec. Mag. } \\
\text { Sep. Tails }\end{array}$ & $\begin{array}{l}\text { Scav. Mag. } \\
\text { Sep. Tails }\end{array}$ & \\
\hline KLD-M1 & 1 & 82.70 & 92.30 & 84.22 & 72.07 & 58.55 & 1.96 & 2725.0 & 31.7 & 31.7 \\
\hline KLD-M2 & 4 & 82.04 & 91.67 & 84.16 & 26.88 & 25.59 & 1.35 & 534.0 & 25.7 & 25.7 \\
\hline
\end{tabular}

Note: Test conducted with Grade-M Magnetite and no D\&R screens.

Table 30. Continuous Integrated Dense-Medium Cyclone Results for Grade-M Magnetite

\begin{tabular}{|c|c|c|c|c|c|c|c|c|c|c|c|c|c|c|c|}
\hline \multirow[b]{3}{*}{$\begin{array}{c}\text { Test } \\
\text { Number }\end{array}$} & \multirow[b]{3}{*}{$\begin{array}{c}\text { Hours } \\
\text { Into Test }\end{array}$} & \multicolumn{14}{|c|}{ Dense-Medium Cyclone Results } \\
\hline & & \multicolumn{6}{|c|}{$48 M \times 200 M$} & \multicolumn{4}{|c|}{$200 M \times 500 M$} & \multicolumn{4}{|c|}{$48 M \times 500 M$} \\
\hline & & Ep & D50 & $\begin{array}{c}\% \text { FD. } \\
\text { Ash }\end{array}$ & $\begin{array}{c}\% \\
\text { C.C. } \\
\text { Ash }\end{array}$ & $\begin{array}{c}\% \\
\text { Ref. } \\
\text { Ash }\end{array}$ & $\begin{array}{c}\% \\
\text { Yield }\end{array}$ & $\begin{array}{c}\text { \% FD. } \\
\text { Ash }\end{array}$ & $\begin{array}{c}\% \\
\text { C.C. } \\
\text { Ash }\end{array}$ & $\begin{array}{c}\% \\
\text { Ref. } \\
\text { Ash }\end{array}$ & $\begin{array}{c}\% \\
\text { Yield }\end{array}$ & $\begin{array}{c}\% \text { FD. } \\
\text { Ash }\end{array}$ & $\begin{array}{c}\% \\
\text { C.C. } \\
\text { Ash }\end{array}$ & $\begin{array}{c}\% \\
\text { Ref. } \\
\text { Ash }\end{array}$ & $\%$ Yield \\
\hline KLD-1 & 1 & --- & --- & 27.26 & 4.57 & 36.72 & 29.43 & 14.55 & 7.46 & 54.46 & 84.92 & 21.75 & 6.56 & 39.22 & 53.49 \\
\hline KLD-2 & 4 & --- & --- & 26.87 & 4.62 & 45.10 & 45.04 & 27.64 & 7.98 & 54.37 & 57.62 & 27.01 & 5.37 & 46.47 & 47.35 \\
\hline
\end{tabular}

Note: Test conducted with Grade-M magnetite and no D\&R screens, dense-medium cyclone had 0.12 sq. in. feed inlet, 1.00 in vortex finder, and 0.625 in. apex at 1.35 s.g. circulating medium. 
Table 30 presents the quality and yield results of the dense-medium cyclone using the Grade-M magnetite after one hour and four hours of continuous testing. As discussed earlier, partition curves were not generated due to the possible effects of the contaminated clarified water on separation performance. However, ash analyses were conducted on the dense-medium cyclone feed, clean coal, and refuse on the $48 \mathrm{M} \times 200 \mathrm{M}$ and $200 \mathrm{M} \times 500 \mathrm{M}$ fractions. These results were then composited to calculate the feed, clean coal, and refuse ash on the $48 \mathrm{M}$ x 500M. The dense-medium cyclone yields were then calculated for these three size fractions. As can be seen, the clean coal ash values for the $48 \mathrm{M} \times 200 \mathrm{M}$ were nearly identical (4.67\% vs. $4.62 \%)$ after one hour and four hours of continuous operation. Reject ash values changed significantly from $36.72 \%$ to $45.10 \%$ which resulted in a significant improvement in the product yield $(29.43 \%$ vs. $45.04 \%)$. In contrast, the $200 \mathrm{M} \times 500 \mathrm{M}$ ash results on the clean coal $(7.45 \%$ vs. $7.98 \%)$ and refuse $(54.46 \%$ vs. $54.37 \%)$ were nearly identical after one hour and four hours of continuous operation. These results may imply that the densemedium cyclone's performance improved somewhat after four continuous hours of operation when compared to one hour of continuous operation. However, in general the ash and yield results from both the one hour and four hour sample periods indicate that the operation of the dense-medium cyclone was poor when using the Grade-M magnetite. This finding is supported by the results discussed earlier in the Component Testing Results Section of this report.

Table 31 presents the Microtrac results from the Grade-M continuous testing. It also presents Microtrac results of the cleaner separator tailings after four hours of continuous testing. As can be seen from this table, the size of the dense-medium cyclone underflow magnetics increased slightly from the one hour to the fourth of continuous operation. However, the size of the dense-medium cyclone overflow and circulating medium magnetics were almost identical from the first to the fourth hour of continuous operation. These findings indicate that, for the most part, the magnetite being lost in the recovery circuits included the entire size range of the magnetics. That is, the finest magnetics were being lost at almost the same rate as the coarser magnetics. This finding is somewhat surprising in that it would be logical that the finest magnetite sizes would first be lost by the recovery circuits resulting in a significant increase in magnetite particle size. This finding is further supported by comparing the bulk magnetite size consist to that of the circulating medium. As can be seen from the table, the bulk magnetite size consist and the circulating medium size consist are nearly identical for the first and fourth hour of continuous operation.

\section{Grade L Pittsburgh Seam Continuous Integrated Testing}

The Pittsburgh No. 8 Seam was tested for 36 continuous hours using the Grade-L magnetite. Material balances and laboratory analysis were completed for the samples collected after one, twelve, and thirty-six hours of continuous operation. Partition curves were generated on the $48 \mathrm{M}$ x $200 \mathrm{M}$ size fraction. Researchers were unable to generate partition curves on the $200 \mathrm{M}$ x 500M size fraction due to insufficient material in the samples collected. As a result, composite partition curves on the $48 \mathrm{M}$ x 500M could also not be generated. 
Table 31. Grade-M Long Duration Microtrac Results

\begin{tabular}{|c|c|c|c|c|c|c|c|}
\hline \multicolumn{8}{|c|}{ Test-KLD-M1 (First Hour) } \\
\hline $\begin{array}{c}\text { Microtrac } \\
\text { Results }\end{array}$ & $\begin{array}{l}\text { D.M. Cyclone } \\
\text { Underflow }\end{array}$ & $\begin{array}{l}\text { D.M. Cyclone } \\
\text { Overflow }\end{array}$ & $\begin{array}{l}\text { Circulating } \\
\text { Medium }\end{array}$ & $\begin{array}{l}\text { Mag. Sep. } \\
\text { Cln. Tails }\end{array}$ & $\begin{array}{l}\text { Mag. Sep. } \\
\text { Sec. Tails }\end{array}$ & $\begin{array}{l}\text { Mag. Sep. } \\
\text { Scav. Tails }\end{array}$ & $\begin{array}{l}\text { Bulk Feed } \\
\text { Magnetite }\end{array}$ \\
\hline $90 \%$ Passing & 7.08 & 5.05 & 5.16 & $*$ & $*$ & $*$ & 5.00 \\
\hline $50 \%$ Passing & 2.87 & 2.68 & 2.71 & $*$ & $*$ & $*$ & 2.70 \\
\hline $10 \%$ Passing & 1.41 & 1.31 & 1.33 & $*$ & $*$ & $*$ & 1.40 \\
\hline MVD & 3.98 & 3.04 & 3.11 & $*$ & $*$ & $*$ & 3.00 \\
\hline
\end{tabular}

\begin{tabular}{||c|c|c|c|c|c|c|c||}
\hline \multicolumn{70}{|c||}{ Test-KLD-M2 (Fourth Hour) } \\
\hline $\begin{array}{c}\text { Microtrac } \\
\text { Results }\end{array}$ & $\begin{array}{c}\text { D.M. Cyclone } \\
\text { Underflow }\end{array}$ & $\begin{array}{c}\text { D.M. Cyclone } \\
\text { Overflow }\end{array}$ & $\begin{array}{c}\text { Circulating } \\
\text { Medium }\end{array}$ & $\begin{array}{c}\text { Mag. Sep. } \\
\text { Cln. Tails }\end{array}$ & $\begin{array}{c}\text { Mag. Sep. } \\
\text { Sec. Tails }\end{array}$ & $\begin{array}{c}\text { Mag. Sep. } \\
\text { Scav. Tails }\end{array}$ & $\begin{array}{c}\text { Bulk Feed } \\
\text { Magnetite }\end{array}$ \\
\hline $90 \%$ Passing & 10.82 & 5.49 & 5.86 & 12.83 & $*$ & $*$ & 5.00 \\
\hline $50 \%$ Passing & 3.03 & 2.67 & 2.78 & 3.41 & $*$ & $*$ & 2.70 \\
\hline $10 \%$ Passing & 1.42 & 1.26 & 1.36 & 1.49 & $*$ & $*$ & 1.40 \\
\hline MVD & 4.79 & 3.23 & 3.33 & 5.58 & $*$ & $*$ & 3.00 \\
\hline
\end{tabular}

*Insufficient material to complete accurate analysis. 
Table 32 presents the percent magnetics in the various flow streams and the magnetite loss per ton of equipment feed and the total circuit magnetite loss for the Grade L continuous integrated testing of the Pittsburgh Seam coal.

As can be seen from this table, the percent magnetics in the primary magnetic separator were nearly identical (88.84 vs 90.01) after one hour and thirty-six hours of continuous operation and was slightly lower (84.31) during the twelfth hour of continuous operation. In general, the magnetics content in the primary magnetic separator is somewhat low indicating that non-magnetic material was being captured in this separator's concentrate throughout the thirty-six hours of continuous operation. In contrast, the cleaner magnetic separator magnetics during the thirty-six hours of continuous operation is much more respectable $(94.36,91.50,93.71)$. These findings indicate that a cleaner stage of separator is desirable to maintain a reasonable level of magnetics in the circulating medium.

The correct medium magnetics continually increased in magnetics content ( 84.50 vs 88.47 vs 92.56 ) throughout the thirty-six hours of continuous operation. This indicates that the quality of the concentrate from the cleaner magnetic separator when combined with the scavenger magnetic separator concentrate improved throughout the thirty-six hours of operation. The percent magnetics in the cleaner magnetic separator tailings, the secondary magnetic separator tailings and the scavenger magnetic separator tailings all significantly trended down from the first hour through the thirty-sixth hour of continuous operation. This indicates that as operating time progressed less magnetic material was being lost by the separators. This result is also reflected in the magnetite loss per ton of equipment feed. For example, the secondary magnetic separator lost $160.7 \mathrm{lb} /$ ton of magnetite after one hour of continuous operation but only $7.5 \mathrm{lb} /$ ton after thirty-six hours of operation and the scavenger magnetic separator, which is, the total magnetite loss for the entire Micro-Mag circuit, lost $14.3 \mathrm{lb} /$ ton after one hour of continuous operation but only $4.2 \mathrm{lb} /$ ton after thirty-six hours of continuous operation.

Table 33 presents the quality and yield results of the dense-medium cyclone and Ep values on the $48 \mathrm{M}$ x 200M size fraction after one hour, twelve hours, and thirty-six hours of continuous operation. As can be seen from this table the performance of the dense-medium cyclone was nearly identical after one, twelve, and thirty-six hours of continuous operation. The clean coal and refuse ash values were all quite good for the $48 \mathrm{M}$ x $200 \mathrm{M}, 200 \mathrm{M}$ x 500M, and the composite $48 \mathrm{M}$ x $500 \mathrm{M}$ fractions. The Ep's and D50 separating points for the 48M x 200M fraction as illustrated in Figure 21 were also nearly identical with Ep's ranging from 0.054 to 0.066 and the $\mathrm{D}_{50}$ separating point ranging from 1.56 S.G. to 1.60 S.G. These findings are supported by the results discussed in the Component Testing Results Section of this report. There was not enough 200M x 500M material available from the sample collection and screening operations to conduct float-sink testing so no distribution curves for this fraction were produced. 
Table 32. Continuous Integrated Magnetite Recovery Results for Grade-L Magnetite

\begin{tabular}{|c|c|c|c|c|c|c|c|c|c|c|}
\hline \multirow{2}{*}{$\begin{array}{l}\text { Test } \\
\text { No. }\end{array}$} & \multirow{2}{*}{$\begin{array}{l}\text { Hours } \\
\text { Into Test }\end{array}$} & \multicolumn{6}{|c|}{ Percent Magnetics } & \multicolumn{2}{|c|}{$\begin{array}{l}\text { Mag. Loss/ton of Equip. } \\
\text { Feed }\end{array}$} & \multirow{2}{*}{$\begin{array}{c}\text { Circuit } \\
\text { Magnetite } \\
\text { Loss (lb/ton) }\end{array}$} \\
\hline & & $\begin{array}{l}\text { Pri. Mag. Sep. } \\
\text { Concentrate }\end{array}$ & $\begin{array}{l}\text { Cln. Mag. Sep. } \\
\text { Concentrate }\end{array}$ & $\begin{array}{l}\text { Correct } \\
\text { Medium }\end{array}$ & $\begin{array}{l}\text { Cln. Mag. } \\
\text { Sep. Tails }\end{array}$ & $\begin{array}{l}\text { Sec. Mag. } \\
\text { Sep. Tails }\end{array}$ & $\begin{array}{l}\text { Scav. Mag. } \\
\text { Sep. Tails }\end{array}$ & $\begin{array}{l}\text { Sec. Mag. } \\
\text { Sep. Tails }\end{array}$ & $\begin{array}{l}\text { Scav. Mag. } \\
\text { Sep. Tails }\end{array}$ & \\
\hline PLD-L1 & 1 & 88.84 & 94.36 & 84.50 & 1.47 & 10.15 & 0.91 & 160.7 & 14.3 & 14.3 \\
\hline PLD-L3 & 12 & 84.31 & 91.50 & 88.47 & 1.53 & 3.07 & 0.61 & 70.7 & 6.8 & 6.8 \\
\hline PLD-L5 & 36 & 90.01 & 93.71 & 92.56 & 0.07 & 0.68 & 0.35 & 7.5 & 4.2 & 4.2 \\
\hline
\end{tabular}

Note: Test conducted with Grade-L magnetite and no D\&R screens. 
Table 33. Continuous Integrated Dense-Medium Cyclone Results for Grade-L Magnetite

\begin{tabular}{|c|c|c|c|c|c|c|c|}
\hline \multirow[b]{2}{*}{ Test } & \multirow[b]{2}{*}{ Hours } & \multicolumn{6}{|c|}{ Dense-Medium Cyclone Results } \\
\hline & & Ep & D50 & $\begin{array}{c}\% \text { FD. } \\
\text { Ash }\end{array}$ & $\begin{array}{c}\text { \% C.C. } \\
\text { Ash }\end{array}$ & $\begin{array}{c}\text { \% Ref. } \\
\text { Ash }\end{array}$ & $\%$ Yield \\
\hline \multicolumn{8}{|c|}{$48 M \times 200 M$} \\
\hline PLD-L1 & 1 & 0.062 & 1.56 & 19.40 & 5.24 & 74.20 & 79.47 \\
\hline PLD-L3 & 12 & 0.054 & 1.58 & 19.95 & 6.88 & 73.75 & 80.38 \\
\hline PLD-L5 & 36 & 0.066 & 1.60 & 17.49 & 5.93 & 71.75 & 82.43 \\
\hline \multicolumn{8}{|c|}{ 200M X 500M } \\
\hline PLD-L1 & 1 & NA & NA & 17.33 & 6.21 & 75.58 & 83.97 \\
\hline PLD-L3 & 12 & NA & NA & 17.44 & 5.96 & 78.73 & 82.97 \\
\hline PLD-L5 & 36 & NA & NA & 14.85 & 5.55 & 77.88 & 82.43 \\
\hline \multicolumn{8}{|c|}{$48 M \times 500 M$} \\
\hline PLD-L1 & 1 & NA & NA & 19.01 & 5.43 & 74.41 & 80.31 \\
\hline PLD-L3 & 12 & NA & NA & 19.56 & 6.73 & 74.56 & 81.09 \\
\hline PLD-L5 & 36 & NA & NA & 17.08 & 5.87 & 72.46 & 83.17 \\
\hline
\end{tabular}

Notes: Test conducted with Grade-L magnetite and no D\&R screens, densemedium cyclone had 0.12 sq. in. feed inlet, 1.00 in vortex finder, and $0.625 \mathrm{in}$. apex at $1.35 \mathrm{s.g}$. circulating medium.

Final samples provided insufficient material for generating distribution curves for the $200 \mathrm{M}$ x $500 \mathrm{M}$ fraction. 


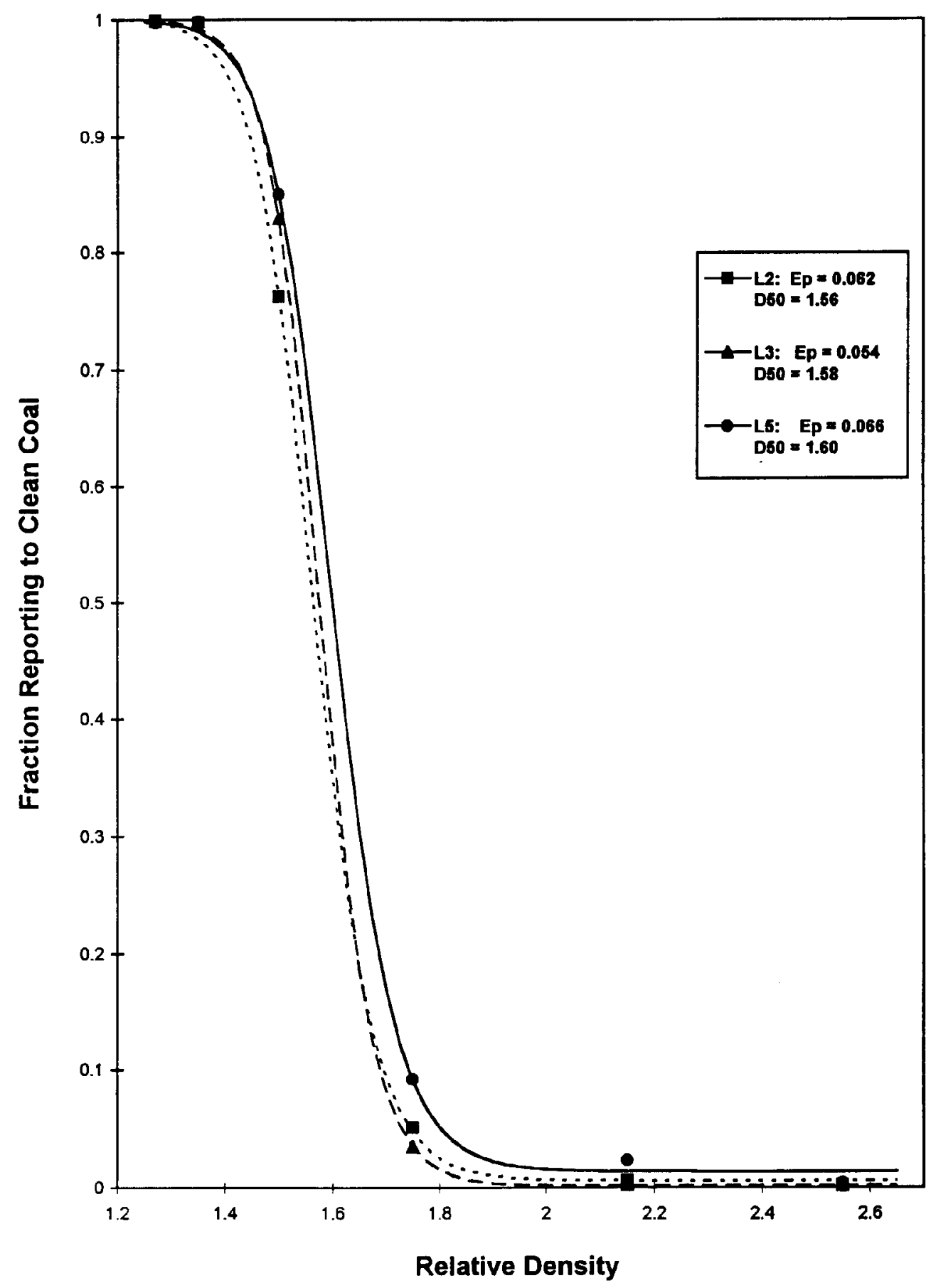

Figure 21. Fitted Partition Curves for Plus-200-Mesh Fraction for Pittsburgh Seam Long-Duration Run (Grade L Magnetite, 78 PSI, 0\% Fines) 


\section{Custom Coal Corporation}

Table 34 presents the Microtrac results of the Grade-L magnetite continuous testing. As can be seen from this table, the size of the dense-medium cyclone underflow magnetics, the dense-medium cyclone overflow magnetics and the circulating medium were nearly identical after one, twelve, and thirty-six hours of operation. This indicates that the magnetite being lost in the recovery circuits included the entire size range of the magnetics. This finding is consistent with that of the Grade-M continuous testing, in that, the finest magnetics were being lost at the same rates as the coarser magnetics. The size distribution of the bulk feed magnetite compares very closely with that of the circulating medium. This conclusion is, once again, supported by comparing the bulk magnetite size consist to that of the circulating medium. As can be seen from the table, the bulk magnetite size consist and the circulating medium size consist are nearly identical for the one, twelfth, and thirtysixth hour of continuous operation. Detailed results of both the Grade-L and Grade-M continuous integrated testing are presented in the Appendices volume of this report.

\section{Continuous Integrated Testing Conclusions}

From Tables 29 through 34 and from Figure 21 the following conclusions and observations can be made:

- Large magnetite losses on the order of $30 \mathrm{lb} /$ ton were experienced when using the Grade-M magnetite during the four continuous hours of operating the Micro-Mag circuit.

- When testing the Grade-M magnetite the scavenger or rare earth magnetic separator recovered a large percentage of the magnetite that was lost by the other three conventional magnetic separators.

- In general, the ash and yield results obtain from the dense-medium cyclone when testing the Grade-M magnetite indicate that the performance of the dense-medium cyclone was poor. This finding is support by the results discussed in the Component Testing Results Section.

- Results from the Grade-L magnetite testing, indicate that a cleaner stage separator is desirable to maintain a reasonable level of magnetics in the circulating medium.

- When using the Grade-L magnetite, the correct medium magnetics stream continuously increased in magnetics content throughout the thirty-six hours of continuous testing.

- When using the Grade-L magnetite, the percent magnetics in the cleaner magnetic separator tailings, the secondary magnetic separator tailings, and the scavenger magnetic separator tailings all significantly trended down indicating that as operating time progressed less magnetic material was being lost by the separators. 
Table 34. Grade-L Long Duration Microtrac Results

\begin{tabular}{||c|c|c|c|c|c|c|c||}
\hline \multicolumn{9}{|c|}{ Test-PLD-L1 (1 Hour) } \\
\hline $\begin{array}{c}\text { Microtrac } \\
\text { Results }\end{array}$ & $\begin{array}{c}\text { D.M. Cyclone } \\
\text { Underflow }\end{array}$ & $\begin{array}{c}\text { D.M. Cyclone } \\
\text { Overflow }\end{array}$ & $\begin{array}{c}\text { Circulating } \\
\text { Medium }\end{array}$ & $\begin{array}{c}\text { Mag. Sep. } \\
\text { Cln. Tails }\end{array}$ & $\begin{array}{c}\text { Mag. Sep. } \\
\text { Sec. Tails }\end{array}$ & $\begin{array}{c}\text { Mag. Sep. } \\
\text { Scav. Tails }\end{array}$ & $\begin{array}{c}\text { Bulk Feed } \\
\text { Magnetite }\end{array}$ \\
\hline $90 \%$ Passing & 13.94 & 10.62 & 10.90 & 10.82 & 12.04 & 11.71 & 12.80 \\
\hline $50 \%$ Passing & 5.44 & 4.68 & 4.65 & 4.63 & 5.23 & 4.76 & 5.70 \\
\hline $10 \%$ Passing & 2.15 & 2.09 & 2.10 & 2.09 & 2.25 & 2.16 & 2.40 \\
\hline MVD & 6.75 & 5.61 & 5.69 & 5.70 & 6.23 & 5.93 & 6.60 \\
\hline
\end{tabular}

\begin{tabular}{||c|c|c|c|c|c|c|c||}
\hline \multicolumn{9}{|c|}{ Test-PLD-L3 (12 Hours) } \\
\hline $\begin{array}{c}\text { Microtrac } \\
\text { Results }\end{array}$ & $\begin{array}{c}\text { D.M. Cyclone } \\
\text { Underflow }\end{array}$ & $\begin{array}{c}\text { D.M. Cyclone } \\
\text { Overflow }\end{array}$ & $\begin{array}{c}\text { Circulating } \\
\text { Medium }\end{array}$ & $\begin{array}{c}\text { Mag. Sep. } \\
\text { Cln. Tails }\end{array}$ & $\begin{array}{c}\text { Mag. Sep. } \\
\text { Sec. Tails }\end{array}$ & $\begin{array}{c}\text { Mag. Sep. } \\
\text { Scav. Tails }\end{array}$ & $\begin{array}{c}\text { Bulk Feed } \\
\text { Magnetite }\end{array}$ \\
\hline $90 \%$ Passing & 13.58 & 10.64 & 12.29 & $*$ & 11.04 & $*$ & 12.80 \\
\hline $50 \%$ Passing & 5.46 & 4.83 & 5.47 & $*$ & 4.85 & $*$ & 5.70 \\
\hline $10 \%$ Passing & 2.21 & 2.13 & 2.37 & $*$ & 2.15 & $*$ & 2.40 \\
\hline MVD & 6.69 & 5.71 & 6.46 & $*$ & 5.87 & $*$ & 6.60 \\
\hline
\end{tabular}

\begin{tabular}{||c|c|c|c|c|c|c|c||}
\hline \multicolumn{10}{|c|}{ Test-PLD-L5 (36 Hours) } \\
\hline $\begin{array}{c}\text { Microtrac } \\
\text { Results }\end{array}$ & $\begin{array}{c}\text { D.M. Cyclone } \\
\text { Underflow }\end{array}$ & $\begin{array}{c}\text { D.M. Cyclone } \\
\text { Overflow }\end{array}$ & $\begin{array}{c}\text { Circulating } \\
\text { Medium }\end{array}$ & $\begin{array}{c}\text { Mag. Sep. } \\
\text { Cln. Tails }\end{array}$ & $\begin{array}{c}\text { Mag. Sep. } \\
\text { Sec. Tails }\end{array}$ & $\begin{array}{c}\text { Mag. Sep. } \\
\text { Scav. Tails }\end{array}$ & $\begin{array}{c}\text { Bulk Feed } \\
\text { Magnetite }\end{array}$ \\
\hline $90 \%$ Passing & 13.16 & 10.13 & 11.33 & $*$ & $*$ & $*$ & 12.80 \\
\hline $50 \%$ Passing & 5.18 & 4.57 & 4.94 & $*$ & $*$ & $*$ & 5.70 \\
\hline $10 \%$ Passing & 2.10 & 2.03 & 2.15 & $*$ & $*$ & $*$ & 2.40 \\
\hline MVD & 6.42 & 5.37 & 5.97 & $*$ & $*$ & $*$ & 6.60 \\
\hline
\end{tabular}

*Insufficient material to complete accurate analysis. 


\section{Custom Coal Corporation}

- Respectable magnetite losses on the order of $4 \mathrm{lb} /$ ton after 36 hours of operation was experienced when using the Grade-L magnetite. As with the Grade-M magnetite, the rare earth scavenger separator play an important part in the recovery of the magnetite.

- Ash, yield, and Ep results obtained from the dense-medium cyclone indicate that the separation performance of the dense-medium cyclone was excellent when using the Grade- $\mathrm{L}$ magnetite and did not degrade over the 36 hours of testing.

- Indications are that the magnetite being lost in the recovery circuits, when using both the Grade- $\mathrm{M}$ and Grade-L magnetites, includes the entire size range of the magnetics. That is, the finest magnetics were being lost at the same rate as the coarser magnetics.

\section{Section 4.10.4 - Quality Assurance and Quality Control Testing Results}

The QA/QC required for the plant testing was broken down into three main areas:

- Sample handing, preparation, and analyses accuracy checks - which required adopting and adhering to certain set procedures and equipment.

- Instrument accuracy checks - which encompassed flowmeters, pressure gauges, and nuclear density gauges.

- $\quad$ Sample and test, repeatability and reproducibility - which was affected by procedures and approach, but were more system dependent (i.e., stabilization time, system consistency, and feed consistency).

The circuit was set up with a number of manual and redundant systems to routinely check the accuracy of the instruments. When coupled with the planned routine maintenance of the instruments, Custom Coals did not experience any significant accuracy problems in those areas, at least none that would skew overall test conclusions and results.

The majority of Custom Coals QA/QC focused on the last two areas, particularly obtaining accurate sample analyses and material balances. For example, Table 35 contains the ASTM Standards for within lab repeatability, and between labs reproducibility, of coal laboratory analyses. Since Custom Coals did all sample preparation at the site, including moisture and ash analyses, a test was done to compare the analyses obtained on samples with FETC's ash furances (the standard method) to CT\&E's commercial laboratory results. Table 36 illustrates, via the duplicate analyses that Custom Coals is well within ASTM repeatability for moisture and ash analyses, using the FETC ash furnaces. Table 36 also illustrates that Custom Coals' analyses match CT\&E's for moisture and ash within ASTM reproducibility. 
Table 35. ASTM Standards for Coal Analytical Variances

\begin{tabular}{||l|l|c|c||}
\hline \multirow{2}{*}{ Analysis } & \multicolumn{1}{|c|}{ Coal Type } & \multicolumn{2}{|c|}{$\begin{array}{c}\text { ASTM Allowable Differences } \\
\text { on Duplicate Samples }\end{array}$} \\
\cline { 3 - 4 } & & $\begin{array}{c}\text { Repeatability } \\
\text { Within Lab }\end{array}$ & $\begin{array}{c}\text { Reproducibility } \\
\text { Between Labs }\end{array}$ \\
\hline Moisture & Any & $0.30 \mathrm{Wt} \%$ & $0.50 \mathrm{Wt} \%$ \\
\hline Ash & Raw Coal & $\begin{array}{c}0.50 \mathrm{Wt} \% \\
0.20 \mathrm{Wt} \%\end{array}$ & $\begin{array}{l}1.00 \mathrm{Wt} \% \\
0.30 \mathrm{Wt} \% \\
\end{array}$ \\
& Clean Coal & $1.00 \mathrm{Wt} \%$ & $2.00 \mathrm{Wt} \%$ \\
\hline \multirow{2}{*}{ Btu/lb. } & Refuse Coal & 50 & 100 \\
\hline Sulfur & Any & $0.05 \mathrm{Wt} \%$ & $0.10 \mathrm{Wt} \%$ \\
& $>2.0 \%$ Sulfur Coal & $0.10 \mathrm{Wt} \%$ & $0.20 \mathrm{Wt} \%$ \\
\hline Pyritic Sulfur & $<2.0 \%$ Pyritic Sulfur Coal & $0.05 \mathrm{Wt} \%$ & $0.30 \mathrm{Wt} \%$ \\
& $>2.0 \%$ Pyritic Sulfur Coal & $0.10 \mathrm{Wt} \%$ & $0.40 \mathrm{Wt} \%$ \\
\hline
\end{tabular}

Table 36. Comparison of Coal Analyses FETC and CT\&E Furnaces (Test PCT \#1, 05/16/95)

\begin{tabular}{||c|l|c|c|c|c||}
\hline \multirow{2}{*}{$\begin{array}{c}\text { Sample } \\
\text { No. }\end{array}$} & \multicolumn{1}{|c|}{ Sample Name } & \multicolumn{2}{l|}{ Residual Moisture (Wt\%) } & \multicolumn{2}{l||}{ Dry Ash Content (Wt\%) } \\
\cline { 3 - 6 } & & FETC & CT\&E & FETC & CT\&E \\
\hline 1 & PRF Feed & $1.93 / 1.93$ & 1.86 & $27.31 / 27.48$ & 26.89 \\
\hline 2 & Class. Cyclone Feed & $1.43 / 1.49$ & 1.50 & $25.98 / 25.97$ & 25.41 \\
\hline 3 & Class. Cyclone Underflow & $1.86 / 1.92$ & 1.92 & $26.88 / 26.66$ & 26.02 \\
\hline 4 & Class. Cyclone Overflow & $1.77 / 1.88$ & 1.70 & $32.21 / 32.37$ & 31.73 \\
\hline 5 & Deslime Screen Unders (South) & $1.04 / 1.04$ & 1.02 & $56.25 / 56.00$ & 54.97 \\
\hline $5 \mathrm{~A}$ & Deslime Screen Unders (North) & $1.72 / 1.68$ & 1.59 & $38.97 / 39.24$ & 38.44 \\
\hline 6 & Deslime Screen Disch. (South) & $1.47 / 1.47$ & 1.41 & $20.91 / 21.04$ & 20.77 \\
\hline $6 \mathrm{~A}$ & Deslime Screen Disch. (North) & $1.77 / 1.83$ & 1.69 & $24.19 / 24.15$ & 23.65 \\
\hline \hline
\end{tabular}


Other QA/QC issues that were addressed and tested include:

- $\quad$ MTU/IMP Laboratory Investigation Results.

- Davis-Tube Separation and Magnetic Moment Measurement Reproducibility Testing done by MTU's IMP.

- Wet Screening Accuracy Testing done by Custom Coals.

- Duplicate Testing and Sample Reproducibility Checks, done by Custom Coals during the Heavy-Media Cyclone Components Tests.

- Duplicate EMU Analysis on the Grade-M magnetite.

\section{MTU/IMP DAVIS-TUBE AND MAGNETIC MOMENT REPRODUCIBILITY TESTING}

MTU's IMP performed a number of duplicate analyses to observe the reproducibility and closure of the Davis-Tube magnetics separations and magnetic moment measurements they performed, as part of their routine analyses for the project. Table 37 illustrates duplicate Davis-Tube separations for two methods tested during the project. All four separations were performed with identical dried splits of a Combined Drain Screen Underflow Sample. The two methods tested included:

- Complete water evaporation of the Davis-Tube products to ensure complete, particle recovery, followed by magnetics moment analyses (Lab. No. S-8-1A \& S-8-1B).

- $\quad$ Partial settling of Davis-Tube products followed by decanting and micropore filtering (Lab. No. S-8-2A \& S-8-2B).

The second method was the standard method MTU's IMP normally employs.

The results in Table 37, and in other duplicate tests, illustrates that either method leads to very good reproducibility of separations (i.e., magnetics yields, moment measurements, and moment distributions). The major difference is that the water evaporation method causes a significant weight gain in the non-mags due to precipitation of solids from the vast amount of water used in the DavisTube Procedure; whereas, the normal method leads to a slight weight loss due to decanting and filtering losses. Custom Coals decided that the normal method (i.e., decanting and filtering) was preferred, and setup procedures to maximize sample size so that the slight losses of colloidal and/or soluble particles did not skew results. 
Table 37. Davis-Tube Separation Accuracy and Repeatability Testing (Pittsburgh No. 8 Seam Coal, Grade-K Magnetite)

\begin{tabular}{|c|c|c|c|c|c|c|}
\hline $\begin{array}{l}\text { MTU/IMP } \\
\text { Lab. No. }\end{array}$ & $\begin{array}{l}\text { Particle Recovery } \\
\text { Method/Approach }\end{array}$ & $\begin{array}{l}\text { Davis Tube } \\
\text { Product }\end{array}$ & $\begin{array}{c}\text { Weight } \\
\text { (g) }\end{array}$ & $\begin{array}{l}\text { Weight } \\
\text { (Wt\%) }\end{array}$ & $\begin{array}{l}\text { Moment } \\
\text { (EMU/g) }\end{array}$ & $\begin{array}{l}\text { Moment } \\
\text { Dist. (\%) }\end{array}$ \\
\hline $5-8-1 \mathrm{~A}$ & Wate & $\begin{array}{l}\text { Mags } \\
\text { Non Mags } \\
\text { Recon. Feed } \\
\text { Head }\end{array}$ & $\begin{array}{l}6.444 \\
1.371 \\
7.815 \\
7.537\end{array}$ & $\begin{array}{r}82.46 \\
17.45 \\
100.00 \\
----\end{array}$ & $\begin{array}{r}85.099 \\
0.601 \\
70.275 \\
74.084\end{array}$ & $\begin{array}{r}99.85 \\
0.15 \\
100.00 \\
----\end{array}$ \\
\hline $5-8-1 B$ & Water & $\begin{array}{l}\text { Mags } \\
\text { Non Mags } \\
\text { Recon Feed } \\
\text { Head }\end{array}$ & $\begin{array}{l}6.893 \\
1.504 \\
8.397 \\
8.064\end{array}$ & $\begin{array}{r}82.09 \\
17.91 \\
100.00 \\
----\end{array}$ & $\begin{array}{r}86.007 \\
0.652 \\
70.719 \\
74.084\end{array}$ & $\begin{array}{r}99.83 \\
0.17 \\
100.00 \\
----\end{array}$ \\
\hline $5-8-2 \mathrm{~A}$ & cant \& Filter & $\begin{array}{l}\text { Mags } \\
\text { Non Mags } \\
\text { Recon Feed } \\
\text { Head }\end{array}$ & $\begin{array}{l}6.424 \\
1.080 \\
7.504 \\
7.527\end{array}$ & $\begin{array}{r}85.61 \\
14.39 \\
100.00 \\
----\end{array}$ & $\begin{array}{r}85.285 \\
0.595 \\
73.096 \\
74.084\end{array}$ & $\begin{array}{r}99.84 \\
0.16 \\
100.00 \\
----\end{array}$ \\
\hline $5-8-2 B$ & Settle, Decant \& Filter & $\begin{array}{l}\text { Mags } \\
\text { Non Mags } \\
\text { Total } \\
\text { Head } \\
\end{array}$ & $\begin{array}{l}5.301 \\
\underline{0.866} \\
6.167 \\
6.254 \\
\end{array}$ & $\begin{array}{r}84.96 \\
14.04 \\
100.00 \\
----\end{array}$ & $\begin{array}{r}87.052 \\
0.855 \\
74.948 \\
73.986 \\
\end{array}$ & $\begin{array}{r}99.84 \\
0.16 \\
100.00 \\
----\end{array}$ \\
\hline
\end{tabular}

Notes: All four separations done with identical splits of Test CMT\#1, Sample \#16 (Combined Drain Screen Underflow), from Commissioning Tests.

Similarly, Table 38 contains a number of duplicate magnetic moment measurements for samples with vastly differing magnetics contents. The results illustrate that the moment measurements are reproducible to within 0.3 to $0.7 \mathrm{EMU} / \mathrm{g}$. This does not create a problem for high-EMU content samples, but can cause significant percentage-basis errors for samples containing minute amounts of magnetite (i.e., see R.E. Magnetic Separator Tailings in Table 38). Custom Coals duplicated and tripulated the magnetic moment samples, and also combined the moment measurements with DavisTube separations, to reduce the likelihood of errors and ensure that accurate determinations of magnetics losses were obtained during testing.

\section{WET SCREENING ACCURACY TESTING}

Custom Coals performed QA/QC testing to assess the completeness of the $500 \mathrm{M}$ wet screening being done with the homemade, vibrating-vacuum unit used at the site (see results in Table 39). In the testing, samples of dense-medium cyclone overflow (Sample \#9A), underflow (Sample \#8A), and feed (Sample \#7) were subjected to normal screening and washing, where the sample is assumed 
complete once the lab screen effluent becomes clear (PHT \#1). The washing amounts were also doubled in a similar test to access any improvement (PHT \#2). Since all the magnetite is slightly finer than 500M the distribution of magnetics offers the best possible quantification of screening efficiency. The results in Table 39 illustrate, that in all cases, over $99.95 \mathrm{Wt} \%$ of the sample magnetics were screened into the $500 \mathrm{M}$ x 0 fraction, where they belong. This is extremely efficient, and illustrates that the normal washing approach was more than adequate for the test samples.

Table 38. Magnetic Moment Measurement Reproducibility (Pittsburgh No. 8 Seam Coal, Grade-K Magnetite)

\begin{tabular}{|c|c|c|c|c|c|c|c|}
\hline \multirow[b]{2}{*}{$\begin{array}{c}\text { MTU/IMP } \\
\text { Lab No. }\end{array}$} & \multirow[b]{2}{*}{$\begin{array}{c}\text { Test } \\
\text { Number }\end{array}$} & \multirow[b]{2}{*}{$\begin{array}{l}\text { Sample } \\
\text { Number }\end{array}$} & \multirow[b]{2}{*}{$\begin{array}{c}\text { Sample } \\
\text { Description }\end{array}$} & \multirow[b]{2}{*}{$\begin{array}{c}\text { Davis- } \\
\text { Tube } \\
\text { Product }\end{array}$} & \multicolumn{3}{|c|}{ Magnetic Moment } \\
\hline & & & & & $\begin{array}{l}\text { Dup. \#1 } \\
\text { (EMU/g) }\end{array}$ & $\begin{array}{l}\text { Dup. \#2 } \\
\text { (EMU/g) }\end{array}$ & $\begin{array}{c}\text { Avg. } \\
\text { (EMU/g) }\end{array}$ \\
\hline S-2 & MT \#2 & $\# 40$ & $\begin{array}{l}\text { Cleaner Magnetic } \\
\text { Separator Conc. }\end{array}$ & $\begin{array}{l}\text { Head } \\
\text { Mags }\end{array}$ & $\begin{array}{l}86.995 \\
87.324\end{array}$ & $\begin{array}{l}86.800 \\
86.989\end{array}$ & $\begin{array}{l}86.897 \\
87.156\end{array}$ \\
\hline $\mathrm{S}-8$ & CMT \#1 & $\# 16$ & $\begin{array}{l}\text { Combined Drain } \\
\text { Screen Effluent }\end{array}$ & $\begin{array}{c}\text { Head } \\
\text { Mags } \\
\text { NonMags }\end{array}$ & $\begin{array}{r}74.886 \\
85.577 \\
0.636\end{array}$ & $\begin{array}{r}74.783 \\
84.993 \\
0.554\end{array}$ & $\begin{array}{r}74.834 \\
85.285 \\
0.595\end{array}$ \\
\hline S-14 & CMT \#1 & $\# 22$ & $\begin{array}{l}\text { Rinse Screen } \\
\text { Refuse Discharge }\end{array}$ & $\begin{array}{c}\text { Head } \\
\text { NonMags }\end{array}$ & $\begin{array}{l}8.746 \\
0.297\end{array}$ & $\begin{array}{l}9.44 \\
0.316\end{array}$ & $\begin{array}{l}9.093 \\
0.307\end{array}$ \\
\hline S-16 & CMT \#1 & \#36 & $\begin{array}{l}\text { R.E. Magnetic } \\
\text { Separator Tails }\end{array}$ & $\begin{array}{c}\text { Head } \\
\text { NonMags }\end{array}$ & $\begin{array}{l}0.922 \\
0.723\end{array}$ & $\begin{array}{l}0.940 \\
0.437\end{array}$ & $\begin{array}{l}0.931 \\
0.580\end{array}$ \\
\hline
\end{tabular}

Note: All measurements done with 0.03 to 0.15 gram sample dependent on bulk density of sample. 
Table 39. QA/QC Test for On-Site Wet Screening (Pittsburgh No. 8 Seam Coal, Grade-K Magnetite)

\begin{tabular}{||l|c|c|c|c|c||}
\hline \multirow{2}{*}{} & \multicolumn{2}{|c|}{ PHT \#1 (Normal Washing) } & \multicolumn{2}{c||}{ PHT \#2 (Double Washing) } \\
\cline { 2 - 6 } & $\begin{array}{c}\text { Sample \#9A } \\
\text { Cyclone } \\
\text { Overflow }\end{array}$ & $\begin{array}{c}\text { Sample \#8A } \\
\text { Cyclone } \\
\text { Underflow }\end{array}$ & $\begin{array}{c}\text { Sample } \\
\text { \#9A } \\
\text { Cyclone } \\
\text { Overflow }\end{array}$ & $\begin{array}{c}\text { Sample } \\
\text { \#8A } \\
\text { Cyclone } \\
\text { Underflow }\end{array}$ & $\begin{array}{c}\text { Sample \#7 } \\
\text { Actual } \\
\text { Feed }\end{array}$ \\
\hline Top x 325M Size Fraction & & & & & \\
Weight Distribution (Wt\%) & 44.9 & 7.3 & 47.4 & 4.2 & 22.9 \\
Magnetics (Wt\%) & 0.01 & 0.44 & 0.01 & 0.41 & 0.07 \\
Magnetics Distribution (Wt\%) & 0.01 & 0.04 & 0.01 & 0.02 & 0.02 \\
\hline 325 x 500M Size Fraction & & & & & \\
Weight Distribution (Wt\%) & 5.7 & 2.4 & 7.9 & 1.5 & 4.2 \\
Magnetics (Wt\%) & 0.03 & 0.40 & 0.04 & 0.47 & 0.17 \\
Magnetics Distribution (Wt\%) & 0.00 & 0.01 & 0.01 & 0.01 & 0.01 \\
\hline 500M x 0 Size Fraction & & & & & \\
Weight Distribution (Wt\%) & 49.4 & 90.3 & 44.7 & 94.3 & 72.9 \\
Magnetics (Wt\%) & 93.78 & 96.97 & 85.33 & 94.96 & 94.22 \\
Magnetics Distribution (Wt\%) & 99.99 & 99.95 & 99.98 & 99.97 & 99.97 \\
\hline Combined Size Fractions & & & & & \\
\hline Weight Distribution (Wt\%) & 100.0 & 100.0 & 100.0 & 100.0 & 100.0 \\
Magnetics (Wt\%) & 46.33 & 87.61 & 38.15 & 89.57 & 68.71 \\
Magnetics Distribution (Wt\%) & 100.00 & 100.00 & 100.00 & 100.00 & 100.00 \\
\hline \hline
\end{tabular}

Note: Magnetics (Wt\%) determined from Davis-Tube Separations on all size fractions.

\section{DUPLICATE TESTING AND SAMPLE REPRODUCIBILITY}

Other QA/QC-related tests performed were duplicate testing and sampling done as part of the DenseMedium Cyclone Component Testing. These tests were performed during the second batch of Dense-Medium Cyclone Component Tests (PHT \#11-\#20), at 10:1 media-to-coal ratio. Table 40 contains the results from two identical, back-to-back tests and illustrates the good reproducibility that occurred when the mixing stays steady.

By contrast, Table 41 shows the variability of a number of "actual" and "reconstituted" feed samples that were taken over a slightly longer period. The results indicate that the mixing was not yet perfect, and there are random and biased variations that occur as the sump volume dropped that need to be considered when drawing conclusions from the data. 
Table 40. Duplicate Test Results Dense-Medium Cyclone Component Tests (Pittsburgh No. 8 Seam Coal, Grade-K Magnetite)

\begin{tabular}{|c|c|c|c|c|c|c|}
\hline & \multicolumn{3}{|c|}{ Test PHT \#18 Results } & \multicolumn{3}{|c|}{ Test PHT \#19 Results } \\
\hline & $\begin{array}{c}\text { Sample 9A } \\
\text { Cyclone } \\
\text { Overflow }\end{array}$ & $\begin{array}{c}\text { Sample 8A } \\
\text { Cyclone } \\
\text { Underflow }\end{array}$ & $\begin{array}{c}\text { Recon. } \\
\text { Feed }\end{array}$ & $\begin{array}{c}\text { Sample 9A } \\
\text { Cyclone } \\
\text { Overflow }\end{array}$ & $\begin{array}{c}\text { Sample 8A } \\
\text { Cyclone } \\
\text { Underflow }\end{array}$ & $\begin{array}{c}\text { Recon. } \\
\text { Feed }\end{array}$ \\
\hline $\begin{array}{l}\text { Slurry Composition } \\
\text { Slurry Feedrate (GPM) } \\
\text { Slurry SG } \\
\text { Solids Content }(\mathrm{Wt} \%)\end{array}$ & $\begin{array}{l}-- \\
1.31 \\
48.3\end{array}$ & $\begin{array}{l}-- \\
1.80 \\
59.3\end{array}$ & $\begin{array}{c}36.2 \\
1.48 \\
53.1\end{array}$ & $\begin{array}{l}-- \\
1.32 \\
48.6\end{array}$ & $\begin{array}{l}-- \\
1.80 \\
59.5\end{array}$ & $\begin{array}{l}36.2 \\
1.50 \\
53.4\end{array}$ \\
\hline $\begin{array}{l}\text { Overall Solids Performance } \\
\text { Yield }(\mathrm{Wt} \%) \\
\text { Proportion }(\mathrm{Wt} \%) \\
\text { Ash Content }(\mathrm{Wt} \%)\end{array}$ & $\begin{array}{c}51.6 \\
100.0 \\
42.49\end{array}$ & $\begin{array}{c}48.4 \\
100.0 \\
87.15\end{array}$ & $\begin{array}{c}100.0 \\
100.0 \\
64.11\end{array}$ & $\begin{array}{c}50.9 \\
100.0 \\
45.17\end{array}$ & $\begin{array}{c}49.1 \\
100.0 \\
89.32\end{array}$ & $\begin{array}{r}100.0 \\
100.0 \\
66.81\end{array}$ \\
\hline $\begin{array}{l}\text { Top x 325M Performance } \\
\text { Yield }(\mathrm{Wt} \%) \\
\text { Proportion }(\mathrm{Wt} \%) \\
\text { Ash Content }(\mathrm{Wt} \%)\end{array}$ & $\begin{array}{c}79.4 \\
25.3 \\
6.19\end{array}$ & $\begin{array}{c}20.6 \\
7.0 \\
58.38\end{array}$ & $\begin{array}{c}100.0 \\
16.5 \\
16.94\end{array}$ & $\begin{array}{r}78.8 \\
23.7 \\
6.32\end{array}$ & $\begin{array}{c}21.2 \\
6.6 \\
59.82\end{array}$ & $\begin{array}{c}100.0 \\
15.3 \\
17.66\end{array}$ \\
\hline $\begin{array}{l}325 \times 500 \mathrm{M} \text { Performance } \\
\text { Yield }(\mathrm{Wt} \%) \\
\text { Proportion }(\mathrm{Wt} \%) \\
\text { Ash Content }(\mathrm{Wt} \%)\end{array}$ & $\begin{array}{c}76.3 \\
12.1 \\
4.83\end{array}$ & $\begin{array}{c}23.7 \\
4.0 \\
24.00\end{array}$ & $\begin{array}{c}100.0 \\
8.2 \\
9.37\end{array}$ & $\begin{array}{c}75.0 \\
11.3 \\
4.96\end{array}$ & $\begin{array}{c}25.0 \\
3.9 \\
26.24\end{array}$ & $\begin{array}{c}100.0 \\
7.7 \\
10.28\end{array}$ \\
\hline $\begin{array}{l}\text { 500M x 0 Performance } \\
\text { Yield }(\mathrm{Wt} \%) \\
\text { Proportion }(\mathrm{Wt} \%) \\
\text { Ash Content }(\mathrm{Wt} \%)\end{array}$ & $\begin{array}{l}42.8 \\
62.5 \\
64.46\end{array}$ & $\begin{array}{l}57.2 \\
88.9 \\
92.35\end{array}$ & $\begin{array}{l}100.0 \\
75.3 \\
80.41\end{array}$ & $\begin{array}{l}43.0 \\
65.0 \\
66.32 \\
\end{array}$ & $\begin{array}{l}57.0 \\
89.5 \\
94.24\end{array}$ & $\begin{array}{c}100.0 \\
77.0 \\
82.23\end{array}$ \\
\hline
\end{tabular}

Note: Both tests performed at 10:1 media-to-coal ratio, at 90 PSI feed pressure, with 0.12 square inch inlet 1.0 inch vortex, and 0.875 inch apex in 4" Dense-Medium Cyclone. 
Table 41. Duplicate Feed Sample Results Dense-Medium Cyclone Component Tests (Pittsburgh No. 8 Seam Coal, Grade-K Magnetite)

\begin{tabular}{|c|c|c|c|c|c|}
\hline & \multicolumn{2}{|c|}{ Test PHT \#18 Results } & \multirow{2}{*}{$\begin{array}{c}\text { Test } \\
\text { PHT \#19 } \\
\text { Results } \\
\begin{array}{c}\text { Recon. } \\
\text { Feed }\end{array}\end{array}$} & \multicolumn{2}{|c|}{ Test PHT \#20 Results } \\
\hline & $\begin{array}{c}\text { Actual } \\
\text { Feed }\end{array}$ & $\begin{array}{c}\text { Recon. } \\
\text { Feed }\end{array}$ & & $\begin{array}{c}\text { Recon. } \\
\text { Feed }\end{array}$ & $\begin{array}{c}\text { Actual } \\
\text { Feed }\end{array}$ \\
\hline \multicolumn{6}{|l|}{ Slurry Composition } \\
\hline Slurry SG & --- & 1.48 & 1.50 & 1.50 & --- \\
\hline Solids Content (Wt\%) & 53.4 & 53.1 & 53.4 & 53.4 & 53.4 \\
\hline \multicolumn{6}{|l|}{ Overall Solids Analysis } \\
\hline Proportion (Wt\%) & 100.0 & 100.0 & 100.0 & 100.0 & 100.0 \\
\hline Ash Content (Wt\%) & 69.82 & 64.11 & 66.81 & 67.01 & 64.84 \\
\hline \multicolumn{6}{|l|}{ Top x 325M Analysis } \\
\hline Proportion (Wt\%) & 13.4 & 16.5 & 15.3 & 15.1 & 16.7 \\
\hline Ash Content (Wt\%) & 19.36 & 16.94 & 17.66 & 17.64 & 16.56 \\
\hline \multicolumn{6}{|l|}{$\underline{325 \times 500 \mathrm{M} \text { Analysis }}$} \\
\hline Proportion (Wt\%) & 7.2 & 8.2 & 7.7 & 7.5 & 8.1 \\
\hline Ash Content (Wt\%) & 11.33 & 9.37 & 10.28 & 9.35 & 9.09 \\
\hline \multicolumn{6}{|l|}{$500 \mathrm{M}$ x 0 Analysis } \\
\hline Proportion $(\mathrm{Wt} \%)$ & 79.4 & 75.3 & 77.0 & 77.4 & 75.2 \\
\hline Ash Content (Wt\%) & 83.64 & 80.41 & 82.23 & 82.23 & 81.57 \\
\hline
\end{tabular}

Note: All tests performed with same feed batch at 40.0 Wt\% Medium Contamination. 


\section{RECONSTITUTION OF GRADE-L MAGNETITE}

During the project concerns arose, regarding the Microtrac results of the "as received" magnetite vs. the 1.7 Amp Davis-Tube magnetics of the magnetite in that the magnetics fraction of the magnetite was approximately 1 MVD finer than that of the "as received" magnetite. As a result, MTU's IMP performed Microtrac analysis on:

- The Grade-L “as received” magnetite.

- The 1.7 Amp Davis-Tube magnetics from the Grade-L magnetite, and

- The 1.7 Amp Davis-Tube non-magnetics from the Grade-L magnetite.

MTU's IMP then reconstituted the magnetics and non-magnetics fractions to obtain a reconstituted "as received" sample. The results are contained in Table 42.

Table 42. Reconstituted Grade-L Magnetite Comparison

\begin{tabular}{|c|c|c|c|c|}
\hline Size ( ) & $\begin{array}{c}\text { Cumulative } \\
\text { As Received } \\
(\mathbf{W t} \%)\end{array}$ & $\begin{array}{l}\text { Cumulative } \\
\text { Magnetics } \\
(\mathbf{W t} \%)\end{array}$ & $\begin{array}{c}\text { Cumulative } \\
\text { Non-Magnetics } \\
(\mathbf{W t} \%)\end{array}$ & $\begin{array}{c}\text { Cumulative } \\
\text { Reconstituted } \\
\text { Head }\end{array}$ \\
\hline+88 & 0.0 & 0.0 & 0.0 & 0.0 \\
\hline $88 \times 62$ & 0.0 & 0.0 & 0.0 & 0.0 \\
\hline $62 \times 44$ & 0.0 & 0.0 & 0.0 & 0.0 \\
\hline $44 \times 31$ & 0.0 & 0.0 & 0.0 & 0.0 \\
\hline $31 \times 22$ & 0.0 & 0.0 & 0.0 & 0.0 \\
\hline $22 \times 16$ & 1.1 & 0.8 & 3.5 & 0.9 \\
\hline $16 \times 11$ & 8.6 & 7.9 & 13.7 & 8.2 \\
\hline $11 \times 7.8$ & 24.5 & 23.2 & 27.0 & 23.4 \\
\hline $7.8 \times 5.5$ & 43.7 & 42.6 & 40.3 & 42.5 \\
\hline $5.5 \times 3.9$ & 58.9 & 57.9 & 50.5 & 57.6 \\
\hline $3.9 \times 2.8$ & 75.9 & 76.8 & 65.1 & 76.3 \\
\hline $2.8 \times 1.9$ & 91.0 & 92.1 & 82.6 & 91.7 \\
\hline $1.9 \times 1.4$ & 96.3 & 96.6 & 91.3 & 96.4 \\
\hline $1.4 \times 0.9$ & 99.3 & 99.2 & 97.3 & 99.1 \\
\hline-0.9 & 100.1 & 100.1 & 99.8 & 100.1 \\
\hline
\end{tabular}


As can be seen from Table 42, the reconstituted head results agree extremely well with the "asreceived" results. Table 42 also indicates that the non-magnetics fraction is coarser than the magnetics fraction which explains the 1 MVD size difference between the "as-received" magnetite and the 1.7 Amp Davis-Tube magnetics.

\section{GRADE-L MAGNETITE COMPARISONS}

During the project a sample of circulating medium using Grade-L magnetite from the Micro-Mag circuit was obtained and analyzed for size and magnetic moment. This was done to assure that the magnetite quality did not change after numerous hours of processing (multiple days of intermittent testing) during the primary integrated testing. Table 43 compares the results for the Grade-L magnetics after processing to the as received Grade-L magnetics.

Table 43. Grade-L Magnetite Magnetics Comparison

\begin{tabular}{|c|c|c|c|c|}
\hline \multirow[t]{2}{*}{ Size ( ) } & \multicolumn{2}{|c|}{ As Received } & \multicolumn{2}{|c|}{ After Processing } \\
\hline & Vol. & Cum. & Vol. & Cum \\
\hline+22 & 3.1 & 100.0 & 3.4 & 100.0 \\
\hline $22 \times 16$ & 10.7 & 96.9 & 10.1 & 96.6 \\
\hline $16 \times 11$ & 17.6 & 86.2 & 16.4 & 86.5 \\
\hline $11 \times 7.8$ & 20.1 & 68.6 & 19.2 & 70.2 \\
\hline $7.8 \times 5.5$ & 18.3 & 48.5 & 18.0 & 50.9 \\
\hline $5.5 \times 3.9$ & 15.8 & 30.2 & 17.3 & 32.9 \\
\hline $3.9 \times 2.8$ & 10.0 & 14.5 & 11.1 & 15.6 \\
\hline $2.8 \times 1.9$ & 2.7 & 4.5 & 2.7 & 4.5 \\
\hline $1.9 \times 1.4$ & 1.5 & 1.7 & 1.5 & 1.8 \\
\hline-0.9 & 0.3 & 0.3 & 0.3 & 0.3 \\
\hline MVD & \multicolumn{2}{|c|}{6.64} & \multirow{2}{*}{\multicolumn{2}{|c|}{$\begin{array}{c}6.51 \\
12.72\end{array}$}} \\
\hline $\mathrm{D}_{90}$ & \multirow{2}{*}{\multicolumn{2}{|c|}{$\begin{array}{c}12.78 \\
5.67\end{array}$}} & & \\
\hline $\mathrm{D}_{50}$ & & & \multicolumn{2}{|c|}{5.42} \\
\hline $\mathrm{D}_{10}$ & \multicolumn{2}{|c|}{2.40} & \multicolumn{2}{|c|}{2.34} \\
\hline EMU/g & \multicolumn{2}{|c|}{77.24} & \multicolumn{2}{|c|}{77.02} \\
\hline
\end{tabular}

As can be seen from Table 44, the magnetics fraction of the Grade-L magnetite quality after processing in the Micro-Mag circuit is identical to that of the as received. 


\section{GRADE-M DUPLICATE MAGNETIC MOMENT ANALYSIS}

While performing Davis-Tube magnetic analysis on the two Grade-M primary integrated tests (PIT \#9 and \#10) it became obvious from the high ash contents in the Davis-Tube tailings that the DavisTube was unable to provide accurate magnetic analysis on the Grade-M magnetite. As a result, researchers were unable to compare the Davis-Tube magnetics to those of the magnetic moment magnetics to assure accurate magnetic analysis are being obtained. With no second method to verify magnetic content of samples, researchers decided to run duplicate magnetic moment analysis on numerous samples to assure that the magnetic moment analysis was repeatable and could by itself be relied upon for magnetic analysis. The results from these duplicate samples are contained in Table 44.

Table 44. Comparison of Duplicate Magnetic Moment Analysis

\begin{tabular}{||c|c|c||}
\hline Sample No. & Original EMU Measurement & Duplicate EMU Measurement \\
\hline 84 & 76.629 & 76.025 \\
\hline 85 & 74.479 & 74.411 \\
\hline 87 & 44.545 & 44.544 \\
\hline 88 & 21.862 & 22.037 \\
\hline 90 & 64.929 & 65.227 \\
\hline 92 & 79.201 & 80.005 \\
\hline 99 & 59.337 & 60.091 \\
\hline 100 & 23.539 & 23.007 \\
\hline 102 & 51.289 & 51.298 \\
\hline
\end{tabular}

As can be seen from Table 44, the duplicate magnetic moment measurements compare extremely well to the original magnetic moment measurements. With such excellent duplication results, magnetic moment measurements were used to determine magnetic content on all Grade-M magnetite test runs.

\section{SECTION 5 - ECONOMIC EVALUATION}

The economics of installing and operating a commercial scale Micro-Mag type circuit are extremely complex and would have to be evaluated on a case by case basis. Some of the factors that would greatly influence the economics would include: 


\section{Custom Coal Corporation}

- The amount of additional yield realized from this type circuit. This would depend on such things as plant feed quality and size consist. This would also depend on comparing other processes, such as column flotation, and their efficiency to that of the micronized magnetite process.

- The additional capital cost of installing a micronized magnetite process. These capital costs would then have to be compared to the capital cost of other processes capable of processing this fine material or combination of processes such as spiral concentrators cleaning the $48 \mathrm{M} \mathrm{x}$ $150 \mathrm{M}$ and column flotation cleaning the $150 \mathrm{M} \times 500 \mathrm{M}$.

- The additional maintenance and operating cost associated with the installation of a micronized magnetite process. Once again, these costs would have to be compared to other processes.

- The selling price of the clean coal. For example, a high-sulfur non-compliance coal would sell for much less than a low-sulfur compliance coal.

Additionally, some costs are not available, such as the price for a Grade K, L, or M magnetite. There are no commercial producers of bulk qualities of micronized magnetite. However, based on manufacturer estimates the cost for micronized magnetites are expected to be $\$ 150-200 /$ ton FOB.

However, to obtain at least a very rough economic analysis the following assumptions were made:

- A company wishes to build a $500 \mathrm{TPH}$ preparation plant capable of processing 2.5 million tons per year of raw coal. The plant is designed for a 30 year life expectance.

- The fine circuit of the plant consist of spiral concentrators processing $1 \mathrm{~mm} \times 150 \mathrm{M}$ with the $150 \mathrm{M} \times 500 \mathrm{M}$ being discarded to refuse.

- The $1 \mathrm{~mm} \times 150 \mathrm{M}$ comprises $20 \%$ of the raw feed and the $150 \mathrm{M} \times 500 \mathrm{M}$ comprises $4 \%$ of the raw feed.

- The clean coal produced at the plant is compliance quality and sells for $\$ 31.00$ per ton.

- A micronized magnetite circuit is installed to process the middlings of the spiral concentrators that is combined with the $150 \mathrm{M} \times 500 \mathrm{M}$ raw coal. The middlings of the spiral concentrators are $3 \%$ of the total plant feed.

- A total increase of $4 \%$ yield is realized by recleaning the spiral middlings combined with the $150 \mathrm{M} \times 500 \mathrm{M}$ raw coal.

- Operating and maintenance cost for the micronized magnetite circuit are $\$ 5$ per ton of circuit feed or in this case $\$ 875,000$ per year (.07 x 2,500,000 x $\$ 5.00)$. 
Using the above assumptions, the preparation plant would gross an additional 100,000 tons of clean coal a year valued at $\$ 3.1$ million. Subtracting the $\$ 875,000$ per year operational cost, this would allow $\$ 2,225,000$ per year to support capital cost. A large capital cost such as \$20 million financed over 30 years at $12 \%$ interest would be approximately $\$ 1.4$ million per year still leaving an additional annual profit of $\$ 825,000$.

\section{SECTION 6 - CONCLUSIONS AND RECOMMENDATIONS}

This bench-scale project was broken down into three basic testing areas:

- $\quad$ Component Testing - The primary goal of this phase of the project was to determine the ability of the classifying circuit to make a separation at or about 40 microns and the effect of medium-to-coal ratio, feed pressure, magnetite size, magnetite purity, and cyclone configuration on the separation efficiency of the dense-medium cyclone.

- $\quad$ Primary Testing - The primary goal of this phase was to determine the technical and economic feasibility of various unit operations and systems in optimizing the separation and recovery of the micronized magnetite from the coal products.

- $\quad$ Continuous Integrated Testing - The primary goal of this phase was to determine the affects of operating time on the characteristics of the recirculating medium (including purity and magnetite losses and size distribution) in a continuous integrated processing circuit, and, subsequently, the sensitivity of cyclone separation performance to the quality of the recirculating medium.

The component testing of the dense-medium cyclone produced some interesting and in some cases surprising results. Some of the more important findings included:

- At low medium-contamination levels, the separation performance of the 4-inch dense-medium cyclone is very efficient down to 500M particle size for both the Grade K \& L magnetites. Probable errors were produced in the range of about 0.050 to 0.090 for the $48 \mathrm{M}$ x $200 \mathrm{M}$ fraction and 0.110 to 0.160 for the $200 \mathrm{M}$ x 500M fraction.

- Surprisingly, the finest magnetite, Grade-M, resulted in the worst dense-medium cyclone performance with an Ep of 0.094 on the 48M x 200M size fraction and a Ep of 0.282 on the 200M x 500M size fraction.

- Of the three grades of micronized magnetite, the Grade-L magnetite resulted in the best overall cyclone performance with the Grade-K magnetite closely approaching the Grade-L's overall performance. 


\section{Custom Coal Corporation}

- $\quad$ Performance using a Grade E magnetite appeared to be surprisingly good down to 500M when using the 4-inch dense-medium cyclone at high pressures.

- At high medium-contamination levels the dense-medium cyclone performance deteriorated significantly. However, high feed pressures help buffer the detrimental affects of the contamination.

- The $\mathrm{D}_{50}$ or separating gravity decreased as the magnetite size decreased. This was true in general for all size fractions with and without fines contamination present.

- Changing variables, such as cyclone inlet size and apex size appeared to have little affect on cyclone performance when using the same grade of magnetite.

Some of the conclusions that were drawn from the primary testing phase of the project include:

- In all tests, extremely large amounts of magnetite were being lost in the discharge of the rinse screen when 200M decks are used. It appears that a slight negative angle on the rinse screen helped to reduce the amount of magnetite lost when 200M decks were used but the losses even at a negative angle were significant.

- When using the Grade K \& L magnetites with $100 \mathrm{M}$ decks only small amounts of magnetite were being lost in the discharge of the rinse screen. However, when coupled with the magnetite loss from the rare earth magnetic separator the total circuit losses for the Grade- $\mathrm{K}$ were on the order of 4.1 to $4.6 \mathrm{lb} / \mathrm{ton}$ of circuit feed and the total circuit losses for the Grade$\mathrm{L}$ were slightly over $12.1 \mathrm{lb} / \mathrm{ton}$.

- When using the Grade-M magnetite with 100M decks huge amounts of magnetite were being lost in the discharge of the rinse screen. This was most likely caused by the magnetite particles becoming magnetized when being recovered by the magnetic separator circuits. This would of caused the magnetite particles to adhere together making it difficult for the sprays on the rinse screen to rinse the magnetite particles through the screen.

- The circuit that produced the best overall magnetite recovery was by-passing the drain and rinse screens which resulted in the dense-medium cyclone products reporting directly to the magnetic separator circuits. This was true for all three magnetites tested. This circuit resulted in a $3.8 \mathrm{lb} /$ ton magnetite loss when using the Grade- $\mathrm{K}$ magnetite, a $5.8 \mathrm{lb} / \mathrm{ton}$ magnetite loss when using the Grade- $\mathrm{L}$ magnetite, and a $94.0 \mathrm{lb} /$ ton magnetite loss when using the Grade-M magnetite. The magnetite losses for the Grade K \& L magnetites were very respectable. However, the Grade-M magnetite losses were extremely high. These large losses are not surprising since only about $81 \%$ of the as-received magnetite was recovered in the Davis-Tube at 1.7 amps (3,700 gauss). 


\section{Custom Coal Corporation}

- $\quad$ As might be expected, the combined drain screen effluent magnetics were higher $(90.99 \%$ to $94.52 \%$ ) when $200 \mathrm{M}$ decks were installed on the drain screen than when $100 \mathrm{M}$ decks were installed (81.00\% to $88.45 \%)$.

- The magnetic content of both the primary and cleaner magnetic separator concentrates were very high with magnetics generally in the mid to high nineties. This was true for all three grades of magnetite.

- The correct or circulating medium magnetic content was extremely good when using the Grade-K magnetite $(95.60 \%$ to $98.80 \%)$. However, the circulating medium deteriorated (74.67\% to $84.36 \%$ ) when using the Grade-L and Grade-M magnetites. Since the cleaner magnetic separator concentrates were extremely high in magnetic content, the non-magnetic contamination in the circulating medium must have been contributed by the rare earth magnetic separator concentrate.

The continuous integrated testing conclusions are not surprisingly supported by both the component testing and primary testing phase of the project. Some of the more important conclusions drawn from this phase of the project testing include:

- $\quad$ Consistent with earlier findings, the dense-medium cyclone separation ash and yield results produced during the continuous, integrated testing using the Grade-M magnetite indicated poor separation performance.

- Large magnetite losses on the order of $30 \mathrm{lb} /$ ton was experienced when using the Grade-M magnetite during the four continuous hours of operating the Micro-Mag circuit.

- When testing the Grade-M magnetite the scavenger or rare earth magnetic separator recovered a large percentage of the magnetite that was lost by the other three conventional magnetic separators.

- Ash, yield, and Ep's results obtained from the continuous integrated testing using the Grade-L magnetite indicate that the performance of the dense-medium cyclone was excellent. Probable error values for the $48 \mathrm{M} \times 200 \mathrm{M}$ fraction were in the range of $0.054-0.066$ for the entire 36hour testing period. Probable error values for the $200 \mathrm{M}$ x 500M fraction were not available but yield and ash values indicate performance equal to that obtained during the Primary Integrated Testing.

- Very low magnetite losses on the order of $4 \mathrm{lb} / \mathrm{ton}$ after 36 hours of operation were experienced when using the Grade-L magnetite. As with the Grade-M magnetite, the rare earth scavenger separator play an important part in the recovery of the magnetite. 


\section{Custom Coal Corporation}

- $\quad$ Results from the Grade-L magnetite testing, indicate that a cleaner stage separator is desirable to maintain a reasonable level of magnetics in the circulating medium.

- When using the Grade-L magnetite, the correct medium magnetics continually increased in magnetics content throughout the thirty-six hours of continuous testing.

- When using the Grade-L magnetite, the percent magnetics in the cleaner magnetic separator tailings, the secondary magnetic separator tailings, and the scavenger magnetic separator tailings all significantly trended down indicating that as operating time progressed less magnetic material was being lost by the separators.

- Indications are that the magnetite being lost in the recovery circuits, when using both the Grade-M and Grade-L magnetites, include the entire size range of the magnetics. That is, the finest magnetics were being lost at the same rate as the coarser magnetics.

Recommendations on the findings in this report include:

- Additional component testing on the dense-medium cyclone using different grades of magnetite. This recommendation stems from the finding regarding the poor performance of the dense-medium cyclone when testing the finest magnetite (Grade-M). Traditionally, the finest magnetite used in dense-medium cyclones resulted in the best performance. The findings in this report indicate that at some point to fine of a magnetite results in extremely poor dense-medium cyclone performance. Additional, testing using a magnetite finer than the Grade- $\mathrm{L}$ and coarser than the Grade-M is recommended.

- $\quad$ Additional magnetite recovery tests using a different type of recovery circuit(s), perhaps such as a high-gradient magnetic separator, should be investigated. Although, low magnetite losses on the order of $4 \mathrm{lb} /$ ton were achieved during the Grade-L magnetite integrated testing improvements could possibly be made using a different type of recovery circuit.

- An in depth economic analysis of the micronized magnetite process should be investigated. Although, the limited economical analysis performed in this report suggest this process could be economical a more in depth approach should be investigated by a coal preparation design and engineering company. 